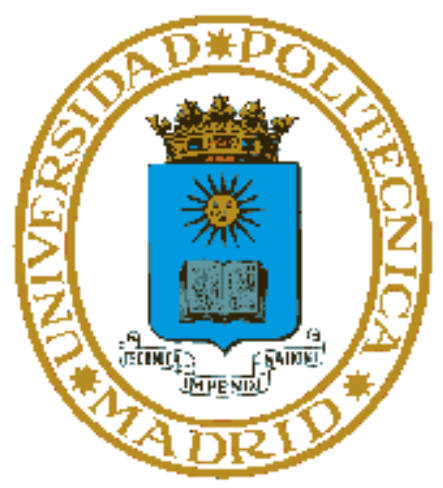

TECHNICAL UNIVERSITY OF MADRID

ESCUELA DE INGENIEROS DE CAMINOS, CANALES Y PUERTOS

\title{
OPTIMAL JOINT DAY-AHEAD ENERGY AND SECONDARY REGULATION RESERVE SCHEDULING OF PUMPED- STORAGE POWER PLANTS OPERATING WITH VARIABLE SPEED OR IN HYDRAULIC SHORT-CIRCUIT MODE IN THE IBERIAN ELECTRICITY MARKET
}

Thesis submitted for the degree of Doctor in Civil Engineering Systems

by

\section{Manuel Chazarra Jover}

Ingeniero Industrial (ICAI-Universidad Pontificia Comillas)

Máster Universitario en Sistemas de Energía Eléctrica (ICAI-Universidad Pontificia Comillas) 
ESCUELA DE INGENIEROS DE CAMINOS, CANALES Y PUERTOS

DEPARTMENT OF HYDRAULIC, ENERGY AND

ENVIRONMENTAL ENGINEERING

\title{
OPTIMAL JOINT DAY-AHEAD ENERGY AND SECONDARY REGULATION RESERVE SCHEDULING OF PUMPED- STORAGE POWER PLANTS OPERATING WITH VARIABLE SPEED OR IN HYDRAULIC SHORT-CIRCUIT MODE IN THE IBERIAN ELECTRICITY MARKET
}

\author{
$\underline{\text { Author }}$ \\ Manuel Chazarra Jover \\ Ingeniero Industrial (ICAI-Universidad Pontificia Comillas) \\ Máster Universitario en Sistemas de Energía Eléctrica (ICAI-Universidad Pontificia \\ Comillas)
}

\author{
$\underline{\text { Supervisors }}$ \\ Juan Ignacio Pérez Díaz \\ Doctor Ingeniero de Caminos, Canales y Puertos (UPM) \\ Javier García González \\ Doctor Ingeniero Industrial (Universidad Pontificia Comillas)
}

Madrid, July 2017 
a mis padres 


\section{Agradecimientos}

Numerosas son las personas y situaciones que han contribuido muy significativamente a la realización de esta Tesis Doctoral.

Por ser justos, debo remontarme a mi educación recibida en el Colegio Marista de Murcia, en donde me enseñaron unos valores que han permanecido desde entonces, e intuyo que se mantendrán a lo largo de toda mi vida. Y los amigos que allí hice, que forman parte de mi pasado, presente y futuro.

A esto se le añade la Universidad Pontifica Comillas, que me ha formado como Ingeniero y también como persona, incluyéndome los valores de la Compañía de Jesús con bastante profundidad. Debo agradecer especialmente a Cesáreo García del Cerro que me ayudara en tantos aspectos de mi vida. Su recuerdo, igualmente, me acompañará siempre.

Por supuesto, mi etapa en el IIT ha jugado un papel crucial en mi formación como profesional y como persona, con grandes retos y haciéndome amigo de grandes personas.

Finalmente, el salto a la Universidad Politécnica de Madrid ha terminado por darle el impulso definitivo a mi formación y a esta Tesis, haciéndome sentir orgulloso del trabajo realizado y agradecido por la ayuda recibida.

A todas estas etapas se le añaden destinos y lugares más fugaces pero que también han dejado su huella. Los más destacados son: Trondheim, Lima, Leeds, Mullingar, Paris, Eskilstuna, Estocolmo y Leek. Todos ellos tienen detrás unas historias, unas vivencias y unas personas que he podido disfrutar y que completan el CV de mi vida, ese CV que no suele revisarse en las entrevistas de trabajo pero que, posiblemente, tenga más valor.

En cuanto a las personas que han recorrido una o varias etapas de mi vida y que han contribuido a apoyarme y darme fuerzas para seguir adelante, y que han influido en mi formación como ingeniero y como persona, me gustaría incluir: tanto los que no están, como es mi abuela y el arriba mencionado Cesáreo, como los que espero que sigan durante muchas más décadas, Lucía, Sergio, Clara, Mari, Ángel, Manuel, David, Rubén, Carlos, Pablo, María del Mar, Miguel, Almudena, Pepe, Jesús, José María, Jesús, Miguel, Álvaro, Daniel, Christian, Eva, Mariola, César, Isabel, Jaime, Alfonso, Víctor, Antonio, María, Guillermo, José Ignacio, Daniel, Rocío, Daniel, Salvador, Laura, Ana, Manuel, Alfonso, Miguel, Pedro, Raúl, José Luis, Arild, Hno Román, Elisabeth, Hno Millán, Juan, mis primos y mis tíos, y otras muchas más que hacen la lista interminable.

Mis dos directores de Tesis, Juan Ignacio y Javier.

Por supuesto, a David, que desde 2006 ha transformado mi vida.

Y por último, las dos personas más importantes de mi vida, mi padre y mi madre. A ellos les debo TODO. Gracias.

"La felicidad de tu vida depende de la calidad de tus pensamientos" 
This dissertation has been approved by:

- Prof. Dr. Juan Ignacio Pérez Díaz (Universidad Politécnica de Madrid, Supervisor)

- Prof. Dr. Javier García González (Universidad Pontificia Comillas, Supervisor)

This dissertation has been reviewed by:

- Dr. Arild Helseth (SINTEF Energy Research, Supervisor in the Research Stay)

- Dr. Luiz Augusto Nobrega Barroso (President of EPE - Empresa de Pesquisa Energética, the Brazil's Energy Planning Office)

Composition of the Doctoral Committee:

- Prof. Dr. José Manuel Arroyo Sánchez (Universidad de Castilla La Mancha)

- Dr. Marte Fodstad (SINTEF Energy Research)

- Prof. Dr. Javier Heredia Cervera (Universidad Politècnica de Catalunya)

- Prof. Dr. Ignacio Guisández González (Universidad Politécnica de Madrid)

- Dr. Jesús María Latorre Canteli (Universidad Pontificia Comillas)

- Deputy Members:

- Dr. Pablo Dueñas Martínez (Massachusetts Institute of Technology)

- Prof. Dr. Araceli Hernández Bayo (Universidad Politécnica de Madrid)

Copyright () Manuel Chazarra, 2017

This doctoral research was funded by the Spanish Ministry of Economy and Competitiveness under the project "Optimal operation and control of pumped-storage hydropower plants" of The National Scientific Research, Development and Technological Innovation Plan 2008-2011 with the project reference ENE2012-32207, and under the predoctoral grant with the reference BES-2013-064153. The research stay in Trondheim (Norway) was funded, in part, by the Spanish Ministry of Economy and Competitiveness under the grant reference EEBB-I-15-09485 within the predoctoral grant, and, in part, by SINTEF Energy Research. 


\section{Contents}

1 Introduction $\quad 14$

1.1 The role of pumped-storage in the electric power industry . . . . . . . . . . . 14

1.1.1 Pumped-storage - Description of the technology and historical evolution 14

1.1.2 The integration of renewable energy sources . . . . . . . . . . . . . . 20

1.1.3 Last technical developments . . . . . . . . . . . . . . . . . . . 24

1.1.3.1 Variable speed technology . . . . . . . . . . . . . 24

1.1.3.2 Operation in hydraulic short-circuit mode . . . . . . . . . . 28

1.1.4 System perspective analysis . . . . . . . . . . . . . 30

1.2 The electricity market framework . . . . . . . . . . . . . . . . . 35

1.2.1 General electricity market . . . . . . . . . . . . . . . 36

1.2.2 Spanish electricity market . . . . . . . . . . . . . . . 37

1.2.2.1 Energy markets . . . . . . . . . . . . . 37

1.2.2.2 Ancillary services . . . . . . . . . . . . . 38

1.2.3 The agent perspective/Capital intensive . . . . . . . . . . . . . 41

1.2.4 Looking to the future . . . . . . . . . . . . . . . . . . . 42

1.2.5 Required decision support models . . . . . . . . . . . . . . 43

1.2.5.1 Assessing the investment . . . . . . . . . . . . . 43

1.2.5.2 Operation models . . . . . . . . . . . . . 44

1.3 State of the art and motivation . . . . . . . . . . . . . 45

1.3.1 Dimensions to be considered . . . . . . . . . . . . . . 45

1.3.2 Optimal scheduling models . . . . . . . . . . . . . . . . . 47

1.3.3 Economic viability . . . . . . . . . . . . . . . . 55

1.3.4 Identified research gaps and challenges . . . . . . . . . . . . 57

1.4 Objectives of the Thesis . . . . . . . . . . . . . . . 60

1.4.1 Main objective . . . . . . . . . . . . . . . 60

1.4.2 Secondary objectives . . . . . . . . . . . . . . . . 60

1.5 Summary of publications . . . . . . . . . . . . . . . . . . . 62

1.5.1 JCR Journal publications . . . . . . . . . . . . . . . . . . 62 
1.5.2 Non-JCR Journal publications . . . . . . . . . . . . . . . . 64

1.5.3 International Conferences . . . . . . . . . . . . . . . . . 64

1.6 Methodology . . . . . . . . . . . . . . . . . . . 66

2 Publications $\quad 69$

2.1 Paper-A: Optimal Energy and Reserve Scheduling of Pumped-Storage Power Plants Considering Hydraulic Short-Circuit Operation . . . . . . . . . . . . 69

2.2 Paper-B: Optimal Joint Energy and Secondary Regulation Reserve Hourly Scheduling of Variable Speed Pumped Storage Hydropower Plants . . . . . . 70

2.3 Paper-C: Economic Viability of Pumped-Storage Power Plants Participating in the Secondary Regulation Service . . . . . . . . . . . . . . . . 71

2.4 Paper-D: Value of Perfect Information of Spot Prices in the Joint Energy and Reserve Hourly Scheduling of Pumped Storage Plants . . . . . . . . . . . 73

2.5 Paper-H: Economic Impact of Forecasting Errors in Residual Reserve Curves in the Day-ahead Scheduling of Pumped Storage Plants . . . . . . . . . . . . . 74

2.6 Paper-E: Deriving Optimal End of Day Storage for Pumped-Storage Power Plants in the Joint Energy and Reserve Day-ahead Scheduling . . . . . . . . . . 75

3 Risk-averse model with look-ahead period $\quad 76$

3.1 Value of perfect information . . . . . . . . . . . . . 76

3.1 .1 Day-ahead energy prices . . . . . . . . . . . . . 77

3.1.2 Residual reserve curves of the secondary regulation reserve market . . . 77

3.1 .3 Secondary regulation energy prices . . . . . . . . . . . . 78

3.1.4 Real-time use of the committed secondary regulation reserves . . . . . . 79

3.2 Model formulation for VS-PSHP . . . . . . . . . . . . . . . . . 82

3.2 .1 Objective Function . . . . . . . . . . . . . . . . . . . 82

3.2.2 Risk-Aversion Constraints . . . . . . . . . . . . . . 83

3.2 .3 Water Balance . . . . . . . . . . . . . . . . . 84

3.2.4 Hydropower Generation . . . . . . . . . . . . . . . . . . 84

3.2.5 Secondary Regulation Service . . . . . . . . . . . . . . 86

3.2.6 Other Constraints . . . . . . . . . . . . . . . . 88

3.3 Model formulation for SC-PSHP . . . . . . . . . . . . . . . . . 89

3.4 Model formulation for FS-PSHP . . . . . . . . . . . . . . . 89

3.5 Case study . . . . . . . . . . . . . . . . . . . 90

3.6 Methodology . . . . . . . . . . . . . . . . 93

3.7 Results and discussion . . . . . . . . . . . . . . . . . . . . . . 94 
$\begin{array}{llr}4 & \text { Conclusions } & 98\end{array}$

4.1 Conclusions . . . . . . . . . . . . . . . . . . . . . 98

4.2 Future works . . . . . . . . . . . . . . . . . . . 103 


\section{List of Figures}

1.1 Scheme of a pumped-storage hydropower plant $[\mathrm{NHA}, \mathrm{b}] \ldots \ldots \ldots$

1.2 History of the development of installed nuclear power plants and PSHPs projects in the world $[\mathrm{NHA}, \mathrm{a}] \ldots \ldots \ldots \ldots \ldots$

1.3 Worldwide distribution of pumped-storage installed capacity (in GW) at the end of 2016 [IHA (International Hydropower Association), 2017] . . . . . . . . 19

1.4 Worldwide distribution of pumped-storage capacity planned or under construction at the end of $2015[\mathrm{IHA}, 2016] \ldots \ldots \ldots \ldots$

1.5 Generation and consumption curves of a variable-speed and fixed-speed pumpturbine unit for two given heads of the upper reservoir. . . . . . . . . . . 26

1.6 Pumped-storage power plant operating in hydraulic short-circuit mode [Illwerke, ] 28

1.7 I/O curve of a ternary unit in hydraulic short-circuit. Dashed line for generating mode, black dot for pumping mode and solid line for short-circuit mode . . . . 29

1.8 Scheme for the objectives of the Thesis . . . . . . . . . . . . . . . . . 61

1.9 Scheme for the articles included in the Thesis . . . . . . . . . . . . . . 62

1.10 Methodology to obtain the value of perfect information (VPI) of the random

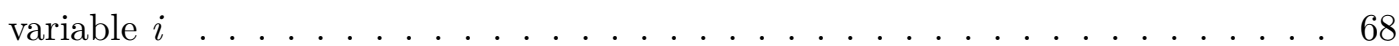

3.1 Annual income per MW of the installed capacity in generating mode of each PSHP equipped with fixed-speed pump-turbine units, participating only in the day-ahead energy market (left chart) and also in the secondary regulation service (right chart) with and without look-ahead period, and assuming perfect information . . . . . . . . . . . . . . . . . . . 94

3.2 Annual income per MW of the installed capacity in generating mode of each PSHP equipped with fixed-speed pump-turbine units, participating only in the day-ahead energy market (left chart) and also in the secondary regulation service (right chart) with and without look-ahead period, and with imperfect

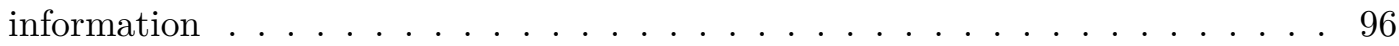


3.3 Annual income per MW of the installed capacity in generating mode of each PSHP equipped with fixed-speed (FS) or variable-speed pump-turbine units (15q and 30q), participating in the day-ahead energy market and in the secondary regulation service with look-ahead period and with imperfect information. The results are compared to the ones obtained from real PSHPs $\quad \ldots . \ldots$ 


\section{List of Tables}

1.1 Regulation ranges, in percentage of the maximum generation/consumption power, in each mode of operation for different types of PSHPs equipped with variable-speed pump-turbine units . . . . . . . . . . . . . . 27

1.2 Regulation ranges, in percentage of the maximum generation power, in each mode of operation for different types of PSHPs operated in hydraulic shortcircuit mode . . . . . . . . . . . . . . . . . . . 30

1.3 Typical operating characteristics of different thermal power plant technologies and for pumped-storage hydropower plants (based on [Deane et al., 2010]) . . . 35

1.4 Sessions of the Spanish intraday markets . . . . . . . . . . . . . 38

1.5 Summary of the revised articles from the technical literature . . . . . . . . 48

3.1 Cases to forecast the upward (ER2UP) and downward (ER2DW) secondary regulation energy prices, and the Mean Absolute Percentage Error (MAPE)

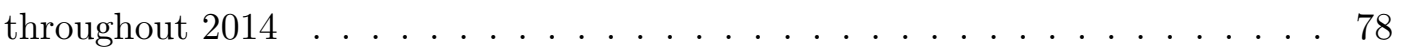

3.2 Economic results and the VPI-ER2 throughout 2014. Income, profit and VPI-

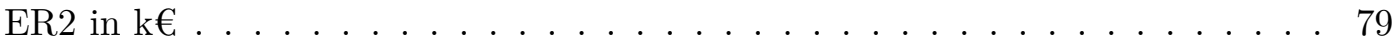

3.3 Cases to forecast the percentages of the upward and downward real-time use of the committed reserves, and the Mean Absolute Percentage Error (MAPE)

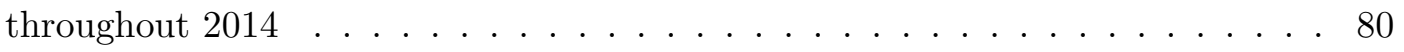

3.4 Economic results and the VPI-RTURs throughout 2014. Income, profit and VPI-RTURs in $\mathrm{k} € \ldots \ldots \ldots$. . . . . . . . . . . . . . . 81

3.5 Technical data of the fixed-speed pump-turbine units. $g$ refers to power, $q$ refers to flow and $c S U$ refers to start-up cost. Superscript $d$ refers to generating mode whereas $p$ refers to pumping mode. Flows in $\mathrm{m}^{3} / \mathrm{s}$, power in $M W$ and start-up costs in $€ \ldots \ldots \ldots \ldots \ldots$. . . . . . . . . . . . . . . . 91

3.6 Technical data of the variable-speed pump-turbine units with an operating range between the maximum and the $85 \%$ of the maximum pumped water . . . 91

3.7 Technical data of the variable-speed pump-turbine units with an operating range between the maximum and the $70 \%$ of the maximum pumped water . . . 92 


\section{Abstract}

This Thesis deals with the operation of closed-loop and daily-cycle pumped storage hydropower plants participating in the day-ahead energy market and in the frequency regulation service of the Iberian and the Spanish electricity systems, respectively. The pumped storage hydropower plants are equipped with variable-speed pump-turbine units or are operated in hydraulic short-circuit mode in order to further increase their flexibility.

Once the most relevant articles from the technical literature have been reviewed, the main gaps and challenges (detected and suggested to be carried out in the Thesis) can be summarised as follows:

1. There is a lack of optimisation models for the short-term operation of pumped storage hydropower plants equipped with variable-speed pump-turbine units, or operated in hydraulic short-circuit mode. Among others, their most promising advantage is that they are also able to regulate power in pumping mode, having the possibility to participate in the frequency regulation service also in the said mode as a controllable load.

2. Including the uncertainty of the real-time use of the assigned reserves is still a pending task that could contribute to obtain a more realistic operation of pumped storage hydropower plants in the frequency regulation service. Hence, the forecast, modelling and analysis of the economic impact of forecasting errors of the mentioned real-time use of reserves can be improved.

3. The hierarchical coordination between the long- and short-term to derive end-of-day water storages in the joint day-ahead energy and reserve scheduling of pumped storage hydropower plants is still pending to be further studied. The traditional operation strategy of starting the following day empty may not be optimum to participate in the frequency regulation service during the first hours of each day, when there is usually a big amount of base power plants with little or inefficient regulation capabilities.

In this Thesis, several risk-averse optimisation models with look-ahead period are developed for the proposed pumped storage hydropower plants: equipped with variable-speed pumpturbine units or operated in hydraulic short-circuit mode. The models are based on mixed 
integer quadratic programming. The pumped storage hydropower plants are assumed to be price-takers when they participate in the day-ahead energy market and price-makers when they participate in the frequency regulation reserve market. Uncertainty is considered in all the electric power system data of the problem, which are modelled and predicted according to the results of the analyses carried out in the Thesis when the value of perfect information is studied. The methodology based on a look-ahead period is used to derive the optimal end-of-day storages as a result of each run of the models.

The presented models in the Thesis aims at maximising the conditional value at risk, the net income from the day-ahead energy market (income due to the sold energy minus cost due to the purchased energy), the income for the reserves put at disposal of the transmission system operator, and the net income due to the activation of the committed reserves, whereas the start-up costs in generating and pumping modes are minimised. The optimal solution of the models is composed by the hourly schedules of the day-ahead energy market and for the frequency regulation reserves, in addition to the hourly schedules of the activation of the reserves. Among others, the operation of the plants is restricted to the technical limits of the pump-turbine units, the rules of the Iberian and Spanish electricity markets, and the limits of the storage capacity of the upper reservoir.

Furthermore, an estimation of the economic viability of pumped storage hydropower plants equipped with fixed-speed or variable-speed units and/or having the possibility to operate in hydraulic short-circuit mode is also carried out in the Thesis. The economic viability is estimated using the minimum number of years that the investment costs are expected to be recovered. The minimum number of years are estimated from the maximum theoretical incomes, which are obtained using the models developed in the Thesis, and the investment costs, which are estimated from available data in the technical literature.

The main results of this Thesis are resumed as follows:

1. The value of perfect information of the day-ahead energy market prices is significant (up to $29 \%$ of the maximum theoretical income). However, the participation in the frequency regulation service reduces notably the value of perfect information, comparing to participate only in the day-ahead energy market (from $40 \%$ to $29 \%$ of the maximum theoretical income). Furthermore, the value of perfect information of the electric power system data from the frequency regulation service (13\% of the maximum theoretical income) is significantly lower than the one of the day-ahead energy market prices.

2. The economic viability of pumped storage hydropower plants is not discarded, as the minimum number of years to recover the investment costs are in most cases lower than their lifetime, whether the investment cost is lower than 2.5 M€/MW. Moreover, the inclusion of the variable speed technology or the operation in hydraulic short-circuit 
mode significantly decrease the minimum number of years that the investment costs are expected to be recovered.

3. The methodology based on a look-ahead period enlarges the maximum theoretical income of the pumped storage hydropower plants if they only participate in the day-ahead energy market and if they also participate in the frequency regulation reserve service, in comparison to methodologies without a look-ahead period. 


\section{Resumen}

Esta Tesis se centra en estudiar la operación de centrales hidroeléctricas reversibles de bombeo puro y de ciclo diario participando en el mercado diario de energía eléctrica y en el servicio de control de frecuencia del sistema eléctrico ibérico y español, respectivamente. Las centrales reversibles está equipadas con grupos de velocidad variable u operadas en corto-circuito hidráulico, con la finalidad de incrementar más aún su flexibilidad.

Tras ser llevada a cabo la revisión de la literatura científica, los principales retos (detectados y que son incluidos en los objetivos de la Tesis) se presentan a continuación:

1. No se ha encontrado ningún modelo de optimización para la operación de centrales hidroeléctricas reversibles equipadas con grupos de velocidad variable u operadas en corto-circuito hidráulico. Entre otras ventajas de éstas, cabe destacar su capacidad de regular potencia también en modo bombeo, pudiendo participar en el servicio de control de frecuencia también en dicho modo.

2. Incluir la incertidumbre del uso de reserva de regulación no se ha llevado a cabo en la literatura científica. Dicha inclusión puede contribuir a obtener una operación de las centrales reversibles más realista en cuanto a su participación en el servicio de control de frecuencia. Por tanto, la predicción, modelado y análisis del valor de la información perfecta del uso de reserva serán tratados en la presente Tesis.

3. La coordinación entre el largo y corto plazo para obtener los volúmenes óptimos del vaso superior al inicio de cada día está pendiente de ser estudiado en detalle en el nuevo contexto de la participación de centrales reversibles en el servicio de control de frecuencia. La estrategia tradicional de operar las centrales reversibles comenzando cada día con el vaso superior vacío puede no ser óptima si la central participa también en el servicio de control de frecuencia.

En la Tesis se desarrollan diversos modelos de optimización con aversión al riesgo y utilizando información a futuro (look-ahead), para la operación de las mencionadas centrales reversibles equipadas con grupos de velocidad variable u operadas en corto-circuito hidráulico. Los modelos desarrollados están basados en programación cuadrática entera mixta. Las centrales 
reversibles son consideradas como tomadoras de precios en el mercado diario y como fijadoras de precios en el mercado de reserva. La incertidumbre está considerada en todas las variables aleatorias del problema, las cuales son modeladas y predichas de acuerdo con los resultados del valor de la información perfecta de la Tesis. La metodología propuesta utilizando información a futuro (look-ahead) es usada para obtener los volúmenes óptimos al inicio de cada día de explotación en cada ejecución de los modelos.

Los modelos propuestos en la Tesis tienen como objetivo maximizar el valor en riesgo condicional, el beneficio obtenido en el mercado diario (ingresos por energía vendida menos gastos por energía comprada), el ingreso obtenido en el mercado de reserva, y el beneficio obtenido por uso de las reservas, mientras que se minimiza los costes de arranque de los grupos en modo generación y consumo. La solución óptima de los modelos está formada por los programas horarios en el mercado diario y en el de reserva, así como el programa horario por el uso de las reservas. La operación de las centrales reversibles están sujetas a los límites técnicos de los grupos, a las reglas de los mercados ibérico y español, y a los límites de almacenamiento del vaso superior, entre otras.

Adicionalmente, se lleva a cabo en la Tesis la estimación de la viabilidad económica de centrales reversibles equipadas con grupos de velocidad variable y/u operadas en corto-circuito hidráulico. La viabilidad económica es estimada mediante el número mínimo de años necesarios para recuperar la inversión. Dicho número mínimo de años es estimado a partir de los ingresos máximos teóricos, los cuales son obtenidos a partir de los modelos desarrollados en la Tesis, y los costes de inversión de las centrales, los cuales son estimados a partir de la literatura científica.

Los principales resultados obtenidos en la Tesis se resumen a continuación:

1. El valor de la información perfecta de los precios del mercado diario es significativo (29\% de los ingresos máximos teóricos). Sin embargo, si la central reversible participa también en el servicio de control de frecuencia, dicho valor se reduce de manera notable (del $40 \%$ al $29 \%$ de los ingresos máximos teóricos). Adicionalmente, el valor de la información perfecta de las variables aleatorias asociadas el servicio de control de frecuencia $(13 \%$ de los ingresos máximos teóricos) es significativamente menor que el de los precios del mercado diario.

2. La viabilidad económica de centrales reversibles no está descartada si los costes de inversión son inferiores a 2.5 M€/MW, ya que el número mínimo de años para recuperar la inversión es mayor que su vida útil en la mayoría de los casos. Además, si las centrales reversibles están equipadas con grupos de velocidad variable u operadas en corto-circuito hidráulico, el número mínimo de años de recuperación de la inversión decrece de forma significativa. 
3. La metodología propuesta basada en utilizar información a futuro (look-ahead) aumenta los ingresos máximos teóricos de centrales reversibles tanto si únicamente participan en el mercado diario como si además también participan en el servicio de control de frecuencia, con respecto a los ingresos máximos teóricos obtenidos con metodologías que no usan información a futuro. 


\section{Chapter 1}

\section{Introduction}

Chapter 1 is organised as follows. The role of the pumped-storage technology in the electric power industry is presented in Section 1.1. The framework in which the pumped-storage hydropower plants participate (the electricity markets) is presented in Section 1.2. The rest of the Chapter includes the state of the art and motivation of the presented Thesis in Section 1.3, the main and secondary objectives of the Thesis in Section 1.4, the summary of the publications included in the Thesis in Section 1.5 and, finally, the resume of the overall methodology used in the Thesis in Section 1.6.

\subsection{The role of pumped-storage in the electric power industry}

Section 1.1 is divided into a brief description of the pumped-storage technology and its historical evolution in subsection 1.1.1, the role of the pumped-storage technology in the integration of renewable energy sources is presented in subsection 1.1.2, a resume of the main last technical development of pumped-storage hydropower plants for the provision of power regulation in pumping mode in subsection 1.1.3 and, finally, the role of pumped-storage technology from the system perspective is presented in subsection 1.1.4.

\subsubsection{Pumped-storage - Description of the technology and historical evol- ution}

The system of a pumped-storage hydropower plant (PSHP) is composed, in general, by an upper and a lower reservoir, and a power station formed by one or several hydropower units, Figure 1.1. The technology is based on: i) storing energy in the form of potential energy of water by pumping water (and therefore consuming energy from the grid) from the lower to the upper reservoir, and ii) transforming the stored energy into electricity injected into the grid, by discharging water from the upper to the lower reservoir. 
In centralised power systems, PSHPs have been traditionally operated by the so-called peak-shaving strategy [Deb, 2000]. The strategy is based on pumping water from the lower to the upper reservoirs at off-peak hours, and discharging water from the upper to the lower reservoir when the system demand is high. One of the main advantages of this strategy is the net social gain due to the operation of the thermal power plants close to their maximum efficiency, trying to achieve the same marginal cost in all the hours of the time horizon. The peak-shaving strategy is also called load-smoothing strategy [Crampes \& Moreaux, 2010].

In liberalised electricity markets, PSHPs have been traditionally operated by the so-called price-arbitrage strategy [Graves et al., 1999]. The strategy is based on selling energy (discharging water from the upper to the lower reservoirs) when energy prices are high, and purchasing energy (pumping water from the lower to the upper reservoirs) when energy prices are low.

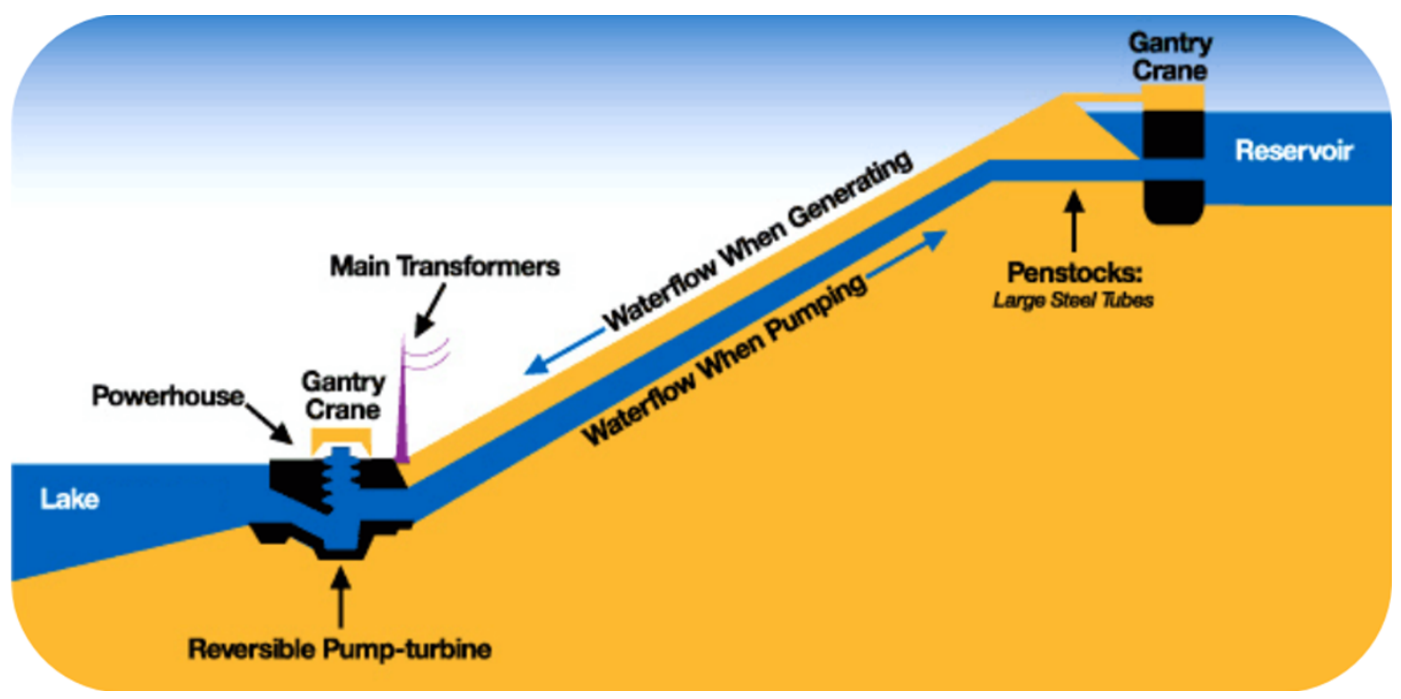

Figure 1.1: Scheme of a pumped-storage hydropower plant [NHA, b]

According to [Pérez-Díaz et al., 2015], the PSHPs can be classified by:

1. Closed-loop PSHPs (also called pure PSHPs or off-stream PSHPs [Deane et al., 2010]): the PSHP does not receive natural water inflows in the upper reservoir, and the lower reservoir can be or not in a river water course. For instance, all closed-loop PSHPs in Spain have the lower reservoir in a river water course so it does release and receive water. The presented Thesis deals with this type of PSHPs, assuming that the lower reservoir is not in a river water course.

2. Open-loop PSHPs: the PSHP does receive water inflows in the upper reservoir in the form of natural water inflows or water inflows from upstream reservoirs.

Besides, the PSHPs can be also classified as a function of their energy storage capacity, as follows: 
1. Daily-cycle PSHPs: the upper reservoir can be emptied or refilled in less than 12 hours at maximum water release rate or maximum pumped water rate, respectively. The traditional price-arbitrage strategy for these PSHPs consists in discharging water at peak hours of each day and pumping water at off-peak hours of each day, in the dayahead energy market. The scheduling horizon is from one day to few days. The presented Thesis deals with this type of PSHPs.

2. Weekly-cycle PSHPs: the upper reservoir can be emptied or refilled in between 12 hours and few days at maximum water release rate or maximum pumped water rate, respectively. The traditional price-arbitrage strategy for this PSHPs consists on discharging water at peak hours of the day-ahead energy market of each labour day (Monday to Friday), where the prices tend to be higher as the most expensive generators need to be committed, and pumping water at off-peak hours of each labour day and at the weekends, where prices tend to be lower. The scheduling horizon is from one week to few weeks.

3. Seasonal PSHPs: the PSHP can generate energy during months in which the day-ahead energy market prices are high (for example, in Winter or in Summer in Spain) and pump water during months in which the prices are low (for example, in Autumn or in Spring in Spain).

Furthermore, and according to [Pérez-Díaz et al., 2014a], the configuration of the power station of the PSHPs can be classified depending on the type of units with which they are equipped:

1. Binary unit (one hydraulic machine and one electrical machine): it is composed by a pump-turbine hydraulic unit and a motor-generator electrical machine. This type of unit was firstly introduced in the 1930s, and has become the dominant design for PSHPs in the world since then [Rehman et al., 2015]. The main reason for this is because they are the cheapest one. The most common configuration of a binary unit comprises a singlestage pump-turbine (i.e., with one impeller and volute to generate pressure) coupled to a synchronous electrical machine, directly connected to the grid. The unit rotates in one direction when injecting energy to the grid and in the opposite direction when consuming energy from the grid. Single-stage pump-turbine units can be used for heads between 10-700 m. There are many examples of PSHPs with binary units in the world. In [Deane et al., 2010], most of the new Austrian, Portuguese, Spanish and Swiss PSHPs that were expected to be in operation before 2016 are constructed with binary units.

2. Ternary unit (two hydraulic machines and one electrical machine): it is composed by a turbine, a pump and a motor-generator electrical machine. The latter is typically a 
synchronous machine. Prior to the introduction of binary units (1930s), this was the dominant type of unit that was used in the world. Nowadays, this type of unit is mainly used when single-stage pump-turbines are not appropriate (for example, for too large heads above $700 \mathrm{~m}$ ), or when the PSHP is designed to operate in hydraulic short-circuit mode (see [Mitteregger \& Penninger, 2008]). An example of a PSHP with ternary units is the Swiss PSHP of Veytaux, which belongs to the Swiss company Forces Motrices Hongrin-Léman [Lippold et al., 2012].

3. Quaternary unit (two hydraulic machines and two electrical machines): it is composed by a turbine, a pump, a motor and a generator electrical machines. The PSHPs usually have two different power stations: one for the pump and the motor and the other for the turbine and the generator. An example of a PSHP with quaternary units can be found in the Spanish wind-hydro power plant of Gorona del viento [Merino et al., 2012], at the Canary island of El Hierro and commissioned in 2014. The hydraulic circuit of the PSHP of Gorona del viento consists of one upper reservoir and one lower reservoir, connected to each other by two different penstocks, one for releasing water and the other one for pumping water.

The first PSHPs were commissioned at the end of the 19th century and at the beginning of the 20th century, in the Alpine regions of Switzerland, Austria, and Italy [Rehman et al., 2015] because those regions had (and still have) rich hydro resources, proper ground formations, and an appropriate difference in elevation between the upper and the lower reservoirs for PSHPs. Specifically, the earliest conceptual demonstration of a PSHP appeared in Zurich, Switzerland in 1882, whereas the earliest commissioned PSHP appeared in Schlaffhausen, Switzerland in 1909, with an installed capacity of 1.5 MW [Chalisgaonkar \& Mohan, 2015]. Several small PSHPs were constructed in Europe in the following decades, mostly in Germany, until the commission of the first large-scale PSHPs: the first plant over $20 \mathrm{MW}$ was opened near Dresden, Germany in 1928, and the first large-scale plant in the U.S. was the Rocky River PSHP, constructed in 1929 on the Housatonic River in Connecticut [Teale, 1930], with an installed capacity of $32 \mathrm{MW}$ in generating mode and 11.9 MW in pumping mode. Although the design of the Rocky River PSHP used separate pumps and turbines aligned with the motors and generators, respectively (quaternary units), ternary units were the dominant type of units up to the introduction of the first reversible pump-turbine units (binary units) in the 1930s. This advancement meant a crucial milestone in the history of PSHPs because they approximately saved $30 \%$ of the investment costs [Chalisgaonkar \& Mohan, 2015] and, currently, this is the most used scheme in the world [Pérez-Díaz et al., 2014a].

The development of PSHPs remained relatively slow until the 1960s, when State owned utilities in many countries began to build them in order to help the operation of the power 
system given the inflexibility of the increasing number of nuclear power plants that were installed. Many PSHPs were intended to complement nuclear power for providing peaking power in order to allow nuclear generators to operate almost permanently close to their highest efficiency [Crampes \& Moreaux, 2010] and to balance the system demand. Accordingly, the primary massive development of PSHPs occurred in the 1970s, and early 1980s in parallel with the construction of a large number of nuclear power plants [NHA, a]. Figure 1.2 depicts the worldwide evolution of the total installed capacity of nuclear power plants (yearly installed capacity in red bars and cummulated installed capacity in red line) and the total installed capacity of PSHPs (yearly installed capacity in blue bars and cummulated installed capacity in blue line) from the 1960s. It clearly shows the high commission of nuclear power plants and PSHPs in the 1970s and 1980s.

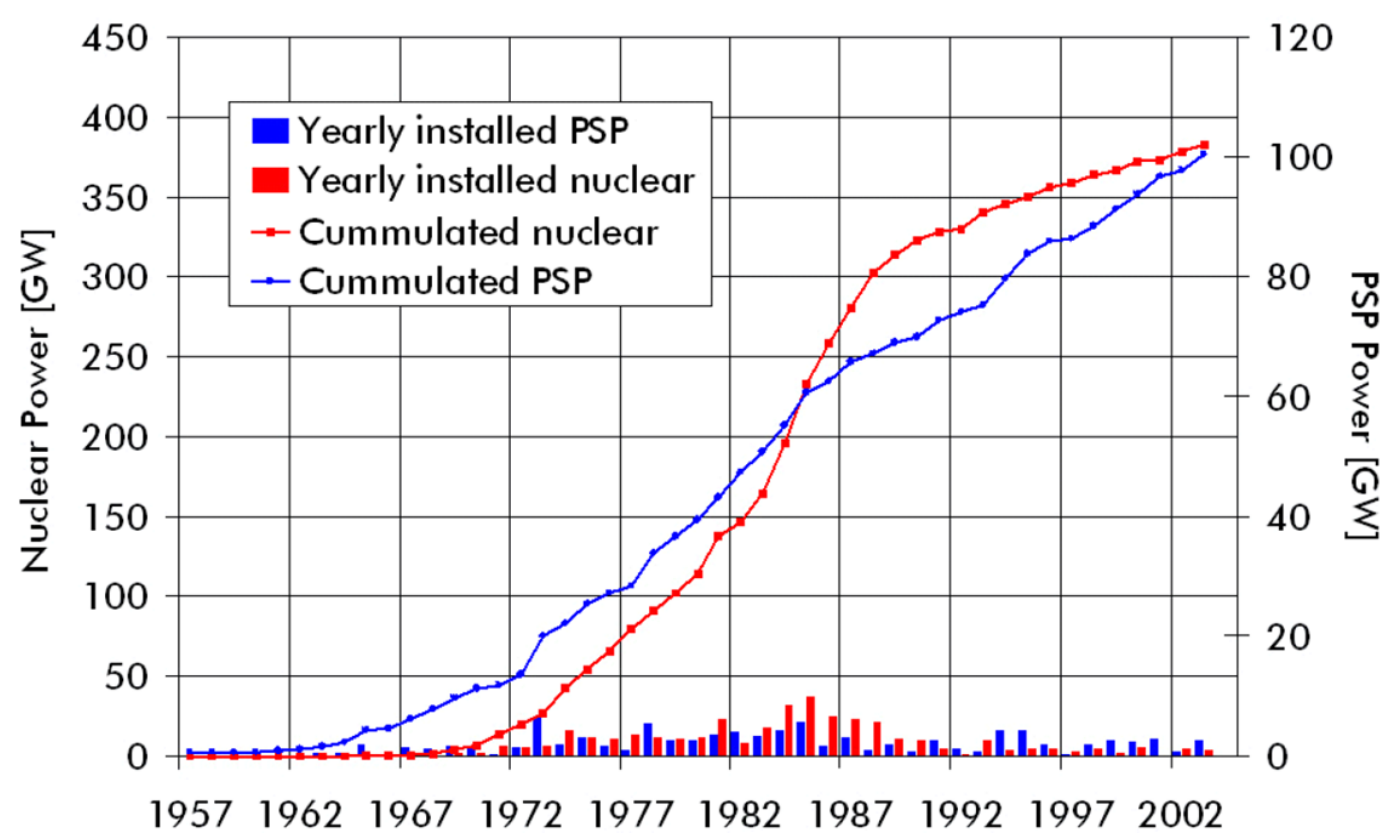

Figure 1.2: History of the development of installed nuclear power plants and PSHPs projects in the world $[\mathrm{NHA}, \mathrm{a}]$

In the 1990s, the development of PSHPs significantly slowed down in many countries. There were three main reasons for this. Firstly, the low prices of natural gas and the lower capital costs of gas power plants permitted them to be more competitive than PSHPs in supplying energy at peak periods [Rehman et al., 2015]. Secondly, environmental issues caused both the cancellation of many PSHPs projects and significantly prolonged the permitting process. For instance, in the U.S., the Federal Energy Regulatory Commission (FERC) issued 45 preliminary permits to study the feasibility of PSHP projects from 1986 to 2005. However, only seven of them obtained the license [Yang \& Jackson, 2011]. Thirdly, as it is well-known, electricity regulators in many countries restructured the power sector in the 1990s, positioning, in some of them, PSHPs as a non-power-generating facility because their net power output 
is negative ${ }^{1}$ (the typical round-trip efficiency of PSHPs is between 70-80\% [Teller, 2012]). Therefore, it was unclear how or whether PSHPs could participate in the context of the liberalised power sector. Continuing the case of the U.S. presented in [Yang \& Jackson, 2011], six of the seven PSHPs projects that obtained license from FERC were abandoned due to the above-mentioned market uncertainties.

Finally, in the period between the 2000s and the present, the increase of the interest in PSHPs from the industry and investors has become notable. For instance, there was an installed capacity of PSHPs of 36 GW in Europe by 2010 [Deane et al., 2010] and, according to [Ardizzon et al., 2014], it is expected to increase with extra 7.6 GW in the current decade. One of the main reason to this has been the high increase of the penetration of intermittent renewable energy sources (mainly wind and solar power). At the end of 2016, there were $154 \mathrm{GW}$ of pumped-storage installed capacity in the world [IHA (International Hydropower Association), 2017]. The worldwide distribution of pumped-storage installed capacity is shown in Figure 1.3, with Japan as still the country with the highest pumped-storage installed capacity in the world.

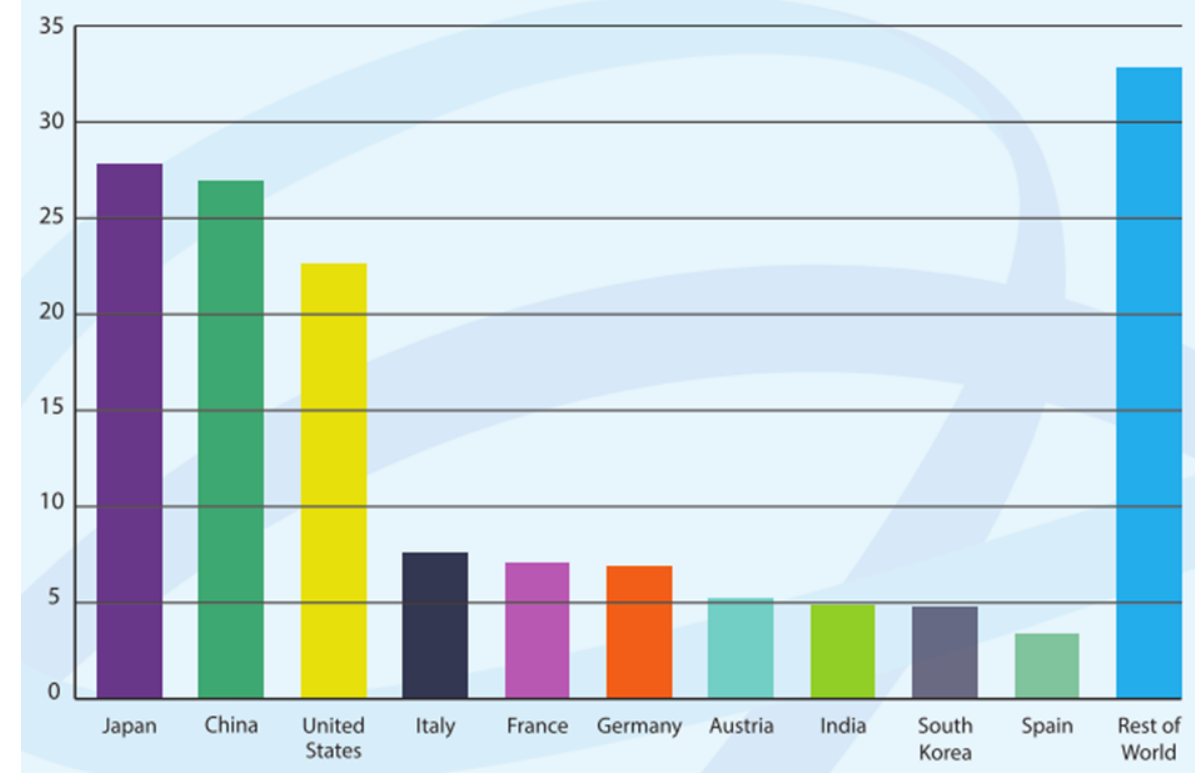

Figure 1.3: Worldwide distribution of pumped-storage installed capacity (in GW) at the end of 2016 [IHA (International Hydropower Association), 2017]

\footnotetext{
${ }^{1}$ Note that it did not happen in the Spanish electricity system as PSHPs were able to present offers of selling energy (at hours in which they were operated in generating mode) and bids for purchasing energy (at hours in which they were operated in pumping mode) since the liberalisation of the system in 1997.
} 


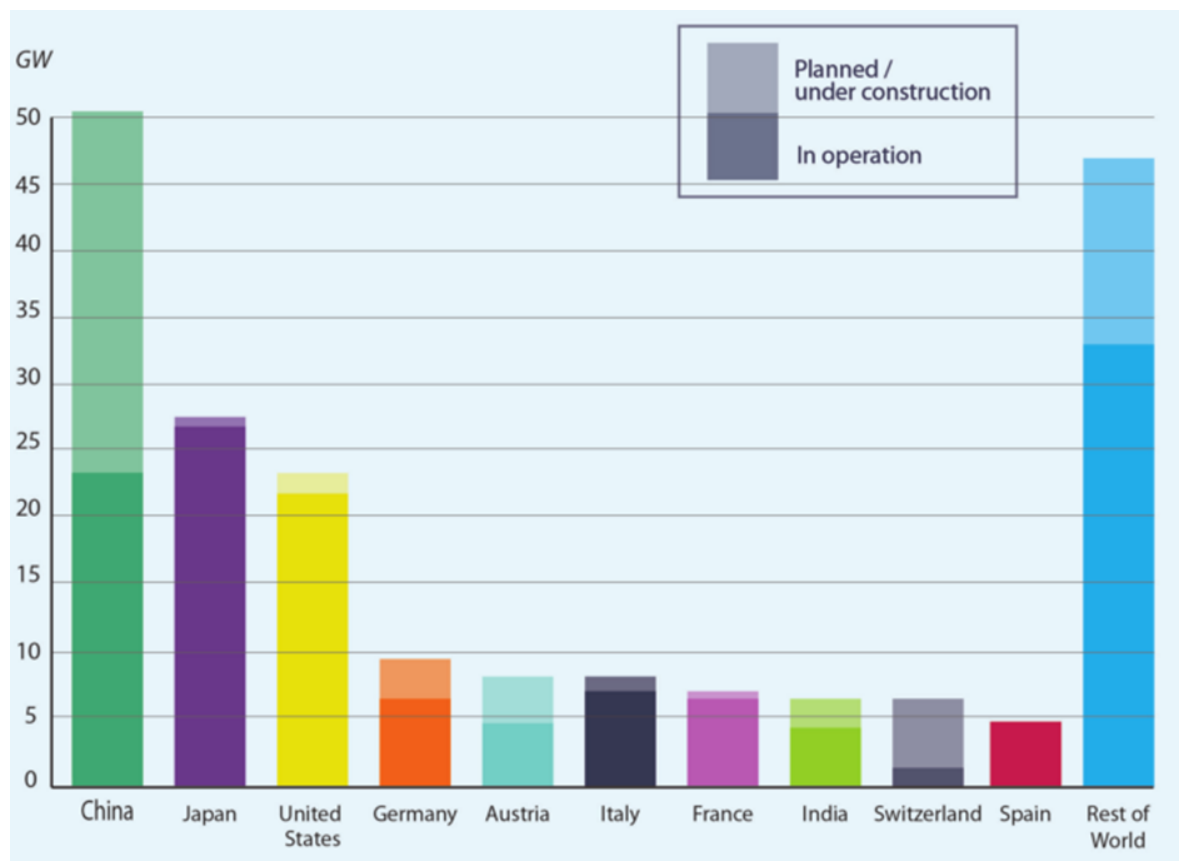

Figure 1.4: Worldwide distribution of pumped-storage capacity planned or under construction at the end of 2015 [IHA, 2016]

In addition to this, and according to the most updated information, presented in [IHA, 2016], the planned or under construction worldwide pumped-storage capacity was $59 \mathrm{GW}$ at the end of 2015. The worldwide distribution of pumped-storage capacity planned or under construction is shown in Figure 1.4, with China as the country with a tremendous planned increase in absolute terms and Switzerland in relative terms.

The new role of the PSHPs in the integration of even more intermittent renewable energy sources is further discussed in subsection 1.1.2 of this Thesis, with a likely promising future thanks to the last technical developments described in subsection 1.1.3, i.e., the variable speed technology and the operation in hydraulic short-circuit mode.

\subsubsection{The integration of renewable energy sources}

The installed capacity of wind and solar power has increased significantly in many countries during the last two decades thanks to, among others, different renewable energy support policies at European level firstly in [European Comission, 2009] and recently in [European Council, 2014], and worldwide [Ambrosio et al., 2017]. In [European Council, 2014], the European Council adopted, at the meeting on the 23-24 October 2014, an European Union target of at least $27 \%$ of all final energy consumption covered by renewable energy sources in order to reduce the greenhouse gases emissions and the energy dependency. This target is expected to be reviewed by 2020, having in mind an increase up to 30\%. The European Union target of $27 \%$ has been translated into $46-49 \%$ of the electricity production from renewable energy 
sources [European Wind Energy Association, 2015], expecting the European Commission an installed capacity of wind energy of $305 \mathrm{GW}$ in 2030, what means $176 \mathrm{GW}$ more than at the end of 2014 [European Wind Energy Association, 2015]. Furthermore, the installed capacity of wind and solar power is expected to increase even more due to the recognition in the COP $21^{2}$ that the current global policies will not guarantee global warming under $2^{\circ} \mathrm{C}$ in 2100 , and due to the announcement in the mentioned COP21 to create a financial credit of 100 billion dollars for trying to reach $1.5^{\circ} \mathrm{C}$ as a feasible target for maximum global warming [Ambrosio et al., 2017].

There are important advantages related to the promotion of renewable energy sources. Among others, their fuel costs are zero (although their variable costs are not zero since their operational and management costs cannot be neglected). Therefore, each MWh that replaces production from fossil thermal power plants saves fuel costs for the electric power system. In addition, the reduced production of fossil-fuel-fired power plants lowers the overall emissions in the system [Weigt, 2009].

Among all renewable energy sources, wind seems to be at present the most commercially and economically competitive renewable energy source [Caralis et al., 2012] and the one with the largest potential [Lu et al., 2009]. This is confirmed by studies such as [Ortega et al., 2013], where the benefits and costs of the power generation from renewable energy sources in Spain in the period 2002-2011 were assessed. Benefits are monetary quantified for the $\mathrm{CO}_{2}$ avoided emissions and for the reduction of fossil-fuel imports whereas costs refer to the public support of renewable energy sources through the feed-in-tariff system. The authors showed that the benefits were higher than the costs for wind power and small hydro power, specially in the former, whereas the costs were higher than the benefits for solar photovoltaic power plants and solar thermoelectric power plants, specially in the former. Or it is also confirmed by studies such as [Weigt, 2009], in which the authors found that the cost-saving potential for electricity production of wind power is significant and exceeds the subsidies in the context of the German electricity system.

Furthermore wind power has an impact, among others, in the day-ahead energy market prices. For instance, [Sáenz de Miera et al., 2008] analyses the impact of increased wind power in the day-ahead energy market prices of the Spanish electricity system. By applying a simulation analysis of the system dispatch, authors show a negative correlation between wind power and energy prices. In the period 2005-2007, mean price reductions of 9-25\% were observed. In addition, wind power also has an impact in the requirement of ancillary services of an electric power system. For example, [González et al., 2014] observed that the amount of ancillary services and consequently, the economic volume negotiated in the cor-

\footnotetext{
${ }^{2}$ Note that COP stands for the Conference of the Parties, referring the "Parties" to the countries that have signed up to the 1992 United Nations Framework Convention on Climate Change.
} 
responding markets of the Spanish electricity system, have increased during recent years due to the increase of the penetration of intermittent renewable energy sources (from a monthly contribution, in $\%$, of the ancillary services into the final average cost of the electricity in the Spanish market around $4.5 \%$ at the beginning of the 2000 s to $7.5 \%$ at the beginning of the 2010s), and are expected to increase because the Spanish government is intended to reach the $40 \%$ of the total electricity generation to be supplied by renewable sources by 2020 [Ministerio de Industria Turismo y Comercio de España, 2010].

Wind power presents the highest variability among the commercially available renewable energy sources, and it is the most difficult to predict [Greaves et al., 2009]. Therefore, the presence of high levels of wind power is challenging the operation of power systems [Holttinen et al., 2011]. On the one hand, wind power inherent variability and uncertainty require more advanced scheduling models, having a direct impact on the amount and type of the required operation reserves [Ela et al., 2011]. On the other hand, both wind and solar power generators cannot decide to defer their generation as they are subject to the instantaneous meteorological conditions. Thus, curtailments in the renewable energy sources can occur in case of having an excess of supply (particularly during off-peak hours) when conventional generators cannot reduce their output due to technical constraints.

In this context, increasing the electrical energy storage, both at a local and at a system level, is considered as a natural way to mitigate this problem [Díaz-González et al., 2012]. Among all the energy storage technologies, pumped-storage is the one with the highest lifetime, among the ones with the highest number of charging-discharging cycles, storage durability and round-trip efficiency, and without being among the ones with the highest total capital costs [Zakeri \& Syri, 2015]. Therefore, PSHPs can play an important role in the integration of more intermittent renewable energy sources.

Three main advantages can make PSHPs play an important role in the integration of intermittent renewable energy sources:

- The technology permits to store large amounts of energy, being possible to use an existing water reservoir as lower reservoir and build a small upper reservoir with a low capacity but sufficient for at least 1-3 days of cycle operation.

- The surplus energy in the system can be stored fast and with high efficiency (the typical efficiency in pumping mode is $90 \%$ ). Besides, the conversion of the stored energy into electrical energy that is injected into the grid is also done quickly and efficiently (the typical efficiency in generating mode is between $75-90 \%$ ).

- The technology is considered as a mature and reliable technology. As it is above explained, the first PSHP was commissioned in 1909, therefore, the technology has been applied for more than a century. 
Several papers can be found in the technical literature studying the contribution of PSHPs, equipped with fixed-speed pump-turbine units, to the integration of renewable energy sources (mainly wind power). In [de Boer et al., 2014] and [Tuohy \& O'Malley, 2011], the contribution of PSHPs to reduce the curtailed wind energy in the Dutch and Irish power systems, respectively, considering different levels of wind power penetration, is studied. Results show that PSHPs reduce the amount of curtailed wind energy. In [Foley et al., 2015], the impact of PSHPs in the generation capacity expansion plans of the Northern Ireland power system is analysed considering different levels of installed wind power capacity and costs of fuel and emissions. In [Pérez-Díaz \& Jiménez, 2016], the impact of the installation of a new PSHP for different levels of extra penetration of wind power in the Great Canary island in Spain is studied. Results show that the presence of the PSHP mitigates wind curtailments in all cases. Besides, as the installed capacity of the PSHP increases, its contribution in the integration of wind power in the system increases. The percentage of the available wind power used for pumping is between 7-30\%. In [Ummels et al., 2008], it is estimated the decrease in curtailed wind energy thanks to PSHPs, by using heuristic algorithms and dynamic programming. Results show that the solution formed by combined heat and power plants is found to be more profitable for the integration of large-scale wind power in the Netherlands than PSHPs. It is important to remark that the contribution of PSHPs, equipped with variablespeed pump-turbine units, to the integration of renewable energy sources, is also studied in [Caralis et al., 2012]. Results show that all the cases with variable-speed PSHPs store a higher percentage of the wind energy surplus and have a higher degree of utilisation than the cases with fixed-speed PSHPs.

The combination between an intermittent renewable energy source with a PSHP is considered as a solution to mitigate the above-mentioned inherent problems of the former (variability and difficulty to predict) by means of the following:

- The PSHP can produce the extra power needed for the renewable energy source if the real-time production of the latter is lower than the one previously assigned in the dayahead energy market, avoiding deviation costs.

- The PSHP can consume the extra power produced by the renewable energy source if the real-time production of the latter is higher than the one previously assigned in the day-ahead energy market, avoiding unprofitable energy curtailments.

Several hybrid generation-storage systems comprising renewable generation (wind and/or solar photovoltaic, PV) and PSHPs have been studied in the technical literature in order to reduce the disadvantages of the intermittent renewable energy sources, and make the investment in the latter more profitable and its penetration much higher [Rehman et al., 2015]. The concept under the hybrid generation-storage systems is the following: the power produced 
by the renewable energy source (wind and/or solar photovoltaic) is injected to the grid, and the extra energy during, typically, off peak hours is used to pump water from a lower to an upper reservoir in the PSHP. The water from the upper reservoir is released through the turbines to inject energy to the grid during peak hours, or to mitigate deviations of the renewable energy source production. Examples of papers where a wind-PSHP system is studied can be seen in [Kapsali et al., 2012], where a solar PV-PSHP system is studied can be seen in [Ma et al., 2015], and where a solar PV-wind-PSHP system is studied can be seen in [Ma et al., 2014]. Note that hybrid wind and/or solar PV, and PSHP systems have been mainly studied in the context of isolated power systems.

It is important to remark that the PSHPs can play even a more important role in the integration of even more intermittent renewable energy sources whether the last technical developments (the variable speed technology and the operation in hydraulic short-circuit mode), which are described in subsection 1.1.3, are further studied and investigated.

\subsubsection{Last technical developments}

Two recent technical developments in PSHPs are being given special attention by diverse stakeholders in the electricity sector: i) the variable speed technology, which is further described in subsection 1.1.3.1, and ii) the operation in hydraulic short-circuit mode, which is further described in subsection 1.1.3.2. Although the Thesis author refers to them as "last technical developments", it must be said that the former is 30 years old whereas the latter is at least 9 years old, as it will be mentioned below. Among others, the most promising characteristic of these technical developments is that the PSHPs are also able to regulate power in pumping mode, having the possibility to also participate in the frequency regulation service in the said mode as a controllable load. This characteristic permits not only to integrate even more intermittent renewable energy sources but also to enlarge the income that the PSHP owner can obtain from the reserve markets. The latter is further studied in the presented Thesis.

\subsubsection{Variable speed technology}

As far as the Thesis author knows, the Kansai Electric Power company and Hitachi commissioned in 1987 the first demonstration of a PSHP equipped with variable-speed units with the Narude PSHP [Nagura et al., 2010], which had an installed capacity of 17.5 MW. Three years later, in 1990, the 87.4-MW variable-speed unit 2 of the Yagisawa PSHP, owned by the Tokyo Electric Power company and constructed by Toshiba, became operational [Furuya et al., 1993]. In 1995, the two largest variable-speed units of the world (400 MW each) was commissioned in the Ohkawachi PSHP, owned by the Kansai Electric Power com- 
pany [Kuwabara et al., 1996]. During the 1990s, the introduction of PSHPs equipped with variable-speed units took place mainly in Japan, with at least four extra PSHPs, and in China with the Panjiakou PSHP [Galasso, 1991]. An example of the four extra PSHPs equipped with variable-speed units in Japan during the 1990s is the Okukiyotsu PSHP, with two 300-MW units [Pérez-Díaz, 2008]. Furthermore, two PSHPs are interesting to be mentioned regarding the earliest installations of variable-speed units in Europe: the German PSHP of Forbach with a 20-MW unit, installed in 1991, and the Spanish PSHP of Compuerto, which was chosen for a pilot project installing one of the two units with variable-speed in 1994 (with a rated power of $10 \mathrm{MW}$ ) [Merino \& Lopez, 1996]. In the 2000s, large variable-speed PSHPs were also commissioned in Europe, being the German Goldisltahl PSHP the first one commissioned in 2002 [Grotenburg et al., 2001], with two of the four units equipped with variable speed (300 MW each). In this period, the interest in variable-speed PSHPs has increased considerably in Europe, with $1060 \mathrm{MW}$ of installed capacity, which is expected to further increase by 4410 MW in the period 2011-2020 [Sivakumar et al., 2014]. Manufacturers that have supplied hydraulic machines (pump-turbines), electrical machines (motors-generators), rotor excitation and control systems for variable-speed PSHPs include Toshiba, Hitachi, Mitsubishi, Andritz, Alstom, General Electric, ABB and Voith [Koritarov et al., 2014b].

Currently, there are two different types of pump-turbine units that can operate with variable speed: 1) the unit is equipped with a synchronous machine and a converter between the stator and the grid [Schlunegger \& Thöni, 2013] or 2) the unit is equipped with a doubly-fed induction machine and a converter between the rotor and the grid [Bocquel \& Janning, 2005]. The converter rating in the former case is the same as the machine rating, introducing higher costs and power losses. Therefore, this scheme is only used in a few cases with high demands on the operating range [Are Suul, 2009]. The converter rating in the latter case is usually $20 \%$ of the machine rating [Kunz, 2015], reducing the costs and power losses. Thus, the second scheme is the most popular one in current power systems [Pérez-Díaz et al., 2015].

The main advantage of variable-speed pump-turbine units is that they are able to regulate power in pumping mode. The variable speed allows the head-flow curve of the pump to be shifted, thus allowing the flow-power relation to be adjusted within a certain range. Thanks to this advantage, the variable speed PSHPs have the possibility to also participate in the frequency regulation service in pumping mode. Other advantages are summarised as follows [Are Suul, 2009], [Pérez et al., 2008] and [Henry et al., 2012]:

1. they have the possibility to improve the hydraulic efficiency in both, generating and pumping mode because the speed corresponding to the maximum hydraulic efficiency is different for the operation in each mode, and also changes with the net head.

2. they have the possibility to be operated in a wider head range by allowing the head-flow 
curve and cavitation-flow curve to move together towards higher or lower heads.

3. problems with water hammering in the turbine can be more easily controlled.

4. the response speed of active power control increases.

5. the range of reactive power control increases.

In order to squeeze as much as possible the above-mentioned potential benefits of PSHPs equipped with variable-speed units, it is necessary to implement certain features in the day-ahead energy and reserve scheduling models. This entails to adapt and modify the input/output curves of the pump-turbine units as outlined in Figure 1.5. The solid lines in generating mode (first quadrant) and the single dots in pumping mode (third quadrant) correspond to a fixed-speed pump-turbine unit whereas the dotted lines in generating and pumping modes correspond to a variable-speed pump-turbine unit.

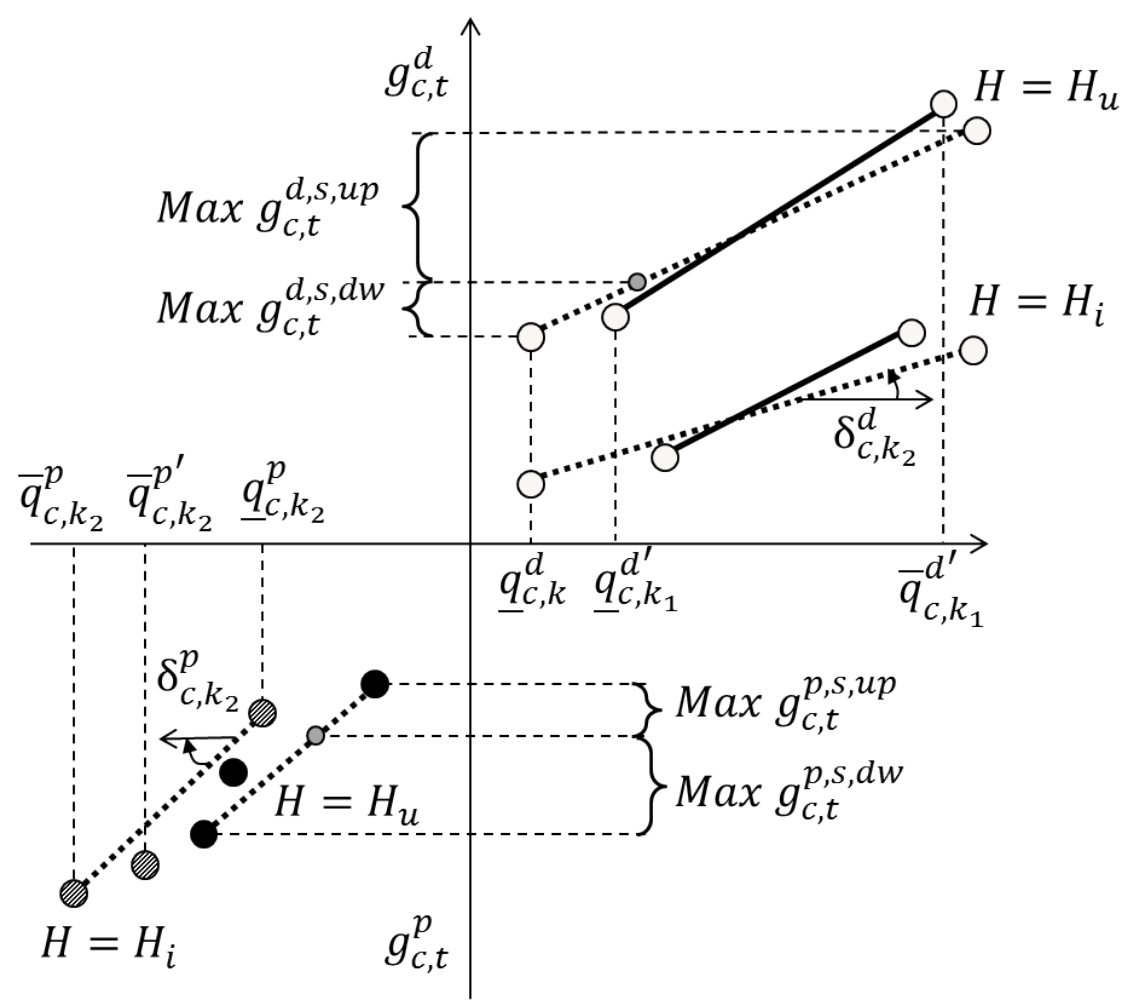

Figure 1.5: Generation and consumption curves of a variable-speed and fixed-speed pumpturbine unit for two given heads of the upper reservoir.

The input/output curves in generating and pumping modes, with both fixed speed and variable speed, will strongly depend on the pump-turbine performance curves and the electrical efficiency. Figure 1.5 corresponds to the most common case, in which: the water discharge range in generating mode with variable speed is wider than the one with fixed speed, both at the maximum efficiency head $\left(H_{u}\right)$ and at a lower head $\left(H_{i}\right)$; the power generation of a unit $c$ 
in the time period $t, g_{c, t}^{d}$ at design flow $\left(\bar{q}_{c, k}^{d}\right)$ is lower with variable speed since the increase of the hydraulic efficiency is lower than the decrease of the electrical efficiency due to the losses in the converters; and the power consumption $g_{c, t}^{p}$ at design flow $\left(\bar{q}_{c, k}^{p}\right)$ is higher with variable speed since the increase of the hydraulic efficiency is lower than the decrease of the electrical efficiency due to the losses in the converters.

In order to participate in the frequency regulation service, the maximum upward reserve of a unit $c$ in the time period $t, \max g_{c, t}^{d, s, u p}$, in generating mode is the difference between the maximum minus the current generated power whereas the maximum downward reserve, $\max g_{c, t}^{d, s, d w}$, in generating mode is the difference between the current minus the minimum generated power, first quadrant of Figure 1.5. In pumping mode, the maximum upward reserve of a unit $c$ in the time period $t, \max g_{c, t}^{p, s, u p}$, is the difference between the current minus the minimum consumed power whereas the maximum downward reserve, $\max g_{c, t}^{p, s, d w}$, is the difference between the maximum minus the current consumed power.

TABLE 1.1: Regulation ranges, in percentage of the maximum generation/consumption power, in each mode of operation for different types of PSHPs equipped with variable-speed pump-turbine units

\begin{tabular}{|c|c|c|}
\hline & \multicolumn{2}{|c|}{ Regulation range } \\
\hline PSHP & Generating mode & Pumping mode \\
\hline \hline FS & $100-49.8 \%$ & No regulation \\
\hline VS-FF & $100-17.7 \%$ & $100-58.7 \%$ \\
\hline VS-BFF & $100-53.9 \%$ & $100-58.7 \%$ \\
\hline VS-DF & $100-49.2 \%$ & $100-82.2 \%$ \\
\hline
\end{tabular}

Table 1.1 summarises the regulation ranges in generating and pumping modes for different types of PSHPs equipped with variable-speed pump-turbine units in comparison to a PSHP equipped with fixed-speed pump-turbine units. A FS PSHP stands for a PSHP whose units are equipped with a Francis pump-turbine without frequency converter. A VS-FF PSHP stands for a PSHP whose units are equipped with a Francis pump-turbine and a synchronous machine connected to the grid through a frequency converter with the same power rating as the synchronous machine. A VS-BFF PSHP stands for a PSHP in which the frequency converter of the VS-FF is bypassed in generating mode by connecting the stator directly to the grid through a suitable bypass switch. A VS-DF PSHP stands for a PSHP with an induction machine whose rotor is connected to the grid through a frequency converter with a power rating lower than the one of the induction machine in the VS-FF PSHP. 


\subsubsection{Operation in hydraulic short-circuit mode}

As far as the Thesis author knows, there are only four PSHPs in the world that can be operated in hydraulic short-circuit mode: Kops II, Malta, Geesthacht and Luenersee. Kops II, owned by Vorarlberger Illwerke (Austria), was commissioned in 2008 and it is the most documented one [Mitteregger \& Penninger, 2008], [Kop, ]. The power station scheme of a PSHP operating in hydraulic short-circuit mode is presented in Figure 1.6, in which the PSHP is consuming $150 \mathrm{MW}$ with the pump and is generating $50 \mathrm{MW}$ with the turbine, consuming a net power of $100 \mathrm{MW}$ from the grid. The scheme presented in Figure 1.6 has a single ternary unit, which is composed by a Pelton turbine, a fixed-speed pump and a motor/generator electric machine, all connected vertically. Thanks to a clutch, both the turbine and the pump of the ternary unit can be operated simultaneously. The main advantage of this is that the PSHP is able to regulate power (and therefore, to participate in the frequency regulation service) while it is consuming energy, with a power regulation range equals to that of the turbines in operation. In other words, the PSHP operating in hydraulic short-circuit mode can be considered as a controllable load, contributing to a much better integration of intermittent renewable energy and to balance generation and demand in real time better than PSHPs equipped with fixed-speed pump-turbine units.

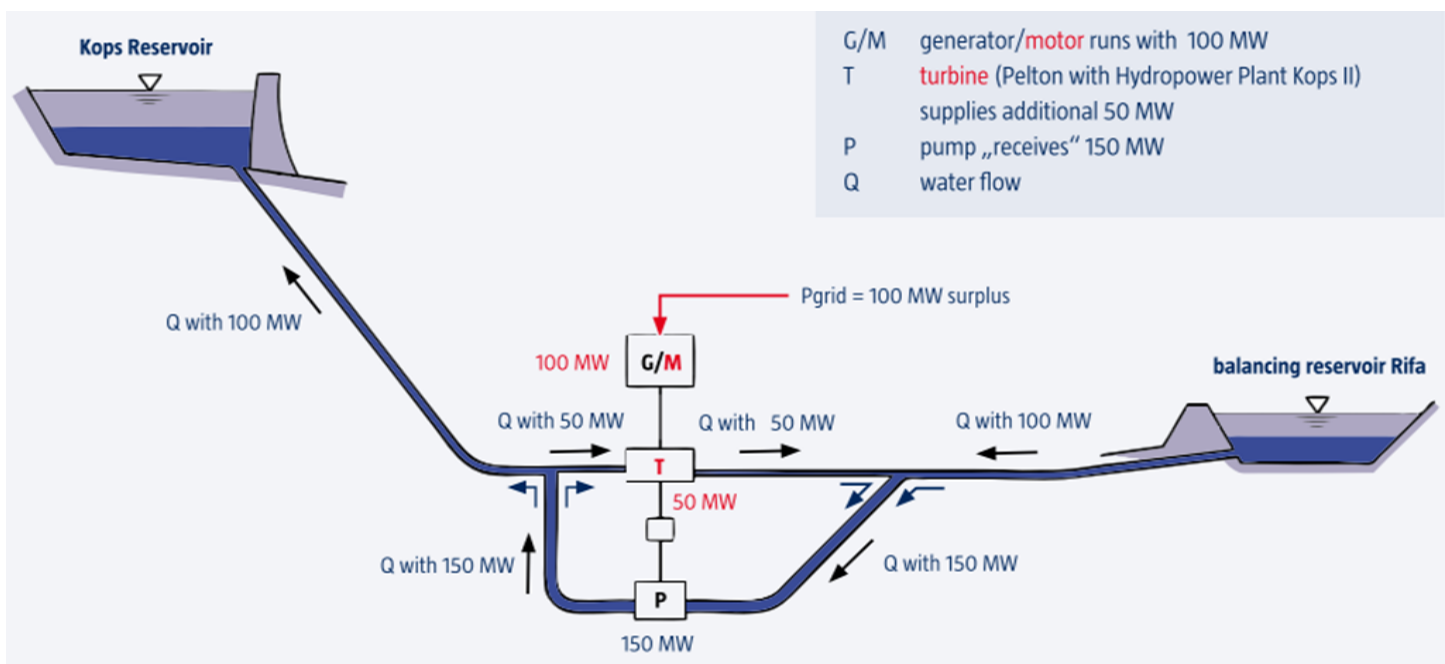

Figure 1.6: Pumped-storage power plant operating in hydraulic short-circuit mode [Illwerke, ]

From the point of view of modelling, three operating modes must be taken into account: generating, pumping and hydraulic short-circuit modes. The Input/Output curve of a single ternary unit, for a certain water level in the upper reservoir is presented in Figure 1.7. In generating mode (dashed line), water is discharged from the upper to the lower reservoir through the Pelton turbine (while the pump is off) and energy is injected to the grid. When the unit is operated in pumping mode (black dot), water is pumped from the lower to the upper reservoir through the fixed-speed pump and energy is consumed from the grid. Finally, 
when the unit is operated in hydraulic short-circuit mode (solid line, obtained by means of a simple translation of the generating mode curve in such a way that the origin is moved to the point that corresponds to the pumping mode at fixed rate, i.e., the black dot), both turbine and pump are on. A percentage of water that is taken from the lower reservoir is pumped to the upper reservoir and the rest is passed through the turbine, which is in charge of regulating the net output power if necessary. The maximum upward reserve of a unit $c$ in the time period $t, \max g_{c, t}^{s e c, u p}$ and the maximum downward reserve, max $g_{c, t}^{s e c, d w}$ in both, generating and hydraulic short-circuit modes are shown in Figure 1.7 (it is not possible to regulate in pumping mode since the pump operates with fixed speed). Frequency regulation reserves that are requested in real time are supplied as following: upward and downward regulation energy is delivered by increasing and decreasing, respectively, the water discharge through the turbines.

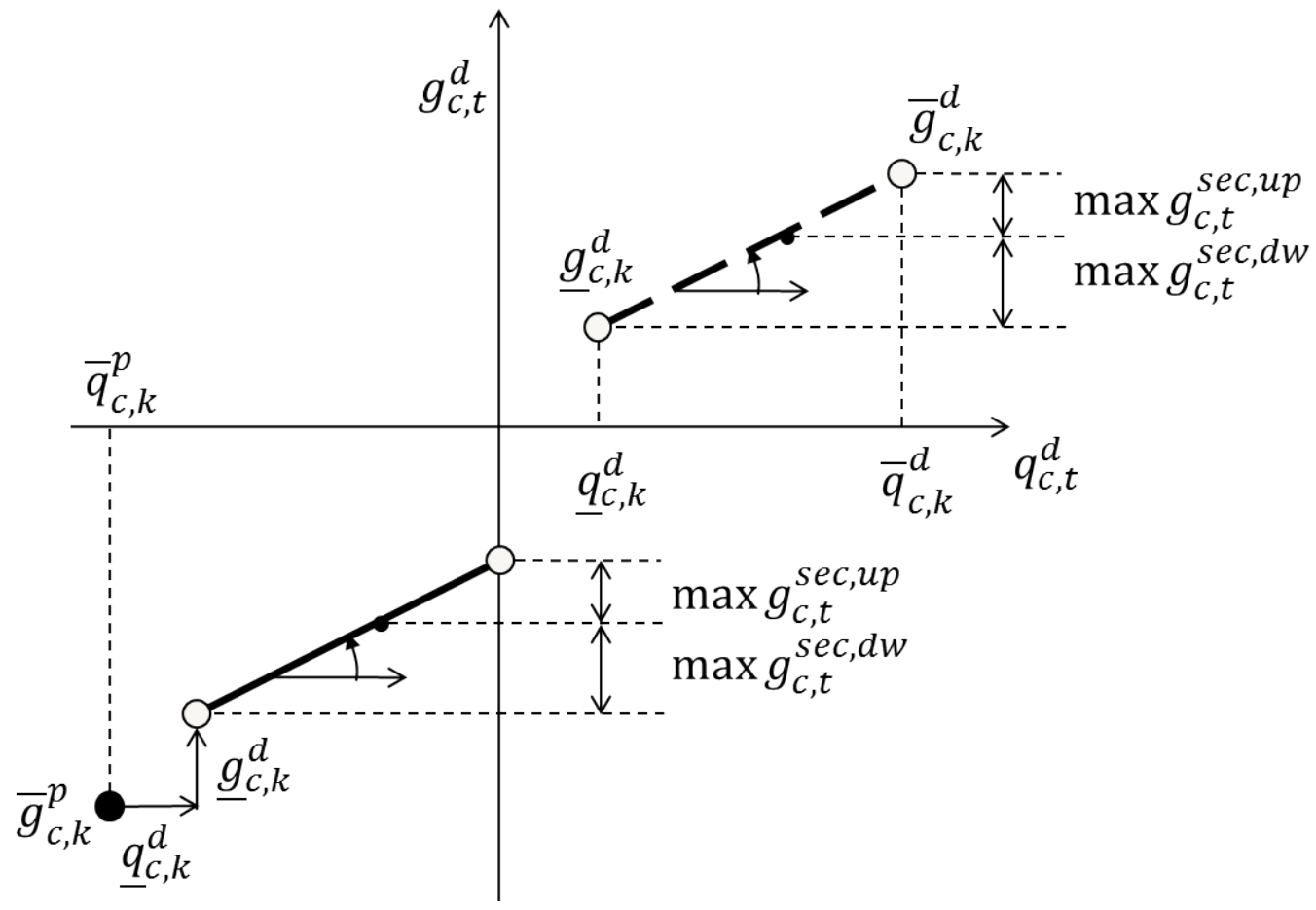

Fig. 1.7: I/O curve of a ternary unit in hydraulic short-circuit. Dashed line for generating mode, black dot for pumping mode and solid line for short-circuit mode

If the PSHP is composed by several ternary units, all pumps and turbines can be operated simultaneously in hydraulic short-circuit mode, with a total regulation range equals to that of all turbines in operation. Finally, although as far as the Thesis author knows there is no PSHP operating in hydraulic short-circuit mode with binary units, theoretically, they could be also operated in the said mode, as long as they comprise two or more units (at least one unit must operate in pumping mode and another in generating mode). Nonetheless, the power regulation range of PSHPs operating in hydraulic short-circuit mode with binary units is significantly 
lower than with ternary units, since each binary unit must be operated as a turbine or as a pump but not simultaneously in both modes. Furthermore, the power regulation range of a Francis pump-turbine is notably lower than that of a Pelton turbine. In the presented Thesis, the operation and income of a PSHP with ternary units operating in hydraulic short circuit mode are compared, among others, to those of a conventional PSHP with binary units and with a PSHP operating in hydraulic short circuit mode with binary units.

TABLE 1.2: Regulation ranges, in percentage of the maximum generation power, in each mode of operation for different types of PSHPs operated in hydraulic short-circuit mode

\begin{tabular}{|c|c|c|c|}
\hline & \multicolumn{3}{|c|}{ Regulation range } \\
\hline PSHP & Generating mode & Pumping mode & Hydraulic SC mode \\
\hline \hline FS & $100-49.8 \%$ & No regulation & Not applied \\
\hline SC-B & $100-49.8 \%$ & No regulation & $100-49.8 \%$ \\
\hline SC-TF & $100-24.4 \%$ & No regulation & $100-24.4 \%$ \\
\hline SC-TP & $100-14.5 \%$ & No regulation & $100-14.5 \%$ \\
\hline
\end{tabular}

Table 1.2 summarises the regulation ranges in generating, pumping and hydraulic shortcircuit modes for different types of PSHPs with the possibility to be operated in hydraulic short-circuit mode in comparison to a PSHP equipped with fixed-speed pump-turbine units. A FS PSHP stands for a PSHP whose units are equipped with Francis pump-turbines without frequency converter. A SC-B PSHP stands for a PSHP similar to the FS PSHP but with the possibility of being operated in hydraulic short-circuit mode. A SC-TF/SC-TP PSHP stands for a PSHP equipped with ternary units with Francis/Pelton turbines, respectively, and being operated in hydraulic short-circuit mode.

\subsubsection{System perspective analysis}

PSHPs are pretty versatile, and are able to provide many benefits to the power system in which they are installed. A resume of the detected benefits are here presented based on [Koritarov et al., 2014a], [Ibrahim et al., 2008] and [Koritarov et al., 2014b]. The resume presents not only a qualitative but also a quantitative assessment of the benefits.

- Inertial response: in a power system, frequency must be maintained within a narrow band around its nominal value (50 Hz in Europe). To achieve this, the amount of mechanical power produced by the generators must match the power being consumed by the demand in real-time. Any imbalance causes an accelerating torque that i) increases the speed of the rotating machines, and thus the frequency, if the total generated mechanical power is greater than the demand, or ii) decreases the speed of the rotating machines, and thus the frequency if the total mechanical power is less than the demand. As it was 
mentioned in subsection 1.1.2, the installed capacity of intermittent renewable energy sources have increased significantly during the last two decades. As most of them are connected to the grid through power electronic converters, they do not have rotating inertia. Therefore, the higher the penetration of intermittent renewable energy sources, the lower the total inertia of the power system, leading to higher frequency decay rates due to power imbalance, and to lower minimum frequency reached in the dynamic response [Iswadi et al., 2015]. A PSHP has the ability to supply inertial response to the system because it is equipped with conventional rotating machines with inherent inertial response due to the physics of the device.

- Frequency regulation: in Europe, it is common to refer to three sorts of frequency regulation services, depending on the activation time after a disturbance. The three frequency regulation services are: primary, secondary and tertiary regulation services. Also called, respectively, frequency containment, restoration and replacement. Each one is further described as follows:

- Primary regulation service: nomenclature with respect to the frequency-control services in the American and European power systems significantly differs. In the former, it has been detected the regulation reserves, the spinning reserves, the non-spinning reserves and the replacement reserves whereas in the latter, it is used the primary, secondary and tertiary regulation reserves. In this Thesis, the European nomenclature is used because that is based on the Spanish power system. The comparison between reserves in the U.S. and European power system follows the one presented in [González et al., 2014]: the regulation reserves correspond to primary and secondary regulation reserves, the spinning reserves to secondary regulation reserves, the non-spinning reserves to tertiary regulation reserves, and, finally, the replacement reserves to tertiary regulation reserves. The main goal of the primary regulation service is to stabilise the frequency of the system at a stationary value in the time-frame of seconds after an imbalance has occurred [UCTE, 2009]. Note that this service is typically a requirement for all spinning generators in many countries (for example, in Spain, in France or in the U.S. systems). All PSHPs have the ability to supply primary regulation reserves in generating mode as conventional thermal power plants whereas PSHPs equipped with variable-speed units or PSHPs operated with the hydraulic short-circuit mode also have the ability to supply primary regulation reserves in pumping mode.

- Secondary regulation service: the main goal of the secondary regulation service is to minimise the deviations with respect to the generation schedule in the interconnections, to free the primary regulation reserves to be ready again for new imbalances, 
and also to bring the frequency of the system back to the nominal value (for instance, $50 \mathrm{~Hz}$ in Europe or $60 \mathrm{~Hz}$ in U.S. Systems) in the time-frame of seconds up to typically 15 minutes after an imbalance has occurred. The service is based on the secondary regulation reserves that are under the automatic generation control system (AGC) [UCTE, 2009]. The main core of the presented Thesis is based on the participation of the PSHPs in the secondary regulation service of the Spanish electricity system. As it is mentioned for the primary regulation service, all PSHPs have the ability to supply secondary regulation reserves in generating mode as conventional thermal power plants whereas PSHPs equipped with variable-speed units or PSHPs operated with the hydraulic short-circuit mode also have the ability to supply secondary regulation reserves in pumping mode [Henry et al., 2012]. The impact of the latter in the optimal scheduling and in the economic viability of PSHPs is deeply analysed in the Thesis.

- Tertiary regulation service: the main goal of the tertiary regulation service is to replace the deployed secondary regulation reserves thus allowing them to be again available for new imbalances after larger incidents. The service is based on the tertiary regulation reserves usually activated manually by the transmission system operators whether the real-time use of the secondary regulation reserves is observed or expected to be maintained more than 15 minutes. Similarly to the primary and secondary regulation services, PSHPs are pretty suitable for the provision of the tertiary regulation service in all the PSHPs (with fixed-speed units, with variablespeed units or operated in hydraulic short-circuit mode). Note that in pumping mode, some PSHPs with fixed-speed units are able to provide tertiary regulation reserves both as spinning and non-spinning reserves (quick-start units), and that PSHPs with variable-speed units or operated in hydraulic short-circuit mode are also able to provide tertiary regulation reserves both as spinning and non-spinning reserves. An example of a scheduling model for a hydro system composed by hydropower plants and PSHPs participating in the secondary and tertiary regulation services is [Ortner \& Graf, 2013].

- Peak Shaving (also called load smoothing in regulated power systems and price arbitrage in liberalised power systems): although it is further described in subsection 1.1.1, here it is briefly presented the impact of the energy arbitrage, carried out among others by PSHPs, from the system perspective. The energy arbitrage is primarily driven by economic reasons, however, it is beneficial from the system perspective in both regulated power systems and in restructured power systems. In the former, energy arbitrage reduces overall system production costs by smoothing the system demand (removing 
high-cost peaking units during hours of high demand and increasing the use of low-cost base load units during hours of low demand). In the latter, energy arbitrage helps to reduce high electricity prices during peak hours while taking advantage of low prices during off-peak hours. This impact is expected to be even more helpful with higher penetrations of intermittent renewable energy sources.

- Generating Capacity: a PSHP typically has an installed capacity of several hundred MW. This has a positive impact on system reliability because it provides a significant amount of flexible capacity to the power system, fast response to meet peak demand, or reserves for outages of other power plants and large deviations of intermittent renewable energy sources. As the start-up times of PSHPs are very short and they can be quickly ramped up, being at full generation capacity in several minutes, PSHPs match and even outperform the characteristics of thermal power plants typically used for meeting peak demand. Furthermore, PSHPs have an extra advantage in comparison to the thermal power plants typically used for meeting peak demand: the former can also be operated in pumping mode.

- Emission Reductions: PSHPs may have a net positive or negative impact in the emission reductions depending on the generation mix of the system in which they are operated. It is clear that during peak hours, the participation of PSHPs reduces the total emissions of the system because they are substituting thermal power plants that increase emissions. Nevertheless, PSHPs may increase the total emissions of the system during off-peak hours because they add extra demand to the system when they are pumping. This increase depends on the generation mix at off-peak hours in the system in which the PSHP is operated. For example, [Koritarov et al., 2014b] presents the net emissions reductions due to the participation of new PSHPs equipped with fixed-speed units, for the current situation of intermittent renewable energy sources (base case) and for a higher wind power scenario in, among others, the American Western Interconnection power system. It is interesting to remark that, in the base case, there is an increase of the $\mathrm{CO}_{2}, \mathrm{NO}_{x}$ and $\mathrm{SO}_{2}$ system emissions between $0.5-2 \%$ whereas, in the higher wind power scenario, there is a decrease of the $\mathrm{CO}_{2}, \mathrm{NO}_{x}$ and $\mathrm{SO}_{2}$ system emissions of $2 \%$.

- Integration of Intermittent Renewable Energy Sources: the benefits of PSHPs in the integration of intermittent renewable energy sources is further discussed in subsection 1.1.2. As it is mentioned, among others, there are two benefits that PSHPs can provide to increase their integration: they can store the excess of wind and solar production when it exceeds the system demand, and provide a large quantity of quick-response capacity to compensate the variability and uncertainty of intermittent renewable energy sources. 
- Reduced Cycling of Thermal Generating Units: the flexibility of PSHPs, their fast ramping characteristics, and the energy arbitrage operation create a flatter net system demand for thermal power plants. It helps them to be operated in a steadier mode, reducing costs due to the ramping and the number of start-ups and shut-downs. For instance, [Pérez-Díaz \& Jiménez, 2016] presents the interhourly variations of the energy schedules of thermal power plants in the Great Canary island (Spain) with and without a new PSHP, showing that the inclusion of a new PSHP increases the capacity factor of the base-load thermal power plants and decreases the one of the peaking thermal power plants, reducing system costs due to ramping. Furthermore, [Pérez-Díaz \& Jiménez, 2016] also presents the average number of start-ups of thermal power plants with and without a new PSHP, showing that the inclusion of a new PSHP is able to reduce the number of start-ups up to $91 \%$ for the gasoil thermal power plants, up to $97 \%$ for the fuel thermal power plants and up to $87 \%$ for the diesel thermal power plants, in comparison to the ones without PSHP.

- Reduced Transmission Congestion: [Koritarov et al., 2014b] shows empirical evidence from simulations carried out in the research that PSHPs can help to mitigate transmission congestion as the research found lower transmission congestion prices in cases with PSHPs. For example, simulations in [Koritarov et al., 2014b] show, under the base case in the American Western Interconnection power system, that the mean transmission congestion prices decrease from $4 \$ /$ MWh whether there are no PSHPs operating in the system to $2 \$ / M W h$ whether both PSHPs with fixed-speed and variable-speed pump-turbine units are operating in the system.

- Transmission Deferral: high frequency of congestions in transmission lines suggests a need to strengthen the grid in certain parts by adding new transmission lines. However, in many cases, as energy storage devices in general and PSHPs in particular, can be used to inject or remove power from the grid, they can be operated to modify the power flows, and, hence, to reduce transmission congestions. A strategically located PSHP may defer the requirements for construction of new transmission lines. For further reading regarding this issue, see [Denholm \& Sioshansi, 2009] in which the compressed air energy storage technology is evaluated in order to decrease transmission costs and to increase the transmission utilisation.

- Voltage Control: the voltages of the electric power systems must be maintained typically within $\pm 5 \%$ around the nominal value in order to guarantee the quality and security of the service. The voltage control is carried out by controlling the supply of reactive power. However, while the frequency quickly becomes the same in an interconnected electric power system, voltage control is a relatively local issue and, therefore, it is not 


\begin{tabular}{|c|c|c|c|c|c|}
\hline & $\begin{array}{c}\text { Nuclear } \\
\text { power } \\
\text { plant }\end{array}$ & $\begin{array}{c}\text { Coal } \\
\text { power } \\
\text { plant }\end{array}$ & Oil power plant & $\begin{array}{c}\text { Gas power } \\
\text { plant }\end{array}$ & PSHP \\
\hline Normal duty cycle & Base load & Base load & Midmerit load & Peak load & Peak load \\
\hline Daily unit start-up & No & No & Yes, hot & Yes & Yes \\
\hline Load following & No & Yes & Yes & Yes & Yes \\
\hline Quick start (2 min) & No & No & No & No & Yes \\
\hline Frequency regulation & No & No & Yes & Yes & Yes \\
\hline Black start & No & No & No & Yes & Yes \\
\hline
\end{tabular}

Table 1.3: Typical operating characteristics of different thermal power plant technologies and for pumped-storage hydropower plants (based on [Deane et al., 2010])

possible to deliver reactive power over long distances. PSHPs, as they are composed by generators, have the ability to supply reactive power and, therefore, contribute to the voltage control service. Besides, variable-speed PSHPs, due to the converters, are also capable to contribute to the voltage control service. In [Padrón et al., 2011], it is studied, among others, the contribution of PSHPs to the voltage control. Results show that the planned PSHPs in the case study of the Spanish Great Canary island contributes to the stability of system voltages.

- Black-Start Capability: although extreme events to lead to a partial or total blackout of an electric power system are unlikely to occur, system restoration paths are recommended to be defined. This implies that generating units that have the ability to start themselves (called black-start units), are identified to start the restoration if required. As it is stated in [Koritarov et al., 2014b], PSHPs are able to efficiently provide black-start capabilities as they employ generators. However, variable-speed PSHPs are less candidates to provide black-start capabilities because the converters require an external source of power, which is not available in a black-out. In [Quaia et al., 2005], it is presented a research in which the system restoration paths in a black-out are suggested to be carried out using PSHPs based on the Italian electric system.

The operational characteristics of PSHPs in comparison to conventional thermal power plants are provided in Table 1.3, which is based on [Deane et al., 2010]. The comparison between technologies as regards the above-mentioned operational characteristics points to both gas turbine-peaker plants and PSHPs offering much more power system operation services than nuclear, coal and oil-fired power plants.

\subsection{The electricity market framework}

Section 1.2 includes a brief description and a detailed description of a general electricity market and of the Spanish electricity market, respectively, in subsection 1.2.1 and 1.2.2, a 
summary of the most important cost components of a pumped storage project, as well as some approximate figures for the capital cost of a pumped storage project in subsection 1.2.3, a brief description of the expected future market framework in the European market price coupling in subsection 1.2.4, and finally, the required decision support models than an agent should have in order to deal with the analysis of the economic viability and the short-term operation of pumped storage hydropower plants in subsection 1.2.5.

\subsubsection{General electricity market}

Since the early 1990s, power systems all over the world have been introducing a certain degree of liberalisation, being UK and Norway the pioneers [Al-Sunaidy \& Green, 2006]. As a result of the liberalisation process, many electricity market schemes have appeared. In spite of the differences among the distinct designs and rules of the existing electricity markets, the activities of purchasing and selling energy are typically organised in a short-term wholesale energy market. This market is supervised by an independent agent usually referred to as the market operator. The market operator is responsible for the market clearing process, using the purchasing and selling bids submitted by the consumers and the generation companies, respectively, to perform the mentioned process. As a result of the market clearing process, the market operator determines, at each programming period of the time horizon, how much energy will be delivered by every power generation company, power plant or group of power plants as well as the energy prices to remunerate the producers.

Most of the energy at each programming period of the time horizon is traded on the above-mentioned short-term wholesale energy market. Nevertheless, deviations in the assigned purchasing and/or selling bids may take place between the gate closure of the wholesale energy market and the energy delivery next day. For example, deviations can happen due to unexpected unit unavailabilities or weather conditions. Different successive markets, usually referred to as intraday market, take place every day once that the wholesale energy market has been cleared. At the intraday market, producers and consumers can trade energy close to real time to bring the system back in balance as much as possible.

Apart from the wholesale energy market (typically called the day-ahead energy market) and the intraday market, there exist other markets that contribute to guaranteeing the quality, reliability and security of supply. In this markets, energy and power reserves are negotiated for the so-called ancillary services. Among all the ancillary services, the frequency control is the one with the highest economic volume negotiated in the markets. The reader is referred to subsection 1.1.4 for further reading of ancillary services. 


\subsubsection{Spanish electricity market}

The PSHPs are proposed to participate, in this Thesis, in the day-ahead energy market and in the secondary regulation service of the Spanish electricity system. Therefore, they will be further described in this subsection. It is important to remark that the electricity power systems are constantly developing and adapting to the current contexts. For instance, in Europe, the price coupling of regions, PCR, (market coupling for the day-ahead energy market in the European power system) or the cross-border intraday market project, XBID, (for the intraday market in the European power system). Both are briefly described in subsection 1.2 .4 .

\subsubsection{Energy markets}

There are two main energy markets in the Spanish electricity system: i) the day-ahead energy market and ii) the intraday market. Although, the intraday market is not used in the presented Thesis, the Thesis author considers interesting the inclusion of a brief description of it because it is proposed as a future work that the PSHPs also participate in it.

Most of the energy of the Spanish electricity system is negotiated in the day-ahead energy market. The power producers are obliged to submit offers for selling energy in the dayahead energy market. The day-ahead energy market occurs every day at $12 \mathrm{pm}$, having a scheduling time horizon from 0:00 to 23:59 of the following day. The scheduling time horizon is divided into hourly programming periods. There is an auction in each hourly period with the offers of all producers and the bids of all consumers where the price is established applying marginal cost pricing principles [Schweppe, 1988]. Therefore, all the producers are remunerated with the price of the last assigned offer and all the consumers pay that price for the consumed energy. The market rules of the day-ahead energy market are available in [Ministerio de Industria Energía y Turismo, 2015]. The energy schedule obtained after having cleared the day-ahead energy market is called the programa diario base de la casación (the assigned base daily schedule). The energy that has been committed previously by bilateral contracts is included to the assigned base daily schedule in order to form the so-called programa diario base de funcionamiento (the functioning base daily schedule).

According to [Ministerio de Industria Energía y Turismo, 2015], the main goal of the intraday market is to attend any changes that have appeared in the supply and/or demand of energy after having cleared the day-ahead energy market and before the delivery of energy in real time. In the Spanish electricity system, the intraday market is organised/structured in six daily sessions. Each session opens and closes at a different hour and has a different scheduling time horizon. All scheduling time horizons are divided into hourly periods. See Table 1.4 for further details of each session. 
TABLE 1.4: Sessions of the Spanish intraday markets

\begin{tabular}{|c|c|c|c|c|c|c|}
\hline & Session 1 & Session 2 & Session 3 & Session 4 & Session 5 & Session 6 \\
\hline \hline $\begin{array}{c}\text { Opening } \\
\text { session }\end{array}$ & $17: 00$ & $21: 00$ & $01: 00$ & $04: 00$ & $08: 00$ & $12: 00$ \\
\hline $\begin{array}{c}\text { Gate } \\
\text { closure }\end{array}$ & $18: 45$ & $21: 45$ & $01: 45$ & $04: 45$ & $08: 45$ & $12: 45$ \\
\hline $\begin{array}{c}\text { Clearing } \\
\text { hour }\end{array}$ & $19: 30$ & $22: 30$ & $02: 30$ & $05: 30$ & $09: 30$ & $13: 30$ \\
\hline $\begin{array}{c}\text { Schedule } \\
\text { publication }\end{array}$ & $20: 45$ & $23: 45$ & $03: 45$ & $06: 45$ & $10: 45$ & $14: 45$ \\
\hline $\begin{array}{c}\text { Scheduling } \\
\text { time } \\
\text { horizon }\end{array}$ & $27 \mathrm{~h} \mathrm{(22-24)}$ & $24 \mathrm{~h}(1-24)$ & $20 \mathrm{~h} \mathrm{(5-24)}$ & $17 \mathrm{~h} \mathrm{(8-24)}$ & $13 \mathrm{~h} \mathrm{(12-24)}$ & $9 \mathrm{~h} \mathrm{(16-24)}$ \\
\hline
\end{tabular}

As can be seen in Table 1.4, the energy schedule between hours 22-24 in each day, i.e., those that start at 21:00 and finish at 23:59, can be changed up to seven times: in the first and second sessions of the previous day, and the third to sixth sessions and the first session of the current day. All the markets agents (producers and consumers) can participate in each session of the intraday market if they have previously participated in the corresponding session of the day-ahead energy market. As the day-ahead energy market, the price of the intraday market is a marginal one: all the producers are remunerated/consumers pay the price of the last assigned bid. The market rules of the intraday market are available in [Ministerio de Industria Energía y Turismo, 2015]. The reader is referred to [Chaves-Ávila \& Fernandes, 2015] for further reading about the Spanish intraday market.

\subsubsection{Ancillary services}

There are many markets related to the ancillary services in the Spanish electricity system: i) congestion management mechanism of the day-ahead energy market, ii) congestion management mechanism of the intraday market, iii) congestion management mechanism in real-time, iv) secondary regulation service, v) tertiary regulation service and vi) deviation management mechanism. For the sake of clarity, here it is only presented the secondary and tertiary regulation services because the former directly applies to the main core of the Thesis, and because, in the latter, the participation of the PSHPs is also proposed as a future work and the secondary regulation energy prices depend on the tertiary regulation energy prices. The reader is referred to [Delgadillo \& Reneses, 2013] for further reading about the congestion management mechanism market in the Spanish system.

The secondary regulation service comprises two concepts: the secondary regulation reserve 
capacity (power) and the real-time use of the committed reserves (energy). The former is divided into the upward and downward secondary regulation reserve. They are the maximum variation that is possible to change the power generation in the regulation zones of the Spanish electricity system in less than $100 \mathrm{~s}$ after an imbalance has occurred. Besides, the power variation must be kept the following 15 minutes after an imbalance. The upward/downward secondary regulation reserves increase/decrease the power generation, respectively, in order to carry out the frequency-control of the system and to restore the primary reserves of the system in real time. The requirements of the system for the secondary regulation reserves fulfil technical issues that are described in the Operational Procurement 7.2 for the secondary regulation [Ministerio de Industria Energía y Turismo, 2009a].

The aim of the secondary regulation service is to remove the deviations that appear with respect to the committed international exchange energy schedules, and to maintain the frequency of the system as close as possible to the reference value (in Europe, $50 \mathrm{~Hz}$ ).

The secondary regulation service is provided by the so-called regulation zones, following the targets imposed by the master regulator of the Spanish transmission system operator, called sistema de Regulación Compartida Peninsular (peninsular shared regulation system). The regulation zones are formed by power generators ${ }^{3}$, that have been assessed by the Spanish transmission system operator for providing the secondary regulation service, and that are able to respond to the control signals sent by the automatic generation control system in the regulation zone in which they are, responding to the targets imposed by the peninsular shared regulation system.

Everyday, before $4 \mathrm{pm}$, the Spanish transmission system operator publishes the upward and downward secondary regulation reserve requirements of the system, for each hour of the following day. The market agents that own the power generators of each regulation zone can present bids, until 5:30 pm, composed by the upward and downward secondary regulation reserves, in MW, and the same price for the upward and downward reserves, in $€ / M W$, for each hour of the following day. The secondary regulation reserve market is cleared between 5:30-5:45 pm, with the criterion of minimising the required cost to provide this service.

The rules of the secondary regulation reserve market are published in the Operating procedure 7.2 [Ministerio de Industria Energía y Turismo, 2009a] and further reading can be seen in [Fernandes et al., 2016]. The secondary regulation reserve market is based on a marginal price. Therefore, the market price results from the assigned secondary regulation reserve bid with the higher price.

As above-mentioned, the provision of the secondary regulation service is remunerated,

\footnotetext{
${ }^{3}$ The current rules of the Spanish electricity system do not consider the participation of pumped-storage hydropower plants in the provision of the secondary regulation service in pumping mode (when the plant is consuming energy).
} 
on the one hand, according to the power availability committed in the secondary regulation reserve market and, on the other hand, for the real-time use of the secondary regulation reserves. The real-time use of the secondary regulation reserves depends on the response to the control signals sent by the automatic generation control in each regulation zone. The net secondary regulation energy is valued according to the prices of the tertiary regulation energy ${ }^{4}$.

The tertiary regulation reserve is the maximum power variation that a power producer or a pumped-storage hydropower plant (in generating or in consuming modes) are able to carry out in less than 15 minutes. There can be upward and downward maximum power variation (upward and downward tertiary regulation reserves, respectively). Besides, the power variation must be kept in, at least, two consecutive hours.

The aim of the tertiary regulation service is to restore the secondary regulation reserves that have been used, by means of adapting the energy schedules of the power producers or the pumped-storage hydropower plant (in generating or in consuming modes) that have been previously assessed by the Spanish transmission system operator for the provision of the service.

Everyday, before $9 \mathrm{pm}$, the Spanish transmission system operator publishes the upward and downward tertiary regulation reserve requirements of the system, for each hour of the following day. The market agents that own the generators that are able to provide the tertiary regulation service according to the Spanish transmission system operator requirements, must present, before $11 \mathrm{pm}$, a bid for their whole tertiary regulation reserves (both, upward and downward tertiary reserves), for each hour of the following day. The tertiary regulation reserve market is cleared in real-time, and it is carried out taking into account economic criteria (cost minimisation for providing the requirements), being a marginalist market.

The rules of the tertiary regulation reserve market are published in the Operating procedure 7.3 [Ministerio de Industria Energía y Turismo, 2009b] and further reading can be seen in [Fernandes et al., 2016]. It is important to note that there is a price for the upward tertiary regulation reserve different than the price for the downward tertiary regulation reserve, unlike in the secondary regulation reserve market. Therefore, the market prices result from the assigned upward and downward tertiary regulation reserve bids with the higher price, respectively. In the Spanish electricity system, only the use of the tertiary regulation reserves (energy) is remunerated. The upward tertiary regulation reserves represent an income to the power generator whereas the downward tertiary regulation reserves represent a cost.

\footnotetext{
${ }^{4}$ If the net secondary regulation energy is negative (downward energy), the power generator must purchase energy according to the price of the downward tertiary regulation energy.
} 


\subsubsection{The agent perspective/Capital intensive}

The pumped-storage technology is pretty capital intensive. For instance, an investment cost per MW of installed capacity of 0.5 M€/MW is shown in [Ummels et al., 2008] for a typical combined-cycle gas turbine (CCGT), which is also used at peak hours, whereas the studied PSHP in [Ummels et al., 2008] has an investment cost of $1.06 \mathrm{M} € / \mathrm{MW}$. In order to build a completely new PSHP, at least the following costs must be taken into account [Krajačić et al., 2013]:

- Turbines and generators.

- Pumps and motors.

- Upper and lower reservoirs.

- Penstock.

- Grid connection.

- Control system.

- Other costs: transportation equipment, personal and others.

However, investment costs of PSHPs are strongly site-dependent. In each project, the investment cost depends, among others, on whether or not the PSHP uses existing reservoirs, whether the project is new or upgraded by enlarging the existing reservoirs or increasing the installed capacity [Deane et al., 2010]. In the technical literature, to the best of the Thesis author's knowledge, there are no papers where the investment costs of PSHPs equipped with fixed-speed ternary units or with variable-speed binary units are analysed. Several papers can be found regarding investment costs of PSHPs equipped with fixed-speed binary units. As examples, [Connolly et al., 2011] proposes a range between 0.47-2.17 M€/MW from pro-

jects in countries such as Spain, Portugal or Switzerland, among others. [Steffen, 2012] proposes a range between 0.775-1.28 M€/MW from projects in Germany and Luxembourg. Or [Barbour et al., 2016], which proposes a range between 2-4.3 M $\$ / \mathrm{MW}$. Note that the latter is expressed in $\$$.

According to [Botterud et al., 2014], hydro industry experts estimate an increase between $30-40 \%$ of the investment costs when the PSHP is equipped with ternary units and between $7-15 \%$ when the plant is equipped with variable speed units, with respect to PSHPs equipped with fixed-speed binary units.

Besides, to the best of the Thesis author's knowledge, there is an absolute lack of information about the extra cost that would imply to allow the PSHP to operate in hydraulic short-circuit mode. This extra investment cost is due to both 1) the reinforcement of the 
pipes in the short-circuit link and 2) the more complex design of the said pipe section in order to, respectively, resist pressure oscillations of a higher amplitude [Pérez-Díaz et al., 2014b] and to reduce the hydraulic losses. In this Thesis, it is assumed an extra investment cost related to permit a PSHP to operate in the hydraulic short-circuit mode of $3 \%$, according to confidential conversations with hydro industry experts during the Thesis.

\subsubsection{Looking to the future}

The electricity power systems are constantly developing and adapting to the current contexts. For instance, in Europe, the price coupling of regions, PCR, (market coupling for the dayahead energy market in the European power system) or the cross-border intraday market project, XBID, (for the intraday market in the European power system).

Since 18th October 2010, EEX and EPEX SPOT ${ }^{5}$ calculate and publish the called European Electricity Index (ELIX), for each delivery day at EPEX SPOT. The index is calculated on the basis of the actual aggregated supply and demand curves of the day-ahead energy markets of France, Germany, Austria and Switzerland, which represent 36\% of the European electricity consumption. ELIX is an essential benchmark price for truly integrated and single European market, as it is the market price that would result in a physically unconstrained market environment. Therefore, ELIX can be seen as a display of how close the final electricity prices are to a market price in a fully integrated European market. It also shows the remaining additional benefit that could be achieved through further market integration. As an example, the mean hourly price of the Spanish day-ahead energy price was $50.4 € / \mathrm{MWh}$ in 2015 whereas the ELIX was $32 € / M W h$.

The price coupling of regions for the European power system implies two-step optimisation process. On the first step market players present offers to sell and bids to purchase electricity to the market operator, and the optimal state of the national power system is determined. The market operator then uses the available cross-border transmission capacity to minimise the price difference between market areas. Consequently, market participants do not explicitly allocate cross-border capacities: it is the matter of export and import flows optimisation taking into account the existing boundaries.

Regarding the XBID project, it is a joint initiative from EPEX SPOT, GME (Italy), Nord Pool (Scandinavian countries) and OMIE (Spain), together with the transmission system operators of eleven countries. The XBID project aims at the integration of the European intraday markets. An integrated intraday market is expected to enhance effective competition and pricing, increase liquidity and enable a more efficient utilisation of the European gener-

\footnotetext{
${ }^{5}$ EPEX SPOT is the exchange of power for the day-ahead energy markets of the heart of Europe, covering Germany, France, United Kingdom, the Netherlands, Belgium, Austria, Switzerland and Luxembourg. EPEX SPOT represents $50 \%$ of European electricity consumption.
} 
ation resources. The integrated intraday market will also enable continuous trading across Europe. This means that offers and bids from the market participants in one country are able to be met by offers and bids in any other country continuously, as long as there is enough available transmission capacity. One of the motivations of the XBID project is to reduce the need and costs of frequency regulation reserves due to the the increasing amount of intermittent renewable energy sources, which makes the generation and demand balance more and more challenging for market participants after the closing of the day-ahead energy markets. The XBID project is expected to be functioning by the first quarter of 2018 .

Finally, the European day-ahead and intraday energy markets are not only developing and adapting to the current contexts but also the balancing services. Currently, it is being evaluating a draft from the European Commission for establishing a guideline on the procurement and the settlement of frequency containment reserves, frequency restoration reserves and replacement reserves, and a common methodology for the activation of frequency restoration reserves and replacement reserves. The main goal of the European Commission is to integrate balancing markets to enhance effective competition, transparency, short-term efficiency in the balancing service and in the European and national balancing markets, as well as long-term efficiency in the operation and development of the European transmission network.

\subsubsection{Required decision support models}

Investors and power producers of PSHPs have to take many difficult decisions. The former has to analyse, in advance, the expected revenues of the plants subject to a variety of uncertainty sources. The latter will try to maximise the income in the short-term by the participation in the markets. In both situations, decision support models based on optimisation techniques are able to significantly help in the decision processes.

\subsubsection{Assessing the investment}

As above-mentioned, the investment in the pumped-storage technology is pretty capital intensive and strongly site-dependent. Therefore, estimating the expected return is a difficult, risky and challenging task. In a liberalised power system, new investors will enter into the market only if the expected income obtained from the operation of the PSHP is higher than the expected total costs. During the preliminary phases of the investment, the former is usu-

ally approximated by means of obtaining the so-called maximum theoretical income based on a proper research design and using decision support models. The decision support models must take into account in which markets the PSHP is going to participate, who are the competitors and how they usually behaves in the markets, what is the impact of the technical constraints in the operation of the PSHP,... The maximum theoretical income can be seen as an effi- 
cient information (powerful, and cheap and fast to compute) for analysing the investment because if the expected capital costs are higher than this threshold, the investment is able to be abandoned at preliminary phases, avoiding unnecessary extra costs. Whether the maximum theoretical incomes are higher than the expected capital costs, further research must be carried out. Decisions of a power producer in electricity markets are full of uncertainty, which affects prices, demand, production of intermittent renewable energy sources, strategic behaviour of competitors,... Analysing the reduction of the maximum theoretical income due to the consideration of imperfect information of the electric power system data is also required for investors and can be carried out using decision support models and forecasting models.

The decision support models for assessing the investment in a PSHP are pretty versatile, permitting the decision maker to:

- calculate the optimal storage capacity of the upper and lower reservoirs, and the optimal installed power capacity of the PSHP, with the objective of maximising the expected return of the investment.

- choose the type of units that the PSHP should be equipped with: binary, ternary or quaternary units, depending on the electric power system and the markets in which the PSHP is proposed to participate in.

- study if the variable speed technology or the operation in hydraulic short-circuit mode is more profitable than fixed speed pump-turbine units, analysing the extra expected income that they are able to introduce and the extra capital costs that they require.

\subsubsection{Operation models}

Once that the investment has been carried out and before commissioning the PSHP, the owner should deal with the issues of how the plant will be operated. This is important in the way that the operation will affect the return of the investment from the previous subsection. In the context of daily-cycle PSHPs, they are operated in the short-term, with a time horizon of the problem between one day and few days. However, the power producer has to take complex decisions to operate the plant in an optimised way. The decisions can be supported by mathematical models, which are able to obtain the global optimal solution from complex problems that reproduce the real technical constraints and the rules of the markets in which the PSHP is proposed to participate in. The decision support models must be developed taking into account the trade-off between the maximum detail level of the mathematical formulation and the CPU computational burden that makes it possible to run the model on a daily basis.

In a daily based operation of PSHPs, the decision support models must help the power producer in, at least, the following problems: 
- To present bids to the several markets in which the PSHP is proposed to participate in. This entails, among other issues, knowing the market structures and rules, and predicting the random variables that are involved in the electric power system data.

- To operate the plant accordingly to the bids assigned in the markets. This entails, among others issues, knowing the technical aspects of the units and if they are equipped with variable-speed units or with the operation in hydraulic short-circuit mode, with binary or ternary units.

\subsection{State of the art and motivation}

Section 1.3 presents the current state of the art of the Thesis and detects the main research gaps from the literature to be covered in the Thesis. It is divided into subsection 1.3.1, in which the main topics related to the Thesis are briefly described. Afterwards, the state of the art of scheduling models with a direct impact to the Thesis is presented in detail in subsection 1.3.2 whereas the one of the economic viability analyses of PSHPs is presented in detail in subsection 1.3.3. Finally, the main research gaps from the literature to be covered in the Thesis are detected and presented in subsection 1.3.4.

\subsubsection{Dimensions to be considered}

In the presented Thesis, the following aspects are proposed to be analysed and discussed to properly tackle the development of optimal scheduling models to operate PSHPs and advanced PSHPs, and to analyse the economic viability of them:

- Market framework: the operation of PSHPs only in the day-ahead energy market might not provide the required return to make profitable the investment in this technology. Therefore, it has been proposed in the technical literature from almost two decades ago, that PSHPs also participate in other markets and services. Due to this, the scheduling tools of PSHPs are being subject to improvements in order to co-optimise the operation from a multi-market perspective, in which the decision maker has to deal with the trade-off between which quantity of the scarce resource is used in one market and which quantity in others.

- Treatment of uncertainty: all generators that participate in liberalised electric power systems must deal with one or more sources of uncertainty when the decisions have to be taken to operate their assets. Besides, in the context of the participation in more than one market, the uncertainty sources significantly increase, becoming the problem even more difficult. The uncertainty sources are suggested to be detected and, if possible, 
analysed in order to determine whether the impact of the forecasting errors is significant or not.

- Risk aversion: due to the intrinsic nature of the problem, a decision maker has to deal with risk when he/she participates in market-based power systems. Hence, the tradeoff between higher expected income but with a higher risk or lower expected income but with a higher probability should be taken into account in the scheduling of PSHPs. In the literature, several approaches to deal with the risk-aversion of a decision maker have been presented, and will be discussed.

- Forecasting tools: the treatment of the uncertainty does not only depend on how it is model in the scheduling tools but also how the expected values of the future data are obtained and how accurate they are. It can be expected that the lower the error of the forecasting data, the higher the expected income obtained in the operation of PSHPs. Therefore, the forecasting tools play a crucial role as a mean to optimise the operation of the PSHPs in liberalised electric power systems.

- Technologies to regulate in pumping mode: in order to integrate more intermittent renewable energy sources and to enlarge the income from the markets, it has been developing in the recent years and decades advanced PSHPs, which are able to regulate power also in pumping mode. Two technologies are starting to be further studied in the technical literature in order to increase even more the flexibility of PSHPs: the variable speed technology and the operation in hydraulic short-circuit mode. The scarcity of technical papers published in the literature regarding optimal scheduling models will be presented and further discussed.

- Strategic behaviour: a power producer has a market quota depending on the size of the generators that are operated in liberalised electric power systems. Therefore, decisions and scheduling models depend on whether the market quota is significant or not. In the former, a price-maker approach is highly recommended whereas in the latter, a pricetaker approach can be enough. The price-maker approach assumes that the bids offered in the market have a notable impact in the clearing price. Therefore, the behaviour of the competitors must be predicted. A price-taker approach only requires to predict the corresponding market prices whereas a price-maker approach needs to evaluate the impact that the offers of the agent have in the marginal price of the market.

- Hierarchical coordination: both in large and in small upper reservoirs of PSHPs, the future information of the electric power system data has an impact in the current operation of the plants. Therefore, proper future signals are recommended to be calculated in order to enlarge the income of PSHPs, becoming the investment more profitable. In 
particular, the traditional operation of small upper reservoirs of PSHPs has been based on fulfil the daily-cycle, i.e., starting and finishing each day at the same water storage. Due to the multi-market operation, the future information of the electric power system data increases and, therefore, the future signals are able to change with respect to the one used in the traditional operation of small upper reservoir PSHPs.

\subsubsection{Optimal scheduling models}

A summary of the main characteristics of the revised articles from the technical literature is presented in Table 1.5. Regarding the market framework, MM and CMin stand for the operation of the PSHPs in several markets (multi-market) and for the cost minimisation for meeting the system demand, respectively. In case the uncertainty is considered, DM, SM, ER and RTUR stand for considering the uncertainty in the day-ahead energy and secondary regulation reserve markets, the secondary regulation energy prices and the percentages of the real-time use of the committed reserves, respectively, whereas Dem and RES stand for the system demand and the power generation of renewable energy sources. Bmin, VaR, CVaR stand for the minimum profit, the value at risk and the conditional value at risk approaches to model the risk aversion, respectively. Regarding the possibility of providing reserves in pumping mode, VS and SC stand for variable speed and hydraulic short-circuit operation, respectively. PT and PM stand for price-taker and price-maker approaches, respectively, of the strategic behaviour of the market agent.

As it has been described previously, the operation of PSHPs in liberalised electricity systems is changing from the traditional price-arbitrage strategy in which the PSHPs only participate in the day-ahead energy market to novel strategies to include other markets. According to the literature and to the best of the Thesis author's knowledge, [Deb, 2000] is the first paper where the importance of the share of profits that a PSHP could obtain in the ancillary service markets is emphasised. In that paper, two bidding strategies are compared in terms of the expected revenues; the former consists in bidding only for energy by using the well-known peak shaving method, whereas the latter consists in bidding for both energy and ancillary services, by using a heuristic algorithm similar to the previous one, which compares the income the PSHP can obtain in the energy and ancillary services markets with the expected income the PSHP will obtain with the stored water, given by the so-called water

value. The results obtained in that paper showed that a PSHP might almost double its daily income by simultaneously bidding in energy and ancillary services markets, with respect to the income obtained by bidding only in the energy market.

Some years later, [Lu et al., 2004] used a marginal approach to optimally schedule the energy and reserves (both spinning and non-spinning) of a closed-loop PSHP, and obtained an analytical condition that should be fulfilled in order for the schedule to be profitable. The ana- 


\begin{tabular}{|c|c|c|c|c|c|c|c|c|c|c|c|c|c|c|c|c|c|c|c|c|c|c|}
\hline 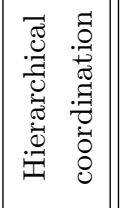 & 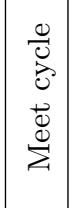 & 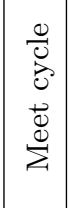 & 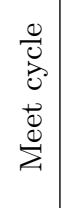 & 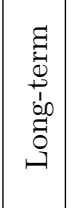 & 竞 & 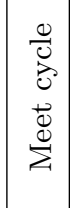 & 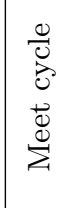 & 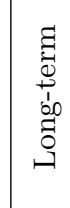 & 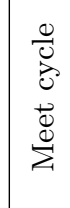 & 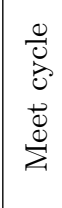 & 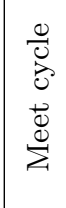 & 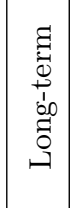 & 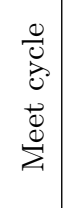 & 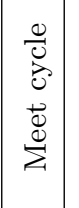 & & 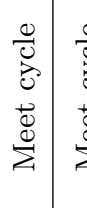 & 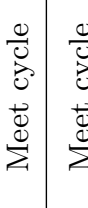 & 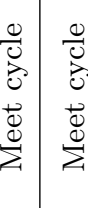 & 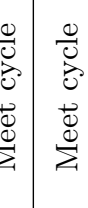 & 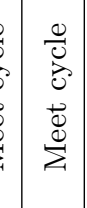 & 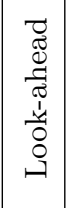 & 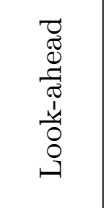 \\
\hline 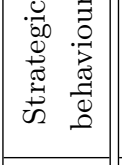 & $\vec{\omega}$ & 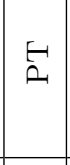 & $\vec{\omega}$ & $E$ & $\underline{\omega}$ & $\underline{\omega}$ & $\stackrel{\vec{\omega}}{\mathrm{a}}$ & $\sum$ & $\stackrel{\pi}{a}$ & $\sum$ & ¿ & $\stackrel{\omega}{\omega}$ & $\stackrel{\pi}{a}$ & $\stackrel{\pi}{\rightleftarrows}$ & & $\underline{\omega}$ & 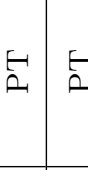 & $5 \mid E$ & $\Sigma \sum_{\Sigma}$ & $\sum$ & $\sum$ & ¿ \\
\hline 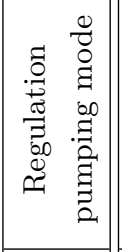 & $\stackrel{\circ}{2}$ & z̊ & 号 & $\check{z}$ & $\stackrel{\circ}{z}$ & そ̊ & $\stackrel{\infty}{>}$ & $\not ̊$ & ஜ̊ & 望 & $\stackrel{8}{2}$ & $\stackrel{\infty}{>}$ & $\infty_{>}^{2}$ & $\stackrel{\infty}{>}$ & 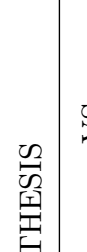 & $n^{2}$ & \begin{tabular}{l|l}
0 \\
$z$
\end{tabular} & \begin{tabular}{c|c}
$U_{2}$ & $\pi^{2}$
\end{tabular} & $r^{2} \quad \%$ & $\stackrel{\circ}{z}$ & 号 & 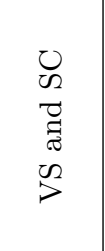 \\
\hline 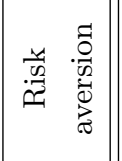 & 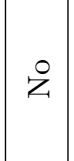 & $\stackrel{8}{2}$ & $\stackrel{\circ}{2}$ & 号 & $\overbrace{્ 1}^{\infty}$ & 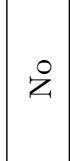 & 号 & 号 & 号 & 年 & 号 & 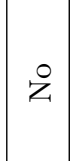 & $\check{z}$ & \& & 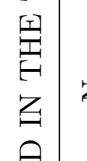 & r & 8 & $\stackrel{0}{2}$ & 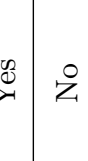 & $\stackrel{\circ}{z}$ & 号 & 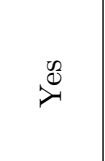 \\
\hline 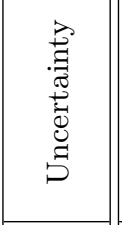 & $\begin{array}{l}\vec{\lambda} \\
\hat{\omega} \\
\vec{\lambda} \\
-\end{array}$ & $\vec{\Delta}$ & $\begin{array}{l}\vec{z} \\
\omega \\
\sum \\
\bar{n}\end{array}$ & $\stackrel{\circ}{z}$ & $\begin{array}{l}\text { E } \\
\text { D } \\
\text { E }\end{array}$ & $\stackrel{8}{8}$ & $\ddot{z}$ & E. & そ & そ̊ & ฉ & 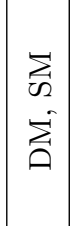 & 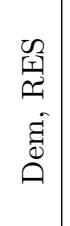 & $\vec{z}$ & 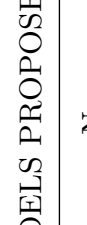 & \& & 点 & $\begin{array}{l}\vec{Z} \\
\vec{B} \\
\dot{B}\end{array}$ & 芒 & $\sum_{\infty}$ & 号 & 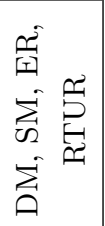 \\
\hline 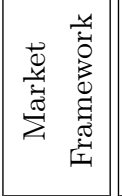 & $\vec{\Delta}$ & $\sum_{i}$ & $\bar{\sum}$ & $\bar{\Sigma}$ & $\sum_{\Sigma}$ & $\vec{\sum}$ & $\sum$ & $\vec{\Delta}$ & 胥 & ¿ & $\overrightarrow{\lambda_{1}}$ & $\bar{\sum}$ & $\sum_{0}^{\Xi}$ & छี & $\begin{array}{l}0 \\
\sum_{2} \\
0 \\
z \\
3 \\
3 \\
0 \\
0\end{array}$ & $\sum_{2}$ & $\sum_{\Sigma}$ & 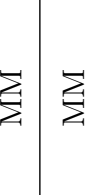 & $\bar{\Sigma}$ & $\sum_{\Sigma}$ & $\sum_{i}$ & $\sum_{\Delta}$ \\
\hline & 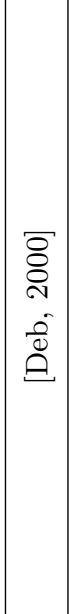 & 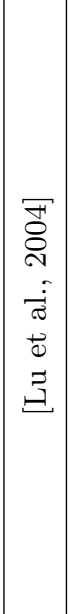 & 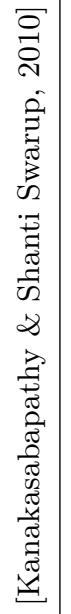 & 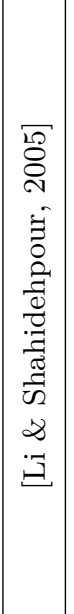 & 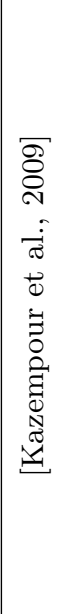 & 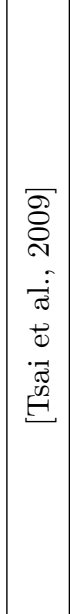 & 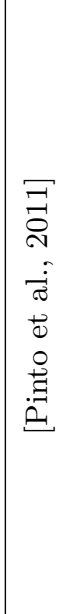 & 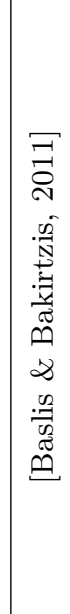 & 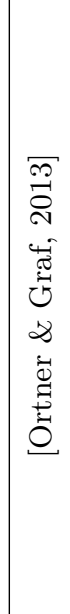 & 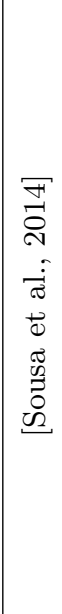 & 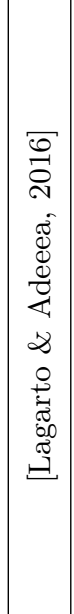 & 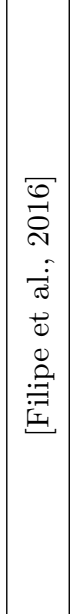 & 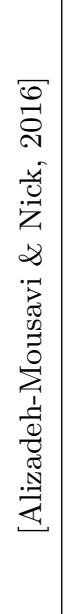 & 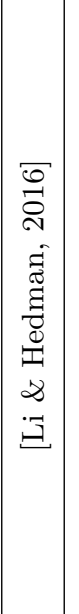 & 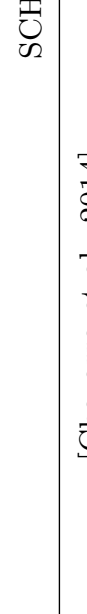 & 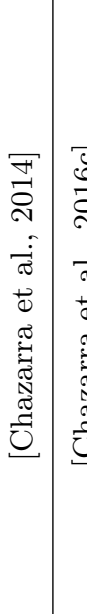 & 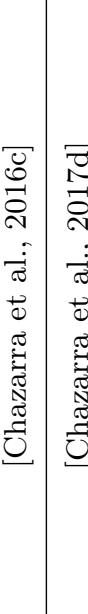 & 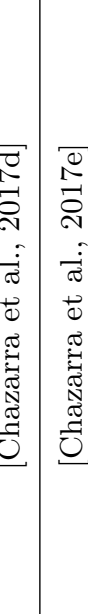 & 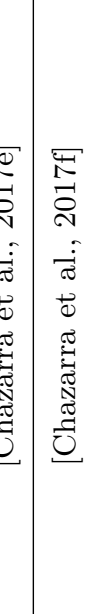 & 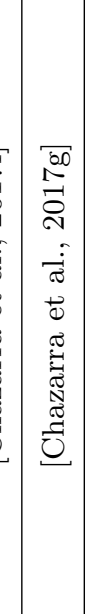 & 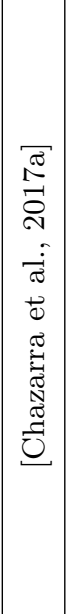 & 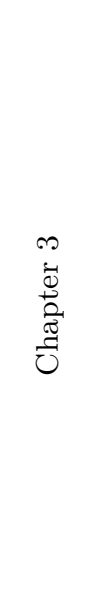 \\
\hline
\end{tabular}


lytical condition depends on the energy and reserve prices, as well as on the efficiency of the generation-pumping cycle. Authors applied the strategy in two periods of four weeks in the New York Independence System Operator (NYISO) market, and observed that within a season, the energy schedules (generation and consumption) do not change significantly: the PSHP generates more on weekdays and pumps on the weekends; both generating and pumping hours in summer are almost twice than those in winter. In [Kanakasabapathy \& Shanti Swarup, 2010], the above-mentioned analytical condition was revised in order to consider the unit's start-up and shut-down costs and the head dependency of the unit's power limits and efficiency. The revised strategy was applied to schedule the energy and reserves of a single-unit closed-loop PSHP in a 1 week period, considering both daily and weekly operating modes, in the NYISO market. Results show that the weekly operating mode may yield a higher profit, as well as a more efficient use of the energy stored capacity. Furthermore, the expected weekly profit of the revised strategy was compared with those proposed in [Deb, 2000] and [Lu et al., 2004], as well as with a traditional operation strategy (as referred to by the authors), based on filling the upper reservoir during off-peak hours, and emptying it during peak hours; the revised strategy yielded $4 \%, 6 \%$ and $24 \%$ higher profits.

In [Li \& Shahidehpour, 2005], a comparison between mixed integer linear programming (MILP) and Lagrangian Relaxation (LR) abilities to solve a deterministic unit commitment problem of a power generation company is presented. The company is assumed to own a set of thermal, combined cycle, cascaded-hydro and PSHPs. Market prices for energy and reserves (both spinning and non-spinning) are considered deterministic. Authors assume that spinning and non-spinning reserves scheduled are always used. In the MILP formulation, each operation mode of the units of the PSHPs (generating, idle and pumping) is modelled as a pseudo-unit, as referred to by the authors. Transition costs between different operation modes as well as minimum on/off times for each mode are considered in the paper. Upper bounds for the total energy and ancillary services supplied by the company are considered in the paper. In order to cope with such a complicating constraint, authors propose a three-step sequential solution procedure, both for the MILP and LR formulations. At each step the problem is solved considering a different subset of power generation units (cascade-hydro, pumpedstorage, and thermal and combined cycle). The above-mentioned upper bound is updated at the beginning of each step by subtracting the energy and ancillary services obtained in the previous step. Three different cases depending on the considered type of units are studied in the paper: cascaded-hydro, PSHPs, and thermal and combined cycle. The expected profit obtained with the MILP based model is higher than the one obtained with the LR based one in the three cases. The operation schedules of the cascaded-hydro and pumped-storage units obtained with the MILP based turned out to be more responsive to market prices and made better use of limited water resources. The results of the third case show that even though 
it takes longer for the MILP based model to find an initial feasible solution, this solution is much closer to the optimal one than that of the LR based model. The results of the fourth case show that the computation times of both the MILP and LR based models increase almost linearly with the number of scheduling periods up to certain value beyond which that of the MILP based model increases abruptly whereas that of the LR based one still follows a linear trend.

In [Kazempour et al., 2009], a risk-constrained dynamic self-scheduling model for the operation of a weekly-cycle and price-taker PSHP participating in the day-ahead energy, the spinning reserve and the regulation markets of the Spanish electricity system is presented. The risk aversion of the decision maker is modelled by means of calculating the variances of each market price and minimising them in the objective function. The dynamic self-scheduling refers to that the problem is updated at the beginning of each day (within the time horizon of the problem that is one week) considering the used spinning reserves and the occurred regulation states in the previous day. The uncertainty is considered in the market prices, and in the power delivery request from the ancillary services. The former is taken into account by forecasting tools and explicitly introducing the risk terms in the objective function using the variances of each price from historical data. The latter is taken into account by defining the probability of the spinning reserve delivery request, and the probabilities of the upward and downward regulation request. As it is mentioned by the authors, the result of model significantly change by applying different ancillary service delivery request probabilities. Results in the case study shows that the participation of the PSHP in the spinning reserve and the regulation markets strongly increase the expected profit in a specific week, independently of the risk aversion level of the decision maker.

In [Tsai et al., 2009], a co-optimal optimization model is presented to operate a closedloop and daily-cycle PSHP selling energy in the real-time energy market and participating in several ancillary services of the ERCOT power system (the ERCOT power system is based on the Texas State from U.S., and is divided into four zones: the North, the South, the West and the Houston zones). The time horizon of the problem is one day discretised in hourly periods. The proposed ancillary services to participate in are divided into ramp-up and ramp-down services. The former refers to the responsive, the non-spinning and the upward regulation services whereas the latter refers to downward regulation service, according to the definitions in the ERCOT power system. The optimised operation of the PSHP is restricted to fulfil the daily-cycle of the PSHP, i.e., the stored energy in the upper reservoir at the beginning of the day is required to be the same as at the end of the day. Although the optimization model is some-what simplified, the observations presented in the case study, applied to the West and Houston zones, are interesting. Note that the results obtained in the paper are preliminary as only two days are analysed (04-05/02/2009). It is shown that the water volume trajectory of 
the upper reservoir is usually in the middle of the reservoir capacity rather than in the highest water level because of the inclusion of the ancillary services in the scheduling procedure. In addition to this, it is shown that most of the profits obtained with the proposed model come from the ancillary services.

A similar result of the last observation from [Tsai et al., 2009] was also presented in [Pinto et al., 2011]. That paper presented a MILP based deterministic model is used to calculate the bids of a price-taker PSHP for the day-ahead and spinning reserve markets; bids consist in a single hourly value for each market. The hourly prices of the day-ahead and spinning reserve market, as well as those corresponding to both the upward and downward regulation energy requested in real time by the transmission system operator, are modelled by means of a single scenario. A fixed percentage of the committed spinning reserve is assumed to be requested in real time by the transmission system operator. Three different cases were analysed in the paper in terms of the share of wind generation in the power demand supply; the bigger the share of wind, the lower the day-ahead market prices and the higher those of the spinning reserve market. Even though the presented model is some-what simplified and that the design parameters of the PSHP used in the case study are somewhat particular, some results presented in the paper are worthy of mentioning. Such is the case of the fact that in the three above-mentioned cases, the optimal operation strategy leads to negative revenue in the day-ahead market. Considering only the so-called base case, in which the hourly prices of the day-ahead and reserve markets, as well as the power delivery requests in the latter, are historical, the revenue obtained in the day-ahead market is negative, whereas that obtained in the spinning reserve market is positive and more than one order of magnitude bigger than the previous one, in absolute value. According to the results, the expected share of revenue obtained in the spinning reserve market could even increase with respect to the base case as the share of wind generation increases, under the assumptions used in the paper to predict the impact of such increase in the share of wind on the day-ahead and spinning reserve markets prices.

In [Baslis \& Bakirtzis, 2011], a stochastic mid-term optimisation model for the operation of hydro and PSHPs that participate in the day-ahead energy market is presented. The model takes into account the impact of the short-term decisions in the mid-term operation. Although it is not a multi-market based optimisation model, the Thesis author considers interesting to included it in the state of the art of the Thesis because the producer is modelled as a price-maker. The price-maker approach makes the problem non-linear. However, the mathematical formulation presented in [Baslis \& Bakirtzis, 2011] is linearised using binary variables, becoming the model based on mixed integer linear programming. Stochasticity is modelled by a three-stage scenario tree of the natural water inflows and the residual demand curves of the day-ahead energy market. The scenario tree is composed by 90 scenarios: i) the 
first stage has a single scenario and runs for one month, ii) the second stage has $5 \times 3$ scenarios of the water inflows and residual demand curves, respectively, and runs for the following four months, and iii) in the third stage, each scenario of the second stage has others $3 \times 2$ scenarios and runs for the last seven months. In the case study, the proposed model is applied for a hydro system composed by ten hydropower plants and two PSHPs, based on the Greek electric power system. Results show that the decision maker keeps back capacity during peak hours and consumes part of the hydro resources during off-peak hours in comparison to a price-taker approach, irrespective of the water inflow scenario. This observation is explained by the market power approach in the day-ahead energy market. Besides, the solution of a unique large-scale problem based on mixed integer linear programming has been proved to be feasible, avoiding the need of using decomposition techniques. It is interesting to remark that the problem, composed by 9.5 millions of equations and 23.2 millions of variables, which 3.5 millions of them are integer variables, is solved in 28 hours.

In [Ortner \& Graf, 2013], a deterministic model to minimise the hourly costs of the hydrothermal and open-loop PSHP energy schedules for meeting the residual demand (after subtracting must-run generation), and the reserve and energy schedules for balancing services is presented. The model formulation is based on linear programming in order to obtain, as an endogenous result of the model via dual variables of the demand constraints, the prices of the reserve capacity (power), of the energy due to the real-time use of the reserves, and of the system demand energy. The balancing services comprises the secondary and tertiary regulation services, considered only as upward regulation reserve (downward regulation reserve is omitted). The case study minimises the costs of the hourly generation portfolio scheduling for system demand and secondary and tertiary balancing services of 2012 in Germany, Austria and in a merged zone of Germany and Austria. In Germany, while hydropower plants provide reserves irrespective the storage capacity, PSHPs are more committed to participate in balancing services the more storage capacity they have. A similar analysis is presented for Austria. It is important to remark that PSHPs considered in this work are not able to provide neither secondary regulation nor tertiary regulation reserves in pumping mode. The solution of the merged zone does not bring any further important conclusion. In addition to this, results show certain correlation between water inflows and the secondary regulation marginal costs in Germany and Austria. In general, when water inflows in both systems are high, secondary regulation marginal costs are low. As the Austrian power system presents a higher relative installed capacity of hydropower technology in the generation portfolio than the German one, the studied correlation is stronger in Austria than in Germany.

In [Sousa et al., 2014], a non-linear optimisation model for the profit maximisation of the operation of a price-maker, closed-loop and weekly-cycle PSHP participating in the day-ahead energy market of the Iberian electricity system is presented. The operation of the PSHP is 
compared to the one considering the plant as a price-taker in the day-ahead energy market. Besides, the operation under both approaches is compared to the ones in which the PSHP is standalone or integrated in a portfolio with other thermal power plants. It is important to remark that the operation and maintenance costs of the PSHP and the thermal power plants, as well as the fuel costs of the thermal power plants are assumed to be null. Although it is not a multi-market based optimisation model, the Thesis author considers interesting to included it in the state of the art of the Thesis because of the comparison between the price-taker and the price-maker approaches. As expected, results show that the price-taker standalone PSHP follows a price-arbitrage strategy, pumping when the wind generation decreases prices and generating when there is low wind availability and high prices. Therefore, the PSHP contributes to the integration of wind power. However, results change in the price-maker standalone context, as the day-ahead energy market prices increase when the PSHP decides to pump water, and decrease when it decides to generate power. Thus, the PSHP reduces the contribution of the integration of wind power. Whether the PSHP is included in a portfolio mainly composed by base load thermal power plants, the operation of the PSHP changes, being operated in pumping mode during more hours than in the price-maker standalone context: it is shown that the operation of the PSHP is driven more by the demand elasticity of the day-ahead energy market than by the market cleared price.

In [Lagarto \& Adeeea, 2016], an optimization model for the operation of a thermal power plant and a PSHP participating in the day-ahead energy market and in the secondary regulation reserve market of the Portuguese electricity system is presented. Note that the Portuguese day-ahead energy market is coupled to the Spanish one whereas the Portuguese secondary regulation reserve market is not coupled to the Spanish one. Six scenarios are compared in the research: i) the operation of the thermal power plant is optimised, acting as a price-taker in both markets, ii) the operation of the PSHP is optimised, acting as a price-taker in both markets, iii) the operation of both, the thermal power plant and the PSHP is optimised, acting as price-takers in both markets, and, finally, iv)-vi) the operation of the thermal power plant only, the PSHP only and both the thermal power plant and the PSHP, respectively, is optimised acting as price-makers in both markets. It is interesting to highlight that the scenario of acting as a price-taker in the day-ahead energy market and as a price-marker in the secondary regulation reserve market is not considered. Among others, results show the importance of considering the price-maker effects in the optimisation model because the profits increase $30 \%, 7.5 \%$ and $67 \%$ in the operation of only the thermal power plant, only the PSHP and both, the thermal power plant and the PSHP, respectively, with respect to the operation considering the plants as a price-taker. Increases occur because the cleared market prices considering the plants as price-takers (which are evaluated in a post-optimal simulation process with the optimal energy and reserve schedules), decrease more than the ones obtained 
considering the plants as price-makers. It is interesting to remark that the proposed PSHP in the case study has the possibility to regulate power also in pumping mode. However, [Lagarto \& Adeeea, 2016] does not mention that the PSHP is equipped with variable-speed pump-turbine units, and the effects of the possibility of regulating power in pumping in comparison to not regulating power in the said mode are not studied.

In [Filipe et al., 2016], a bidding strategy to plan and operate large PSHPs equipped with variable-speed pump-turbine units is presented. The research is similar to the article entitled "Optimal Operation of Variable Speed Pumped Storage Hydropower Plants Participating in Secondary Regulation Reserve Markets" from this Thesis as it is expressed in [Filipe et al., 2016]. The mid-term optimisation takes into account the seasonality and variability of the natural water inflows and the day-ahead energy price forecasts to find the optimal end-of-week water storage. The time horizon of the mid-term model is one year, discretised in weekly periods. Note that the derivation of the end-of-week water storages does not take into account the participation of the PSHP in the secondary regulation service. The short-term optimisation proposes the PSHP to participate in the day-ahead energy market and in the secondary regulation reserve market of the Portuguese electricity system, without taking into account the real-time use of the reserve. To avoid violations of the minimum or maximum water storages due to the real-time use of reserves, the authors assume that a portion of the storage is reserved solely for the deployment of the secondary regulation reserves in real-time. Note that the latter is evaluated in a post-optimal simulation process with the historic hourly values. Among others, results show that the profits obtained by the PSHP with variablespeed pump-turbine units duplicate the ones obtained with fixed-speed pump-turbine units, and that the above-mentioned portion of the storage capacity reserved solely for the deployment of the reserves can be $7 \%$ of the maximum storage capacity below the maximum and $7 \%$ above the minimum.

In [Alizadeh-Mousavi \& Nick, 2016], a security constrained unit commitment optimisation model is presented in order to obtain the energy and reserves schedules from the system perspective, taking into account the grid and the security of supply in case of contingencies due to a single outage of generating units or transmission elements (the N-1 criterion) by means of security constraints. Stochasticity is considered in the renewable energy power generation and in the system demand. The main goal of the optimisation model is to minimise the operational costs to fulfil the system demand and the requirements for reserves. The generation portfolio of the system is composed by thermal power plants, conventional hydropower plants and PSHPs. The proposed model is used to analyse the technical benefits of PSHPs equipped with variable-speed pump-turbine units in comparison to the ones equipped with fixed-speed pump-turbine units, from the point of view of the system operation. In the case study, three PSHPs are connected to bus 22 of the IEEE RTS 24-bus system. Results show that the 
system operation cost decreases $10 \%$ in the case with PSHPs equipped with variable-speed pump-turbine units in comparison to the one with fixed-speed pump-turbine units, because the former introduces flexibilities that allow more scheduling of less flexible thermal power plants with less start-ups and shut-downs.

In [Li \& Hedman, 2016], a deterministic system-based optimisation model for the operation of a closed-loop PSHP equipped with variable-speed pump-turbine units is presented. The PSHP is assumed to be a system tool operated by the transmission system operator. The optimisation model minimises the total system operation costs and the system security violation costs, which include the costs to correct load shedding and reserve requirement violations. It is interesting to remark that the grid and the power flows on the transmission lines are also included in the model formulation. The PSHP is proposed to be operated covering the system demand, and providing several ancillary services: spinning reserves, nonspinning reserves and upward and downward regulation reserves, in the context of a power system from the United States. The time horizon of the model is 6 hours, discretised in 10minute periods, and the formulation is divided into two steps: the unit commitment model and the dispatch model. In the unit commitment model, the energy and reserve schedules are obtained. In the dispatch model, the system is simulated against 150 wind scenarios in order to analyse the real-time use of the committed reserves in the first step addressing the wind power uncertainties. Result shows that the PSHP equipped with variable-speed pumpturbine units in comparison to the one equipped with fixed-speed pump-turbine units reduces the total system costs, reduces the system wind curtailments, and is more effective in dealing with uncertainties and variations of the wind power.

\subsubsection{Economic viability}

As it has been emphasised first in [Deb, 2000], and later, among others, in [Swider, 2007] and [Ugedo \& Lobato, 2010], the revenues that a PSHP can obtain from providing ancillary services may be of a pretty considerable magnitude in comparison with those that can obtain from the price-arbitrage strategy. It is worthy to mention, regarding the revenues that a PSHP can obtain from the price-arbitrage strategy, the work presented in [Connolly et al., 2011].

In [Connolly et al., 2011], authors compare different price-arbitrage strategies in a series of energy-only electricity markets where no ancillary service markets are considered. All strategies are based on a set of operation rules, and they differ from each other essentially in the future time horizon for which the hourly energy prices are assumed to be known. The operation of a PSHP with six hours of empting and refilling the upper reservoir, following each strategy, is simulated during a period of one year, using data from different electricity markets. Results show that the expected profit of the PSHP differ significantly from one electricity market to another (the maximum expected profit ranges from 20 to 23 times the 
minimum one). From the results of the research, the authors determined the most profitable strategy and simulated the operation of the PSHP, in accordance with the said strategy, during a 5-year period (2005-2009), using data from different electricity markets: United Kingdom, Alberta, Italy, Nordpool, Portugal and New Hampshire. The obtained results show that even for the same electricity market, the expected profit may vary considerably from one year to another. In order to gain insight on the economic viability of the PSHP, the expected profits were compared to the annual repayments corresponding to different values of the interest rate and the initial investment cost. Results show that even with a low investment cost and a low interest rate, a PSHP is a risky investment in most electricity markets, as long as the operation strategy is based on the price arbitrage. Results obtained in [Connolly et al., 2011] give full evidence that the operation strategies based on the traditional price-arbitrage strategy are far from being economically viable for a PSHP in a liberalized market context, and provide a sound numerical support to the conclusions drawn in [Deb, 2000] and [Ugedo \& Lobato, 2010], regarding the importance of making a profit from other markets such as the reserve markets.

Furthermore, several papers have been found in the technical literature analysing the economic viability of PSHPs equipped with fixed-speed pump-turbine units from the point of view of the agent-based perspective in liberalised power systems or analysing the contribution to the system by means, among others, of scheduling cost savings or wind energy curtailment from the point of view of the system-based perspective in liberalised power systems.

Considering the analysis of the contribution to the system by means of scheduling cost savings or wind energy curtailment, there are many papers published in the technical literature and several of them are here presented as examples. In [Ummels et al., 2008], authors estimate the scheduling cost savings and the decrease in curtailed wind energy caused by energy storage, by using heuristic algorithms and dynamic programming. They conclude that combined heat and power plants are found to be more profitable solutions for the integration of largescale wind power in the Netherlands than energy storage. In [Tuohy \& O'Malley, 2011], the contribution of PSHPs to reduce the scheduling costs, wind curtailments and carbon dioxide emissions from thermal power plants in the Irish power system, considering different levels of wind power penetration, is assessed. Results show that the main benefit from storage is the decrease in wind curtailment. In [de Boer et al., 2014], authors assess the contribution of PSHPs, compressed air energy storage and a relatively new storage technology called powerto-gas, to reduce the scheduling costs, carbon dioxide emissions and the excess of electricity production in the Dutch power system. The power-to-gas energy storage technology refers to the conversion of electricity into methane, by means of using electrolysis and methanation. Results show that the energy storage technology that reduces the most the scheduling costs of the system is the pumped-storage technology, between $0.8-5.2 \%$ of the base case costs, depending on the extra installed capacity of wind power and the storage capacity of the 
upper reservoir. Results also show that all the analysed storage technologies similarly reduce the greenhouse gases emissions and the amount of curtailed wind power.

The economic viability of PSHPs equipped with fixed-speed pump-turbine units from the point of view of the agent-based perspective has been also studied in the technical literature, specially with the well-known price-arbitrage strategy. Apart from the abovedescribed research presented in [Connolly et al., 2011], which concludes that the recovery of the investment costs is not possible almost in all the analysed markets (United Kingdom, Alberta, Italy, Nordpool, Portugal and New Hampshire) with the price-arbitrage strategy, there are other papers published in the technical literature regarding this issue. Results in [Bradbury et al., 2014] show that PSHPs are profitable in almost all the seven real-time energy markets analysed in the United States, such as ERCOT (Texas) or NYISO (New York). Results can be considered slightly optimistic as they are obtained for 2008, when there was a significant difference between peak and off-peak energy prices and also reaching in some months the highest average prices of the last decade. [Ekman \& Jensen, 2010] analyses the economic viability of PSHPs equipped with fixed-speed pump-turbine units participating also in the regulation market. Results in [Ekman \& Jensen, 2010] show that the considered PSHP cannot recover the investment costs if it only participates in the day-ahead energy market and can recover the investment costs only for a limited range of the storage size if it also participates in the regulation market.

It is important to remark that, according to the best of the Thesis author's knowledge, there is no published paper in the technical literature in which the economic viability of PSHPs equipped with variable speed units and/or operating in hydraulic short circuit mode is analysed, in the context of a liberalised power system.

\subsubsection{Identified research gaps and challenges}

Once the most relevant articles from technical literature have been reviewed, the main gaps and challenges detected from the point of view of the operation of close-loop and daily-cycle PSHPs, can be summarised as follows:

1. As it has been presented in Table 1.5 and described in subsection 1.3.2, there is a lack of optimisation models in the technical literature for the short-term operation of PSHPs equipped with variable-speed pump-turbine units, or operated in hydraulic shortcircuit mode. The Thesis author believes that the scheduling strategies may significantly change due to the higher flexibility that the variable speed technology or the operation in hydraulic short-circuit mode introduces in comparison to the cost-save strategy or pricearbitrage strategy, described in subsection 1.1.1, for PSHPs equipped with fixed-speed pump-turbine units. The advantages of the variable speed technology and the operation 
in hydraulic short-circuit mode are further described in subsection 1.1.3. Among others, the most promising one is that the PSHPs are also able to regulate power in pumping mode, having the possibility to also participate in the secondary regulation service in the said mode as a controllable load.

2. The Thesis author considers that including the uncertainty of the percentages of the real-time use of the assigned secondary regulation reserves for ancillary services purposes is still a pending task that could contribute to increase the participation of PSHPs in the said services, and thus to increase the penetration of intermittent renewable energy sources. Hence, the forecast, modelling and analysis of the economic impact of forecasting errors of the percentages of the real-time use of the committed reserves can be improved and is suggested to be carried out in the Thesis. Besides, it is expected that the introduction of the real-time use of reserves in the optimisation model could have an impact in the operation of the PSHPs, making it closer to reality and, therefore, improving the analysis of the economic viability of PSHPs with and without variablespeed pump-turbine units, and with and without the operation in hydraulic short-circuit mode. In the technical literature, plenty of day-ahead energy market prices forecasting models can be found. Examples are [García et al., 2005], which proposes a GARCH model, [Conejo et al., 2005], which proposes a wavelet transformation with ARIMA models, [Amjady \& Keynia, 2011], which proposes a model based on neural network or [Mateo et al., 2005], which proposes input/output hidden Markov models. A review of day-ahead energy market prices forecasting models in deregulated markets can be seen in [Aggarwal et al., 2009]. Besides, quite few secondary regulation reserve or balancing market prices forecasting models have been published in the technical literature. Examples are [Campos et al., 2016], which forecast the residual demand curves of the secondary regulation reserve market with a model based on a neural network, or [Olsson \& Söder, 2008], which is based on a combination of SARIMA and Markov processes. However, to the Thesis author's knowledge, there are no published articles that forecast the percentages of the real-time use of the committed reserves, or that analyse the economic impact due to the forecasting errors.

3. In the context of the operation of PSHPs also participating in the provision of ancillary services apart from in the day-ahead energy market, the Thesis author believes that the hierarchical coordination between the long-term and the short-term to derive end-ofday and end-of-week water storages is an interesting topic to be analysed in detail. The traditional operation strategy of starting the following day empty may not be optimum because the PSHP does not have enough water to participate in the secondary regulation service during the first hours of each day, when there is usually a big amount of base 
power plants with little and/or inefficient power regulation capabilities. The derivation of the end-of-day and end-of-week water storages has been studied in the technical literature. [Deane et al., 2013] proposes, for deriving end-of-week water storages, the use of a look-ahead period of up to 6 days for the day-ahead energy and reserve scheduling of PSHPs from a centralized (system-based) point of view, whereas [Brijs et al., 2016] proposes a methodology similar to the one in [Deane et al., 2013] to derive end-of-day water storages from a liberalised (agent-based) point of view participating the PSHP in the day-ahead energy market with the price-arbitrage strategy. However, the derivation of end-of-day and end-of-week water storages for the joint energy and secondary regulation reserve schedules of PSHPs in liberalised power systems is still pending to be further studied. 


\subsection{Objectives of the Thesis}

The objectives of the Thesis are divided into the main objective and other secondary objectives that have detected in the technical literature. Further details of each objective are presented in the following subsections.

\subsubsection{Main objective}

The main objective of the Thesis is to develop a risk-averse optimisation model with lookahead period for the day-ahead energy and secondary regulation reserve hourly scheduling in the context of closed-loop and daily-cycle pumped-storage hydropower plants participating in the Iberian electricity system. In the developed model, it will be taken into account that the pumped-storage hydropower plants are equipped with variable-speed pump-turbine units and have the possibility to operate in hydraulic short-circuit mode. Hence, they will be able to also regulate power in pumping mode. In addition to this, the pumped-storage hydropower plants will be modelled as a price-taker in the day-ahead energy market and as a price-maker in the secondary regulation reserve market.

\subsubsection{Secondary objectives}

1. To analyse the value of perfect information (also called the profit loss due to the forecasting errors) of the electric power system data of the context of the Thesis: the day-ahead energy market prices (DM Prices), the residual demand curves of the secondary regulation reserve market (Reserve Curves), the upward and downward secondary regulation energy prices (ER2 Prices) and, finally, the percentages of the real-time use of the upward and downward secondary regulation reserves of the Spanish electricity system (see Figure 1.8).

2. To estimate the economic viability of pumped-storage hydropower plants by means of obtaining the maximum theoretical income participating in the day-ahead energy and the secondary regulation reserve markets of the Iberian electricity system. The economic viability will be estimated for pumped-storage hydropower plants equipped with fixedspeed or variable-speed units and/or having the possibility to operate in hydraulic shortcircuit mode. The maximum theoretical income assumes perfect knowledge of all the data from the electric power system, and can be seen as a threshold to reject or not the investment in the preliminary stages.

3. To analyse different methodologies to derive the optimal end-of-day storages of closedloop and daily-cycle pumped-storage hydropower plants in the day-ahead energy and secondary regulation reserve hourly scheduling. The methodologies to derive optimal 
end-of-day storages will be analysed for pumped-storage hydropower plants with different sizes of the power station, and equipped with fixed-speed pump-turbine units.

4. To develop forecasting models to predict the residual demand curves of the secondary regulation reserve market, and to predict the percentages of the real-time use of the upward and downward secondary regulation reserves of the Spanish electricity system.

The scheme of the objectives of the Thesis is shown in Figure 1.8.

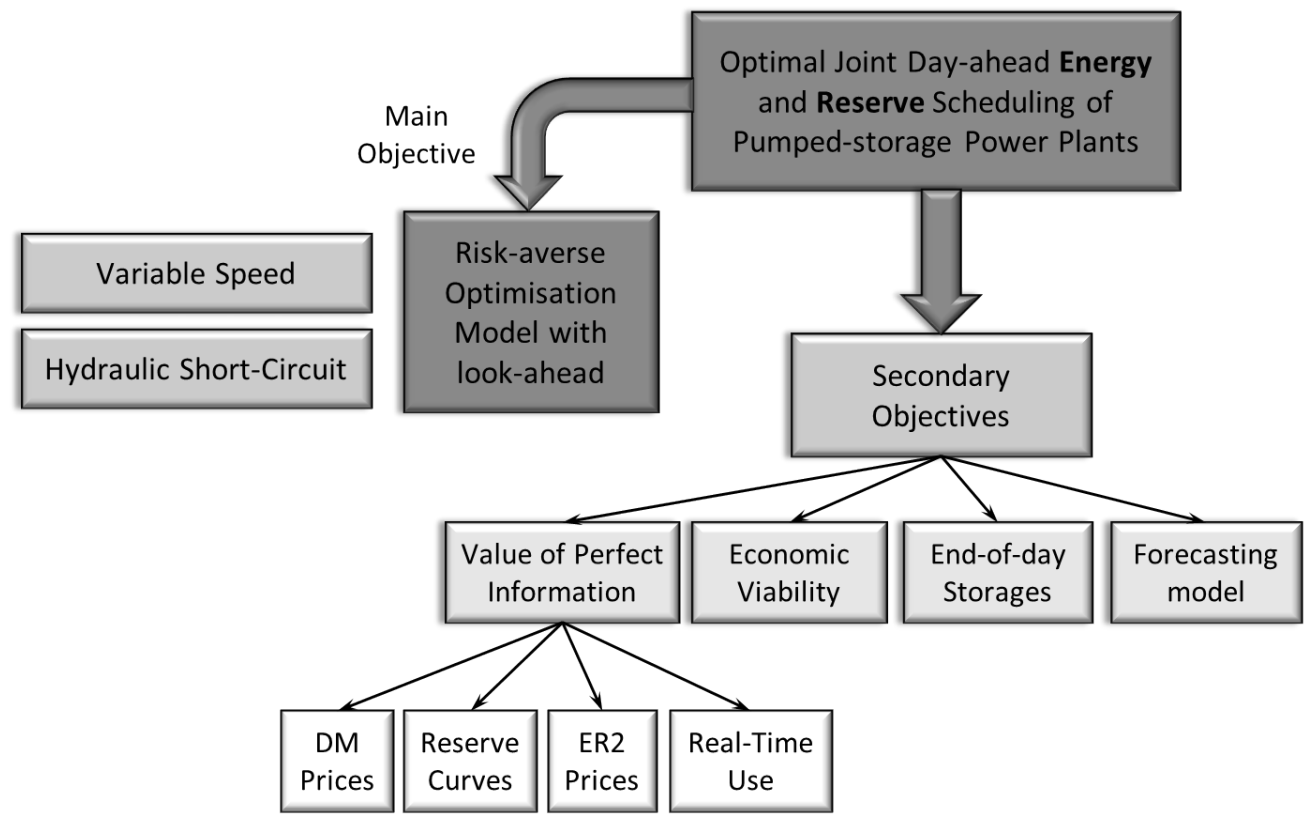

Figure 1.8: Scheme for the objectives of the Thesis 


\subsection{Summary of publications}

The articles that are included in the presented Thesis are composed by papers that have been published in JCR Journals and non-JCR Journals, papers that are currently under review to be published in JCR Journals, and finally, papers that have been presented at International Conferences with a review process. The scheme of the articles included in the presented Thesis is shown in Figure 1.9, with the acronym of the Journal or Conference of the most representative articles linked to each objective of the Thesis, under or beside a grey box. Further details of each article are presented in the following subsections.

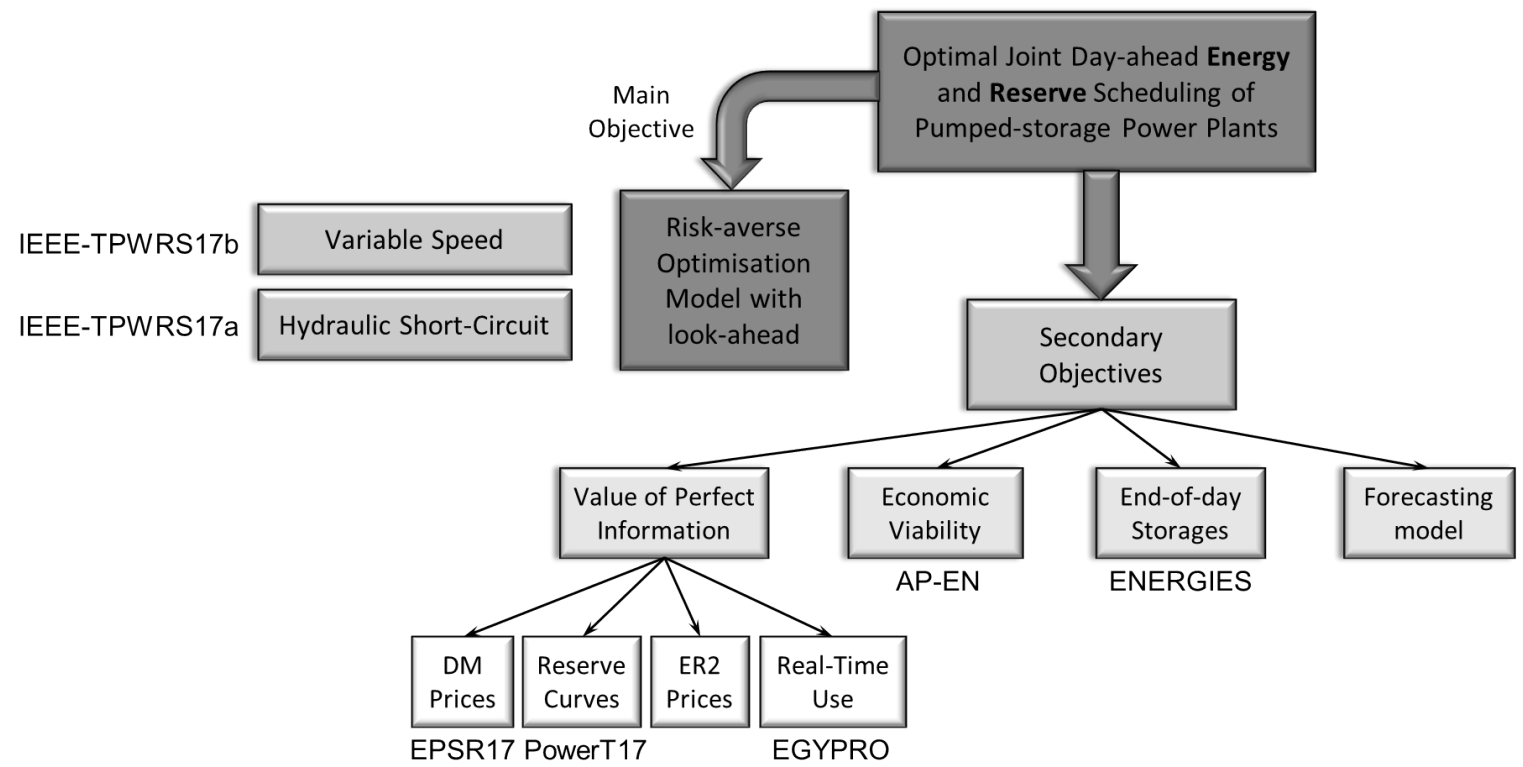

Figure 1.9: Scheme for the articles included in the Thesis

\subsubsection{JCR Journal publications}

The JCR Journal articles presented in the Thesis are composed by papers that have been already published in the technical literature and papers that have been submitted and are currently in the first or successive revisions:

1. Paper-A: Optimal Energy and Reserve Scheduling of Pumped-Storage Power Plants Considering Hydraulic Short-Circuit Operation.

- Authors: Manuel Chazarra, Juan Ignacio Pérez-Díaz and Javier García-González.

- Journal: IEEE Transactions on Power Systems, vol. 32, no. 1, pp. 344-353, 2017.

- Impact factor: 3.342 (2015).

- The acronym in Figure 1.9 is IEEE-TPWRS17a.

- This paper is cited in the Thesis with [Chazarra et al., 2017d]. 
2. Paper-B: Optimal Joint Energy and Secondary Regulation Reserve Hourly Scheduling of Variable Speed Pumped Storage Hydropower Plants.

- Authors: Manuel Chazarra, Juan Ignacio Pérez-Díaz and Javier García-González.

- Journal: IEEE Transactions on Power Systems, in press.

- Impact factor: 3.342 (2015).

- The acronym in Figure 1.9 is IEEE-TPWRS17b.

- This paper is cited in the Thesis with [Chazarra et al., 2017e].

3. Paper-C: Economic Viability of Pumped-Storage Power Plants Participating in the Secondary Regulation Service.

- Authors: Manuel Chazarra, Juan Ignacio Pérez-Díaz and Javier García-González.

- Journal: Applied Energy.

- Impact factor: 5.746 (2015).

- The acronym in Figure 1.9 is AP-EN.

- This paper is cited in the Thesis with [Chazarra et al., 2017c].

4. Paper-D: Value of Perfect Information of Spot Prices in the Joint Energy and Reserve Hourly Scheduling of Pumped Storage Plants.

- Authors: Manuel Chazarra, Juan Ignacio Pérez-Díaz and Javier García-González.

- Journal: Electric Power Systems Research. vol. 148, pp. 303-310, 2017.

- Impact factor: 1.809 (2015).

- The acronym in Figure 1.9 is EPSR17.

- This paper is cited in the Thesis with [Chazarra et al., 2017f].

5. Paper-E: Deriving Optimal End of Day Storage for Pumped-Storage Power Plants in the Joint Energy and Reserve Day-ahead Scheduling.

- Authors: Manuel Chazarra, Juan Ignacio Pérez-Díaz and Javier García-González.

- Journal: Special Issue Hydropower 2017 of the Journal, Energies.

- Impact factor: 2.077 (2015).

- The acronym in Figure 1.9 is ENERGIES.

- This paper is cited in the Thesis with [Chazarra et al., 2017a]. 


\subsubsection{Non-JCR Journal publications}

The non-JCR Journal articles that have been published in the technical literature and are included in the presented research are the following:

1. Paper-F: Economic Viability of Pumped-Storage Power Plants Equipped with Ternary Units and Considering Hydraulic Short-Circuit Operation.

- Authors: Manuel Chazarra, Juan Ignacio Pérez-Díaz and Javier García-González.

- Journal: Journal of Physics: Conference Series, vol. 813, 2017.

- The research was orally presented at the HYPERBOLE Conference, Porto, Portugal, 2-3 February 2017.

- This paper is cited in the Thesis with [Chazarra et al., 2017b].

2. Paper-G: Modeling the Real-Time Use of Reserves in the Joint Energy and Reserve Hourly Scheduling of a Pumped Storage Plant.

- Authors: Manuel Chazarra, Juan Ignacio Pérez-Díaz, Javier García-González and Arild Helseth.

- Journal: Energy Procedia, vol. 87, pp. 53-60, 2016.

- The research was orally presented at the $5^{\text {th }}$ International Workshop on Hydro Scheduling in Competitive Electricity Markets, Trondheim, Norway, 17-18 September 2015 .

- The acronym in Figure 1.9 is EGYPRO.

- This paper is cited in the Thesis with [Chazarra et al., 2016c].

\subsubsection{International Conferences}

The articles that have been orally presented at International Conferences and that are included in this research are the following:

1. Paper-H: Economic Impact of Forecasting Errors in Residual Reserve Curves in the Day-ahead Scheduling of Pumped Storage Plants.

- Authors: Manuel Chazarra, Juan Ignacio Pérez-Díaz, Javier García-González and Arild Helseth.

- Conference: $12^{\text {th }}$ IEEE PES PowerTech Conference, Manchester, UK, 18-22 June 2017.

- The acronym in Figure 1.9 is PowerT17. 
- This paper is cited in the Thesis with [Chazarra et al., 2017g].

2. Paper-I: Optimal Energy and Reserve Scheduling of Pumped-Storage Power Plants Considering Hydraulic Short-Circuit Operation.

- Authors: Manuel Chazarra, Juan Ignacio Pérez-Díaz and Javier García-González.

- Conference: $12^{\text {th }}$ IEEE PES PowerTech Conference, Manchester, UK, 18-22 June 2017.

- The paper has been invited for oral presentation at the Conference, and has been previously published in the Journal, IEEE Transactions on Power Systems, vol. 32, no. 1, pp. 344-353, 2017.

- This paper is cited in the Thesis with [Chazarra et al., 2017d].

3. Paper-J: Value of Perfect Information of Spot Prices in the Joint Energy and Reserve Hourly Scheduling of Pumped Storage Plants.

- Authors: Manuel Chazarra, Juan Ignacio Pérez-Díaz and Javier García-González.

- Conference: $13^{\text {th }}$ International Conference on the European Energy Market, Porto, Portugal, 6-9 June 2016.

- This paper is cited in the Thesis with [Chazarra et al., 2016b].

4. Paper-K: Optimal Operation of Variable Speed Pumped Storage Hydropower Plants Participating in Secondary Regulation Reserve Markets.

- Authors: Manuel Chazarra, Juan Ignacio Pérez-Díaz and Javier García-González.

- Conference: $11^{\text {th }}$ International Conference on the European Energy Market, Cracow, Poland, 28-30 May 2014.

- This paper is cited in the Thesis with [Chazarra et al., 2014]. 


\subsection{Methodology}

In order to fulfil the main objective and the secondary objectives of the Thesis, the following stages been carried out. Note that the order of the stages is the same as the one of the articles from the Thesis in Chapter 2:

1. To develop optimisation models which assume perfect information of the electric power system data of the problem. In the Thesis, four optimization models are developed depending on the pumped-storage hydropower plant: i) with fixed-speed units, ii) with variable-speed units and iii) with the possibility to operate in hydraulic-short circuit mode with binary units and, finally, iv) with the possibility to operate in hydraulicshort circuit mode with ternary units. The articles that are linked to this step are the ones entitled "Optimal Energy and Reserve Scheduling of Pumped-Storage Power Plants Considering Hydraulic Short-Circuit Operation" and "Optimal Joint Energy and Secondary Regulation Reserve Hourly Scheduling of Variable Speed Pumped Storage Hydropower Plants", which has an early version entitled "Optimal Operation of Variable Speed Pumped Storage Hydropower Plants Participating in Secondary Regulation Reserve Markets" and presented in an International Conference.

2. To estimate the economic viability of pumped-storage hydropower plants with the previously mentioned optimisation models, by means of obtaining the maximum theoretical income participating in the day-ahead energy and the secondary regulation reserve markets of the Iberian electricity system. The articles that are linked to this step are the ones entitled "Economic Viability of Pumped-Storage Power Plants Participating in the Secondary Regulation Service" and the early version of it, "Economic Viability of Pumped-Storage Power Plants Equipped with Ternary Units and Considering Hydraulic Short-Circuit Operation". The technical data of the hydraulic and electrical equipment of the studied pumped-storage hydropower plants were provided by General Electric, from some of its last prototypes or studies. Hence, the interest of the hydropower industry in the results of this part of the Thesis is guaranteed.

3. To study the value of perfect information of the electric power system data of the problem, in the context of the operation of closed-loop and daily-cycle pumped-storage hydropower plants participating in the day-ahead energy market as a price-taker and in the secondary regulation reserve market as a price maker. The value of perfect information is calculated by following the next three steps, also shown in Figure 1.10:

(a) the optimal generation and consumption schedules of the pumped-storage hydropower plant are obtained sequentially (day by day) by solving an optimisation 
model proposed in the Thesis with imperfect information of the random variable under study and perfect information of the rest. The electric power system data of the problem are: 1) the day-ahead energy market prices, 2) the residual demand curves of the secondary regulation reserve market, 3) the upward secondary regulation energy prices, 4) the downward secondary regulation energy prices, 5) the percentages of the real-time use of the upward reserves, and 6) the percentages of the real-time use of the downward reserves. The model is solved by the branch and cut algorithm in Cplex (365 daily problems in each forecasting model case and in each random variable).

(b) the actual profits and schedules are calculated in a post-optimal simulation process from the optimal energy schedule obtained in the previous step and the historical hourly values of the random variable under study.

(c) the value of perfect information of the random variable under study is calculated as the difference between the maximum theoretical income (MTI), which considers perfect knowledge in all the random variables, and the actual profits (AP) from the previous step.

- The articles that are linked to this step are the ones entitled "Value of Perfect Information of Spot Prices in the Joint Energy and Reserve Hourly Scheduling of Pumped Storage Plants" and its early version with the same title presented in an International Conference, and "Economic Impact of Forecasting Errors in Residual Reserve Curves in the Day-ahead Scheduling of Pumped Storage Plants". Preliminary results of the analysis of the value of perfect information of the rest of the electric power system data of the problem have been published in the article from this Thesis entitled "Modeling the Real-Time Use of Reserves in the Joint Energy and Reserve Hourly Scheduling of a Pumped Storage Plant". However, the main part of them are not published yet but will be presented in the Thesis in Chapter 3. 


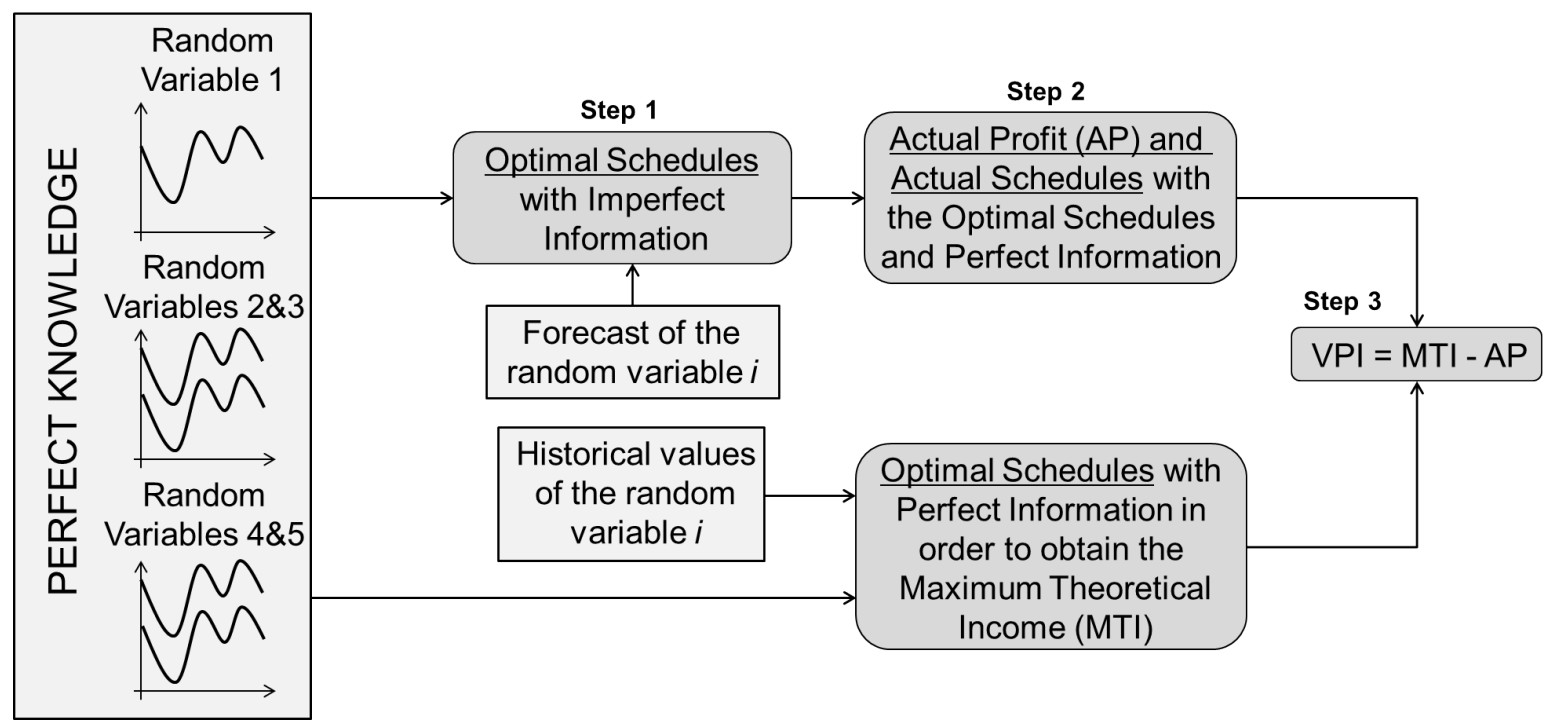

Figure 1.10: Methodology to obtain the value of perfect information (VPI) of the random variable $i$

4. To propose a methodology to derive the optimal end-of-day storages of closed-loop and daily-cycle pumped-storage hydropower plants in the day-ahead energy and secondary regulation reserve hourly scheduling. The optimisation model that is used in this step is based on the ones previously published, assuming perfect information of the electric power system data of the problem. The article that is linked to this step is the one entitled "Deriving Optimal End of Day Storage for Pumped-Storage Power Plants in the Joint Energy and Reserve Day-ahead Scheduling".

The developed optimisation models are implemented using the software MATLAB and are solved using the software GAMS. The models are based on mixed integer linear programming for the price-taker approaches and on mixed integer quadratic programming for the pricemaker approaches. The post-optimal simulation processes and the analysis of the results are usually carried out in the software MATLAB. For developing the forecasting models, the software MATLAB is utilised. Most of the articles of the Thesis have been prepared using the software Lyx, which is based on Latex, and a few of them using the software Microsoft Word. Finally, all the presentations from the results obtained in the Thesis at International Conferences and at the project "Optimal operation and control of pumped-storage hydropower plants" of The National Scientific Research, Development and Technological Innovation Plan 2008-2011, have been prepared using the software Microsoft Power Point. 


\section{Chapter 2}

\section{Publications}

\subsection{Paper-A: Optimal Energy and Reserve Scheduling of Pumped- Storage Power Plants Considering Hydraulic Short-Circuit Operation}

In this paper entitled "Optimal Energy and Reserve Scheduling of Pumped-Storage Power Plants Considering Hydraulic Short-Circuit Operation" [Chazarra et al., 2017d], it is presented an optimisation model based on mixed integer linear programming for obtaining the day-ahead energy and reserve scheduling of a closed-loop and daily-cycle PSHP, considering the operation in hydraulic short-circuit mode with binary units or ternary units. The PSHP is modelled as a price-taker in both in the day-ahead energy market and the secondary regulation reserve market of the Iberian and the Spanish electricity power systems, respectively. The activation of the secondary regulation reserves is also considered in the model formulation. The model assumes perfect information in all the electric power system data.

This publication is linked to the objectives of the Thesis (Figure 1.8) as follows: as far as the Thesis author knows, it was the first time in which the optimal scheduling of PSHPs operating in hydraulic short-circuit mode and participating in the day-ahead energy and reserve markets has been explicitly formulated. Therefore, it is used as a basis to develop the main goal of the Thesis (the risk-averse optimisation model with look ahead period, Chapter 3) and it is used as a tool for a part of the second secondary objective of the Thesis (to estimate the economic viability of PSHPs with the possibility of being operated in hydraulic short-circuit mode). 


\title{
Optimal Energy and Reserve Scheduling of Pumped-Storage Power Plants Considering Hydraulic Short-Circuit Operation
}

\author{
Manuel Chazarra, Juan Ignacio Pérez-Díaz, and Javier García-González, Member, IEEE
}

\begin{abstract}
This paper presents a mixed-integer model for the hourly energy and reserve scheduling of a price-taker and closedloop pumped-storage hydropower plant operating in hydraulic short-circuit mode. The plant participates in the spot market and in the secondary regulation reserve market, taking into account the regulation energy due to the real-time use of the regulation-up and -down reserves. The proposed model is used to compare the maximum theoretical income of the plant with and without considering hydraulic short-circuit operation. Numerical results demonstrate that the operation in hydraulic short-circuit mode could help significantly to enlarge the income of the power plant and that the secondary regulation reserve market might be the main source of revenue in a realistic setting characterized by a high level of renewable energy sources in the generation mix.
\end{abstract}

Index Terms-Hydraulic short-circuit technology, pumped storage plant, secondary regulation service.

\section{NOMENCLATURE}

\section{Subscripts/Superscripts:}

$c \quad$ subscript for hydropower unit, running from 1 to $\mathrm{C}$.

$d$ superscript that indicates that the magnitude is related to generation/discharge.

$k \quad$ subscript for discrete generation curves.

$p \quad$ superscript that indicates that the magnitude is related to consumption/pumping.

sec superscript that indicates that the magnitude is related to the secondary regulation service (reserve or energy).

$t \quad$ subscript for hourly period, running from 1 to $\mathrm{T}$.

\section{Parameters:}

$c S U_{c}^{d} \quad$ start-up cost of the turbine of hydro unit $c, €$.

Manuscript received August 4, 2015; revised December 16, 2015 and February 5, 2016; accepted March 20, 2016. Date of publication March 23, 2016; date of current version December 20, 2016. This work was supported in part by the Spanish Ministry of Economy and Competitiveness under the project "Optimal operation and control of pumped-storage hydropower plants" of The National Scientific Research, Development, and Technological Innovation Plan 2008-2011 (Ref. ENE2012-32207). This paper was presented in part at the 11th International Conference on the European Energy Market, Krakow, Poland, May 2014. Paper no. TPWRS-01105-2015.

M. Chazarra and J. I. Pérez-Díaz are with the Department of Hydraulic, Energy, and Environment Engineering, Escuela de Ingenieros de Caminos, Canales y Puertos, Technical University of Madrid, Madrid 28040, Spain (e-mail: manuel.chazarra@upm.es; ji.perez@upm.es).

J. García-González is with the Institute for Research in Technology, ICAI School of Engineering, Comillas Pontifical University, Madrid 28015, Spain (e-mail: javiergg@ comillas.edu).

Color versions of one or more of the figures in this paper are available online at http://ieeexplore.ieee.org.

Digital Object Identifier 10.1109/TPWRS.2016.2545740 $c S U_{c}^{p} \quad$ start-up cost of the pump of hydro unit $c, €$.

$\delta_{c, k}^{d} \quad$ energy coefficient in generating mode, $\mathrm{MW} / \mathrm{hm}^{3} / \mathrm{h}$.

$f v$ target water volume in last hour of time horizon, $\mathrm{hm}^{3}$.

$\bar{g}_{c, k}^{d}, \underline{g}_{c, k}^{d} \quad$ maximum and minimum technical power generation, MW.

$\bar{g}_{c, k}^{p}, \underline{g}_{c, k}^{p} \quad$ maximum and minimum technical power consumption, MW.

$l_{t} \quad$ time length of period $t, 1 \mathrm{~h}$.

$\lambda_{D, t} \quad$ day-ahead electricity market price, $€ / M W \cdot h$.

$\lambda_{S, t} \quad$ secondary regulation reserve market price, $€ / \mathrm{MW}$.

$\lambda_{\text {up }, t}$ secondary regulation-up energy market price, $€ / M W \cdot h$.

$\lambda_{\mathrm{dw}, t} \quad$ secondary regulation-down energy market price, $€ / M W \cdot h$.

$M \quad$ a big number, $10^{6}$.

$\bar{\eta}_{c, k}^{d}, \underline{\eta}_{c, k}^{d} \quad$ turbine efficiency at maximum and minimum flow, $\%$.

$\eta_{c, k}^{p} \quad$ pump efficiency, $\%$.

$\bar{q}_{c, k}^{d}, \underline{q}_{c, k}^{d} \quad$ maximum and minimum technical water discharge, $\mathrm{hm}^{3} / \mathrm{h}$.

$\bar{q}_{c, k}^{p}, \underline{q}_{c, k}^{p} \quad$ maximum and minimum technical pumped water, $\mathrm{hm}^{3} / \mathrm{h}$.

$\rho_{t}^{\mathrm{up}}, \rho_{t}^{\mathrm{dw}} \quad$ percentage of real-time use of secondary regulationup and down reserves.

$R_{t}^{\mathrm{SM}} \quad$ ratio between secondary regulation-up reserve and total regulation reserve, set by the transmission system operator (TSO) in advance.

$\bar{v}, \underline{v} \quad$ maximum and minimum technical water storage limits of upper reservoir due to design characteristics, $\mathrm{hm}^{3}$.

\section{Positive Variables:}

$g_{c, t}^{d} \quad$ power generation, MW.

$g_{c, t}^{p} \quad$ power consumption, MW.

$q_{c, t}^{d} \quad$ total water discharge, which includes water flow for real-time use of secondary regulation-up and down reserves, $\mathrm{hm}^{3} / \mathrm{h}$.

$q_{c, t}^{p} \quad$ pumped water, $\mathrm{hm}^{3} / \mathrm{h}$.

$q s_{c, t}^{d} \quad$ water discharge above the minimum technical limit, $\mathrm{hm}^{3} / \mathrm{h}$.

$g_{c, t}^{\text {sec,up }} \quad$ secondary regulation-up reserve, MW.

$g_{c, t}^{\text {sec,dw }}$ secondary regulation-down reserve, MW.

aux $g_{c, t}^{\mathrm{sec}}$ auxiliary variable associated with $g_{c, t}^{\mathrm{sec}, \mathrm{dw}}$, MW. 


$$
\begin{array}{ll}
e_{t}^{\text {sec, up }} & \begin{array}{l}
\text { secondary regulation-up reserve requested in real } \\
\text { time by the TSO, MW } \cdot \mathrm{h} .
\end{array} \\
e_{t}^{\mathrm{sec}, \mathrm{dw}} & \begin{array}{l}
\text { secondary regulation-down reserve requested in real } \\
\text { time by the TSO, } \mathrm{MW} \cdot \mathrm{h} .
\end{array} \\
& \text { water volume of the reservoir, } \mathrm{hm}^{3} .
\end{array}
$$

\section{Binary Variables:}

$d_{t} \quad$ used for the discretization of the hydropower generation/consumption curves.

$u_{c, t}^{d} \quad$ On/Off state in generating mode.

$u_{c, t}^{p} \quad$ On/Off state in pumping mode.

$y_{c, t}^{d} \quad 1$ if the turbine of a hydro unit is started-up, 0 otherwise.

$y_{c, t}^{p} \quad 1$ if the pump of a hydro unit is started-up, 0 otherwise.

$\phi_{t} \quad 1$ if there is more secondary regulation-up reserve requested in real time than regulation-down reserve, 0 otherwise.

\section{INTRODUCTION}

$\mathbf{P}$ UMPED storage hydropower plants (PSHPs) are deemed as a mature economic and large-scale feasible solution to store energy in an efficient way comparing to other technologies such as supercapacitors or electrochemical batteries [1]. Typical ratings of PSHPs are around $1000 \mathrm{MW}$ and, in most cases, they are capable to discharge water at rated power during several hours [2]. In addition to this, they can participate in ancillary services markets, offering regulating frequency reserve, emergency reserves, etc.

However, the construction of a PSHP requires high investment costs (between 470 to $2170 € / \mathrm{kW}$ [3]), which could be a barrier for commissioning new projects. Many factors could jeopardise the recovery of investment costs [4]: 1) income from price arbitrage between peak and off-peak hours is enough in just a few electricity markets [3], 2) PSHPs are obliged to pay grid fees for the usage of transmission lines when they are consuming, as it occurs in many power systems such as the Spanish system or 3) high water fees for utilising rivers or lakes reduce profits of PSHP operation.

Several researches have shown that PSHPs can hardly recover their capital costs from the price arbitrage or load-shifting traditional operation (see [3] in deregulated electricity markets or [5] in a centralised electricity market). In the context of liberalised electricity systems, the participation of PSHPs in other markets, mainly in the provision of regulation service, becomes critical to improve the profitability of the pumped-storage facility [6], [7]. In [8], secondary regulation reserve market (SM) proves to be the most important income source for a PSHP in a real day of the Portuguese electricity system and in other two synthetic 24-h scenarios.

Currently, most PSHPs in the world (hereafter referred to as conventional PSHPs) pump water at a fixed speed and therefore, are not able to provide load-frequency control in pumping mode. However, in order to help the integration of more intermittent renewable energy sources, during last years the hydropower industry has put special attention in technical solutions which allow providing load-frequency control while pumping, such as variable speed [9] and hydraulic short-circuit (SC) operation [10].

The aim of this paper is twofold: 1) to present a mixed integer linear programming (MILP) model for the energy and reserve scheduling of a realistic closed-loop ${ }^{1}$ and daily-cycle PSHP, considering hydraulic SC operation, 2) to show and to quantify the extent to which hydraulic SC operation is able to increase the income of a price-taker PSHP that participates both in the day-ahead energy market (DM) also called spot market, and the secondary regulation service of the Spanish electricity power system. The secondary regulation service in the Spanish electricity market comprises two different concepts: i) a reserve market, which takes place at 5:30 pm of the previous day (after having cleared the spot market) where power reserve availability is remunerated by the marginal market price, and ii) power reserve delivery in real time, which is remunerated by the marginal price of the tertiary regulation market [11]. The model, used to estimate the maximum theoretical income in the above-mentioned markets and services, is based on the one proposed in [12], which has been revised in order to consider several units within the same PSHP, and the head dependency of both power and available spinning reserve, as well as to allow for the operation in hydraulic SC mode instead of variable speed operation.

Diverse optimization models for bidding and/or scheduling conventional PSHPs in the day-ahead energy market [3], [13][15] and simultaneously in the energy and reserve markets [16]-[21] have been published in the literature. However, to the authors' knowledge, there are no papers where the optimal scheduling of PSHPs operating in hydraulic SC mode and participating in the energy and reserve markets has been explicitly formulated [7].

Main contributions with respect previous studies are the following: 1) an MILP model for the energy and reserve scheduling of a PSHP considering hydraulic SC operation and the real-time use of reserves is proposed in the paper. The model considers a variable number of PSHP units, the units' start-up costs and the head dependency in both power and available spinning reserve, and 2) the increase in the maximum theoretical income of a PSHP due to the operation in hydraulic SC mode has been quantified. The features considered in the proposed model have not been taken into account in previous studies. Therefore, the conclusions derived from the presented results can help to assess the profitability of the different configurations of PSHPs.

The paper is organised as follows: Section II describes the operation of PSHPs in hydraulic SC. Section III presents the scheduling model formulation. The application of the model to a realistic PSHP is presented in Section IV and finally, conclusions are described in Section V.

\section{Pumped-Storage Power Plants in Hydraulic SC OPERATION}

To the best of our knowledge, Kops II, Malta, Geesthacht and Luenersee are the only four PSHPs that are operated in

\footnotetext{
${ }^{1}$ Closed-loop PSHPs do not receive natural water inflows in the upper reservoir and do not release water from the lower reservoir.
} 


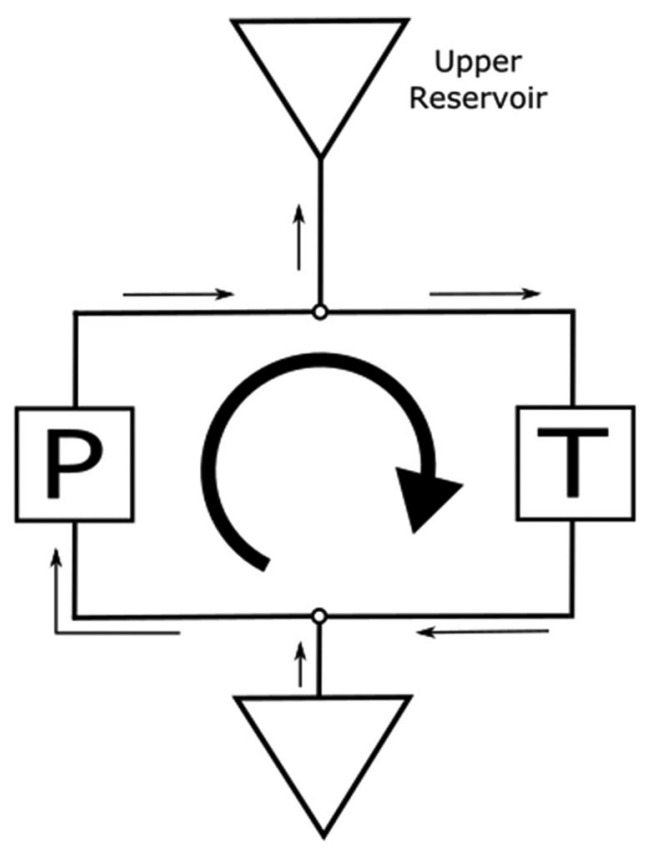

Fig. 1. Pumped-storage power plant operating in hydraulic SC mode.

hydraulic SC mode in the world. Kops II, owned by Vorarlberger Illwerke (Austria), was commissioned in 2008 and it is the most documented [22], [23]. The power station scheme of a PSHP operating in hydraulic SC mode with a single ternary unit is presented in Fig. 1. A ternary unit is composed by a Pelton turbine, a fixed-speed pump and a motor/generator electric machine, all connected vertically. Thanks to a clutch, both the turbine and the pump of the ternary unit can be operated simultaneously. The main advantage of this is that the PSHP is able to regulate power (and therefore, to participate in the secondary regulation service) while it is consuming energy, with a power regulation range equal to that of the turbines in operation. In other words, the PSHP operating in hydraulic SC mode can be considered as a controllable load, contributing to a much better integration of intermittent renewable energy and to balance generation and demand in real time better than conventional PSHPs.

From the point of view of modelling, three operating modes must be taken into account: generating, pumping and hydraulic SC modes. The input/output curve (I/O curve) of a single ternary unit, for a certain water level in the upper reservoir is presented in Fig. 2. In generating mode (dashed line), water is discharged from the upper to the lower reservoir through the Pelton turbine (while the pump is off) and energy is injected to the grid. When the unit is operated in pumping mode (black dot), water is pumped from the lower to the upper reservoir through the fixed-speed pump and energy is consumed from the grid. Finally, when the unit is operated in hydraulic SC mode (solid line, obtained by means of a simple translation of the generating mode curve in such a way that origin is moved to the point that corresponds to the pumping mode at fixed rate), both turbine and pump are on. A percentage of water that is taken from the lower reservoir is pumped to the upper reservoir and the rest is

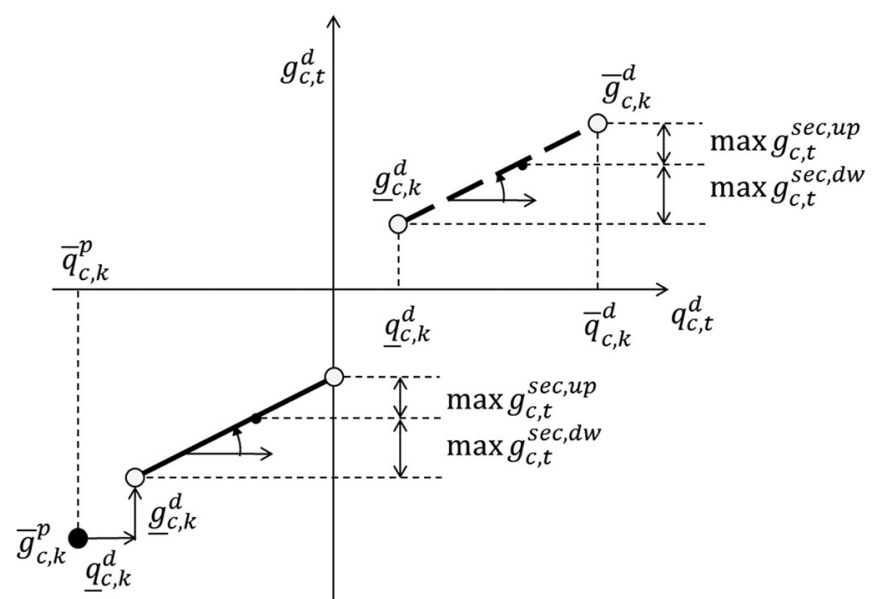

Fig. 2. I/O curve of a ternary unit in hydraulic SC. Dashed line for generating mode, black dot for pumping mode and solid line for SC mode.

TABLE I

MODES OF OPERATION OF DIFFERENT PSHPS

\begin{tabular}{|c|c|c|c|}
\hline PSHP & Pumping & Generating & Hydraulic SC \\
\hline Conv & fixed speed & Francis pump-turbine & $\mathrm{n} / \mathrm{a}$ \\
\hline SC-B & fixed speed & Francis pump-turbine & two or more units \\
\hline SC-T & fixed speed & Pelton & one or more units \\
\hline
\end{tabular}

passed through the turbine, delivering energy to the grid and regulating the output power if necessary. The maximum secondary regulation-up, $\max g_{c, t}^{\mathrm{sec}, \mathrm{up}}$ and down, $\max g_{c, t}^{\mathrm{sec}, \mathrm{dw}}$ reserves, in generating and hydraulic SC modes are shown in Fig. 2 (it is not possible to regulate in pumping mode since the pump operates with fixed speed). Reserves that are requested in real time are supplied as following: regulation-up (resp. down) energy is delivered by increasing (resp. reducing) the water discharge through the turbines.

If the PSHP is composed by several ternary units, all pumps and turbines can be operated simultaneously in hydraulic SC mode, with a total regulation range equal to that of all turbines in operation. Finally, although as far as we know there is no PSHP operating in hydraulic SC mode with binary units (SC-B) (a binary unit is composed by a reversible Francis pumpturbine and a motor/generator electric machine), theoretically, they could be also operated in the said mode, as long as they comprise two or more units (at least one unit must operate in pumping mode and another in generating mode). Nonetheless, the power regulation range of PSHPs operating in hydraulic SC-B is significantly lower than with ternary units, since each binary unit must be operated as a turbine or as a pump but not simultaneously. Furthermore, the power regulation range of a Francis pump-turbine is notably lower than that of a Pelton turbine. In Section IV, the operation and income of a PSHP with ternary units operating in hydraulic SC mode are compared with those of a conventional PSHP with binary units and with a PSHP operating in hydraulic SC-B.

Table I summarises the main features of the pumping, generating and hydraulic SC operating modes of the configurations 
of conventional PSHPs (Conv), PSHPs operating in hydraulic SC-B and PSHPs operating in hydraulic SC mode with ternary units (SC-T) considered in Section IV.

\section{MODEL ForMULATION}

In this section, three models are presented. Section III-A shows the model formulation of PSHPs operating in hydraulic SC-T (SC-T PSHP) whereas Section III-B describes the model formulation of PSHPs operating in hydraulic SC-B (SC-B PSHP). Differences between a PSHP operating in hydraulic SC-T and SC-B are explained in Section II. Finally, Section III$\mathrm{C}$ presents the model formulation of conventional PSHPs (Conv PSHP).

\section{A. Model Formulation for SC-T PSHP}

1) Objective Function: The objective function consists in maximizing the net income of a PSHP participating in the DM and the secondary regulation service in the framework of the Spanish electricity market [11]. In (1), the first line expresses the net income for the regulation energy due to the real-time use of the secondary regulation reserves. The second line expresses the net income in the DM and the income for reserves put at disposal of the TSO in the SM. And, finally, the third line expresses the start-up costs of turbines and pumps, respectively,

$$
\begin{aligned}
\operatorname{Max} z= & \sum_{t}\left\{\left(e_{t}^{\mathrm{sec}, \mathrm{up}} \cdot \lambda_{\mathrm{up}, t}-e_{t}^{\mathrm{sec}, \mathrm{dw}} \cdot \lambda_{\mathrm{dw}, t}\right)\right. \\
& +\sum_{c}\left[\left(g_{c, t}^{d}-g_{c, t}^{p}\right) \cdot \lambda_{D, t}+\left(g_{c, t}^{\mathrm{sec}, \mathrm{up}}+g_{c, t}^{\mathrm{sec}, \mathrm{dw}}\right)\right. \\
& \left.\left.\cdot \lambda_{S, t}-c S U_{c}^{d} \cdot y_{c, t}^{d}-c S U_{c}^{p} \cdot y_{c, t}^{p}\right]\right\} .
\end{aligned}
$$

2) Water Balance: The water balance, (2) does not include any water inflow because a closed-loop PSHP is considered in this article. Furthermore, in order to express all terms of the water balance equation with the same dimension, time duration of each period $t$ is included with flow variables even though its value is one hour. In addition to this, water limits are imposed to water volume in the upper reservoir, $v_{t}$ in all time period $t$, (3). Water balance and limits in the lower reservoir are not included in the model formulation for the shake of clarity,

$$
\begin{aligned}
& v_{t}=v_{t-1}+\sum_{c} l_{t} \cdot\left(q_{c, t}^{p}-q_{c, t}^{d}\right) \quad \forall t \\
& \underline{v} \leq v_{t} \leq \bar{v} \quad \forall t .
\end{aligned}
$$

In the upper reservoir, a target water volume is imposed, (4), where $\mathrm{T}$ stands for the last period of the time horizon. The target water volume is deemed as input data to the model and equals initial volume in Section IV

$$
v_{t}=f v \quad \forall t=\mathrm{T} .
$$

3) Hydropower Generation: Generation/consumption curves of each unit of SC-T PSHPs are modelled by equations (7)-(24) (see Fig. 2 in Section II). The presented formulation for generation/consumption curves follows the one proposed in [24].
Two generation/consumption curves, $k_{1}$ and $k_{2}$ have been considered in the formulation, and correspond to two different reservoir levels. Each curve is selected using the binary variable, $d_{t}$ that depends on the water volume of the upper reservoir, (5) and (6). The power generation is calculated from (7)-(10), as a function of $d_{t}$ and $u_{c, t}^{d}$. With equations (11) and (12), the maximum and minimum water discharges, which depend on the water level in the upper reservoir, are considered. In addition to this, the water discharge takes into account not only the flow that is used to produce the energy committed or scheduled in the spot market but also the extra flow that is required for providing regulation-up energy, and the flow that is kept upstream in order to provide regulation-down energy, (13)-(16). The water discharge used for deploying the secondary regulation energy also depends on the water level in the upper reservoir. This has been modelled by using the appropriate energy coefficient of each generation curve, $\delta_{k_{1}}^{d}$ and $\delta_{k_{2}}^{d}$. Head dependency in consumed power and pumped water is included in (17)-(24). Start-up decisions are modelled in (25) for turbines and (26) for pumps. In the case that the maximum variation of the water level in the upper reservoir can be negligible in comparison with the available gross head, the corresponding equations can be derived in a straightforward manner from those used in this paper

$$
\begin{aligned}
v_{t} \geq & \underline{v} \cdot\left(1-d_{t}\right)+\left(\underline{v}+\frac{\bar{v}-\underline{v}}{2}\right) \cdot d_{t} \quad \forall t \\
v_{t} \leq & \bar{v} \cdot d_{t}+\left(\underline{v}+\frac{\bar{v}-\underline{v}}{2}\right) \cdot\left(1-d_{t}\right) \quad \forall t \\
g_{c, t}^{d} \leq & u_{c, t}^{d} \cdot \underline{g}_{c, k}^{d}+q s_{c, t}^{d} \cdot \delta_{k}^{d}+M \cdot d_{t} \quad \forall c, t, k=k_{1} \\
g_{c, t}^{d} \geq & u_{c, t}^{d} \cdot \underline{g}_{c, k}^{d}+q s_{c, t}^{d} \cdot \delta_{k}^{d}-M \cdot d_{t} \quad \forall c, t, k=k_{1} \\
g_{c, t}^{d} \leq & u_{c, t}^{d} \cdot \underline{g}_{c, k}^{d}+q s_{c, t}^{d} \cdot \delta_{k}^{d}+M \cdot\left(1-d_{t}\right) \\
& \forall c, t, k=k_{2} \\
g_{c, t}^{d} \geq & u_{c, t}^{d} \cdot \underline{g}_{c, k}^{d}+q s_{c, t}^{d} \cdot \delta_{k}^{d}-M \cdot\left(1-d_{t}\right) \\
& \forall c, t, k=k_{2} \\
q s_{c, t}^{d} \leq & u_{c, t}^{d} \cdot M \quad \forall c, t \\
q_{c, t}^{d} \leq & \left(\bar{q}_{c, k_{1}}^{d}-\underline{q}_{c, k_{1}}^{d}\right) \cdot\left(1-d_{t}\right) \\
& +\left(\bar{q}_{c, k_{2}}^{d}-\underline{q}_{c, k_{2}}^{d}\right) \cdot d_{t} \quad \forall c, t \\
q_{c, t}^{d} \leq & u_{c, t}^{d} \cdot \underline{q}_{c, k}^{d}+q s_{c, t}^{d}+M \cdot d_{t}+\frac{1}{\delta_{k}^{d}} \cdot\left(\rho_{t}^{\mathrm{up}} \cdot g_{c, t}^{\mathrm{sec}, \mathrm{up}}\right. \\
& \left.-\rho_{t}^{\mathrm{dw}} \cdot g_{c, t}^{\mathrm{sec}, \mathrm{dw}}\right) \quad \forall c, t, k=k_{1} \\
q_{c, t}^{d} \leq & u_{c, t}^{d} \cdot \underline{q}_{c, k}^{d}+q s_{c, t}^{d}+M \cdot\left(1-d_{t}\right)+\frac{1}{\delta_{k}^{d}} \cdot\left(\rho_{t}^{\mathrm{up}}\right. \\
& \left.\cdot g_{c, t}^{\mathrm{sec}, \mathrm{up}}-\rho_{t}^{\mathrm{dw}} \cdot g_{c, t}^{\mathrm{sec}, \mathrm{dw}}\right) \quad \forall c, t, k=k_{2} \\
& u_{c, t}^{d} \cdot \underline{q}_{c, k}^{d}+q s_{c, t}^{p}-M \cdot d_{t}+\frac{1}{\delta_{k}^{d}} \cdot\left(\rho_{t}^{\mathrm{up}} \cdot g_{c, t}^{\mathrm{sec}, \mathrm{up}}\right. \\
&
\end{aligned}
$$




$$
\begin{aligned}
q_{c, t}^{d} \geq & u_{c, t}^{d} \cdot \underline{q}_{c, k}^{d}+q s_{c, t}^{d}-M \cdot\left(1-d_{t}\right)+\frac{1}{\delta_{k}^{d}} \cdot\left(\rho_{t}^{\mathrm{up}}\right. \\
& \left.\cdot g_{c, t}^{\mathrm{sec}, \mathrm{up}}-\rho_{t}^{\mathrm{dw}} \cdot g_{c, t}^{\mathrm{sec}, \mathrm{dw}}\right) \quad \forall c, t, k=k_{2} \\
g_{c, t}^{p} \leq & u_{c, t}^{p} \cdot \bar{g}_{c, k}^{p}+M \cdot d_{t} \quad \forall c, t, k=k_{1} \\
g_{c, t}^{p} \geq & u_{c, t}^{p} \cdot \bar{g}_{c, k}^{p}-M \cdot d_{t} \quad \forall c, t, k=k_{1} \\
g_{c, t}^{p} \leq & u_{c, t}^{p} \cdot \bar{g}_{c, k}^{p}+M \cdot\left(1-d_{t}\right) \quad \forall c, t, k=k_{2} \\
g_{c, t}^{p} \geq & u_{c, t}^{p} \cdot \bar{g}_{c, k}^{p}-M \cdot\left(1-d_{t}\right) \quad \forall c, t, k=k_{2} \\
q_{c, t}^{p} \leq & u_{c, t}^{p} \cdot \bar{q}_{c, k}^{p}+M \cdot d_{t} \quad \forall c, t, k=k_{1} \\
q_{c, t}^{p} \geq & u_{c, t}^{p} \cdot \bar{q}_{c, k}^{p}-M \cdot d_{t} \quad \forall c, t, k=k_{1} \\
q_{c, t}^{p} \leq & u_{c, t}^{p} \cdot \bar{q}_{c, k}^{p}+M \cdot\left(1-d_{t}\right) \quad \forall c, t, k=k_{2} \\
q_{c, t}^{p} \geq & u_{c, t}^{p} \cdot \bar{q}_{c, k}^{p}-M \cdot\left(1-d_{t}\right) \quad \forall c, t, k=k_{2} \\
y_{c, t}^{d} \geq & u_{c, t}^{d}-u_{c, t-1}^{d} \quad \forall c, t \quad \forall \\
y_{c, t}^{p} \geq & u_{c, t}^{p}-u_{c, t-1}^{p} \quad \forall c, t .
\end{aligned}
$$

4) Secondary Regulation Service: The secondary regulation service (also called secondary control or load-frequency control service) in the Spanish electricity market comprises the hourly power reserve of each participant, that is committed in a day-ahead reserve market, and the reserve requested in realtime by the TSO. The secondary regulation reserve bids are modelled through (27)-(31). Note that the auxiliary variable $a u x_{-} g_{c, t}^{\mathrm{sec}}$ avoids non-linearities in the formulation of the secondary regulation-down reserve due to the head dependency in the available spinning reserve. When a unit is off in generating mode $\left(u_{c, t}^{d}=0\right)$, there is no available secondary regulation reserve by (29), and $a u x_{-} g_{c, t}^{\mathrm{sec}}$ will take a value greater than or equal to the expression in square brackets in (28) and lower than $M$ by (30). In addition, when a unit is on in generating mode $\left(u_{c, t}^{d}=1\right)$, aux $g_{c, t}^{\mathrm{sec}}$ equals zero through (30). Moreover, the Spanish TSO requires the market agents to fulfil an hourly ratio between regulation-up reserve and total reserve, (31). When a bid is assigned in this market, the PSHP must be ready to use it

$$
\begin{aligned}
& g_{c, t}^{\mathrm{sec}, \mathrm{up}} \leq\left[\bar{g}_{c, k_{2}}^{d} \cdot d_{t}+\bar{g}_{c, k_{1}}^{d}\left(1-d_{t}\right)\right]-g_{c, t}^{d} \quad \forall c, t \\
& g_{c, t}^{\mathrm{sec}, \mathrm{dw}}-a u x_{-} g_{c, t}^{\mathrm{sec}} \leq g_{c, t}^{d} \\
& \quad-\left[\underline{g}_{c, k_{2}}^{d} \cdot d_{t}+\underline{g}_{c, k_{1}}^{d}\left(1-d_{t}\right)\right] \quad \forall c, t \\
& g_{c, t}^{\mathrm{sec}, \mathrm{up}}+g_{c, t}^{\mathrm{sec}, \mathrm{dw}} \leq M \cdot u_{c, t}^{d} \quad \forall c, t \\
& a u x_{-} g_{c, t}^{\mathrm{sec}} \leq M\left(1-u_{c, t}^{d}\right) \quad \forall c, t \\
& \sum_{c}\left(\frac{g_{c, t}^{\mathrm{sec}, \mathrm{up}}}{g_{c, t}^{\mathrm{sec}, \mathrm{up}}+g_{c, t}^{\mathrm{sec}, \mathrm{dw}}}\right)=R_{t}^{\mathrm{SM}} \quad \forall t .
\end{aligned}
$$

The secondary regulation energy in each period $t$ is remunerated according to the net energy, i.e. regulation-up energy minus regulation-down energy, (32)-(34). A positive net regulation energy $\left(\phi_{t}=1\right)$ is remunerated according to the regulation-up energy price and the PSHP must discharge extra water from the upper reservoir whereas if the net regulation energy is negative $\left(\phi_{t}=0\right)$, the PSHP must pay the regulation-down energy price, keeping water in the upper reservoir. If $\phi_{t}=1, e_{t}^{\mathrm{sec}, \mathrm{dw}}=0$ by equation (34) and $e_{t}^{\mathrm{sec} \text {, up }}$ equals the right-side of equation (32). Analogously, if $\phi_{t}=0, e_{t}^{\mathrm{sec}, \mathrm{up}}=0$ by equation (33) and $e_{t}^{\mathrm{sec}, \mathrm{dw}}$ equals the right-side of equation (32)

$$
\begin{aligned}
& e_{t}^{\mathrm{sec}, \mathrm{up}}-e_{t}^{\mathrm{sec}, \mathrm{dw}}=\sum_{c}\left(\rho_{t}^{\mathrm{up}} \cdot g_{c, t}^{\mathrm{sec}, \mathrm{up}}-\rho_{t}^{\mathrm{dw}} \cdot g_{c, t}^{\mathrm{sec}, \mathrm{dw}}\right) \\
& 0 \leq e_{t}^{\mathrm{sec}, \mathrm{up}} \leq \phi_{t} \cdot M \quad \forall t \\
& 0 \leq e_{t}^{\mathrm{sec}, \mathrm{dw}} \leq\left(1-\phi_{t}\right) \cdot M \quad \forall t .
\end{aligned}
$$

\section{B. Model Formulation for SC-B PSHP}

Model formulation of PSHPs operating in hydraulic SC-B is composed by equations (1)-(34) and equation (35). The latter prevents each unit to be operated simultaneously in generating and pumping mode (see Section II for details of binary units). Due to this, the I/O curve of each binary unit is the same as the one of Conv PSHPs, i.e., the one presented in Fig. 2 but with the solid line removed. However, note that the plant can be operated simultaneously in generating and pumping mode if it is equipped by two or more units, thanks to the hydraulic SC

$$
u_{c, t}^{d}+u_{c, t}^{p} \leq 1 \quad \forall c, t .
$$

\section{Model Formulation for Conventional PSHP}

Model formulation of Conv PSHPs is composed by equations (1)-(35) and equation (36). A Conv PSHP can be operated in generating or pumping modes but not in hydraulic SC mode. Therefore, the plant only regulates power in generating mode, losing the opportunity to participate in the secondary regulation service while it is pumping, regardless of the number of pumpturbine units. The I/O curve of their units is the same as the one presented in Fig. 2 but with the solid line removed. In addition to this, Conv PSHPs usually comprise a single penstock between the upper reservoir and the power station. Consequently, if there is at least one unit operating in pumping mode, no unit can be operated in generating mode, and vice versa, (36). For instance, if the Conv PSHP is composed by three units, i.e. $\mathrm{C}=3$, and unit $c_{1}$ is pumping, i.e., $u_{c_{1}, t}^{p}=1$, the right-side of equation (36) is zero when the constraint is evaluated for $c=c_{1}$ and, therefore, the rest of the units of the plant have an off state in generating mode, i.e., $u_{c_{2}, t}^{d}=u_{c_{3}, t}^{d}=0$, left-side of the equation. Due to (35), when a unit is in pumping mode, it cannot be in generating mode, i.e., $u_{c_{1}, t}^{d}=0$ as $u_{c_{1}, t}^{p}=1$

$$
\sum_{c^{\prime} \neq c} u_{c^{\prime}, t}^{d} \leq(\mathrm{C}-1)-(\mathrm{C}-1) \cdot u_{c, t}^{p} \quad \forall c, t .
$$

\section{CAse Study}

\section{A. Data}

1) Electric Power System Data: The electric power system data correspond to historical hourly values of: 1) spot prices, 2) secondary regulation reserve prices, 3 ) secondary regulationup and down energy prices, 4) percentage of real-time use 
TABLE II

TEChNicAl Data of EACH Unit IN THE Proposed PSHPs, Flows IN $\mathrm{m}^{3} / \mathrm{s}$ POWER IN $M W$, EFFICIENCIES IN \% AND START-UP COSTS IN $€$

\begin{tabular}{lcc}
\hline \hline & Conv and SC-B & SC-T \\
\hline $\bar{q}_{c, k}^{d}$ & $115.7 / 115.7$ & $115.7 / 115.7$ \\
$\bar{g}_{c, k}^{d}$ & $297.4 / 314.1$ & $297.4 / 314.1$ \\
$\bar{\eta}_{c, k}^{d}$ & $90 / 92$ & $90 / 92$ \\
$\underline{q}_{c, k}^{d}$ & $49.77 / 49.77$ & $23.15 / 23.15$ \\
$\underline{g}_{c, k}^{d}$ & $107.9 / 114.5$ & $52.87 / 55.99$ \\
$\underline{\eta}_{c, k}^{d}$ & $76 / 78$ & $80 / 82$ \\
$\bar{q}_{c, k}^{p}$ & $115.7 / 115.7$ & $115.7 / 115.7$ \\
$\bar{g}_{c, k}^{p}$ & $389.8 / 402.8$ & $389.8 / 402.8$ \\
$\eta_{c, k}^{p}$ & $90 / 90$ & $90 / 90$ \\
$c S U_{c}^{d}$ & 1650.6 & 1650.6 \\
$c S U_{c}^{p}$ & 1321.5 & 1321.5 \\
\hline \hline
\end{tabular}

of regulation-up and down reserves and 5) the ratio between regulation-up reserve and total reserve determined by the TSO, $R_{t}^{\mathrm{SM}}$.

Actual regulation-up and down energy provided by each power plant in Spain is not publicly available. In order to build the required input data, it is assumed that the hourly real-time use of reserves, $\left(\rho_{t}^{\mathrm{up}}, \rho_{t}^{\mathrm{dw}}\right)$ is given by the historical hourly ratio of aggregate power delivery and aggregate assigned reserves in the entire Spanish power system. The maximum hourly realtime use of reserves is assumed to be $100 \%$. In addition to this, hourly regulation reserve ratio, $R_{t}^{\mathrm{SM}}$ is assumed to be the historical hourly ratio of aggregate secondary regulation-up and total reserve requirements of the entire Spanish power system.

2) Technical Data: Technical data of 1) the reversible Francis pump-turbines for the Conv PSHP and the SC-B PSHP and 2) the Pelton turbines and pumps at fixed speed for the SC-T PSHP are presented in Table II. All data is split into pairs (except start-up costs): values on the left (resp. right) of the slash refers to the I/O curve for the lower (resp. higher) reservoir level. Higher gross head is considered to be $310 \mathrm{~m}$ while lower gross head is assumed to be $300 \mathrm{~m}$. Hydraulic losses, mainly resulting from friction of the water in the penstock, are considered $3 \%$ of the gross head [25], i.e., $9.3 \mathrm{~m}$ for the higher gross head and 9 $\mathrm{m}$ for the lower gross head. It is assumed that the three analysed PSHPs (Conv, SC-B and SC-T) are formed by two identical units.

Maximum water discharge and pumped water flow have been chosen in order to empty and refill the upper reservoir in a minimum time of $6 \mathrm{~h}$ (the upper reservoir capacity is $5 \mathrm{hm}^{3}$, $\bar{v}=5 \mathrm{hm}^{3}$ and $\underline{v}=0 \mathrm{hm}^{3}$ ). In generating mode, the minimum flow and efficiencies at maximum and minimum flows are determined from typical performance curves in [25]. A linear relationship between water discharge and power generation is assumed. As all pumps (and reversible Francis pump-turbines in pumping mode) operate at fixed speed, they have a single operating point with a typical efficiency of 90\% [26]. The round-trip efficiency of the ternary units is between $78 \%$ at the maximum operating point and $69.5 \%$ at the minimum operating point for the higher gross head and between $76.3 \%$ and $67.8 \%$ for the lower gross head. In addition to this, the round-trip efficiency of the binary units is between $78 \%$ at the maximum operating point and $66.1 \%$ at the minimum operating point for the higher gross head and between $76.3 \%$ and $64.4 \%$ for the lower gross head.

Finally, start-up costs of turbines and pumps have been calculated according to [27]. No differences have been considered between reversible Francis in generating mode and Pelton turbines or between reversible Francis in pumping mode and pumps of SC-T PSHPs.

\section{B. Methodology}

The three proposed models in Section III have been applied, respectively, to the closed-loop and daily-cycle PSHPs of Table II to calculate the maximum theoretical income in the abovementioned markets and services in two representative cases. For this purpose, the model was run, day by day, over two different periods of one week (one in summer and one in late autumn) and with a daily initial and final volume in the upper reservoir of $2.5 \mathrm{hm}^{3}$, in order to 1) determine the extra value that the hydraulic SC operation introduces comparing to Conv PSHPs participating in the spot and the secondary regulation service and 2) analyse and compare to each other the power and reserve schedule of Conv PSHPs and PSHPs operating in hydraulic SC mode. Each daily problem is solved with a branch and cut algorithm in Cplex in a 2.2 GHz Dual Core AMD Turion CPU, with 4 GB of RAM memory. Hundreds seconds of CPU time were necessary for each week and each PSHP.

\section{Maximum Theoretical Income}

For Conv, SC-B and SC-T PSHPs, maximum theoretical income in the two cases under study and in the day 11/11/2014, whose operation is discussed in Section IV-D, are shown in Table III. These results consider that all PSHPs are formed by two identical units with the data of Table II. Revenues are composed by the spot market income (DM), secondary regulation reserve market income (SM) and income from secondary regulationup (ER2UP) energy. Costs are related to secondary regulationdown energy (ER2DW) and start-up costs for turbines, $c S U^{d}$ and pumps, $c S U^{p}$. In addition to this, income in the spot market is divided into sold energy when the plant is generating $\left(D M^{+}\right)$ and purchased energy when is pumping $\left(D M^{-}\right)$.

All PSHPs are mainly obtaining their revenues from the secondary regulation reserve market. As the PSHP is more flexible (SC-T PSHPs are more flexible than SC-B PSHPs that are more flexible than Conv PSHPs), the maximum theoretical income from this market and in total are higher, whereas the spot market revenue is lower and even negative (see DM in the first case for all PSHPs and in the second case for the SC-T PSHP). This reflects that the PSHP is using the secondary regulation reserve as the priority source of revenue, and the spot market as a subsidiary means to maximize the participation in the secondary regulation market.

As a consequence of a higher participation in the secondary regulation reserve market, not only the income from the said market is higher as the PSHP is more flexible, but also the 
TABLE III

MAXIMUM THEORETICAL INCOME OF PSHPS, $\left[10^{3} €\right]$

\begin{tabular}{|c|c|c|c|c|}
\hline & & Conv & SC-B & SC-T \\
\hline & $D M^{+}$ & 1663.35 & 1729.06 & 2526.51 \\
\hline & $D M^{-}$ & -1721.60 & -1798.44 & -2924.44 \\
\hline First Case & DM & -58.25 & -69.38 & -397.93 \\
\hline $30 / 06 / 2014$ & SM & 707.28 & 728.43 & 1682.55 \\
\hline to & ER2UP & 131.68 & 140.07 & 441.38 \\
\hline \multirow[t]{6}{*}{$06 / 07 / 2014$} & ER2DW & -165.02 & -171.92 & -287.37 \\
\hline & $c S U^{d}$ & -66.02 & -64.37 & -34.66 \\
\hline & $c S U^{p}$ & -34.36 & -33.04 & -35.68 \\
\hline & Total & 515.31 & 529.80 & 1368.28 \\
\hline & $D M^{+}$ & 1409.07 & 1477.76 & 2102.60 \\
\hline & $D M^{-}$ & -1332.60 & -1430.89 & -2599.97 \\
\hline Second Case & DM & 76.47 & 46.87 & -497.36 \\
\hline 10/11/2014 & SM & 1163.93 & 1180.58 & 2969.99 \\
\hline to & ER2UP & 231.26 & 250.55 & 765.18 \\
\hline \multirow[t]{7}{*}{$16 / 11 / 2014$} & ER2DW & -81.84 & -82.27 & -148.03 \\
\hline & $c S U^{d}$ & -85.83 & -62.72 & -33.01 \\
\hline & $c S U^{p}$ & -58.15 & -43.61 & -50.22 \\
\hline & Total & 1245.84 & 1289.39 & 3006.56 \\
\hline & $D M^{+}$ & 248.80 & 262.76 & 325.40 \\
\hline & $D M^{-}$ & -236.18 & -257.42 & -395.03 \\
\hline & DM & 12.62 & 5.34 & -69.63 \\
\hline Day & SM & 150.22 & 162.80 & 386.76 \\
\hline \multirow{5}{*}{$11 / 11 / 2014$} & ER2UP & 31.40 & 35.40 & 112.28 \\
\hline & ER2DW & -18.11 & -22.48 & -35.95 \\
\hline & $c S U^{d}$ & -9.90 & -8.25 & -4.95 \\
\hline & $c S U^{p}$ & -7.93 & -6.61 & -7.93 \\
\hline & Total & 158.29 & 166.19 & 380.57 \\
\hline
\end{tabular}

profit from the regulation-up and down energy increases. It is important to note that in the Spanish electric power system, the secondary regulation-up (resp. down) energy prices are usually higher (resp. lower) than the spot market prices (in 2014, the mean spot market price was $42.15 € / M W \cdot h$ whereas the mean secondary regulation-up and down energy prices were 47.36 and $31.34 € / \mathrm{MW} \cdot \mathrm{h}$, respectively). Due to this and also due to the importance of the secondary regulation reserve price, a sensitivity analysis of the maximum theoretical income to a variation in the secondary regulation reserve price and in the secondary regulation-up and down energy prices is presented in Section IV-E.

Comparing maximum theoretical income between PSHPs, the highest increase is between Conv and SC-T PSHP, with $165.5 \%$ higher income of SC-T PSHP in the first case, and $141.33 \%$ in the second case. The reason for such significant increment is the high flexibility that hydraulic SC operation with ternary units introduces: in all hours in which Conv PSHP is in pumping mode, it cannot participate in the reserve market whereas SC-T PSHP is able to participate with a regulation range equivalent to that of all turbines in operation. Furthermore, when a unit in the Conv PSHP is operating in pumping mode, this unit and the rest must be off in generating mode whereas when a unit in the SC-T PSHP is operating in pumping mode, this unit and the rest can be on or off in generating mode. Increment in maximum theoretical income between Conv and SC-B PSHP is significantly reduced to $2.81 \%$ in the first case and $3.5 \%$ in the second case. The reason for this small increase is because SC-B PSHP is much less flexible than SC-T PSHP: in the former, the hydraulic SC operation is restricted to the situation where one
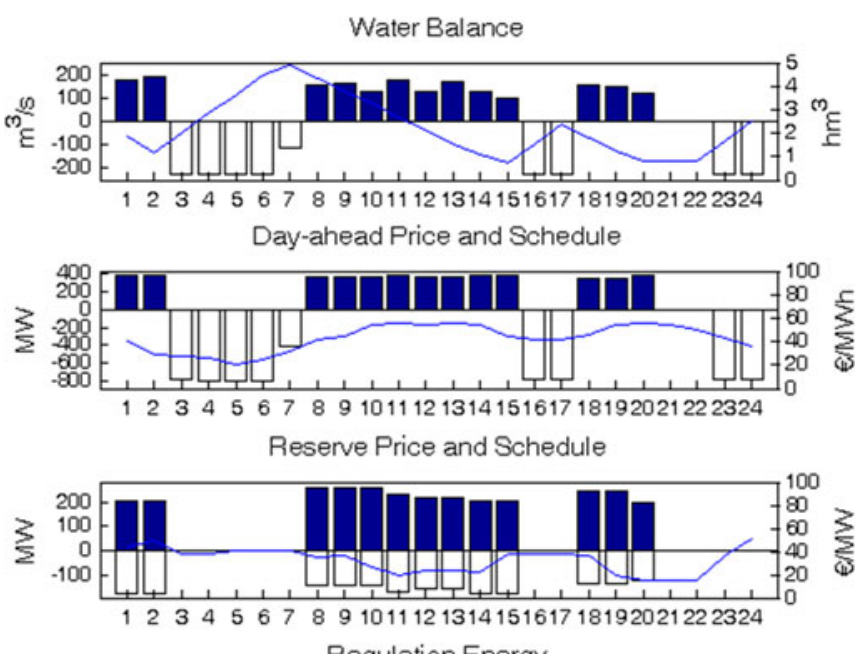
Regulation Energy

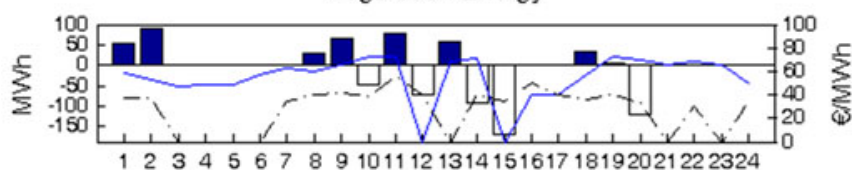

Fig. 3. Optimal operation of Conv PSHP. In regulation energy, regulation-up (resp. down) energy prices are in solid (resp. dashed) line.

unit is operated in pumping mode and the other in generating mode.

\section{PSHP Operation in Hydraulic SC Mode}

The energy and reserve schedule of the Conv PSHP, and the amount of regulation-up and down energy requested in realtime to the plant, according to the hypotheses described above, are shown in Fig. 3, for 11/11/2014; the same variables are shown in Fig. 4 for the SC-T PSHP. The operation of the SCB PSHP is similar to the one of the Conv PSHP. Each figure is divided into four subfigures where the following variables are depicted: 1) upper reservoir water volume in solid line and total water through the turbines (positive) or pumps (negative) in bars, 2) energy schedule in bars and price of the spot market in solid line, 3) reserve schedule in bars and price of the reserve market in solid line and 4) regulation-up and down energy in bars and prices in solid and dashed lines, respectively.

The most important difference between the operation of the Conv and SC-T PSHPs comes, as expected, from the fact that the former can only participate in the secondary regulation reserve market in generating mode, whereas the latter can participate in the said market both in consumption and generating modes. As can be seen in the figures, both PSHPs pump/discharge water to/from the upper reservoir during offpeak/peak hours (lower/higher spot market prices). ${ }^{2}$ The Conv PSHP manages to make some profit from the difference between peak and off-peak spot market prices (the so-called price arbitrage) (see economic results of 11/11/2014 in Table III), whereas the SC-T PSHP obtains a negative revenue in the spot market.

\footnotetext{
${ }^{2}$ There are also some hours with intermediate prices where the PSHP pumps or discharges water in an apparently arbitrary manner, in order to reduce the number of start-ups and to respect the reservoir storage limits.
} 

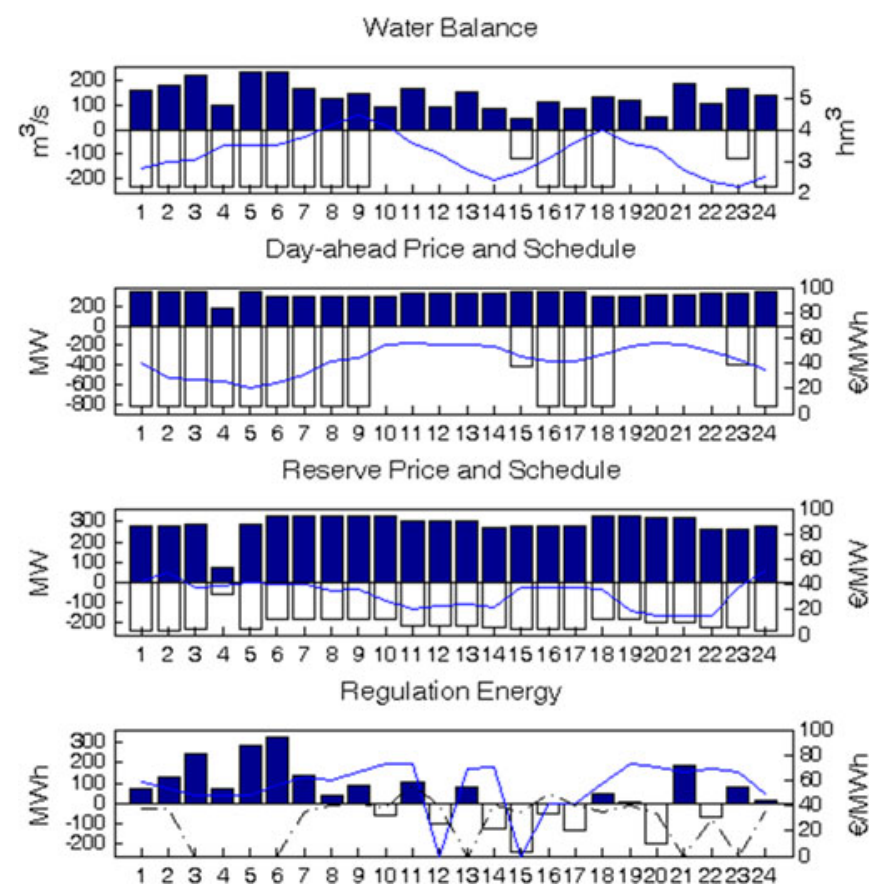

Fig. 4. Optimal operation of PSHP in hydraulic SC with ternary units. In regulation energy, regulation-up (resp. down) energy prices are in solid (resp. dashed) line.

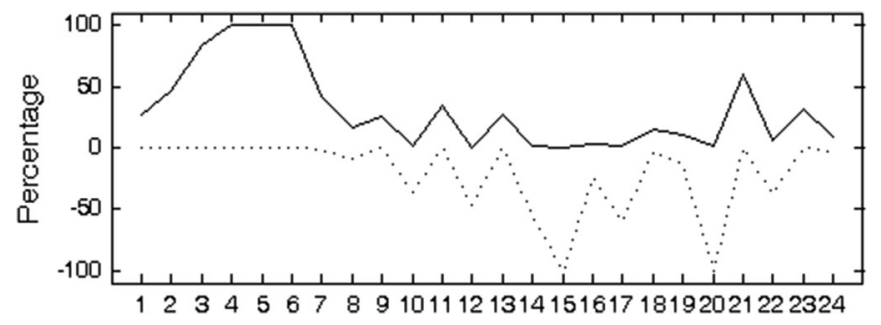

Fig. 5. Real-time use of reserves, regulation-up (resp. down) uses are in solid (resp. dotted) line.

However, the SC-T PSHP benefits also from the reserve prices during off-peak hours in the spot market, which according to unpublished studies carried out by the authors, do have a negative correlation with the spot market prices, and are, therefore, usually higher during off-peak hours of the spot market in the Spanish electricity system. Theoretically, the Conv PSHP could offer energy and reserve in hour 3 , in which the reserve price is quite high. However, as can be seen in Fig. 5, the TSO would ask the PSHP to provide around $85 \%$ of the offered reserve, which might cause the storage capacity in the upper reservoir to run out. Instead, the Conv PSHP chooses to fill up the upper reservoir from hour 3 to hour 7, and to offer again energy and reserve from hour 8 to hour 15 . Of course, the Conv PSHP could choose to alternate one or two hours in pumping mode followed by one or two hours in generating mode, in order to benefit from the higher reserve prices, at the expense of increasing the start-up costs. In Fig. 4, it is even more evident that the operation of the SC-T PSHP is focused on making profit from the secondary regulation reserve market. The SC-T PSHP operates in hydraulic SC mode during peak hours in the reserve market

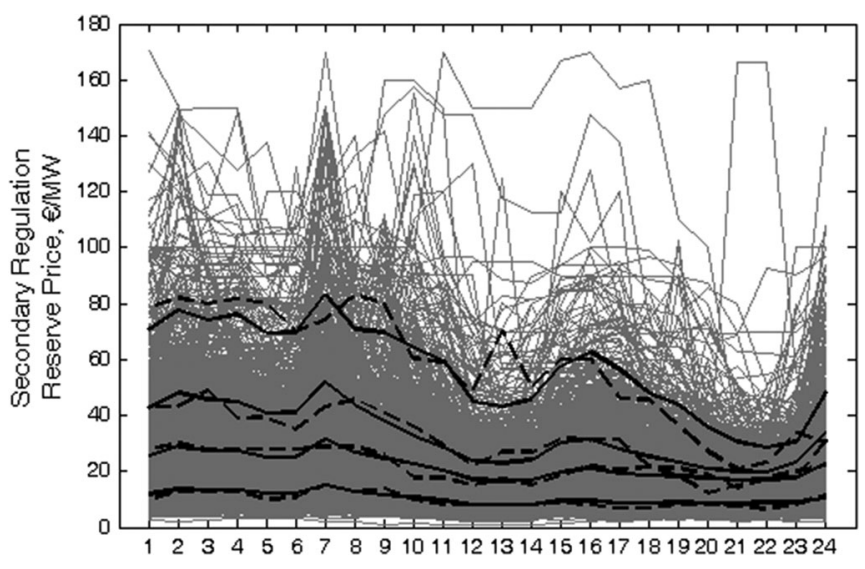

Fig. 6. Clusters (black solid line) and closest historical price profiles (dashed line) for the sensitivity analysis of the secondary regulation reserve price.

and in generating mode during peak hours in the spot market, and offers reserve every single hour.

Finally, it is interesting to note that while the Conv PSHP makes use of the whole storage capacity, the SC-T PSHP uses only a small fraction of its capacity. Even though it is not possible to draw reliable conclusions from the operation of a single day, this could have a positive impact on the storage capacity sizing, and therefore on the investment cost of the PSHP. However, this issue is outside the scope of the paper, and is suggested as a future line of work in Section V.

\section{E. Sensitivity Analysis}

Three sensitivity analyses have been carried out in order to study the sensitivity of the maximum theoretical income to a variation in 1) the secondary reserve price, 2) the secondary regulation-up energy price and 3) the secondary regulationdown energy price. In each sensitivity analysis, price profiles are chosen according to the following methodology.

1) The hourly historical data of the price under study in each day of the period 2010 to $10 / 11 / 2014$ is clustered into four daily groups based on the method of the squared Euclidean distances [28].

2) The real daily historical price profile that is the closest to each centroid is chosen; the distance between each historical price profile and each centroid is measured from the Euclidean distance. Fig. 6 shows the centroids and the closest price profiles of the historical data used in the sensitivity analysis corresponding to the secondary regulation reserve price.

3) The other two price profiles are chosen directly according to the historical data in the days of the previous step. For instance, the prices profiles for the highest centroid in Fig. 6 correspond to 28/12/2013, being the real prices of the secondary reserve and the secondary regulation-up and down energy of this day the ones that are used.

4) The spot prices, the percentages of real-time use of regulation-up and down reserves and the ratios between the regulation-up reserve and the total reserve, $R_{t}^{\mathrm{SM}}$, are those of the day 11/11/2014. 


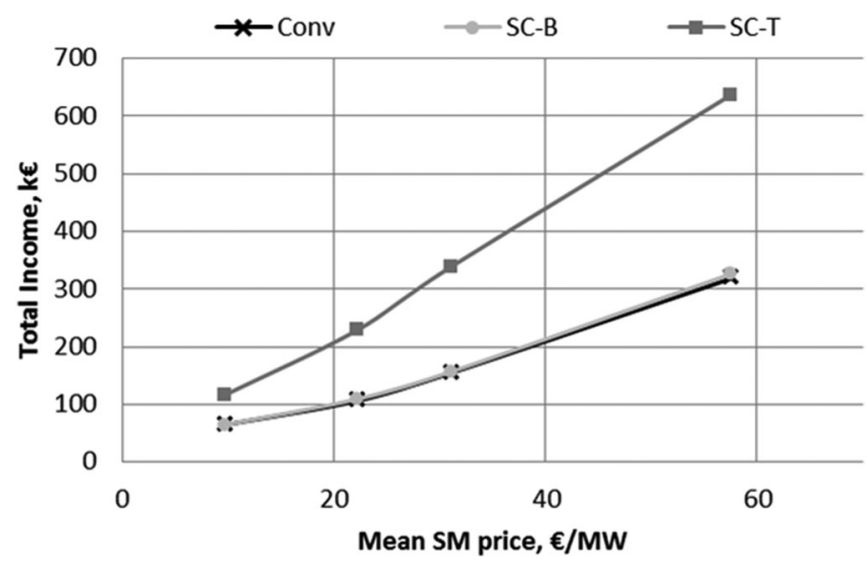

Fig. 7. Sensitivity analysis of the secondary regulation reserve price.

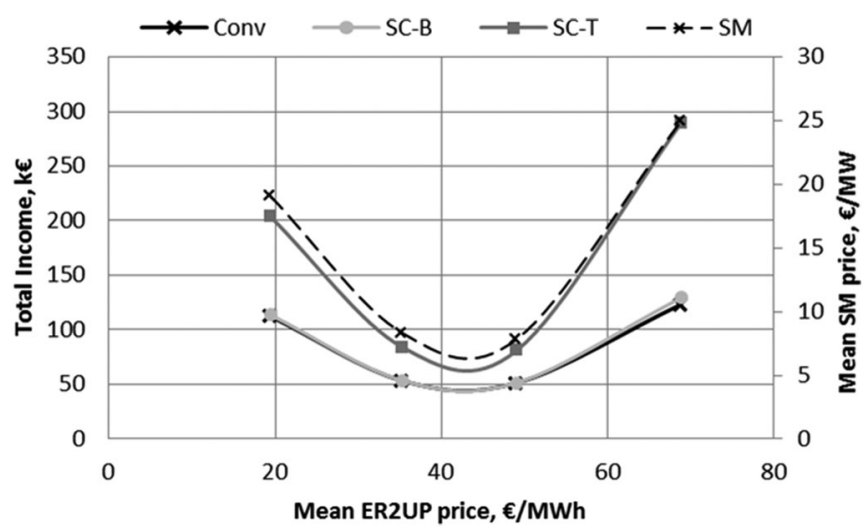

Fig. 8. Sensitivity analysis of the secondary regulation-up energy price.

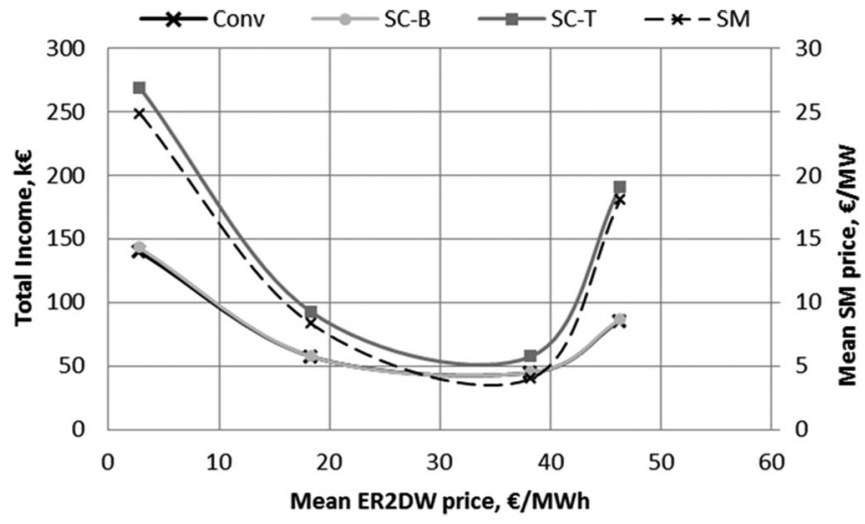

Fig. 9. Sensitivity analysis of the secondary regulation-down energy price

The results of the sensitivity analyses with respect the secondary regulation reserve price, the secondary regulation-up energy price and the secondary regulation-down energy price are shown in Figs. 7-9, respectively. In each figure, the maximum theoretical income of Conv, SC-B and SC-T PSHPs under the above-described assumptions is presented in the left $y$-axis. In addition, the average value of the price under study in the sensitivity analysis is shown in the $x$-axis. In the sensitivity analyses of the secondary regulation-up and down energy prices, the average value of the secondary regulation reserve price is also shown in the right $y$-axis in order to better understand the behaviour of the maximum theoretical income.

The sensitivity of the maximum theoretical income to the mean secondary regulation reserve price is significant, Fig. 7 , varying the former sixfold when the latter varies also sixfold. In the day under study, the sensitivity seems to be quite linear, being higher for SC-T PSHP than for Conv and SC-B PSHPs, whose sensitivity is almost the same. This sensitivity analysis confirms the results obtained in Section IV-C because the income from the secondary regulation reserve market are the most significant and, therefore, a change in its mean price affects considerably the total maximum theoretical income.

The sensitivity of the maximum theoretical income to the mean secondary regulation-up energy price is also significant, Fig. 8, and also higher for SC-T PSHP than for Conv and SC-B PSHPs, whose sensitivity is again almost the same. However, the total income curves are again explained by the mean SM price, first decreasing and then increasing as the mean secondary regulation-up energy price increases. This result also confirms the ones obtained in Section IV-C regarding the small magnitude of the income from the secondary regulation-up energy comparing to the total maximum theoretical income.

Finally, the sensitivity analysis of the mean secondary regulation-down energy price is similar to the one with the mean secondary regulation-up energy price, Fig. 9.

\section{CONCLUSION}

An MILP model for the energy and reserve scheduling of a PSHP considering hydraulic SC operation is presented. Additionally, this study compares maximum theoretical income of a conventional PSHP and a PSHP operating in hydraulic SC mode with binary and ternary units, in the spot and secondary regulation reserve markets of the Spanish electricity system. The plant under study is a closed-loop, daily-cycle and price-taker PSHP. The results obtained in the article show that a PSHP operating in hydraulic SC mode could enlarge its maximum theoretical income up to $162.3 \%$ comparing to a conventional PSHP. In addition to this, the secondary regulation reserve market proves to be the main revenue source for the PSHPs analysed in this article, whereas the spot market would assume a subsidiary role. It is important to consider these results in the context of a pricetaker PSHP and a bidding procedure which assumes perfect knowledge in all the data of the electricity system. Further research, taking into account stochasticity in hourly prices and real-time use of reserves, is required to obtain more realistic figures on the expected revenue of a PSHP operating in hydraulic $\mathrm{SC}$ mode. Furthermore, considering a price-maker approach in the secondary regulation market is deemed as another future work, where the quota of each participant may be of considerable size. Other trading options of the PSHP in, for example, intraday markets and the tertiary regulation service are also part of future work. Finally, some results obtained in the article suggest the need of further research on the optimal sizing of a PSHP operating in hydraulic SC mode. 


\section{REFERENCES}

[1] L. Gaudard and F. Romerio, "The future of hydropower in Europe: Interconnecting climate, markets and policies," Environ. Sci. Policy, vol. 37, pp. 172-181, 2014.

[2] A. Evans, V. Strezov, and T. Evans, "Assessment of utility energy storage options for increased renewable energy penetration," Renew. Sustain. Energy Rev., vol. 16, no. 6, pp. 4141-4147, 2012.

[3] D. Connolly, H. Lund, P. Finn, B. Mathiesen, and M. Leahy, "Practical operation strategies for pumped hydroelectric energy storage (PHES) utilising electricity price arbitrage," Energy Policy, vol. 39, no. 7, pp. 4189-4196, 2011.

[4] B. Steffen, "Prospects for pumped-hydro storage in Germany," Energy Policy, vol. 45, pp. 420-429, 2012.

[5] J. I. Pérez-Díaz, A. Perea, and J. R. Wilhelmi, "Optimal short-term operation and sizing of pumped-storage power plants in systems with high penetration of wind energy," in Proc. Eur. Energy Market, pp. 1-6, 2010.

[6] G. Ardizzon, G. Cavazzini, and G. Pavesi, "A new generation of small hydro and pumped-hydro power plants: Advances and future challenges," Renewable Sustainable Energy Rev., vol. 31, pp. 746-761, Mar. 2014.

[7] J. I. Pérez-Díaz, M. Chazarra, J. García-González, G. Cavazzini, and A. Stoppato, "Trends and challenges in the operation of pumpedstorage hydropower plants," Renew. Sustain. Energy Rev., vol. 44, pp. 767-784, 2015.

[8] J. Pinto, J. Sousa, and M. Neves, "The value of a pumping-hydro generator in a system with increasing integration of wind power," in Proc. Eur. Energy Market, pp. 1-6, 2011.

[9] G. D. Ciocan, O. Teller, and F. Czerwinski, "Variable speed pump-turbines technology," Univ. Politehnica Bucharest Sci. Bull.-D Series: Mech. Eng., vol. 74, no. 1, pp. 33-42, 2012.

[10] C. Nicolet, Y. Vaillant, B. Kawkabani, P. Allenbach, J. Simond, and F. Avellan, "Pumped storage units to stabilize mixed islanded power network: A transient analysis," in Proc. HYDRO Conf., Ljubljana, Slovenia, 2008, pp. 1-13.

[11] E. Lobato, I. Egido, L. Rouco, and G. López, "An overview of ancillary services in Spain," Electr. Power Syst. Res., vol. 78, no. 3, pp. 515-523, 2008

[12] M. Chazarra, J. I. Pérez-díaz, and J. García-González, “Optimal operation of variable speed pumped storage hydropower plants participating in secondary regulation reserve markets," in Proc. Eur. Energy Market, pp. 1-5, 2014

[13] J. García-González, R. Moraga, L. Matres, and A. Mateo, "Stochastic joint optimization of wind generation and pumped-storage units in an electricity market," IEEE Trans. Power Syst., vol. 23, no. 2, pp. 460-468, May 2008.

[14] A. De La Nieta, J. Contreras, and J. Muñoz, "Optimal coordinated windhydro bidding strategies in day-ahead markets," IEEE Trans. Power Syst., vol. 28, no. 2, pp. 798-809, May 2013.

[15] M. Chazarra, J. García-González, J. I. Pérez-Díaz, and M. Arteseros, "Stochastic optimization model for the weekly scheduling of a hydropower system in day-ahead and secondary regulation reserve markets," Electr. Power Syst. Res., vol. 130, pp. 67-77, 2016.

[16] A. Ortner and C. Graf, "Multi-market unit-commitment and capacity reserve prices in systems with a large share of hydro power: A case study," in Proc. Eur. Energy Market, pp. 1-8, 2013.

[17] N. Lu, J. Chow, and A. Desrochers, "Pumped-storage hydro-turbine bidding strategies in a competitive electricity market," IEEE Trans. Power Syst., vol. 19, no. 2, pp. 834-841, May 2004.

[18] T. Li and M. Shahidehpour, "Price-based unit commitment: A case of lagrangian relaxation versus mixed integer programming," IEEE Trans. Power Syst., vol. 20, no. 4, pp. 2015-2025, Nov. 2005.

[19] C. Tsai, Y. Cheng, S. Liang, and W. Lee, "The co-optimal bidding strategy of pumped-storage unit in ERCOT energy market," in Proc. North Amer. Power Symp., pp. 1-6, 2009.

[20] S. Kazempour, M. Moghaddam, M. Haghifam, and G. Yousefi, "Riskconstrained dynamic self-scheduling of a pumped-storage plant in the energy and ancillary service markets," Energy Convers. Manage., vol. 50, no. 5, pp. 1368-1375, 2009.
[21] P. Kanakasabapathy and K. S. Swarup, "Bidding strategy for pumpedstorage plant in pool-based electricity market," Energy Convers. Manage. vol. 51, no. 3, pp. 572-579, 2010 .

[22] A. Mitteregger and G. Penninger, "Austrian pumped storage power stations supply peak demands," World Pumps, pp. 16, 18, 20-21, May 2008.

[23] Kopswerk II Official Web Page. (2016, Apr. 10). [Online]. Available: http://www.kopswerk2.at/

[24] A. Conejo, J. Arroyo, J. Contreras, and F. Apolinar, "Self-scheduling of a hydro producer in a pool-based electricity market," IEEE Trans. Power Syst., vol. 17, no. 4, pp. 1265-1272, Nov. 2002.

[25] U.S. Bureau of Reclamation, "Selecting hydraulic reaction turbines," U.S. Government Printing Office, 1976.

[26] J. Raabe, Hydro Power - The Design, Use and Function of Hydromechanical, Hydraulic and Electrical Equipment. Dusseldorf, Germany: VDI Verlag, 1985.

[27] O. Nilsson and D. Sjelvgren, "Hydro unit start-up costs and their impact on the short term scheduling strategies of Swedish power producers," IEEE Trans. Power Syst., vol. 12, no. 1, pp. 38-44, Feb. 1997.

[28] B. Everitt, S. Landau, M. Leese, and D. Stahl, Cluster Analysis. Chichester, U.K.: Wiley, 2011.

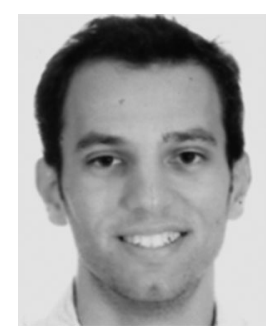

Manuel Chazarra received the Industrial Engineering and the M.Sc. degrees from Comillas Pontifical University, Madrid, Spain, in 2009 and 2012, respectively. He is currently working toward the Ph.D. degree at Technical University of Madrid, Madrid, Spain. His research interest includes optimal operation of power systems.

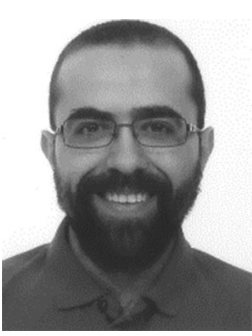

Juan Ignacio Pérez-Díaz received the Ph.D. degree from the Technical University of Madrid (UPM), Madrid, Spain, in 2008.

$\mathrm{He}$ has been a nontenured Associate Professor since 2011 with the UPM. His current research interests include mainly on optimal operation and control of hydro power plants.

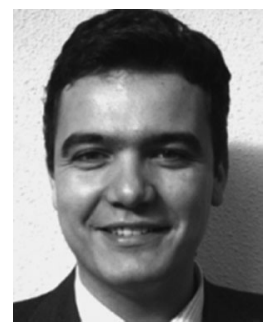

Javier García-González (S'99-M'01) received the Industrial Engineering degree from the Universidad Politécnica de Cataluña, Barcelona, Spain, in 1996, and the Ph.D. degree in 2001 from the Comillas Pontifical University, Madrid, Spain

$\mathrm{He}$ is an Associate Professor in Comillas Pontifical University. He belongs to the Research Staff of the Institute for Research in Technology. His research interests include operations, planning, and economy of power systems. 


\subsection{Paper-B: Optimal Joint Energy and Secondary Regulation Reserve Hourly Scheduling of Variable Speed Pumped Storage Hydropower Plants}

The preliminary version of this paper was published in [Chazarra et al., 2014], and orally presented in an International Conference. In this paper entitled "Optimal Joint Energy and Secondary Regulation Reserve Hourly Scheduling of Variable Speed Pumped Storage Hydropower Plants" [Chazarra et al., 2017e], it is presented an optimisation model based on mixed integer linear programming for obtaining the day-ahead energy and reserve scheduling of a closed-loop and daily-cycle PSHP, equipped with variable-speed pump-turbine units. The variable-speed units can be equipped with synchronous or asynchronous machines, and with and without bypassing the frequency converter in generating mode. The PSHP is modelled as a price-taker in both in the day-ahead energy market, and the secondary regulation reserve market of the Iberian and the Spanish electricity power systems, respectively. The activation of the secondary regulation reserves is also considered in the model formulation. The model assumes perfect information in the secondary regulation energy prices and in the percentages of the real-time use of the committed reserves. Furthermore, the model takes into account uncertainty in the day-ahead energy market prices and in the secondary regulation reserve market prices, and also takes into account the risk-aversion of the decision maker due to the uncertainty.

This publication is linked to the objectives of the Thesis (Figure 1.8) as follows: as far as the Thesis author knows, it is the first time in which the optimal scheduling of PSHPs with variable-speed units equipped with synchronous or asynchronous machines, and with and without bypassing the frequency converter in generating mode, participating in the dayahead energy and reserve markets has been explicitly formulated. Therefore, it is used as a basis to develop the main goal of the Thesis (the risk-averse optimisation model with look ahead period, Chapter 3) and it is used as a tool for a part of the second secondary objective of the Thesis (to estimate the economic viability of PSHPs with variable-speed units). 


\title{
Optimal Joint Energy and Secondary Regulation Reserve Hourly Scheduling of Variable Speed Pumped Storage Hydropower Plants
}

\author{
Manuel Chazarra, Juan I. Pérez-Díaz and Javier García-González, Member, IEEE
}

\begin{abstract}
This paper presents a mixed integer linear programming model for the hourly energy and secondary regulation reserve scheduling of a price-taker and closed-loop variable speed pumped-storage hydropower plant, considering the energy losses due to the use of electronic frequency converters. The plant participates in the day-ahead energy market and in the secondary regulation service of the Iberian electric power system. The model is utilised to compare the income of the plant with and without considering the variable speed technology, with synchronous or asynchronous machines, with and without bypassing the frequency converter in generating mode, and with and without perfect information of the electric power system data. Numerical testing results demonstrate that the operation with the variable speed technology could help notably to enlarge the income of the power plant and that the secondary regulation reserve market might be the main source of revenue for the power plant.
\end{abstract}

Index Terms-Pumped Storage Plant, Secondary Regulation Service, Variable Speed Technology, Risk Aversion, Scenario-based Approach.

\section{NOMENCLATURE}

Superscripts

$d, d^{\prime} \quad$ Indicates that the magnitude is related to generation/discharge. The superscript $d$ refers to pump-turbine units with variable speed (using a converter). When the superscript includes the prime symbol, i.e. $d^{\prime}$, it refers to pump-turbine units with fixed speed (without using a converter)

$p, p^{\prime} \quad$ Indicates that the magnitude is related to consumption/pumping. The superscript $p$ refers to pump-turbine units with variable speed (using a converter). When the superscript includes the prime symbol, i.e. $p^{\prime}$, it refers to pump-turbine units with fixed speed (without using a converter) $s \quad$ Indicates that the magnitude is related to the secondary regulation service (reserve or energy)

This work was supported in part by the Spanish Ministry of Economy and Competitiveness under the project "Optimal operation and control of pumped-storage hydropower plants" of The National Scientific Research, Development and Technological Innovation Plan 2008-2011 (Ref. ENE2012-32207). This paper was presented in part at the 11th International Conference on the European Energy Market, Krakow, Poland, May 2014.

Manuel Chazarra and Juan I. Pérez-Díaz are with the Department of Hydraulic, Energy and Environment Engineering, Escuela de Ingenieros de Caminos, Canales y Puertos, Technical University of Madrid, 28040, Spain. (email: manuel.chazarra@upm.es; ji.perez@upm.es).

Javier García-González is with the Institute for Research in Technology, ICAI School of Engineering, Comillas Pontifical University, 28015, Madrid, Spain. (email: javier.garcia@iit.comillas.edu)

\begin{abstract}
Sets
$c \quad$ Pump-turbine unit, running from 1 to $\mathrm{C}$

$k \quad$ Discrete generation curves

$n \quad$ Price scenario of the day-ahead energy market and the secondary regulation reserve market

$t \quad$ Hourly period, running from 1 to $\mathrm{T}$

\section{Parameters}

$\beta \quad$ Confidence interval

$c S U_{c}^{d} \quad$ Start-up cost in generating mode, $€$

$c S U_{c}^{p} \quad$ Start-up cost in pumping mode, $€$

$\delta_{c, k}^{d} \quad$ Energy coefficient in generating mode, $\mathrm{MW} / \mathrm{Mm}^{3} / \mathrm{h}$

$\delta_{c, k}^{p} \quad$ Energy coefficient in pumping mode, $\mathrm{MW} / \mathrm{Mm}^{3} / \mathrm{h}$

$f v \quad$ Target water volume at the end of the last hour of the time horizon, $\mathrm{Mm}^{3}$
\end{abstract}

$\bar{g}_{c, k}^{d}, \underline{g}_{c, k}^{d}$ Maximum and minimum technical power generation, MW

$\bar{g}_{c, k}^{p^{\prime}} \quad$ Maximum technical power consumption of fixed speed pump-turbine units, MW. Note that the minimum technical power consumption equals the maximum as they operate with fixed speed

$\bar{g}_{c, k}^{p}, \underline{g}_{c, k}^{p}$ Maximum and minimum technical power consumption of variable speed pump-turbine units, MW

$H_{u}, H_{i}$ Gross head at the maximum efficiency and a head lower than $H_{u}$, i.e. $H_{i}<H_{u}$, m

$l_{t} \quad$ Time length of period $t, 1 \mathrm{~h}$

$\lambda_{D, n, t} \quad$ Day-ahead energy market price, $€ / \mathrm{MWh}$

$\lambda_{S, n, t} \quad$ Secondary regulation reserve market price, $€ / M W$

$\lambda_{\text {up }, t} \quad$ Upward secondary regulation energy price, $€ / \mathrm{MWh}$

$\lambda_{d w, t} \quad$ Downward secondary regulation energy price, $€ / M W h$

$\mu \quad$ Risk-averse weight factor, $\mu \in[0,1]$

$\bar{\eta}_{c, k}^{d}, \underline{\eta}_{c, k}^{d}$ Efficiency at maximum and minimum water discharge, $\%$

$\bar{\eta}_{c, k}^{p}, \underline{\eta}_{c, k}^{p}$ Efficiency at maximum and minimum pumped water, \%

$\pi_{n} \quad$ Probability of the price scenario

$\bar{q}_{c, k}^{d^{\prime}}, \underline{q}_{c, k}^{d^{\prime}}$ Maximum and minimum technical water discharge of fixed speed pump-turbine units, $\mathrm{Mm}^{3} / \mathrm{h}$

$\bar{q}_{c, k}^{d}, \underline{q}_{c, k}^{d}$ Maximum and minimum technical water discharge of variable speed pump-turbine units, $\mathrm{Mm}^{3} / \mathrm{h}$

$\bar{q}_{c, k}^{p^{\prime}} \quad$ Maximum technical pumped water of fixed speed pump-turbine units, $\mathrm{Mm}^{3} / \mathrm{h}$

$\bar{q}_{c, k}^{p}, \underline{q}_{c, k}^{p}$ Maximum and minimum technical pumped water of variable speed pump-turbine units, $\mathrm{Mm}^{3} / \mathrm{h}$ 
$\rho_{t}^{u p}, \rho_{t}^{d w}$ Percentage of the real-time use of the upward and downward secondary regulation reserves with respect to the secondary reserve capacity cleared in the market

$R_{t}^{S M} \quad$ Ratio between the upward secondary regulation reserve and the total regulation reserve, set by the TSO in advance, that needs to be satisfied by the offered reserves by each agent

$\bar{v}, \underline{v} \quad$ Maximum and minimum technical water storage limits of the upper reservoir due to design characteristics, $\mathrm{Mm}^{3}$

\section{Positive Variables}

$B_{n} \quad$ Net profit in scenario $n, €$

$B_{n}^{-} \quad$ auxiliary variable which is equal to zero when the net profit is higher than the $V a R$, and it is equal to the difference between them in the opposite case, $€$

$\operatorname{VaR} \quad$ Value at risk, $€$

$C V a R \quad$ Conditional value at risk, $€$

$g_{c, t}^{d} \quad$ Power generation, MW

$g_{c, t}^{p} \quad$ Power consumption, MW

$q_{c, t}^{d}, q_{c, t}^{p}$ Total water discharge and total pumped water, which include water for the real-time use of the upward and downward secondary regulation reserves, $\mathrm{Mm}^{3} / \mathrm{h}$

$q s_{c, t}^{d} \quad$ Water discharge above the minimum technical limit, $\mathrm{Mm}^{3} / \mathrm{h}$

$q s_{c, t}^{p} \quad$ Pumped water above the minimum technical limit, $\mathrm{Mm}^{3} / \mathrm{h}$

$g_{c, t}^{d, s, u p} \quad$ Upward secondary regulation reserve in generating mode, MW

$g_{c, t}^{p, s, u p} \quad$ Upward secondary regulation reserve in pumping mode, MW

$g_{c, t}^{d, s, d w} \quad$ Downward secondary regulation reserve in generating mode, MW

$g_{c, t}^{p, s, d w} \quad$ Downward secondary regulation reserve in pumping mode, MW

aux $\_g_{c, t}^{d, s}$ Auxiliary variable associated with $g_{c, t}^{d, s, d w}$, MW

aux_ $g_{c, t}^{p, s}$ Auxiliary variable associated with $g_{c, t}^{p, s, u p}$, MW

$e_{t}^{s, u p} \quad$ Upward secondary regulation reserve requested in real-time by the TSO, MWh

$e_{t}^{s, d w} \quad$ Downward secondary regulation reserve requested in real-time by the TSO, MWh

$v_{t} \quad$ Water volume of the upper reservoir, $\mathrm{Mm}^{3}$

\section{Binary Variables}

$d_{t} \quad$ Variable used for the discretization of the hydropower generation/consumption curves to take into account the net head dependency

$u_{c, t}^{d} \quad$ On/Off state in generating mode

$u_{c, t}^{p} \quad$ On/Off state in pumping mode

$y_{c, t}^{d, t}$

$y_{c, t}^{p}$ 1 if the pump-turbine unit is started-up in generating mode, 0 otherwise

$\phi_{t} \quad 1$ if there is more upward secondary regulation reserve requested in real-time than downward regulation reserve, 0 otherwise

\section{INTRODUCTION}

The hydropower sector is highly interested in both pumped storage hydropower plants (PSHPs) with variable-speed (VS) technology and PSHPs operated in hydraulic short-circuit mode as a means to increase their flexibility [1]. This paper is a complementary research of [2], where the authors presented a mixed integer linear programming (MILP) model for the hourly energy and reserve scheduling of a closed-loop and daily-cycle PSHP operating in hydraulic short-circuit mode. In the presented paper, we have tried to cover the remaining questions and challenges faced by the VS-PSHPs. In particular, given the variety of possible configurations (type of Hill diagram, type of converter, type of electric machine), this paper presents a generic mathematical formulation that can be used to assess the profitability of each configuration. Note that a VS-PSHP is equipped with variable speed drives whereas in a PSHP operating in hydraulic short-circuit mode the hydro units must operate at synchronous speed both in generating and pumping modes.

VS-PSHPs introduce several advantages when compared to fixed speed (FS) PSHPs (hereafter referred to as FS-PSHPs): 1) higher hydraulic efficiency and wider operation range in generating and pumping modes, 2) ability to regulate power even while in pumping mode and 3) improvements in network stability [3]. However, several factors can hinder the investment in this technology, such as: i) the income from the so-called price arbitrage strategy is not sufficient to recover the investment costs in several electric power systems, as studied in [4], ii) grid fees for transmission lines usage when PSHPs are consuming [5] or iii) water fees for utilising rivers or lakes [5].

In this context, the aim and contribution of this paper is twofold. Firstly, an MILP model for the joint energy and secondary regulation reserve hourly scheduling of a realistic closed-loop ${ }^{1}$ and daily-cycle VS-PSHP is presented. The model takes into account uncertainty in the day-ahead energy prices and in the secondary regulation reserve prices, and also the risk-aversion of the decision maker due to the uncertainty. Secondly, the paper quantifies the extent to which the VS technology with synchronous or asynchronous machines, with and without bypassing the frequency converter in generating mode and with and without perfect knowledge in the electric power system data is able to enlarge the income of a price-taker FS-PSHP that only participates in the day-ahead energy market of the Iberian electric power system (DM) or that in addition participates in the secondary regulation service (SRS) of the Spanish electric power system. The SRS in the Spanish electricity market comprises two concepts: 1) a day-ahead reserve market, which takes place after having cleared the DM and where power reserve availability is remunerated by the marginal market price, and 2) power reserve delivery in real-time, which is remunerated by the marginal price of the tertiary regulation market [6]. Note that the procedure for the procurement of secondary regulation is not exclusive of the Spanish system. For instance, a

\footnotetext{
${ }^{1}$ Closed-loop PSHPs do not receive natural water inflows in the upper reservoir and do not release water from the lower reservoir
} 
similar procedure is implemented in Norway, Sweden, Finland, Slovenia, Czech Republic and Romania in the short-term (less than a week) and in Denmark, Netherlands, Belgium, Germany, Austria and Switzerland in the long-term (more than a week) [7].

Diverse optimization models for bidding and/or scheduling FS-PSHPs in the day-ahead energy market [4], [8]-[10] and simultaneously in the energy and reserve markets [11]-[16] have been published in the literature. In addition to this, [17] presents a hydrothermal model with VS-PSHPs in the context of a centralised system, minimising the cost of the energy and frequency control reserves taking into account the transmission network. However, to the best of our knowledge, there are no papers (apart from [18], the early version of the presented paper) where the optimal scheduling of VS-PSHPs, participating in a liberalised system in the energy and secondary regulation reserve markets, has been explicitly formulated [1].

The proposed model, based on the one presented in [18], has been improved in order to also consider i) several units within the same PSHP, ii) the head dependency in the power generation, in the power consumption and in the available spinning reserve in generating and pumping modes, iii) the units' start-up costs and decisions, iv) the remuneration of the real-time use of the reserves as a function of the hourly net energy (i.e., the upward minus the downward secondary regulation energy), v) that each reversible Francis pump-turbine unit is equipped by an electronic frequency converter, vi) to take into account uncertainty in the day-ahead energy prices and in the secondary regulation reserve prices, by means of a scenario-based approach and, finally, vii) the risk-aversion of the decision maker due to the uncertainty. In addition, the presented case study sheds some light on the profitability of the different proposed PSHP configurations and presents a comprehensive analysis that can help to identify the most appropriate ones, with and without assuming perfect knowledge in the prices.

The paper is organised as follows: Section II describes the variable speed technology and the benefits with respect to FS-PSHPs. Section III presents the model formulation. The application of the model to a realistic PSHP is presented in Section IV and finally, conclusions are described in Section V.

\section{VARiable Speed Pumped Storage Hydropower PLANTS}

The first VS-PSHPs were commissioned at the beginning of the nineties of the past century in Japan [1]. Since then, the interest in VS-PSHPs has increased considerably: $1060 \mathrm{MW}$ of VS-PSHPs were installed in the period 2000-2010 in Europe and another $4410 \mathrm{MW}$ are planned in the period 2011-2020 [3].

Currently, there are two different types of pump-turbine units with VS: 1) the unit is equipped with a synchronous machine and a converter between the stator and the grid [19] or 2) the unit is equipped with a doubly-fed induction machine and a converter between the rotor and the grid [20]. The

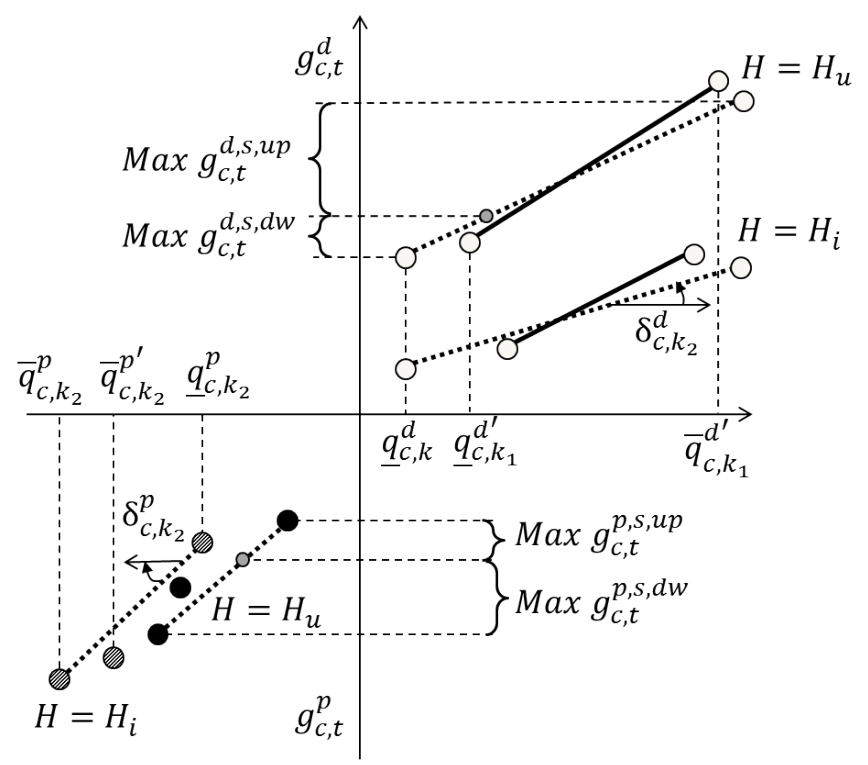

Fig. 1. Generation and consumption curves of a pump-turbine unit with variable speed (dotted lines) and with fixed speed (solid lines and single dots) considered in the article for two given heads of the upper reservoir. First quadrant for generating mode and third quadrant for pumping mode

converter rating in the former case is the same as the machine rating, introducing higher costs and power losses. Therefore, this scheme is only used in a few cases with high demands on the operating range [21]. The converter rating in the latter case is usually $20-30 \%$ of the machine rating, reducing the costs and power losses. Thus, the second scheme is the most popular one in current power systems [1].

Pump-turbine units with VS can regulate power in pumping mode, and therefore participate in the SRS as a controllable load. Other advantages are its wider operating range and higher hydraulic efficiency in generating and pumping modes.

In order to squeeze as much as possible the above-mentioned potential benefits of VS-PSHPs, it is necessary to implement certain features in the day-ahead scheduling. This entails to adapt and modify the Input/output curves of the pump-turbine units (I/O) as outlined in Fig. 1. The solid lines in generating mode (first quadrant) and the single dots in pumping mode (third quadrant) correspond to a pump-turbine unit with FS whereas the dotted lines in generating and pumping modes correspond to a pump-turbine unit with VS.

The real I/O curves in generating and pumping modes, with both FS and VS, will strongly depend on the pump-turbine performance curves and the electrical efficiency. As shown in Fig. 1, we have opted for the most common case, that corresponds to the following characteristics: the water discharge range in generating mode with VS is wider than the one with FS, both at the maximum efficiency head $\left(H_{u}\right)$ and at a lower head $\left(H_{i}\right)$; the power generation $g_{c, t}^{d}$ at design flow $\left(\bar{q}_{c, k}^{d}\right)$ is lower with VS since the increase in hydraulic efficiency is lower than the decrease in the electrical efficiency; and the power consumption $g_{c, t}^{p}$ at design flow $\left(\bar{q}_{c, k}^{p}\right)$ is higher with VS since the increase in hydraulic efficiency is lower than the decrease in the electrical efficiency. 
In order to participate in the secondary regulation reserve market, the maximum upward reserve, $\max g_{c, t}^{d, s, u p}$, in generating mode is the difference between the maximum minus the current generated power and the maximum downward reserve, $\max g_{c, t}^{d, s, d w}$, in generating mode is the difference between the current minus the minimum generated power, first quadrant of Fig. 1. In pumping mode, the maximum upward reserve, $\max g_{c, t}^{p, s, u p}$, is the difference between the current minus the minimum consumed power and the maximum downward reserve, $\max g_{c, t}^{p, s, d w}$, is the difference between the maximum minus the current consumed power.

\section{MODEL FORMULATION}

Model formulation is split in two Sections. Section III-A shows the model formulation of VS-PSHPs whereas Section III-B presents the model formulation of FS-PSHPs.

\section{A. Model Formulation for VS-PSHPs}

1) Objective Function: The objective function (1) maximises simultaneously the expected net income and the conditional value at risk, $C V a R$. Each term is weighted according to $\mu$, depending on the risk-aversion of the decision maker. Note that $\mu=0$ corresponds to the risk-neutral decision.

The net income in scenario $n$, i.e., $B_{n}$, of a VS-PSHP participating in the DM and in the SRS in the framework of the Iberian electricity market [6] is defined in (2). Note that the model formulation is a scenario-based one without non-anticipativity constraints (NAC), as the energy and reserve schedule decisions are taken in a single-stage. The obtained solution is the same for all scenarios, and this fact might resemble the NAC. However, as there is no possibility to adapt the solution in a second stage, there are neither recourse functions so it does not seem appropriate to say that NAC is implicitly implemented. The decisions are robust to the uncertainty of the DM prices and the secondary regulation reserve market prices, thanks to the maximization of the CVaR. The reason why the authors have chosen to take both the energy and reserve schedule decisions in a single stage is motivated by the fact that the information disclosed after the clearing process of the DM has not a significant impact on the information used to take decisions in the secondary regulation reserve market in the Spanish electricity market (for instance, the correlation between the marginal prices of both markets was -0.47 in 2013). The first line in (2) expresses the net income for the secondary regulation energy due to the real-time use of the reserves. The second line accounts for the net income in the DM. The third line accounts for the income for the secondary regulation reserves put at disposal of the TSO in generating and pumping modes. And, finally, the fourth line represents the start-up costs in generating and pumping modes, respectively.

$$
\operatorname{Max} \quad z=(1-\mu) \sum_{n} \pi_{n} B_{n}+\mu \cdot C V a R
$$

$$
\begin{array}{r}
B_{n}=\sum_{t}\left\{\left(e_{t}^{s, u p} \cdot \lambda_{u p, t}-e_{t}^{s, d w} \cdot \lambda_{d w, t}\right)\right. \\
+\sum_{c}\left[\left(g_{c, t}^{d}-g_{c, t}^{p}\right) l_{t} \cdot \lambda_{D, n, t}\right. \\
+\left(g_{c, t}^{d, s, u p}+g_{c, t}^{d, s, d w}+g_{c, t}^{p, s, u p}+g_{c, t}^{p, s, d w}\right) \lambda_{S, n, t} \\
\left.\left.-c S U_{c}^{d} \cdot y_{c, t}^{d}-c S U_{c}^{p} \cdot y_{c, t}^{p}\right]\right\} \quad \forall n
\end{array}
$$

Uncertainty is considered in the day-ahead energy prices and in the secondary regulation reserve prices because their values of perfect information (VPI) are significant. The VPI of the day-ahead energy prices can be up to $26 \%$ of the maximum theoretical income if the PSHP participates in the DM and in the SRS and up to $36 \%$ if it only participates in the DM, according to the results in [22]. Besides, the VPI of the secondary regulation reserve prices can be up to $10 \%$ of the maximum theoretical income according to unpublished results from the authors. Finally, and also according to unpublished results from the authors, the VPI of the secondary regulation energy prices and the real-time use of the reserves are much less important than the VPI of the DM prices and/or the secondary regulation reserve prices.

2) Risk-Aversion Constraints: Several techniques can be found in the technical literature to take into account the risk management in an optimization model. In [23], two techniques are compared: i) the introduction of a minimum profit constraint, by which a minimum profit is required for each scenario and ii) the introduction of a minimum $C V a R$. Both techniques do not guarantee feasible solutions, which depend on the minimum profit and $C V a R$ chosen. In the presented model formulation, the risk management is modelled in a similar way as in [24], which is based on [25], by equations (3) and (4). They represent simultaneously the $V a R$ and $C V a R$. Note that this approach corresponds to a linear formulation and that a feasible solution is always guaranteed.

$$
\begin{gathered}
V a R-\frac{1}{\beta} \sum_{n} \pi_{n} B_{n}^{-} \geq C V a R \\
B_{n}^{-} \geq V a R-B_{n} \quad \forall n
\end{gathered}
$$

3) Water Balance: The water balance, (5) does not include any water inflow because a closed-loop PSHP is considered in this article. Water limits are imposed to water volume variable, $v_{t}$ in all time periods, (6). Water balance and limits in the lower reservoir are not included in the model formulation for simplicity.

$$
\begin{gathered}
v_{t}=v_{t-1}+\sum_{c} l_{t}\left(q_{c, t}^{p}-q_{c, t}^{d}\right) \quad \forall t \\
\underline{v} \leq v_{t} \leq \bar{v} \quad \forall t
\end{gathered}
$$

In the upper reservoir, a target water volume is imposed, (7), where $T$ stands for the last period of the time horizon. The target water volume is deemed as input data to the model and equals initial volume in the case study section.

$$
v_{t}=f v \quad t=\mathrm{T}
$$

The proposed model formulation is limited to closed-loop operation in order to focus the interest of the publication in 
the operation of the plant with the existing water in the system and without considering extra water. However, it can be easily extended to open-loop operation by i) introducing the hourly natural water inflows of the upper reservoir in (5) and ii) including the water balance equation of the lower reservoir, considering the hourly water outflows.

4) Hydropower Generation: Two generation/consumption curves, $k_{1}$ and $k_{2}$ have been considered in the formulation, and correspond to two different reservoir levels. Each curve is selected using the binary variable $d_{t}$ that only depends on the water volume of the upper reservoir (8) and (9), as we consider that the effect of the lower reservoir level on the net head is neglectable.

$$
\begin{aligned}
& v_{t} \geq \underline{v}\left(1-d_{t}\right)+\left(\underline{v}+\frac{\bar{v}-\underline{v}}{2}\right) d_{t} \quad \forall t \\
& v_{t} \leq \bar{v} \cdot d_{t}+\left(\underline{v}+\frac{\bar{v}-\underline{v}}{2}\right)\left(1-d_{t}\right) \quad \forall t \\
& g_{c, t}^{d} \leq u_{c, t}^{d} \cdot \underline{g}_{c, k}^{d}+q s_{c, t}^{d} \cdot \delta_{k}^{d}+\bar{g}_{c, k}^{d} \cdot d_{t} \quad \forall c, t, k=k_{1} \\
& g_{c, t}^{d} \geq u_{c, t}^{d,} \cdot \underline{g}_{c, k}^{d}+q s_{c, t}^{d} \cdot \delta_{k}^{d}-\bar{g}_{c, k}^{d} \cdot d_{t} \quad \forall c, t, k=k_{1} \\
& g_{c, t}^{d,} \leq u_{c, t}^{d} \cdot \underline{g}_{c, k}^{\bar{d}}+q s_{c, t}^{d} \cdot \delta_{k}^{d}+\bar{g}_{c, k}^{d}\left(1-d_{t}\right) \quad \forall c, t, k=k_{2} \\
& g_{c, t}^{d} \geq u_{c, t}^{d} \cdot \underline{g}_{c, k}^{d}+q s_{c, t}^{d} \cdot \delta_{k}^{d}-\bar{g}_{c, k}^{d}\left(1-d_{t}\right) \quad \forall c, t, k=k_{2} \\
& q s_{c, t}^{d} \leq u_{c, t}^{d} \cdot \bar{q}_{c, k_{1}}^{d} \quad \forall c, t \\
& q s_{c, t}^{d} \leq\left(\bar{q}_{c, k_{1}}^{d}-\underline{q}_{c, k_{1}}^{d}\right)\left(1-d_{t}\right)+\left(\bar{q}_{c, k_{2}}^{d}-\underline{q}_{c, k_{2}}^{d}\right) d_{t} \quad \forall c, t \\
& q_{c, t}^{d} \leq u_{c, t}^{d} \cdot \underline{q}_{c, k}^{d}+q s_{c, t}^{d}+\bar{q}_{c, k}^{d} \cdot d_{t} \\
& +\frac{1}{\delta_{k}^{d}}\left(\rho_{t}^{u p} \cdot g_{c, t}^{d, s, u p}-\rho_{t}^{d w} \cdot g_{c, t}^{d, s, d w}\right) \quad \forall c, t, k=k_{1} \\
& q_{c, t}^{d} \geq u_{c, t}^{d} \cdot \underline{q}_{c, k}^{d}+q s_{c, t}^{p}-\bar{q}_{c, k}^{d} \cdot d_{t} \\
& +\frac{1}{\delta_{k}^{d}}\left(\rho_{t}^{u p} \cdot g_{c, t}^{d, s, u p}-\rho_{t}^{d w} \cdot g_{c, t}^{d, s, d w}\right) \quad \forall c, t, k=k_{1} \\
& q_{c, t}^{d} \leq u_{c, t}^{d} \cdot \underline{q}_{c, k}^{d}+q s_{c, t}^{d}+\bar{q}_{c, k}^{d}\left(1-d_{t}\right) \\
& +\frac{1}{\delta_{k}^{d}}\left(\rho_{t}^{u p} \cdot g_{c, t}^{d, s, u p}-\rho_{t}^{d w} \cdot g_{c, t}^{d, s, d w}\right) \quad \forall c, t, k=k_{2} \\
& q_{c, t}^{d} \geq u_{c, t}^{d} \cdot \underline{q}_{c, k}^{d}+q s_{c, t}^{d}-\bar{q}_{c, k}^{d}\left(1-d_{t}\right) \\
& +\frac{1}{\delta_{k}^{d}}\left(\rho_{t}^{u p} \cdot g_{c, t}^{d, s, u p}-\rho_{t}^{d w} \cdot g_{c, t}^{d, s, d w}\right) \quad \forall c, t, k=k_{2} \\
& g_{c, t}^{p} \leq u_{c, t}^{p} \cdot \underline{g}_{c, k}^{p}+q s_{c, t}^{p} \cdot \delta_{k}^{p}+\bar{g}_{c, k}^{p} \cdot d_{t} \quad \forall c, t, k=k_{1} \\
& g_{c, t}^{p,} \geq u_{c, t}^{p,} \cdot \bar{g}_{c, k}^{p}+q s_{c, t}^{p} \cdot \delta_{k}^{p}-\bar{g}_{c, k}^{p, k} \cdot d_{t} \quad \forall c, t, k=k_{1} \\
& g_{c, t}^{p} \leq u_{c, t}^{p} \cdot g_{c, k}^{\bar{p}}+q s_{c, t}^{p} \cdot \delta_{k}^{p}+\bar{g}_{c, k}^{p}\left(1-d_{t}\right) \quad \forall c, t, k=k_{2} \\
& g_{c, t}^{p} \geq u_{c, t}^{p} \cdot \underline{g}_{c, k}^{p}+q s_{c, t}^{p} \cdot \delta_{k}^{p}-\bar{g}_{c, k}^{p}\left(1-d_{t}\right) \quad \forall c, t, k=k_{2} \\
& q s_{c, t}^{p} \leq u_{c, t}^{p} \cdot \bar{q}_{c, k_{2}}^{p} \quad \forall c, t \\
& q s_{c, t}^{p} \leq\left(\bar{q}_{c, k_{1}}^{p}-\underline{q}_{c, k_{1}}^{p}\right)\left(1-d_{t}\right)+\left(\bar{q}_{c, k_{2}}^{p}-\underline{q}_{c, k_{2}}^{p}\right) d_{t} \\
& q_{c, t}^{p} \leq u_{c, t}^{p} \cdot \underline{q}_{c, k}^{p}+q s_{c, t}^{p}+\bar{q}_{c, k}^{p} \cdot d_{t} \\
& +\frac{1}{\delta_{k}^{p}}\left(\rho_{t}^{d w} \cdot g_{c, t}^{p, s, d w}-\rho_{t}^{u p} \cdot g_{c, t}^{p, s, u p}\right) \quad \forall c, t, k=k_{1} \\
& q_{c, t}^{p} \geq u_{c, t}^{p} \cdot \underline{q}_{c, k}^{p}+q s_{c, t}^{p}-\bar{q}_{c, k}^{p} \cdot d_{t} \\
& +\frac{1}{\delta_{k}^{p}}\left(\rho_{t}^{d w} \cdot g_{c, t}^{p, s, d w}-\rho_{t}^{u p} \cdot g_{c, t}^{p, s, u p}\right) \quad \forall c, t, k=k_{1}
\end{aligned}
$$

$$
\begin{array}{cc}
q_{c, t}^{p} \leq u_{c, t}^{p} \cdot \underline{q}_{c, k}^{p}+q s_{c, t}^{p}+\bar{q}_{c, k}^{p}\left(1-d_{t}\right) & \\
\quad+\frac{1}{\delta_{k}^{p}}\left(\rho_{t}^{d w} \cdot g_{c, t}^{p, s, d w}-\rho_{t}^{u p} \cdot g_{c, t}^{p, s, u p}\right) & \forall c, t, k=k_{2} \\
q_{c, t}^{p} \geq u_{c, t}^{p} \cdot \underline{q}_{c, k}^{p}+q s_{c, t}^{p}-\bar{q}_{c, k}^{p}\left(1-d_{t}\right) & \\
\quad+\frac{1}{\delta_{k}^{p}}\left(\rho_{t}^{d w} \cdot g_{c, t}^{p, s, d w}-\rho_{t}^{u p} \cdot g_{c, t}^{p, s, u p}\right) & \forall c, t, k=k_{2}
\end{array}
$$

Generation/consumption curves of each pump-turbine unit with VS are modelled by equations (10)-(29), according to Fig. 1 in Section II; the formulation is based on the one proposed in [26]. The power generation is calculated from (10)-(13), as a function of $d_{t}$ and $u_{c, t}^{d}$. With equations (14) and (15), the maximum and minimum water discharges, which depend on the water level in the upper reservoir, are considered. In addition to this, the water discharge takes into account not only the flow that is used to produce the energy committed or scheduled in the DM but also the extra flow that is required in order to provide the upward regulation energy and the flow that is kept upstream in order to provide the downward regulation energy (16)-(19). The water discharge used for deploying the secondary regulation energy also depends on the water level in the upper reservoir.

Head dependency in consumed power and pumped water is modelled analogously by (20)-(29). The pumped water also takes into account the extra flow that is pumped in order to provide the downward regulation energy and the flow that is kept downstream in order to provide the upward regulation energy (26)-(29).

5) Secondary Regulation Service: The SRS in the Spanish electricity market comprises the hourly power reserve of each participant, that is committed in a day-ahead reserve market, and the reserve deployment requested by the TSO in the real-time operation.

The secondary regulation reserve bids are modelled through (30)-(38). Note that the auxiliary variables $a u x_{-} g_{c, t}^{d, s}$ and $a u x \_g_{c, t}^{p, s}$ avoid non-linearities in the formulation of the downward and upward secondary regulation reserve in generating and pumping modes, respectively, due to the head dependency in the available spinning reserve. When a unit is off in generating mode $\left(u_{c, t}^{d}=0\right)$, there is no available secondary regulation reserve by (32), and $a u x \_g_{c, t}^{d, s}$ will take a value greater than or equal to the expression in square brackets in (31) and lower than $\bar{g}_{c, k_{1}}^{d}$ by (33). In addition, when a unit is on in generating mode $\left(u_{c, t}^{d}=1\right), a u x \_g_{c, t}^{d, s}$ equals zero through (33). The same behaviour can be seen with $a u x_{-} g_{c, t}^{p, s}$ in pumping mode with (35)-(37). Finally, the Spanish TSO requires the market agents to fulfil an hourly ratio between the upward regulation reserve and the total reserve in order to ensure certain equilibrium between the upward and downward reserves, preventing them from offering only upward reserves or only downward reserves (38).

$$
\begin{gathered}
g_{c, t}^{d, s, u p} \leq\left[\bar{g}_{c, k_{2}}^{d} \cdot d_{t}+\bar{g}_{c, k_{1}}^{d}\left(1-d_{t}\right)\right]-g_{c, t}^{d} \quad \forall c, t \\
g_{c, t}^{d, s, d w}-a u x \_g_{c, t}^{d, s} \leq g_{c, t}^{d} \\
-\left[g_{c, k_{2}}^{d} \cdot d_{t}+g_{c, k_{1}}^{d}\left(1-d_{t}\right)\right] \quad \forall c, t \\
g_{c, t}^{d, s, u p}+g_{c, t}^{d, s, d w} \leq \bar{g}_{c, k_{1}}^{d} \cdot u_{c, t}^{d} \quad \forall c, t \\
\quad a u x \_g_{c, t}^{d, s} \leq \bar{g}_{c, k_{1}}^{d}\left(1-u_{c, t}^{d}\right) \quad \forall c, t \\
g_{c, t}^{p, s, d w} \leq\left[\bar{g}_{c, k_{2}}^{p} \cdot d_{t}+\bar{g}_{c, k_{1}}^{p}\left(1-d_{t}\right)\right]-g_{c, t}^{p} \quad \forall c, t
\end{gathered}
$$




$$
\begin{gathered}
g_{c, t}^{p, s, u p}-\text { aux_ } g_{c, t}^{p, s} \leq g_{c, t}^{p} \\
-\left[\underline{g}_{c, k_{2}}^{p} \cdot d_{t}+\underline{g}_{c, k_{1}}^{p}\left(1-d_{t}\right)\right] \quad \forall c, t \\
g_{c, t}^{p, s, u p}+g_{c, t}^{p, s, d w} \leq \bar{g}_{c, k_{2}}^{p} \cdot u_{c, t}^{p} \quad \forall c, t \\
a u x_{-} g_{c, t}^{p, s} \leq \bar{g}_{c, k_{2}}^{p}\left(1-u_{c, t}^{p}\right) \quad \forall c, t \\
\sum_{c}\left(g_{c, t}^{d, s, u p}+g_{c, t}^{p, s, u p}\right)=R_{t}^{S M} \\
\cdot\left(g_{c, t}^{d, s, u p}+g_{c, t}^{p, s, u p}+g_{c, t}^{d, s, d w}+g_{c, t}^{p, s, d w}\right) \quad \forall t
\end{gathered}
$$

The secondary regulation energy in each period $t$ is remunerated according to the net energy, i.e. the upward regulation energy in generating and pumping modes minus the downward regulation energy in generating and pumping modes, (39)-(41). A positive net regulation energy $\left(\phi_{t}=1\right)$ is remunerated according to the upward regulation energy price, whereas if the net regulation energy is negative $\left(\phi_{t}=0\right)$, the PSHP must pay the downward regulation energy price. If $\phi_{t}=1$, $e_{t}^{s, d w}=0$ by equation (41) and $e_{t}^{s, u p}$ equals the right-side of equation (39). Analogously, if $\phi_{t}=0, e_{t}^{s, u p}=0$ by equation (40) and $e_{t}^{s, d w}$ equals the right-side of equation (39).

$$
\begin{aligned}
e_{t}^{s, u p}-e_{t}^{s, d w} & =\sum_{c}\left[\rho_{t}^{u p}\left(g_{c, t}^{d, s, u p}+g_{c, t}^{p, s, u p}\right)\right. \\
& \left.-\rho_{t}^{d w}\left(g_{c, t}^{d, s, d w}+g_{c, t}^{p, s, d w}\right) \quad \forall t\right] \\
0 \leq e_{t}^{s, u p} \leq \phi_{t} \cdot \bar{g}_{c, k_{1}}^{d} \quad \forall t & \\
0 \leq e_{t}^{s, d w} \leq\left(1-\phi_{t}\right) \bar{g}_{c, k_{1}}^{d} \quad \forall t &
\end{aligned}
$$

6) Other Constraints: A pump-turbine unit cannot be operated simultaneously in generating and pumping modes (42).

$$
u_{c, t}^{d}+u_{c, t}^{p} \leq 1 \quad \forall c, t
$$

Moreover, a PSHP usually comprises a single penstock between the upper reservoir and the power station so it cannot operate simultaneously in generating and pumping modes, regardless of the number of pump-turbine units. Consequently, if there is at least one unit operating in pumping mode, no unit can be operated in generating mode, and vice versa (43).

$$
\sum_{c^{\prime} \neq c} u_{c^{\prime}, t}^{d} \leq(\mathrm{C}-1)-(\mathrm{C}-1) u_{c, t}^{p} \quad \forall c, t
$$

Finally, start-up decisions are modelled in generating mode by (44) and in pumping mode by (45).

$$
\begin{array}{ll}
y_{c, t}^{d} \geq u_{c, t}^{d}-u_{c, t-1}^{d} & \forall c, t \\
y_{c, t}^{p} \geq u_{c, t}^{p}-u_{c, t-1}^{p} & \forall c, t
\end{array}
$$

\section{B. Model Formulation for FS-PSHPs}

A FS-PSHP only regulates power in generating mode, losing the opportunity to participate in the SRS while the plant is pumping. The model formulation comprises equations (2)-(45) and the following modifications: 1) the maximum and minimum technical pumped water of each pump-turbine unit with VS, $\bar{q}_{c, k}^{p}$ and $\underline{q}_{c, k}^{p}$, have to be equal to the parameter $\bar{q}_{c, k}^{p^{\prime}}$, i.e. the pumped water at synchronous speed and 2) the maximum and minimum technical power consumption of each pump-turbine unit with VS, $\bar{g}_{c, k}^{p}$ and $\underline{g}_{c, k}^{p}$, have to be equal to the parameter $\bar{g}_{c, k}^{p^{\prime}}$, i.e. the power consumption at synchronous speed. Due to these modifications, $q s_{c, t}^{p}$ is zero in all hours by (25), and the available secondary regulation reserves in pumping mode are zero by (34) and (35) since $g_{c, k}^{p}=\bar{g}_{c, k}^{p}$ in all hours when the pump-turbine unit is in pumping mode.

\section{CASe Study}

\section{A. Data}

1) Electric Power System Data: The data of the Iberian and the Spanish electric power systems considered in this paper are the historical hourly values of: 1) the day-ahead energy prices, 2) the secondary regulation reserve prices, 3) the secondary upward and downward regulation energy prices, 4) the percentage of the real-time use of the upward and downward regulation reserves and 5) the ratio between the upward regulation reserve and the total reserve, $R_{t}^{S M}$, set by the TSO in advance of the secondary regulation reserve auction.

The uncertainty is modelled by one hundred scenarios ( $n=100$ scenarios). Each scenario is composed by a 24 -hour price profile of the DM prices and a 24-hour price profile of the secondary regulation reserve market prices. The scenarios are built by combining ten representative profiles of the DM prices with ten representative profiles of the secondary regulation reserve market prices. In order to generate such representative profiles of both the energy and reserve market prices, the following steps are carried out [27]: 1) the GARCH-ARIMAX model described in [22] is used for the DM prices, 2) a SARIMAX model is fitted for the secondary regulation reserve prices $^{2}, 3$ ) both forecasting models are sampled to obtain 500 vectors of 24-hour profiles and 4) scenario reduction is done by applying clustering techniques.

The real upward and downward regulation energy provided by each power plant in Spain is not publicly available. Thus, it is assumed that the hourly real-time use of reserves, $\left(\rho_{t}^{u p}\right.$, $\rho_{t}^{d w}$ ) is given by the historical hourly ratio of the aggregate power delivery and the aggregate assigned reserves in the entire system. The hourly regulation reserve ratio, $R_{t}^{S M}$ is assumed to be the historical hourly ratio of the aggregate upward regulation reserve and the total reserve of the entire system.

2) Technical Data: Two different PSHPs are considered in this paper, each comprising two identical pump-turbine units. The PSHPs differ from each other in the pump-turbine Hill diagram considered in generating mode: i) the Hill diagram is taken from [28] (p. 509) and ii) the Hill diagram is the one of the Mt. Elbert PSHP units, taken from [29]. The performance of the pump-turbine units in pumping mode is determined from [30] with FS and VS, for both PSHPs. According to this, the following eight cases are studied:

- FS-Raabe and FS-Elbert: the units are equipped by a reversible Francis pump-turbine unit without frequency converter. Thus, they are operated at synchronous speed in generating and pumping mode.

- VS-Raabe and VS-Elbert: the units are equipped by a reversible Francis pump-turbine unit, a synchronous

\footnotetext{
${ }^{2}$ The MAPE of the proposed GARCH-ARIMAX model is $17.8 \%$ throughout 2014 whereas the one of the SARIMAX model is $21.2 \%$ in the same period.
} 
TABLE I

TECHNICAL DATA OF EACH PUMP-TURBINE UNIT, FLOWS IN $\mathrm{m}^{3} / \mathrm{s}$, POWER IN $M W$, EFFICIENCIES IN \% AND START-UP COSTS IN $€$

\begin{tabular}{|c|c|c|c|c|c|c|c|c|}
\hline & FS-Raabe & FS-Elbert & VS-Raabe & VS-Elbert & B-Raabe & B-Elbert & VS-Raabe-A & VS-Elbert-A \\
\hline $\bar{q}_{c, k}^{d}$ & $51.59 / 51.59$ & $51.59 / 51.59$ & $51.59 / 51.59$ & $51.59 / 51.59$ & $51.59 / 51.59$ & $51.59 / 51.59$ & $51.59 / 51.59$ & $51.59 / 51.59$ \\
\hline $\bar{g}_{c, k}^{d}$ & $92.67 / 103.01$ & $96.75 / 106.60$ & $91.03 / 101.42$ & $94.82 / 105.64$ & $92.67 / 103.01$ & $96.75 / 106.60$ & $92.61 / 103.18$ & $96.46 / 107.48$ \\
\hline $\bar{\eta}_{c, k}^{d}$ & $86.2 / 86$ & $90 / 89$ & $86.4 / 86.4$ & $90 / 90$ & $86.2 / 86$ & $90 / 89$ & $86.4 / 86.4$ & $90 / 90$ \\
\hline$\underline{q}_{c, k}^{d}$ & $34.72 / 32.24$ & $27.19 / 23.47$ & $28.79 / 28.79$ & $21.10 / 21.10$ & $34.72 / 32.24$ & $27.19 / 23.47$ & $28.79 / 28.79$ & $21.10 / 21.10$ \\
\hline$\underline{g}_{c, k}^{d}$ & $57.88 / 59.89$ & $45.32 / 43.60$ & $47.03 / 52.40$ & $34.47 / 38.41$ & $57.88 / 59.89$ & $45.32 / 43.60$ & $47.85 / 53.31$ & $35.07 / 39.07$ \\
\hline$\underline{\eta}_{c, k}^{d}$ & $80 / 80$ & $80 / 80$ & $80 / 80$ & $80 / 80$ & $80 / 80$ & $80 / 80$ & $80 / 80$ & $80 / 80$ \\
\hline $\bar{q}_{c, k}^{p}$ & $59.33 / 51.59$ & $59.33 / 51.59$ & $61.90 / 54.68$ & $61.90 / 54.68$ & $61.90 / 54.68$ & $61.90 / 54.68$ & $61.90 / 54.68$ & $61.90 / 54.68$ \\
\hline $\bar{g}_{c, k}^{p}$ & $149.8 / 141.32$ & $149.8 / 141.32$ & $158.28 / 149.8$ & $158.28 / 149.8$ & $158.28 / 149.8$ & $158.28 / 149.8$ & $158.28 / 149.8$ & $158.28 / 149.8$ \\
\hline $\bar{\eta}_{c, k}^{p}$ & $88 / 90$ & $88 / 90$ & $87 / 90$ & $87 / 90$ & $87 / 90$ & $87 / 90$ & $87 / 90$ & $87 / 90$ \\
\hline$\underline{q}_{c, k}^{p}$ & $59.33 / 51.59$ & $59.33 / 51.59$ & $45.91 / 33.02$ & $45.91 / 33.02$ & $45.91 / 33.02$ & $45.91 / 33.02$ & $45.91 / 33.02$ & $45.91 / 33.02$ \\
\hline$\underline{g}_{c, k}^{p}$ & $149.8 / 141.32$ & $149.8 / 141.32$ & $110.23 / 93.27$ & $110.23 / 93.27$ & $110.23 / 93.27$ & $110.23 / 93.27$ & $110.23 / 93.27$ & $110.23 / 93.27$ \\
\hline$\underline{\eta}_{c, k}^{p}$ & $88 / 90$ & $88 / 90$ & $92 / 87$ & $92 / 87$ & $92 / 87$ & $92 / 87$ & $92 / 87$ & $92 / 87$ \\
\hline$c S U_{c}^{d} / c S U_{c}^{p}$ & $362.6 / 424$ & $375.2 / 424$ & $357 / 448$ & $371.9 / 448$ & $362.6 / 448$ & $375.2 / 448$ & $363.2 / 448$ & $378.3 / 448$ \\
\hline
\end{tabular}

machine and a full-scale frequency converter. Hence, they are operated with variable speed in generating and pumping mode. The electrical efficiency is assumed to be 98\% [31].

- B-Raabe and B-Elbert: the frequency converters of the VS-Raabe and VS-Elbert are bypassed in generating mode, being operated the units with fixed speed in generating mode and with variable speed in pumping mode. Bypassing the converter in generating mode is achieved connecting the stator directly to the grid by means of the bypass switch. This operation can be found in the industry, for instance, in the PSHP of Grimsel II [19].

- VS-Raabe-A and VS-Elbert-A: same situation of VS-Raabe and VS-Elbert but with doubly fed asynchronous machines. Due to this, the electrical losses in the frequency converters are lower. The electrical efficiency is assumed to be $99.7 \%$.

Technical data of the pump-turbine units in the eight cases are presented in Table $\mathrm{I}^{3}$. All data is split into pairs (except start-up costs): values on the left and the right of the slash refer to the I/O curve for the lower and the higher reservoir level, respectively. Part of the data was obtained from Guillena PSHP in Spain: the higher gross head is considered to be 244 $\mathrm{m}$, the lower gross head is assumed to be $219 \mathrm{~m}$ and the maximum water discharge has been chosen in order to empty the upper reservoir in a minimum time of 5.95 hours (the upper reservoir capacity is $2.21 \mathrm{Mm}^{3}, \bar{v}=2.21 \mathrm{Mm}^{3}$ and $\underline{v}=0$ $\mathrm{Mm}^{3}$ ). Hydraulic losses, mainly resulting from friction of the water in the penstock, are considered 3\% of the gross head [32]. Finally, start-up costs in generating and pumping modes have been calculated according to [33].

\section{B. Methodology}

The proposed models presented in Section III have been applied for all the above-described cases, to calculate the expected and Real Income (RI) in a representative 1-week

\footnotetext{
${ }^{3}$ Note that the considered technical data might be changed if more updated PSHPs are proposed.
}

period. The risk-averse weight factor and the confidence interval are fixed to $\mu=0.1$ and $95 \%$ ( $\beta=0.05)$, respectively. All the price scenarios have the same probability $\pi_{n}$. The economic results are compared to the maximum theoretical income (MTI), i.e. assuming perfect information in all the electric power system data. For these purposes, the models were run, day by day, over the one-week period and with a daily initial and final volume in the upper reservoir of 1.105 $\mathrm{Mm}^{3}$ (7 problems for each case).

Based on the methodology used in [22], the RI is calculated in a post-optimal simulation process by valuing i) the hourly energy schedule for the DM and ii) the hourly secondary regulation reserve schedule, both obtained from the optimization model, with the real historical hourly price of the DM and the secondary regulation reserve price, respectively.

From the results of all cases, we have 1) determined the extra value that the variable speed operation introduces comparing to FS-PSHPs when the plant only participates in the DM, and in the DM and the SRS and 2) analysed and compared the power and reserve schedule of FS-PSHPs and VS-PSHPs. Each daily problem is solved with a branch and cut algorithm in Cplex in a $2.4 \mathrm{GHz}$ Intel Core i5-450M CPU, with 4 GB of RAM memory. In average, 100 minutes of CPU time were necessary to solve a whole week for each studied case. From the point of view of each daily model, the range of the CPU time was between 3-17 min.

\section{Economic Results}

The RI and the MTI the for all cases are shown in Table II when the PSHP participates in the DM and in Table III when the PSHP participates in the DM and in the SRS. Revenues are composed of the day-ahead energy market income (DMi), which is split into sold energy when the plant is generating $\left(D M^{+}\right)$and purchased energy when is pumping $\left(D M^{-}\right)$, the secondary regulation reserve market income (SM) and the income from the upward secondary regulation energy (ER2UP). Costs comprise the downward secondary regulation energy (ER2DW) and the start-up costs in generating mode, $c S U^{d}$ and in pumping mode, $c S U^{p}$. 
TABLE II

MAXIMUM THEORETICAL INCOME (MTI) AND REAL INCOME (RI) WITHOUT ASSUMING PERFECT KNOWLEDGE, OF THE PROPOSED CASES PARTICIPATING IN THE DAY-AHEAD ENERGY MARKET, $\left[10^{3} €\right]$

\begin{tabular}{|c|c|c|c|c|c|c|c|c|c|}
\hline & & FS-Raabe & FS-Elbert & VS-Raabe & VS-Elbert & B-Raabe & B-Elbert & VS-Raabe-A & VS-Elbert-A \\
\hline \hline \multirow{2}{*}{$D M^{+}$} & MTI & 284.89 & 296.76 & 263.33 & 284.53 & 267.47 & 300.31 & 267.9 & 302.26 \\
\cline { 2 - 10 } & RI & 205.22 & 249.79 & 197.59 & 205.84 & 200.65 & 239.08 & 201.02 & 258.97 \\
\hline \multirow{2}{*}{$D M^{-}$} & MTI & -136.34 & -136.35 & -113.12 & -122.29 & -113.12 & -133.68 & -113.12 & -133.68 \\
\cline { 2 - 10 } & RI & -101.67 & -121.95 & -88.44 & -88.64 & -87.88 & -105.63 & -87.64 & -121.38 \\
\hline \multirow{2}{*}{ DMi } & MTI & 148.55 & 160.41 & 150.21 & 162.24 & 154.35 & 166.63 & 154.78 & 168.58 \\
\cline { 2 - 10 } & RI & 103.54 & 127.84 & 109.15 & 117.20 & 112.78 & 133.45 & 113.39 & 137.59 \\
\hline \multirow{2}{*}{$c S U^{d}$} & MTI & -9.79 & -9.38 & -6.07 & -6.32 & -6.16 & -7.13 & -6.17 & -7.19 \\
\cline { 2 - 10 } & RI & -6.53 & -8.26 & -4.28 & -4.46 & -4.35 & -6.00 & -4.36 & -5.67 \\
\hline \multirow{2}{*}{$c S U^{p}$} & MTI & -6.36 & -6.36 & -6.72 & -7.61 & -6.72 & -8.06 & -6.72 & -8.06 \\
\cline { 2 - 10 } & RI & -4.66 & -5.93 & -4.93 & -4.93 & -4.93 & -6.27 & -5.38 & -6.72 \\
\hline \multirow{2}{*}{ Total } & MTI & 132.4 & 144.67 & 137.42 & 148.31 & 141.47 & 151.44 & 141.89 & 153.33 \\
\cline { 2 - 9 } & RI & 92.35 & 113.65 & 99.94 & 117.81 & 103.50 & 121.18 & 103.66 & 125.20 \\
\hline
\end{tabular}

TABLE III

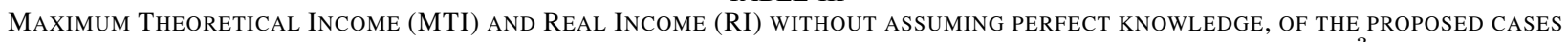
PARTICIPATING IN THE DAY-AHEAD ENERGY MARKET AND IN THE SECONDARY REGULATION SERVICE, [10 $€$ ]

\begin{tabular}{|c|c|c|c|c|c|c|c|c|c|}
\hline & & FS-Raabe & FS-Elbert & VS-Raabe & VS-Elbert & B-Raabe & B-Elbert & VS-Raabe-A & VS-Elbert-A \\
\hline \hline \multirow{2}{*}{$D M^{+}$} & MTI & 342.67 & 421.53 & 473.62 & 499.41 & 491.15 & 506.03 & 489.6 & 505.66 \\
\cline { 2 - 11 } & RI & 348.04 & 405.92 & 427.60 & 432.24 & 434.16 & 438.77 & 432.18 & 461.26 \\
\hline \multirow{2}{*}{$D M^{-}$} & MTI & -256.73 & -355.29 & -481.13 & -496.99 & -489.24 & -512.23 & -495.12 & -493.17 \\
\cline { 2 - 11 } & RI & -282.26 & -356.45 & -428.33 & -436.64 & -447.20 & -442.82 & -429.91 & -464.22 \\
\hline \multirow{2}{*}{ DMi } & MTI & 85.94 & 66.24 & -7.5 & 2.42 & 1.91 & -6.2 & -5.52 & 12.49 \\
\cline { 2 - 11 } & RI & 65.78 & 49.46 & -0.73 & -4.40 & -13.04 & -4.05 & 2.27 & -2.95 \\
\hline \multirow{2}{*}{ SM } & MTI & 181.95 & 340.61 & 577 & 690.93 & 536.33 & 658.73 & 586.15 & 697.08 \\
\cline { 2 - 11 } & RI & 183.03 & 327.14 & 543.62 & 659.01 & 519.37 & 625.00 & 551.35 & 676.89 \\
\hline \multirow{2}{*}{ ER2UP } & MTI & 34.62 & 60.99 & 148.51 & 168.15 & 144.09 & 167.55 & 152.05 & 169.5 \\
\cline { 2 - 10 } & RI & 32.33 & 60.37 & 134.65 & 159.74 & 136.74 & 156.90 & 137.34 & 166.09 \\
\hline \multirow{2}{*}{ ER2DW } & MTI & -8.9 & -23.99 & -25.33 & -38.52 & -21.66 & -33.04 & -25.94 & -40.39 \\
\cline { 2 - 10 } & RI & -12.46 & -23.26 & -23.80 & -33.55 & -18.66 & -29.37 & -24.67 & -35.05 \\
\hline \multirow{2}{*}{$c S U^{d}$} & MTI & -14.5 & -18.39 & -16.78 & -20.08 & -18.49 & -19.51 & -17.8 & -19.29 \\
\cline { 2 - 10 } & RI & -16.32 & -20.26 & -16.06 & -19.71 & -17.77 & -21.01 & -16.71 & -21.56 \\
\hline \multirow{2}{*}{$c S U^{p}$} & MTI & -12.29 & -16.11 & -19.71 & -21.05 & -21.95 & -21.95 & -20.6 & -20.6 \\
\cline { 2 - 10 } & RI & -12.72 & -17.38 & -17.47 & -19.26 & -21.05 & -21.50 & -17.92 & -21.95 \\
\hline \multirow{2}{*}{ Total } & MTI & 266.82 & 409.36 & 656.19 & 781.85 & 620.23 & 745.58 & 668.34 & 798.77 \\
\cline { 2 - 9 } & RI & 239.66 & 376.07 & 620.20 & 741.83 & 585.59 & 705.97 & 631.68 & 761.46 \\
\hline
\end{tabular}

Regarding the economic results participating only in the DM (see Table II), the introduction of the variable speed technology increases the RI and the MTI in all cases: between $3.7-8.2 \%$ and $2.5-3.8 \%$, respectively, in cases with synchronous machines and between 10.1-12.2\% and 6-7.2\%, respectively, with asynchronous machines. The increase of the RI and the MTI with asynchronous machines is higher than with synchronous machines because of the increase in the electrical efficiency. If the converter is bypassed in generating mode, the RI and the MTI increase more than without bypassing the converters.

Regarding the economic results participating in the DM and the SRS (see Table III), the introduction of the variable speed technology increases the RI and the MTI in all cases much more: between $97-159 \%$ and $91-145 \%$, respectively, with synchronous machines and between $102-163 \%$ and $95-150 \%$, respectively, with asynchronous machines. This is due to 1) the participation of the PSHP in the SRS, 2) the increase in the operating range in generating mode with the variable speed technology and 3) the capability to regulate in pumping mode thanks to the variable speed technology. If the frequency converter is bypassed in generating mode, the RI and the MTI increase less than without bypassing the converters.

The results obtained when the frequency converter is bypassed in generating mode seem to be contradictory: the RI and the MTI increase if the PSHP only participates in the DM, and decrease if the PSHP participates in the DM and in the SRS. However, it can be explained as follows: when the frequency converter is bypassed, the higher electrical efficiency in generating mode yields a benefit in the DM, but the narrower operating range has a stronger negative impact in the reserve market.

In all cases, a big part of the revenue is obtained from the secondary regulation reserve market. This reflects that the PSHP is using the secondary regulation reserve as the priority source of revenue, and the DM as a subsidiary means to maximize the participation in the secondary regulation market. As a consequence of a higher participation in the secondary 


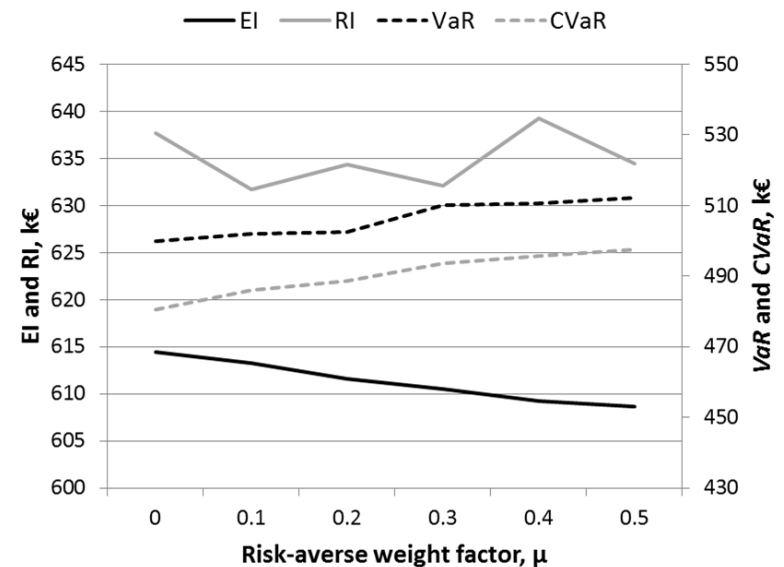

Figure 2. Sensitivity analysis of the risk-averse weight factor $\mu$ for the VS-Raabe-A case

regulation reserve market, the net profit from the upward and downward regulation energy increases. It is important to note that in the Spanish electric power system, the upward and downward secondary regulation energy prices are usually higher and lower, respectively, than the day-ahead energy prices (in 2014, the mean day-ahead energy price was 42.15 $€ / M W h$ whereas the mean upward and downward secondary regulation energy prices were 47.36 and $31.34 € / \mathrm{MWh}$, respectively).

Although analysing the sensitivity of the expected income (EI) and the RI to a variation in the risk-averse weight factor $\mu$ is outside the scope of the presented paper, Fig. 2 shows some interesting tendencies. Only the results for the VS-Raabe-A case are presented for the sake of clarity, being analogous for the rest of the cases. The EI and the RI are shown in the left $\mathrm{y}$-axis whereas the $V a R$ and $C V a R$ are shown in the right $\mathrm{y}$-axis of Fig. 2. As expected, the EI decreases but the $V a R$ and $C V a R$ increases, as the risk-averse weight factor increases. However, the decrease of the EI (between $0.1-0.27 \%$ ) is lower in relative terms than the increase of the $V a R$ and $C V a R$ (between $0.38-0.99 \%$ ). There does not seem to be any clear tendency of the RI with respect to the risk-averse weight factor. Finally, for all $\mu$, the RI is higher than the EI but the difference is less than $4 \%$ of the EI. This could suggest that the scenarios used to model the uncertainty is appropriate.

The inclusion of the VS technology does not only bring an extra income but also requires an extra investment cost. Although analysing the return of the investment of this technology is beyond the scope of the presented work, the following discussion can shed light about its profitability.

Investment cost related to PSHPs is strongly site-dependent. In the literature, several studies can be found regarding investment cost of FS-PSHPs. For example, [4] proposes a range between $470-2170 € / \mathrm{kW}$ from the analysis of projects of FS-PSHPs in countries such as Spain, Portugal and Switzerland, among others, or [5], which proposes a range between 775-1280 $€ / \mathrm{kW}$ from projects in Germany and Luxembourg. In addition, [34] proposes an increase between $7-15 \%$ of the investment cost of a FS-PSHP if the VS technology is included. According to the results obtained in Table II and Table III considering imperfect information, the FS-PSHPs obtain an income between 240-376 $\mathrm{k} €$ and 92-114 $\mathrm{k} €$ if they participate or not in the SRS, respectively, and the VS-PSHPs between 586-761 $\mathrm{k} €$ and $100-125 \mathrm{k} €$ if they participate or not in the SRS, respectively. The investment costs of the FS-PSHPs are between 96-462 M€ using the installed capacity of Table I and the ranges proposed in the literature whereas the ones of the VS-PSHPs are between 105-517 M€, assuming an increase of $11 \%$ with respect to the former. Assuming that each PSHP obtains the same economic results in all the weeks, the pay-back periods of the FS-PSHPs are between 5.1-35.9 years and 17-93.1 years if they participate or not in the SRS, respectively. The pay-back periods of the VS-PSHPs are between 2.8-16.3 years and 17.2-94 years if they participate or not in the SRS, respectively. The inclusion of the VS technology would significantly decrease the pay-back period if the plant participates in the SRS and would slightly increase it if it only participates in the DM. Nevertheless, further research must be carried out to analyse the income of the plants for longer periods of time and taking into account the impact on the energy and reserve prices in case of a substantial increment of the number of PSHPs installed in the system able to provide SRSs while pumping.

\section{Operation with Variable Speed Technology}

The energy and reserve schedules of the FS-Elbert and VS-Elbert-A cases, and the amount of the upward and downward regulation energy delivered in real-time, according to the hypotheses described above, are shown in Fig. 3, for $11 / 11 / 2014$. Note that the schedules shown in Fig. 3 were obtained considering uncertainty in the DM prices and in the secondary regulation reserve prices. The figure is divided into 5 subfigures where the following variables are depicted (note that all the variables presented in white bars correspond to the FS-Elbert case and those in black bars correspond to the VS-Elbert-A case): 1) the upper reservoir water volume of the FS-Elbert case in dotted line and of the VS-Elbert-A case in solid line, and the total water through the turbines (positive) or pumps (negative) in bars, 2) the energy schedule in bars and the historical price of the DM in solid line, 3) the reserve schedule in bars and the historical price of the reserve market in solid line, 4) the regulation energy in bars and the price of the upward and downward secondary regulation energy in solid and dotted line, respectively, and, finally, 5) the percentage of the upward and downward real-time use of reserves in solid and dotted line, respectively.

From the point of view of the decisions in the DM, in both cases, the PSHP generates and consumes energy in almost the same hours (except in hours 2 and 14-15). As can be seen in subfigure 1 and 2 of Fig. 3, in both cases, the PSHP pumps/discharges water to/from the upper reservoir during off-peak/peak hours (lower/higher day-ahead energy prices). However, in the VS-Elbert-A case, the PSHP generates and consumes less energy than in the FS-Elbert case, in most hours. This is due mainly to the fact that in the VS-Elbert-A 


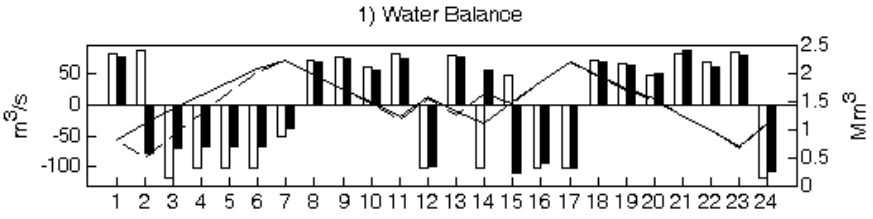

2) Day ahead Price and Schedule

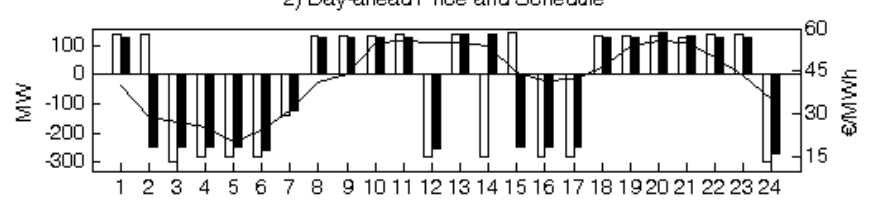

3) Reserve Price and Sohedule

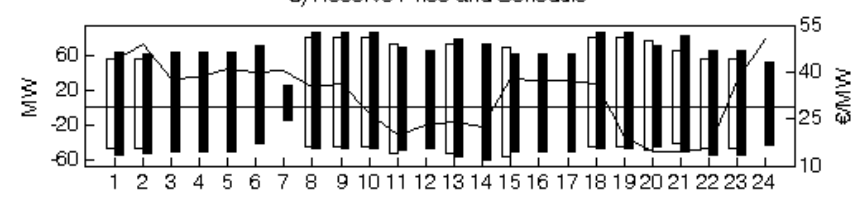

4) Regulation Price and Energy
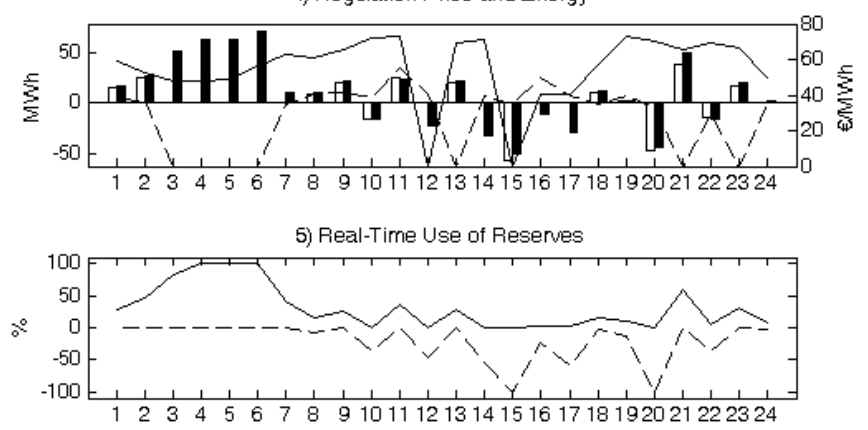

Fig. 3. Optimal operation of FS-Elbert (white bars for flows, power and regulation energy and dotted line for volume) and VS-Elbert-A (black bars for flows, power and regulation energy and solid line for volume) in the day $11 / 11 / 2014$. Upward and downward secondary regulation energy prices and the real-time use of reserves in solid and dotted line, respectively.

case, the PSHP can participate in the reserve market in pumping mode.

From the point of view of the decisions in the secondary regulation reserve market, the most important difference comes, as expected, from the fact that in the FS-Elbert case, the PSHP can participate in the reserve market only in generating mode. In the VS-Elbert-A case, the PSHP can participate in the said market both in generating and pumping modes (see hours 2-7, 12, 15-17 and 24 in subfigure 2 and 3 of Fig. 3). In the VS-Elbert-A case, the PSHP also benefits from the reserve prices during off-peak hours in the DM, which according to unpublished studies carried out by the authors, do have a negative correlation with the day-ahead energy prices, and are, therefore, usually higher during off-peak hours of the DM in the Iberian electricity system. In the VS-Elbert-A case, the operation of the PSHP is focused on making profit from the secondary regulation reserve market as it offers reserve every single hour (see subfigure 3 of Fig. 3).

\section{E. Sensitivity Analysis}

Three sensitivity analyses have been carried out in order to study the sensitivity of the income to a variation in 1) the secondary regulation reserve price, 2) the upward secondary regulation energy price and 3) the downward

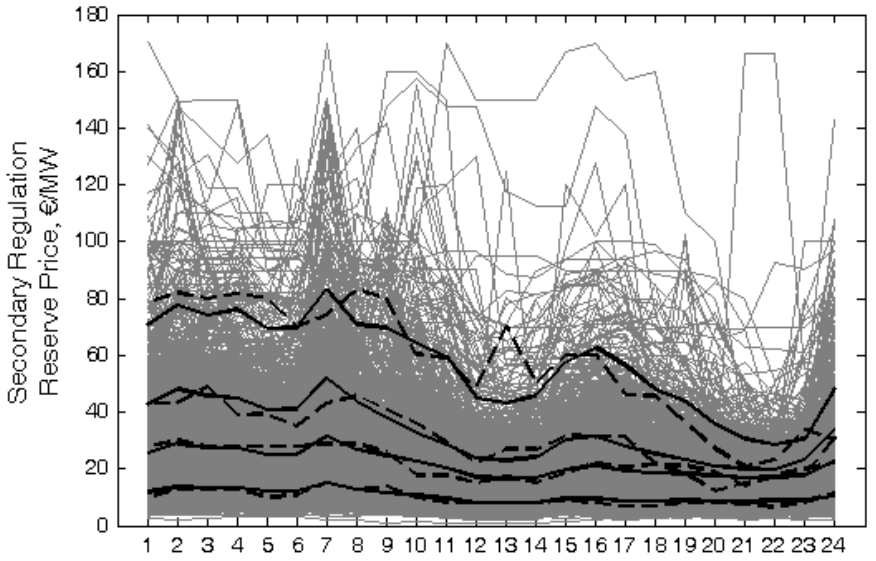

Figure 4. Clusters (black solid line) and closest historical price profiles (dashed line) for the sensitivity analysis of the secondary regulation reserve price

secondary regulation energy price. In each sensitivity analysis, the risk-neutral decision is taken (i.e., $\mu=0$ ) and the electric power system data are chosen according to the following methodology.

1) The hourly historical data of the price under study in each day of the period 2010 to 10/11/2014 is clustered into four daily groups based on the method of the squared Euclidean distances [35].

2) The distance between each historical price profile and each centroid is measured by means of the Euclidean distance. Then the real daily historical price profile that is the closest to each centroid is chosen. Fig. 4 shows the centroids and the closest price profiles of the historical data used in the sensitivity analysis corresponding to the secondary regulation reserve price.

3) The other two price profiles are chosen directly according to the historical data in the days of the profiles chosen in the previous step. For instance, the prices profiles for the highest centroid in Fig. 4 correspond to 28/12/2013, being the real prices of the secondary reserve and the upward and downward secondary regulation energy of this day the ones that are used.

4) The day-ahead energy price profile is a single 24-sequence from the forecasting model proposed in Section IV-B in the day 11/11/2014.

5) The percentages of real-time use of the upward and downward regulation reserves and the ratios between the upward regulation reserve and the total reserve, $R_{t}^{S M}$, are those of the day 11/11/2014.

The results of the sensitivity analyses with respect to the secondary regulation reserve price, the upward secondary regulation energy price and the downward secondary regulation energy price are shown in Fig. 5-7, respectively. In each figure, the total income of all the PSHPs under the above-described assumptions is presented in the left y-axis. In addition, the average value of the price under study in the sensitivity analysis is shown in the $\mathrm{x}$-axis (the four values in the $\mathrm{x}$-axis correspond to the historical average value in the days corresponding to the profiles chosen in step 2). In the 


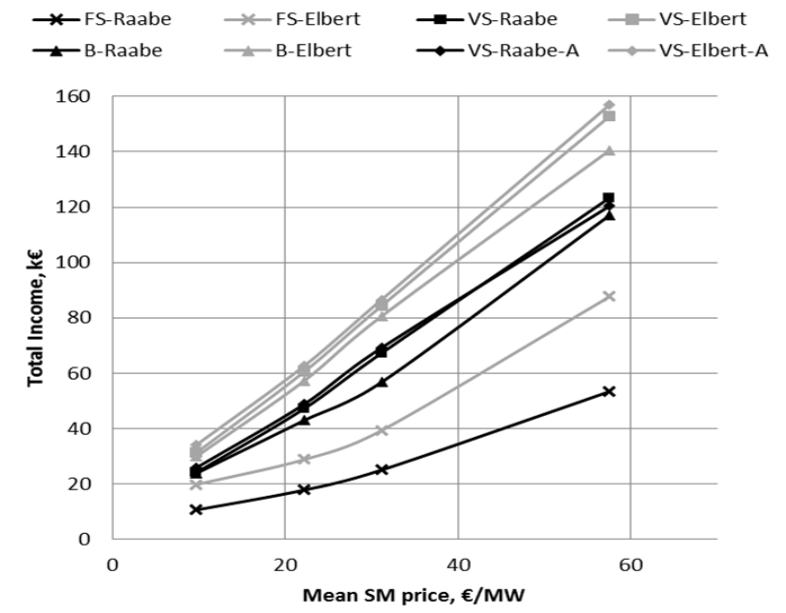

Figure 5. Sensitivity analysis of the secondary regulation reserve price

sensitivity analyses of the upward and downward secondary regulation energy prices, the average value of the secondary regulation reserve price is also shown in the right $y$-axis in order to better understand the behaviour of the income.

The sensitivity of the income to the mean secondary regulation reserve price is significant, Fig. 5, varying the former fourfold when the latter varies sixfold. In the day under study, the sensitivity seems to be quite linear, being higher for VS-PSHPs than for FS-PSHPs. This sensitivity analysis confirms the results obtained in Section IV-C as regards the importance of the secondary regulation reserve market in the PSHP income. Thus, a change in the mean reserve price affects considerably the total income.

The sensitivity of the income to the mean upward secondary regulation energy price is also significant, Fig. 6, and also higher for VS-PSHPs than for FS-PSHPs. However, the total income curves are again explained by the mean secondary regulation reserve price (SM price), first decreasing and then increasing as the mean upward secondary regulation energy price increases. This result also confirms the ones obtained in Section IV-C regarding the small magnitude of the income from the upward secondary regulation energy comparing to the total income.

Finally, the sensitivity analysis of the mean downward secondary regulation energy price is similar to the one with the mean upward secondary regulation energy price, Fig. 7.

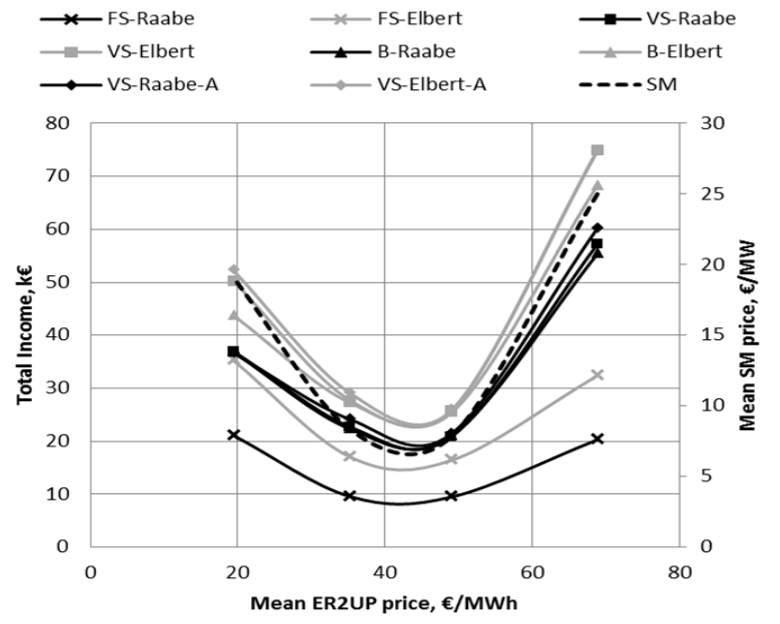

Figure 6. Sensitivity analysis of the upward secondary regulation energy price

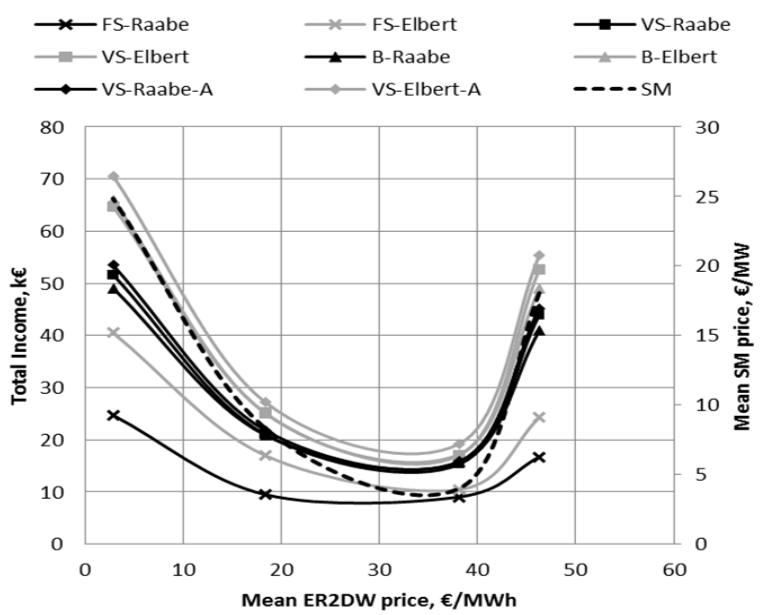

Figure 7. Sensitivity analysis of the downward secondary regulation energy price

\section{Conclusions}

An MILP model for the energy and secondary regulation reserve scheduling of a PSHP with variable speed is presented. The model takes into account uncertainty in the day-ahead energy prices and in the secondary regulation reserve prices, and also the risk-aversion of the decision maker. Additionally, this study preliminarily quantifies the increase in the RI and the MTI, due to the operation with variable speed, of a PSHP participating only in the DM, and participating in the DM and in the SRS of the Iberian electricity system. The PSHP under study is assumed to be closed-loop, daily-cycle and price-taker.

The results obtained in the article show that a VS-PSHP could enlarge its income up to $12.2 \%$ when it only participates in the DM and up to $163 \%$ if it also participates in the SRS, comparing to a FS-PSHP. In addition to this, the results seem to indicate that VS-PSHPs equipped with doubly fed asynchronous machines might obtain a higher income than VS-PSHPs equipped with synchronous machines, and that when the frequency converter is bypassed in generating mode, higher income might be expected when the PSHP only participates in the DM, and lower income might be expected when the PSHP participates in the DM and the 
SRS. It is important to consider these results in the context of a price-taker PSHP and a bidding procedure which considers uncertainty in the day-ahead energy prices and in the secondary regulation reserve prices. Further research, taking into account the uncertainty in the hourly secondary regulation energy prices and the real-time use of reserves, is required to obtain more realistic figures on the expected revenue of VS-PSHPs. Furthermore, considering a price-maker approach in the secondary regulation market, where the quota of each participant may be of considerable size, is deemed as another future work. Other trading options of the PSHP in, for example, intraday markets and the tertiary regulation service are worthy to be considered in future works.

\section{REFERENCES}

[1] J. I. Pérez-Díaz, M. Chazarra, J. García-González, G. Cavazzini, and A. Stoppato, "Trends and challenges in the operation of pumped-storage hydropower plants," Renewable and Sustainable Energy Reviews, vol. 44, pp. 767-784, 2015.

[2] M. Chazarra, J. I. Pérez-Díaz, and J. García-González, "Optimal Energy and Reserve Scheduling of Pumped-Storage Power Plants Considering Hydraulic Short-Circuit Operation," IEEE Transactions on Power Systems, vol. 32, no. 1, pp. 344-353, 2017.

[3] N. Sivakumar, D. Das, and N. Padhy, "Variable speed operation of reversible pump-turbines at Kadamparai pumped storage plant - A case study," Energy Conversion and Management, vol. 78, pp. 96-104, 2014.

[4] D. Connolly, H. Lund, P. Finn, B. Mathiesen, and M. Leahy, "Practical operation strategies for pumped hydroelectric energy storage (PHES) utilising electricity price arbitrage," Energy Policy, vol. 39, no. 7, pp. 4189-4196, 2011.

[5] B. Steffen, "Prospects for pumped-hydro storage in Germany," Energy Policy, vol. 45, pp. 420-429, 2012.

[6] E. Lobato, I. Egido, L. Rouco, and G. López, "An overview of ancillary services in Spain," Electric Power Systems Research, vol. 78, no. 3, pp. 515-523, 2008

[7] ENTSO-E Working Group on Ancillary Services, "Survey on Ancillary services procurement, Balancing market design 2014," Tech. Rep. January, 2015. [Online]. Available: https://www.entsoe.eu/Documents/Publications/MarketCommitteepublication

[8] J. Wang and S. Liu, "Quarter-Hourly Operation of Hydropower Reservoirs with Pumped Storage Plants," Water Resources Planning and Management, no. 138, pp. 13-23, 2012.

[9] J. García-González, R. Moraga, L. Matres, and A. Mateo, "Stochastic joint optimization of wind generation and pumped-storage units in an electricity market," IEEE Transactions on Power Systems, vol. 23, no. 2, pp. $460-468,2008$

[10] M. Chazarra, J. García-González, J. I. Pérez-Díaz, and M. Arteseros, "Stochastic optimization model for the weekly scheduling of a hydropower system in day-ahead and secondary regulation reserve markets," Electric Power Systems Research, vol. 130, pp. 67-77, 2016.

[11] N. Lu, J. Chow, and A. Desrochers, "Pumped-Storage Hydro-Turbine Bidding Strategies in a Competitive Electricity Market," IEEE Transactions on Power Systems, vol. 19, no. 2, pp. 834-841, 2004.

[12] T. Li and M. Shahidehpour, "Price-Based Unit Commitment: A Case of Lagrangian Relaxation Versus Mixed Integer Programming," IEEE Transactions on Power Systems, vol. 20, no. 4, pp. 2015-2025, 2005.

[13] C. Tsai, Y. Cheng, S. Liang, and W. Lee, "The Co-Optimal Bidding Strategy of Pumped-Storage Unit in ERCOT Energy Market," in North American Power Symposium (NAPS), 2009.

[14] A. Ortner and C. Graf, "Multi-market unit-commitment and capacity reserve prices in systems with a large share of hydro power: A case study," in European Energy Market (EEM), 2013.

[15] S. Kazempour, M. Moghaddam, M. Haghifam, and G. Yousefi, "Risk-constrained dynamic self-scheduling of a pumped-storage plant in the energy and ancillary service markets," Energy Conversion and Management, vol. 50, no. 5, pp. 1368-1375, 2009.

[16] P. Kanakasabapathy and K. Shanti Swarup, "Bidding strategy for pumped-storage plant in pool-based electricity market," Energy Conversion and Management, vol. 51, no. 3, pp. 572-579, 2010.

[17] O. Alizadeh-Mousavi and M. Nick, "Stochastic Security Constrained Unit Commitment with Variable-Speed Pumped-Storage Hydropower Plants," in Power Systems Computation Conference (PSCC), 2016.
[18] M. Chazarra, J. Pérez-Díaz, and J. García-González, "Optimal Operation of Variable Speed Pumped Storage Hydropower Plants Participating in Secondary Regulation Reserve Markets," in European Energy Market (EEM), 2014

[19] H. Schlunegger and A. Thöni, "100 MW full-size converter in the Grimsel 2 pumped-storage plant," in HYDRO, 2013.

[20] A. Bocquel and J. Janning, "Analysis of a 300 MW Variable Speed Drive for Pump-Storage Plant Applications," in European Conference on Power Electronics and Applications, 2005.

[21] J. Are Suul, "Variable Speed Pumped Storage Hydropower Plants for Integration of Wind Power in Isolated Power Systems," in Renewable Energy, 2009.

[22] M. Chazarra, J. I. Pérez-Díaz, and J. García-González, "Value of Perfect Information of Spot Prices in the Joint Energy and Reserve Hourly Scheduling of Pumped Storage Plants," in European Energy Market (EEM), 2016

[23] J. García-González, E. Parrilla, and A. Mateo, "Risk-averse profit-based optimal scheduling of a hydro-chain in the day-ahead electricity market," European Journal of Operational Research, vol. 181, no. 3, pp. 1354-1369, sep 2007.

[24] H. M. I. Pousinho, V. M. F. Mendes, and J. P. S. Catalão, "A risk-averse optimization model for trading wind energy in a market environment under uncertainty," Energy, vol. 36, no. 8, pp. 4935-4942, 2011. [Online]. Available: http://dx.doi.org/10.1016/j.energy.2011.05.037

[25] R. T. Rockafellar and S. Uryasev, "Optimization of Conditional Value-at-risk," Journal of Risk, vol. 2, no. 3, pp. 21-41, 2000.

[26] A. Conejo, J. Arroyo, J. Contreras, and F. Apolinar, "Self-scheduling of a hydro producer in a pool-based electricity market," IEEE Transactions on Power Systems, vol. 17, no. 4, pp. 1265-1272, 2002.

[27] M. Fodstad, A. L. Henden, and A. Helseth, "Hydropower Scheduling in Day-ahead and Balancing Markets," in European Energy Market, 2015.

[28] J. Raabe, Hydro Power - The Design, Use and Function of Hydromechanical, Hydraulic and Electrical Equipment. VDI Verlag, 1985.

[29] U.S. Bureau of Reclamation, Estimating reversible pump-turbine characteristics. A Water Resources Technical Publication. U.S Government Printing Office, 1977.

[30] J. Merino and A. Lopez, "ABB Varspeed generator boosts efficiency and operating flexibility of hydropower plant," $A B B$ Review, vol. 3, pp. 33-38, 1996.

[31] Danfoss, Facts Worth Knowing about Frequency Converters, 2014

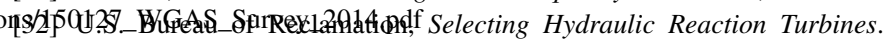
U.S. Government Printing Office, 1976.

[33] O. Nilsson and D. Sjelvgren, "Hydro Unit Start-up Costs and Their Impact on the Short Term Scheduling Strategies of Swedish Power Producers," IEEE Transactions on Power Systems, vol. 12, no. 1, pp. 38-44, 1997.

[34] A. Botterud, T. Levin, and V. Koratirov, "Pumped Storage Hydropower: Benefits for Grid Reliability and Integration of Variable Renewable Energy," Tech. Rep., 2014.

[35] B. Everitt, S. Landau, M. Leese, and D. Stahl, Cluster Analysis. UK: Willey, 2011.

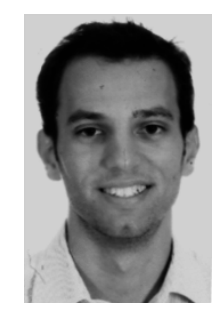

Manuel Chazarra received the Industrial Engineering degree and the M.Sc. degree from the Comillas Pontifical University, Madrid, Spain, in 2009 and 2012, respectively. He is currently pursuing the Ph.D. degree at Technical University of Madrid. His area of interest is optimal operation of power systems.

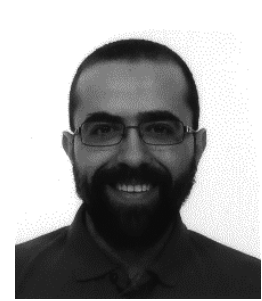

Juan Ignacio Pérez-Díaz received the Ph.D. degree in 2008 from Technical University of Madrid (UPM), where he is a non-tenured associate professor since 2011. His current research interests focus mainly on optimal operation and control of hydro power plants. 


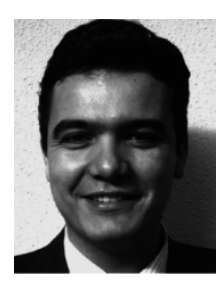

Javier García-González received the Ph.D. degree in 2001 from the Comillas Pontifical University, Madrid, Spain, where he is an Associate Professor. He belongs to the research staff of the Institute for Research in Technology. His research interests include operations, planning, and economy of power systems. 


\subsection{Paper-C: Economic Viability of Pumped-Storage Power Plants Participating in the Secondary Regulation Service}

The preliminary version of this paper was published in [Chazarra et al., 2017b], and orally presented in an International Conference. In this paper entitled "Economic Viability of Pumped-Storage Power Plants Participating in the Secondary Regulation Service" [Chazarra et al., 2017c], it is estimated the economic viability of closed-loop and daily-cycle PSHPs participating in the day-ahead energy market (modelled as a price-taker) and in the secondary regulation reserve market (modelled as a price-maker) of the Iberian and Spanish electricity power systems, respectively. The activation of the secondary regulation reserves is also considered in the model formulation. Different configurations of PSHPs as regards the type of hydraulic machine (Francis pump-turbine, ternary unit with Francis or Pelton turbine), electrical machine and grid connection (synchronous, synchronous with full converter, doubly-fed induction machine), and whether or not the plant can operate in hydraulic short-circuit mode are considered. The mentioned economic viability is estimated using the minimum theoretical pay-back period, i.e. the minimum number of years that the investment costs are expected to be recovered. The minimum theoretical pay-back periods are estimated from the maximum theoretical incomes and the investment costs of the PSHPs. The maximum theoretical incomes are obtained using the deterministic day-ahead energy and secondary regulation reserve hourly scheduling models based on the ones previously published: [Chazarra et al., 2017d] for PSHPs with the possibility to be operated in hydraulic shortcircuit mode and [Chazarra et al., 2017e] for PSHPs equipped with variable-speed units. Note that the maximum theoretical income assumes perfect knowledge in all the random variables from the electric power system data of the problem, and is calculated running the models sequentially day by day for a time period of three years (2013-2015) in order to obtain representative enough as well as useful results for studying the economic viability. The investment costs of the PSHPs are estimated from available data in the technical literature of existing, to be commissioned and projected PSHPs. Part of the technical data of the hydraulic and electrical equipment of the twelve studied PSHPs were provided by General Electric, from some of its last prototypes or studies. Furthermore, the maximum theoretical incomes are compared to the real income obtained by PSHPs that are currently operating in the Iberian system.

This publication is linked to the objectives of the Thesis (Figure 1.8) as follows: as far as the Thesis author knows, it is the first time in which the economic viability of PSHPs equipped with variable-speed units and/or operating in hydraulic short circuit mode is studied, in the context of PSHPs, participating in the day-ahead energy and reserve markets. This paper applies for the second secondary objective of the Thesis (to estimate the economic viability 
of PSHPs). 
Manuscript Number:

Title: Economic Viability of Pumped-Storage Power Plants Participating in the Secondary Regulation Service

Article Type: Research Paper

Keywords: Pumped Storage Plant; Secondary Regulation Service; Variable Speed Technology; Hydraulic Short-circuit Operation; Economic Viability

Corresponding Author: Mr. MANUEL CHAZARRA,

Corresponding Author's Institution:

First Author: MANUEL CHAZARRA

Order of Authors: MANUEL CHAZARRA; Juan I. Pérez-Díaz; Javier GarcíaGonzález

Abstract: This paper analyses the economic viability of twelve pumpedstorage hydropower plants equipped with different fixed-speed and variable-speed units and with and without considering hydraulic shortcircuit operation. The analysed plants are assumed to participate in the day-ahead energy market and in the secondary regulation service of the Iberian power system. A deterministic day-ahead energy and reserve scheduling model is used to estimate the maximum theoretical income of the plants assuming perfect information of the next day prices, the residual demand curves of the secondary regulation reserve market and the percentages of the real-time use of the committed reserves. An estimate of the minimum theoretical pay-back period is obtained from the maximum theoretical income as a result of the scheduling model. Results indicate that the economic viability with and without variable speed units and operating or not in hydraulic short-circuit mode is not discarded if the plants also participate in the secondary regulation service, and that the minimum theoretical pay-back periods can be reduced significantly when the plant is equipped with variable speed units and/or operates in hydraulic short-circuit mode. In addition, the maximum theoretical income obtained with the used optimization model and the proposed pumped-storage hydropower plants are significantly higher than the real income obtained by plants that are currently operating in the Iberian system 


\title{
Economic Viability of Pumped-Storage Power Plants Participating in the Secondary Regulation Service
}

\author{
Manuel Chazarra, Juan I. Pérez-Díaz, Javier García-González, Member, IEEE
}

\begin{abstract}
This paper analyses the economic viability of twelve pumped-storage hydropower plants equipped with different fixed-speed and variable-speed units and with and without considering hydraulic short-circuit operation. The analysed plants are assumed to participate in the day-ahead energy market and in the secondary regulation service of the Iberian power system. A deterministic day-ahead energy and reserve scheduling model is used to estimate the maximum theoretical income of the plants assuming perfect information of the next day prices, the residual demand curves of the secondary regulation reserve market and the percentages of the real-time use of the committed reserves. An estimate of the minimum theoretical pay-back period is obtained from the maximum theoretical income as a result of the scheduling model. Results indicate that the economic viability with and without variable speed units and operating or not in hydraulic short-circuit mode is not discarded if the plants also participate in the secondary regulation service, and that the minimum theoretical pay-back periods can be reduced significantly when the plant is equipped with variable speed units and/or operates in hydraulic short-circuit mode. In addition, the maximum theoretical income obtained with the used optimization model and the proposed pumped-storage hydropower plants are significantly higher than the real income obtained by plants that are currently operating in the Iberian system
\end{abstract}

Index Terms-Pumped Storage Plant, Secondary Regulation Service, Variable Speed Technology, Hydraulic Short-circuit Operation, Economic Viability.

\section{INTRODUCTION}

Pumped-storage hydropower plants (PSHPs) are considered worldwide as a mature technology to store large quantities of energy and to improve the flexibility of the power systems [1]. Therefore, they can play an important role in the context of

This work was supported in part by the Spanish Ministry of Economy and Competitiveness under the project "Optimal operation and control of pumped-storage hydropower plants" of The National Scientific Research, Development and Technological Innovation Plan 2008-2011 (Ref. ENE2012-32207). A preliminary version of a small part of this paper was presented at the HYPERBOLE Conference, Porto, Portugal, 2-3 February 2017. The authors gratefully acknowledge the support of Energías Renovables del Bierzo S.L., in the obtaining of the real income of pumped-storage hydropower plants that are currently operating in the Iberian system. The authors gratefully acknowledge Roland Praus, Pierre Leroy and Laetitia Balarac (General Electric) for the provision of the technical data of the hydraulic and electrical equipment of the theoretical pumped-storage power plants.

Manuel Chazarra and Juan I. Pérez-Díaz are with the Department of Hydraulic, Energy and Environment Engineering, Escuela de Ingenieros de Caminos, Canales y Puertos, Technical University of Madrid, 28040, Spain. (email: manuel.chazarra@upm.es; ji.perez@upm.es).

Javier García-González is with the Institute for Research in Technology, ICAI School of Engineering, Comillas Pontifical University, 28015, Madrid, Spain. (email: javiergg@comillas.edu). a high penetration of intermittent renewable energies such as wind and solar power. However, PSHPs are characterised by high capital costs and even higher if they are equipped with frequency converters or with ternary units, and if the hydraulic short-circuit operation is enabled.

According to [2], the quantity of grid services are necessarily expected to increase in the current context of the increasing penetration of intermittent renewable energies. In [2], several economic opportunities in grid services are presented and, in the presented paper, the following are selected as feasible for PSHPs in order to enlarge their income: the primary, secondary and tertiary frequency control, ramp compensation, peak limiting by means of demand reduction, or emergency service by means of power to maintain critical equipment.

Several papers have been found in the technical literature analysing the economic viability of conventional ${ }^{1}$ PSHPs from the point of view of the agent-based perspective in liberalised power systems or analysing the contribution to the system by means, among others, of scheduling cost savings or wind energy curtailment from the point of view of the system-based perspective in liberalised power systems. Considering the latter, there are many papers published in the technical literature and several of them are here presented as examples. In [3], authors estimate the scheduling cost savings and the decrease in curtailed wind energy caused by energy storage, by using heuristic algorithms and dynamic programming. They conclude that combined heat and power plants are found to be more profitable solutions for the integration of large-scale wind power in the Netherlands than energy storage. In [4], the contribution of PSHPs to reduce the scheduling costs, wind curtailments and carbon dioxide emissions from thermal power plants in the Irish power system, considering different levels of wind power penetration, is assessed. Results show that the main benefit from storage is the decrease in wind curtailment. In [5], authors assess the contribution of PSHPs to reduce the scheduling costs, carbon dioxide emissions and the excess of electricity production in the Dutch power system. They conclude that the energy storage helps to reduce significantly the scheduling costs of the system, the greenhouse gases emissions and the amount of curtailed wind power.

\footnotetext{
${ }^{1}$ In this context, a conventional pumped-storage hydropower plant refers to the operation with fixed speed in generating and in pumping modes (without variable speed units and without the operation in the hydraulic short-circuit mode).
} 
The economic viability of conventional PSHPs from the point of view of the agent-based perspective has been also studied in the technical literature, specially with the well-known price-arbitrage strategy. [6] compares the profits and the investment costs in six electricity markets such as Great Britain or Nordpool, among others, using a heuristic algorithm based on the price-arbitrage strategy to operate the PSHP. Results obtained in [6] show that the recovery of the investment costs is not possible almost in all the analysed markets. However, results in [7] show that PSHPs are profitable in almost all the seven real-time markets analysed in the United States, such as ERCOT (Texas) or NYISO (New York). Results can be considered slightly optimistic as they are obtained for 2008, when there was a significant difference between peak and off-peak energy prices and also reaching in some months the highest average prices of the last decade. [8] analyses the economic viability of conventional PSHPs participating also in the regulation market. Results in [8] show that the considered PSHP cannot recover the investment costs if it only participates in the day-ahead energy market and can recover the investment costs only for a limited range of the storage size if it also participates in the regulation market.

According to the best of our knowledge, there is no published paper in which the economic viability of PSHPs equipped with variable speed units and/or operating in hydraulic short circuit mode is analysed [9], in the context of a liberalised power system.

Therefore, the main goal and contribution of this paper is to estimate the economic viability of closed-loop ${ }^{2}$ and daily-cycle PSHPs participating in the day-ahead energy market and the secondary regulation service, considering different power plant configurations as regards the type of hydraulic machine (Francis pump-turbine, ternary unit with Francis or Pelton turbine), electrical machine and grid connection (synchronous, synchronous with full converter, doubly-fed induction machine), and whether or not the plant can operate in hydraulic short-circuit mode. The reader is referred to [10] and [11] to further read about short-term scheduling models of variable speed PSHPs and PSHPs with the operation in hydraulic short-circuit mode, respectively, and to [12] to further read about the technology of variable speed pumped-storage and the operation in hydraulic short-circuit mode. Consistently with [6], [8] and [9], the PSHPs are proposed to participate not only in the day-ahead energy market (DM) but also in the secondary regulation service (SRS) of the Iberian system.

The SRS in the Iberian system comprises: 1) a day-ahead secondary regulation reserve market $(\mathrm{SM})$, which takes place after having cleared the DM, where the upward and downward secondary regulation reserve requirements of the system are assigned in the same market. The assigned power reserve is remunerated by the same marginal market price, and 2) the secondary regulation energy, i.e., the power reserve used in real-time according to the assigned reserve in the SM and the system requirements in real-time. The upward and

\footnotetext{
${ }^{2}$ Closed-loop means that no natural water inflows are received in the upper reservoir and that no water outflows are released from the lower reservoir of the hydro system.
}

downward secondary regulation energy is remunerated by the marginal price of the upward and downward tertiary regulation market, respectively [13]. The former represents an income to the plant whereas the latter represents a cost. The procedure for the procurement of secondary regulation is not exclusive of the Iberian system. For instance, a similar procedure is implemented in Norway, Sweden, Finland, Slovenia, Czech Republic and Romania in the short-term (less than a week) and in Denmark, Netherlands, Belgium, Germany, Austria and Switzerland in the long-term (more than a week) [14].

The economic viability is evaluated using the minimum theoretical pay-back period (MTPB), i.e. the minimum number of years that the investment costs are expected to be recovered. The MTPB is estimated from the maximum theoretical income (MTI) and the investment costs of the PSHPs. The MTI is obtained from the results of a deterministic day-ahead energy and secondary regulation reserve hourly scheduling model, based on mixed integer quadratic programming, that assumes a perfect knowledge of all uncertain variables involved in the problem. The model is sequentially run day by day for a time period of three years (2013-2015). The investment costs of the PSHPs are estimated from available data in the technical literature of existing, to be commissioned and projected PSHPs. The MTPBs are estimated for the twelve PSHPs proposed by the authors. The technical data of the hydraulic and electrical equipment of the studied PSHPs were provided by General Electric, from some of its last prototypes or studies. The interest of the hydropower industry in the results of the paper is therefore guaranteed. In addition to all of this, the MTI are compared to the real income obtained by PSHPs that are currently operating in the Iberian system.

The paper is organised as follows: the methodology used to obtain the MTI and the description of each PSHP are presented in Section II. The MTIs of each PSHP are shown and discussed in Section III whereas the estimated investment costs of each PSHP according to the technical literature are presented in Section IV. The economic viability of the studied PSHPs is analysed in Section V. Finally, main conclusions are drawn in Section VI.

\section{Methodology}

\section{A. Optimization model}

The main goal of this paper is not to propose an optimization model for the day-ahead energy and reserve scheduling of PSHPs but to estimate their economic viability using the results obtained from scheduling models already available in the literature. For this reason, only the main features of the scheduling models used in the paper are here described. The formulation of the scheduling models used in the paper is based on the ones presented in [10] for PSHPs with variable speed units and in [11] for PSHPs operating in hydraulic short-circuit mode and for PSHPs with fixed speed units. They have in common that the objective function consists in maximizing the net income in the DM (income from selling energy minus cost for purchasing energy), plus the income from the reserves put at disposal of the transmission system operator (TSO) in the SM, plus the net income from the 
secondary regulation energy due to the real-time use of the committed reserves (income/cost due to the real-time use of the upward/downward reserves), minus the start-up costs in generating and pumping modes. The time horizon of the model is one day, discretised in hourly periods. The optimal solution of the model is composed by the hourly schedules in the DM and in the SM, in addition to the hourly schedule of the net secondary regulation energy. The energy stored in the upper reservoir at the end of the day is forced to be the same as the one stored at the beginning of the day in order to fulfil a daily-cycle. The upper reservoir starts each day empty in order to have the whole storage capacity for pumping water at off-peak hours in the DM.

In [10] and [11], the PSHPs are modelled as a price-taker in both, the DM and the SM. Nevertheless, the assumption that the PSHP is a price-taker in the SM can significantly overestimate the MTI obtained in the SRS. Due to this, in this paper, the models from [10] and [11] are adapted to consider the PSHP as a price-maker only in the SM. The formulation used to model the PSHP as a price-maker is based on the one presented in [15]. The price-maker approach makes the scheduling problem non-linear, because the income in the SM is the result of the marginal price multiplied by the reserve. However, the residual demand curves of the SM (RRCs) are approximated linearly in order to transform the income into a quadratic function. Further details can be seen in [15]. Note that the PSHPs are modelled as a price-taker in the DM because the maximum power of the PSHPs (between 158-422 MW) represents between $0.35-0.92 \%$ of the maximum demand of the Spanish system and between $0.75-2 \%$ of the minimum demand of the system. Besides, the PSHPs are modelled as a price-maker in the SM because their available hourly secondary regulation reserves (between 75-320 MW) represents between $4.5-18.8 \%$ of the hourly requirement of reserves for the entire system (the latter has been always lower or equal $1700 \mathrm{MW}$ ).

\section{B. Electric power system data}

In this paper, the MTI of the PSHPs is obtained for a period of three years in order to obtain representative enough as well as useful results. The selected years are 2013-2015. The electric power system data used in the paper are historical hourly values of the prices of the following markets and services for the mentioned years: i) the DM, ii) the SM, iii) the upward secondary regulation energy and iv) the downward secondary regulation energy, as well as the historical hourly percentages of the real-time use of the committed upward and downward secondary regulation reserves. Note that as the PSHPs are modelled as a price-maker in ii), the data used of the SM is composed by the linear approximation of the historical hourly RRCs: the intercept with the price axis and the slope. Besides, the historical hourly percentages of the real-time use of the reserves of each power plant in Spain is not publicly available. Thus, it is assumed that it is given by the historical hourly ratio of the aggregate use of the reserves and the aggregate committed reserves, in the entire system. The hourly upward and total secondary regulation reserve bids must fulfil an hourly ratio. The hourly ratios are not publicly available in Spain. Hence, it is assumed that the hourly ratios are the result of dividing the hourly aggregate upward reserve requirement and the total hourly aggregate reserve (upward + downward) requirement of the entire system.

\section{Technical data}

The technical data of each PSHP can be seen in Table I. All data, or those necessary to compute them, were provided by General Electric, except the storage capacity of the upper reservoir of each PSHP $(\bar{v})$ and the start-up costs in generating $\left(c S U^{d}\right)$ and pumping mode $\left(c S U^{p}\right)$. The former was obtained assuming that the upper reservoir can be emptied in 6 hours at the maximum water discharge. The latter were obtained following the guidelines of [16]. Note that each PSHP is composed by two identical hydro units, and that the technical data of Table I is for one unit. The twelve considered PSHPs are described as follows:

1) FS-B (fixed-speed binary units): the units are equipped with a Francis pump-turbine without frequency converter.

2) FS-TF (fixed-speed ternary units with Francis turbines): the units are equipped with a Francis turbine and a pump, both without frequency converter.

3) FS-TP (fixed-speed ternary units with Pelton turbines): the units are equipped with a Pelton turbine and a pump, both without frequency converter.

4) VS-FF (variable-speed fully-fed): the units are equipped with a Francis pump-turbine and a synchronous machine connected to the grid through a frequency converter with the same power rating as the synchronous machine.

5) VS-BFF (variable-speed fully-fed with bypass): the frequency converter of the VS-FF is bypassed in generating mode by connecting the stator directly to the grid through a suitable bypass switch. This operation can be found in, for instance, the PSHP of Grimsel II [17].

6) VS-DF (variable-speed doubly-fed): same situation of VS-FF but with an induction machine whose rotor is connected to the grid through a frequency converter with a power rating lower than the one of the induction machine. Due to this, the electrical losses in the frequency converters are lower.

7) SC-B (hydraulic short-circuit with binary units): same situation of FS-B but with the possibility of operating in hydraulic short-circuit mode (one unit in pumping mode and the other in generating mode).

8) SC-TF (hydraulic short-circuit with ternary units with Francis turbines): same situation of FS-TF but with the possibility of operating in hydraulic short-circuit mode.

9) SC-TP (hydraulic short-circuit with ternary units with Pelton turbines): same situation of FS-TP but with the possibility of operating in hydraulic short-circuit mode.

10) SC-FF (hydraulic short-circuit with variable-speed fully-fed): same situation of VS-FF but with the possibility of operating in hydraulic short-circuit mode.

11) SC-BFF (hydraulic short-circuit with variable-speed fully-fed with bypass): same situation of VS-BFF 


\begin{tabular}{|c|c|c|c|c|c|c|c|c|c|c|c|c|}
\hline & FS-B & FS-TF & FS-TP & VS-FF & VS-BFF & VS-DF & SC-B & SC-TF & SC-TP & SC-FF & SC-BFF & SC-DF \\
\hline $\bar{g}^{d}$ & 198.14 & 211.38 & 157.92 & 79.06 & 81.11 & 81.86 & 198.14 & 211.38 & 157.92 & 79.06 & 81.11 & 81.86 \\
\hline $\bar{q}^{d}$ & 72.44 & 73.59 & 54.81 & 40 & 40 & 40 & 72.44 & 73.59 & 54.81 & 40 & 40 & 40 \\
\hline$g^{d}$ & 98.68 & 51.5 & 22.94 & 13.97 & 43.74 & 40.32 & 98.68 & 51.5 & 22.94 & 13.97 & 43.74 & 40.32 \\
\hline$\underline{q}^{d}$ & 38.34 & 20.31 & 8.34 & 8 & 21.17 & 19.55 & 38.34 & 20.31 & 8.34 & 8 & 21.17 & 19.55 \\
\hline $\bar{g}^{p}$ & 196.96 & 196.96 & 196.96 & 88.48 & 88.48 & 87.48 & 196.96 & 196.96 & 196.96 & 88.48 & 88.48 & 87.48 \\
\hline $\bar{q}^{p}$ & 55.34 & 55.34 & 55.34 & 33.04 & 33.04 & 33.04 & 55.34 & 55.34 & 55.34 & 33.04 & 33.04 & 33.04 \\
\hline$\underline{g}^{p}$ & 196.96 & 196.96 & 196.96 & 51.95 & 51.95 & 71.96 & 196.96 & 196.96 & 196.96 & 51.95 & 51.95 & 71.96 \\
\hline$\underline{q}^{p}$ & 55.34 & 55.34 & 55.34 & 18.64 & 18.64 & 27.33 & 55.34 & 55.34 & 55.34 & 18.64 & 18.64 & 27.33 \\
\hline$c S U^{d}$ & 760.57 & 802.99 & 631.62 & 378.82 & 385.4 & 387.8 & 760.57 & 802.99 & 631.62 & 378.82 & 385.4 & 387.8 \\
\hline$c S U^{p}$ & 620.54 & 620.54 & 620.54 & 347.83 & 347.83 & 345.32 & 620.54 & 620.54 & 620.54 & 347.83 & 347.83 & 345.32 \\
\hline$H^{d}$ & 308 & 326 & 326 & 235 & 235 & 235 & 308 & 326 & 326 & 235 & 235 & 235 \\
\hline$H^{p}$ & 334 & 334 & 334 & 240 & 240 & 240 & 334 & 334 & 334 & 240 & 240 & 240 \\
\hline $\bar{v}$ & 3.1293 & 3.179 & 2.3679 & 1.728 & 1.728 & 1.728 & 3.1293 & 3.179 & 2.3679 & 1.728 & 1.728 & 1.728 \\
\hline
\end{tabular}

TECHNICAL DATA OF EACH HYDRO POWER UNIT. $g$ REFERS TO POWER, $q$ REFERS TO FLOW, $c S U$ REFERS TO START-UP COST, $H$ REFERS TO NET HEAD AND $v$ REFERS TO WATER STORAGE CAPACITY IN THE UPPER RESERVOIR. SUPERSCRIPT $d$ REFERS TO GENERATING MODE WHEREAS $p$ REFERS TO PUMPING MODE. FLOWS IN $\mathrm{m}^{3} / \mathrm{s}$, POWER IN $M W$, START-UP COSTS IN $€$, HEAD IN METERS AND VOLUME IN $M m^{3}$.

but with the possibility of operating in hydraulic short-circuit mode.

12) SC-DF (hydraulic short-circuit with variable-speed doubly-fed): same situation of VS-DF but with the possibility of operating in hydraulic short-circuit mode.

Note that the technical data of all the PSHPs with the possibility of operating in hydraulic short-circuit mode are the same as those of the plants without the said possibility.

\section{MAXimum theORETICAL INCOME}

The MTIs per MW of installed capacity in generating mode of each PSHP, in each market and service, in each year analysed (2013-2015) and in total are presented in Table II. It shows the income from selling energy in the DM $\left(D M^{+}\right)$, the cost for purchasing energy in the DM $\left(D M^{-}\right)$, the net income in the DM, i.e. $D M^{+}$minus $D M^{-}$, the income in the SM, the income from the real-time use of the upward reserves (ER2UP), the cost for the real-time use of the downward reserves (ER2DW), the start-up costs in generating mode $\left(c S U^{d}\right)$ and in pumping mode $\left(c S U^{p}\right)$ and the total income (Total). We use the term MTI to refer to the income that the PSHP obtains assuming perfect information of the hourly energy prices, the residual demand curves of the reserve market, the percentage of the committed secondary regulation reserves effectively used in real-time and the secondary regulation regulation energy prices.

The use of variable speed binary units increases the MTI per MW of installed capacity in generating mode between 60-163\%. The comparison is established between PSHPs with binary units and without the hydraulic short-circuit mode, i.e., the FS-B PSHP and the VS-FF, VS-BFF and VS-DF PSHPs. The highest increase in the MTI corresponds to the VS-FF PSHP, followed by the VS-BFF PSHP and finally, the lowest increase occurs with the VS-DF PSHP. The reasons to this ranking are: 1) bypassing the frequency converter yields a higher electrical efficiency in generating mode in the VS-BFF
PSHP but a narrower operating range in comparison to the VS-FF PSHP; the narrower operating range has a stronger negative impact for the participation in the SRS than the positive impact of the higher electrical efficiency in generating mode (the VS-FF PSHP obtains $290.8 \mathrm{k} € / \mathrm{MW}$ from the SM in the period 2013-2015 whereas the VS-BFF PSHP obtains $207.17 \mathrm{k} \in / \mathrm{MW}$ ) and 2) the narrower operating range of the VS-DF PSHP with respect to the VS-FF PSHP in generating mode and with respect to the VS-FF and the VS-BFF PSHPs in pumping mode (the VS-DF PSHP obtains $143.2 \mathrm{k} € / \mathrm{MW}$ from the SM in the period 2013-2015).

The possibility of operating in the hydraulic short-circuit mode increases the MTI per MW of installed capacity in generation mode in all PSHPs, between 2-29.5\%. The comparison is established between the PSHP with and without the hydraulic short-circuit mode (for example, between the FS-B and the SC-B PSHPs or between the VS-DF and the SC-DF PSHPs). The increase is much higher if the PSHPs are equipped with ternary units $(+23.6 \%$ with Francis turbines and $+29.5 \%$ with Pelton turbines) than with binary units $(+2 \%$ with fixed speed and $+2.4 \%$ with variable speed Francis pump-turbines). The reason to this is because of the higher flexibility that the operation in hydraulic short-circuit mode introduces in the PSHPs equipped with ternary units, specially for the participation in the SRS. As the turbine and the pump of a ternary unit operate simultaneously in the hydraulic short-circuit mode, the active power regulation range of the PSHP is pretty larger than the one the PSHP would have should it was equipped with binary units. It is important to bear in mind that the operation in hydraulic short-circuit mode with binary units is performed with one unit in pumping mode and the other in generating mode. This is confirmed by the increase in the income from the SM, that are the highest in comparison to the rest of PSHPs: from 198.2 to $305.3 \mathrm{k} € / \mathrm{MW}$ with Pelton turbines (FS-TP and SC-TP PSHPs, respectively) and from 132.1 to $209.6 \mathrm{k} € / \mathrm{MW}$ with Francis turbines (FS-TF 


\begin{tabular}{|c|c|c|c|c|c|c|c|c|c|c|c|c|c|}
\hline & FS-B & FS-TF & FS-TP & VS-FF & VS-BFF & VS-DF & SC-B & SC-TF & SC-TP & SC-FF & SC-BFF & SC-DF & \multirow{10}{*}{2013} \\
\hline$D M^{+}$ & 110.09 & 120.97 & 131.32 & 119.79 & 137.28 & 136.03 & 113.70 & 160.25 & 176.62 & 141.88 & 138.29 & 142.32 & \\
\hline$D M^{-}$ & -85.91 & -96.98 & -104.73 & -122.99 & -136.07 & -117.47 & -90.70 & -161.88 & -182.76 & -143.35 & -139.72 & -126.28 & \\
\hline $\mathrm{DM}$ & 24.18 & 23.99 & 26.59 & -3.19 & 1.21 & 18.56 & 22.99 & -1.62 & -6.14 & -1.46 & -1.43 & 16.04 & \\
\hline SM & 30.99 & 55.66 & 82.52 & 120.70 & 86.72 & 60.35 & 32.87 & 90.59 & 128.01 & 92.63 & 90.29 & 63.78 & \\
\hline ER2UP & 7.38 & 15.67 & 23.30 & 36.00 & 26.93 & 15.80 & 7.70 & 27.42 & 43.67 & 29.08 & 28.35 & 16.95 & \\
\hline ER2DW & -6.06 & -12.07 & -15.10 & -14.75 & -8.35 & -8.08 & -6.16 & -13.62 & -16.24 & -8.81 & -8.59 & -8.28 & \\
\hline$c S U^{d}$ & -2.66 & -3.05 & -3.55 & -3.58 & -3.48 & -3.55 & -2.60 & -2.74 & -2.26 & -3.04 & -2.96 & -3.29 & \\
\hline$c S U^{p}$ & -1.75 & -2.06 & -3.18 & -3.06 & -2.91 & -2.72 & -1.63 & -1.77 & -2.42 & -2.77 & -2.70 & -2.52 & \\
\hline \multirow[t]{2}{*}{ Total } & 52.08 & 78.13 & 110.57 & 132.12 & 100.13 & 80.37 & 53.17 & 98.26 & 144.61 & 105.63 & 102.96 & 82.66 & \\
\hline & FS-B & FS-TF & FS-TP & VS-FF & VS-BFF & VS-DF & SC-B & SC-TF & SC-TP & SC-FF & SC-BFF & SC-DF & \multirow{10}{*}{2014} \\
\hline$D M^{+}$ & 100.60 & 112.23 & 123.14 & 112.02 & 124.35 & 124.82 & 103.03 & 141.32 & 162.59 & 107.33 & 126.09 & 128.20 & \\
\hline$D M^{-}$ & -79.66 & -88.84 & -96.07 & -111.18 & -121.08 & -106.82 & -82.92 & -136.19 & -159.94 & -108.13 & -124.65 & -111.78 & \\
\hline $\mathrm{DM}$ & 20.95 & 23.39 & 27.07 & 0.84 & 3.27 & 18.01 & 20.11 & 5.12 & 2.65 & -0.80 & 1.43 & 16.43 & \\
\hline SM & 22.90 & 42.23 & 63.24 & 93.27 & 66.78 & 46.13 & 24.35 & 67.17 & 97.53 & 95.52 & 69.36 & 48.14 & \\
\hline ER2UP & 6.47 & 13.25 & 19.47 & 30.67 & 22.98 & 13.41 & 6.67 & 22.34 & 36.03 & 32.09 & 24.02 & 14.22 & \\
\hline ER2DW & -5.72 & -12.69 & -16.34 & -15.90 & -8.35 & -8.18 & -5.77 & -13.99 & -17.72 & -16.11 & -8.70 & -8.38 & \\
\hline$c S U^{d}$ & -2.49 & -2.89 & -3.26 & -3.51 & -3.29 & -3.40 & -2.40 & -2.68 & -2.35 & -3.14 & -2.97 & -3.24 & \\
\hline$c S U^{p}$ & -1.64 & -1.85 & -2.82 & -2.84 & -2.73 & -2.53 & -1.56 & -1.75 & -2.33 & -2.66 & -2.67 & -2.43 & \\
\hline \multirow[t]{2}{*}{ Total } & 40.46 & 61.43 & 87.36 & 102.53 & 78.66 & 63.44 & 41.40 & 76.21 & 113.81 & 104.91 & 80.48 & 64.74 & \\
\hline & FS-B & FS-TF & FS-TP & VS-FF & VS-BFF & VS-DF & SC-B & SC-TF & SC-TP & SC-FF & SC-BFF & SC-DF & \multirow{10}{*}{2015} \\
\hline$D M^{+}$ & 105.63 & 124.50 & 141.29 & 125.96 & 135.74 & 135.15 & 107.43 & 152.28 & 185.87 & 121.31 & 136.75 & 138.35 & \\
\hline$D M^{-}$ & -91.36 & -103.89 & -114.82 & -126.55 & -137.17 & -123.03 & -93.76 & -145.78 & -181.34 & -123.36 & -139.34 & -127.26 & \\
\hline $\mathrm{DM}$ & 14.26 & 20.62 & 26.47 & -0.59 & -1.43 & 12.12 & 13.67 & 6.50 & 4.53 & -2.05 & -2.59 & 11.09 & \\
\hline SM & 16.92 & 34.24 & 52.40 & 76.87 & 53.67 & 36.67 & 17.78 & 51.81 & 79.72 & 79.11 & 55.67 & 38.17 & \\
\hline ER2UP & 4.73 & 10.49 & 16.30 & 26.35 & 20.00 & 11.42 & 4.90 & 17.46 & 30.23 & 27.59 & 20.63 & 11.89 & \\
\hline ER2DW & -7.46 & -17.22 & -22.94 & -22.06 & -11.37 & -10.93 & -7.55 & -19.18 & -25.44 & -22.52 & -11.82 & -11.13 & \\
\hline$c S U^{d}$ & -2.13 & -2.68 & -3.02 & -3.41 & -3.15 & -3.08 & -2.15 & -2.73 & -2.48 & -3.22 & -3.00 & -3.05 & \\
\hline$c S U^{p}$ & -1.42 & -1.63 & -2.52 & -2.61 & -2.55 & -2.30 & -1.42 & -1.70 & -2.26 & -2.48 & -2.63 & -2.28 & \\
\hline \multirow[t]{2}{*}{ Total } & 24.89 & 43.81 & 66.70 & 74.55 & 55.18 & 43.90 & 25.21 & 52.16 & 84.29 & 76.43 & 56.26 & 44.69 & \\
\hline & FS-B & FS-TF & FS-TP & VS-FF & VS-BFF & VS-DF & SC-B & SC-TF & SC-TP & SC-FF & SC-BFF & SC-DF & \multirow{10}{*}{ Total } \\
\hline$D M^{+}$ & 316.32 & 357.71 & 395.75 & 357.78 & 397.36 & 396.00 & 324.16 & 453.85 & 525.09 & 341.11 & 401.13 & 408.86 & \\
\hline$D M^{-}$ & -256.93 & -289.72 & -315.62 & -360.72 & -394.32 & -347.31 & -267.38 & -443.85 & -524.04 & -348.60 & -403.71 & -365.31 & \\
\hline DM & 59.39 & 67.99 & 80.13 & -2.94 & 3.05 & 48.69 & 56.77 & 10.00 & 1.04 & -7.49 & -2.58 & 43.55 & \\
\hline SM & 70.81 & 132.12 & 198.15 & 290.84 & 207.17 & 143.15 & 75.00 & 209.57 & 305.26 & 297.91 & 215.32 & 150.08 & \\
\hline ER2UP & 18.58 & 39.41 & 59.07 & 93.01 & 69.92 & 40.63 & 19.26 & 67.21 & 109.93 & 97.14 & 73.00 & 43.07 & \\
\hline ER2DW & -19.24 & -41.99 & -54.39 & -52.71 & -28.07 & -27.19 & -19.49 & -46.78 & -59.41 & -53.43 & -29.11 & -27.79 & \\
\hline$c S U^{d}$ & -7.29 & -8.62 & -9.83 & -10.50 & -9.92 & -10.02 & -7.15 & -8.15 & -7.09 & -9.53 & -8.94 & -9.58 & \\
\hline$c S U^{p}$ & -4.82 & -5.54 & -8.52 & -8.51 & -8.18 & -7.55 & -4.62 & -5.21 & -7.01 & -7.85 & -7.99 & -7.24 & \\
\hline Total & 117.43 & 183.38 & 264.62 & 309.20 & 233.96 & 187.71 & 119.78 & 226.64 & 342.72 & 316.75 & 239.70 & 192.09 & \\
\hline
\end{tabular}

TABLE II

MAXIMUM THEORETICAL INCOME PER MW OF INSTALLED CAPACITY IN GENERATING MODE, IN K€/MW, OF EACH PSHP, IN EACH MARKET AND SERVICE CONSIDERED, IN EACH YEAR AND IN TOTAL.

and SC-TF PSHPs, respectively). In addition to this, the former obtain higher total MTI per MW (264.6 and $342.7 \mathrm{k} € / \mathrm{MW}$ in the FS-TP and SC-TP PSHPs, respectively) than the latter (183.4 and $226.6 \mathrm{k} € / \mathrm{MW}$ in the FS-TF and SC-TF PSHPs, respectively). The reason to this is because the Pelton turbine has a wider operating range than the Francis turbine (see Table I) and, thus, it can enlarge significantly the income from the SM.

As can be seen in Table II, the main income source is the SM in all PSHPs and in all years. This result confirms one of the conclusions of [10], in which the PSHPs are modelled as a price-taker in the SM, and one of the conclusions of [15], in which they are modelled as a price-maker in the SM. If the income from the SM is canalised between years, it decreases with time. The reason to this is the decreasing mean yearly price in the Spanish SM (29.33 €/MW in $2013,23.13 € / M W$ in 2014 and $19.52 € / \mathrm{MW}$ in 2015).

The methodology used to obtain the MTI assumes that the upper reservoir starts and finishes each day with the same amount of stored water (with the upper reservoir emptied). The MTIs have been also obtained starting and finishing each day with half of the storage capacity. The reason to propose this is because on the one hand, starting the day empty may not be optimum because the PSHPs do not have enough water to participate in the SRS in generating mode in the first hours of the day and, on the other hand, starting the day with the upper reservoir full may not be optimum because the PSHPs do not have enough available storage capacity to pump water during the first hours of the day. However, the MTIs with half of the storage capacity are not presented because they are lower than the ones here presented in all cases.

The MTI per MW of installed capacity in generating mode 


\begin{tabular}{|c|c|c|c|c|c|c|c|c|c|c|c|}
\hline FS-B & FS-TF & FS-TP & VS-FF & VS-BFF & VS-DF & SC-B & SC-TF & SC-TP & SC-FF & SC-BFF & SC-DF \\
\hline \hline 0.5 & 0.66 & 0.66 & 0.58 & 0.58 & 0.54 & 0.52 & 0.68 & 0.68 & 0.59 & 0.59 & 0.55 \\
\hline 1 & 1.32 & 1.32 & 1.15 & 1.15 & 1.07 & 1.03 & 1.35 & 1.35 & 1.18 & 1.18 & 1.1 \\
\hline 1.5 & 1.98 & 1.98 & 1.73 & 1.73 & 1.61 & 1.55 & 2.03 & 2.03 & 1.77 & 1.77 & 1.65 \\
\hline 2 & 2.64 & 2.64 & 2.3 & 2.3 & 2.14 & 2.06 & 2.7 & 2.7 & 2.36 & 2.36 & 2.2 \\
\hline 2.5 & 3.3 & 3.3 & 2.88 & 2.88 & 2.68 & 2.58 & 3.38 & 3.38 & 2.95 & 2.95 & 2.75 \\
\hline 3 & 3.96 & 3.96 & 3.45 & 3.45 & 3.21 & 3.09 & 4.05 & 4.05 & 3.54 & 3.54 & 3.3 \\
\hline 3.5 & 4.62 & 4.62 & 4.03 & 4.03 & 3.75 & 3.61 & 4.73 & 4.73 & 4.13 & 4.13 & 3.85 \\
\hline 4 & 5.28 & 5.28 & 4.6 & 4.6 & 4.28 & 4.12 & 5.4 & 5.4 & 4.72 & 4.72 & 4.4 \\
\hline
\end{tabular}

INVESTMENT COST OF EACH PSHP, IN M€/MW, ACCORDING TO THE INFORMATION AVAILABLE IN THE TECHNICAL LITERATURE (0.5-4 M€/MW FOR THE FS-B PSHP).

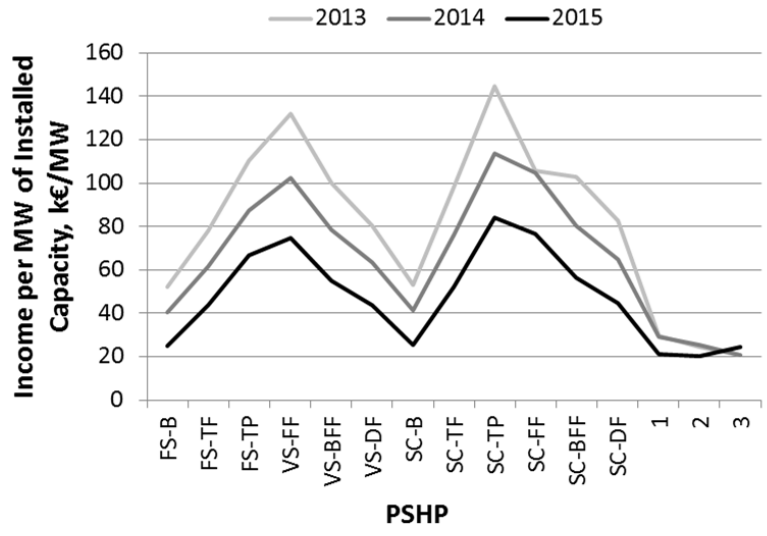

Figure 1. Income per MW of installed capacity in generating mode, in $\mathrm{k} € / \mathrm{MW}$, of the twelve PSHPs analysed in the paper and three closed-loop and daily-cycle PSHPs that are currently operating in the Iberian system

in each year of the period 2013-2015 obtained with the proposed PSHPs (FS-B to SC-DF PSHPs) are compared to the ones obtained by three real closed-loop and daily-cycle PSHPs that are currently operating in the Iberian electricity system (PSHPs 1-3), Fig. 1. Although the economic results are publicly available in the information system of the Spanish TSO, the authors prefer not to reveal their names. The income of the real PSHPs comes from the ones obtained in the DM, the intraday markets, the congestion management markets of the DM, the secondary and the tertiary regulation services, the real-time congestion management market and, finally, the balancing market.

The MTIs per MW of installed capacity of the FS-B, FS-TF and FS-TP PSHPs are higher than the real income obtained by the PSHPs 1-3 in all cases and in all years, with the optimization models described in Section II-A. Note that the PSHPs 1-3 are equipped with fixed-speed units and do not operate in the hydraulic short-circuit mode as the FS-B, FS-TF and FS-TP PSHPs. However, two considerations should be included: 1) the real income of PSHPs 1-3 was obtained with imperfect knowledge of the electric power system data and 2) the FS-B, FS-TF and FS-TP PSHPs only participate in the DM and the SRS while the PSHPs 1-3 participate in more markets and services. If we compare the MTIs per MW of the rest of PSHPs (with variable speed units and/or the possibility of operating in hydraulic short-circuit mode), it can be seen that they are much higher than the real income obtained by the PSHPs 1-3 (except the SC-B PSHP).

\section{INVESTMENT COSTS}

Investment costs of PSHPs are strongly site-dependent. In the technical literature, to the best of our knowledge, there are no papers where the investment costs of conventional PSHPs with ternary units are analysed. However, several papers can be found regarding investment costs of PSHPs equipped with fixed speed binary units (FS-B PSHP). As examples, [6] proposes a range between 0.47-2.17 $\mathrm{M} € / \mathrm{MW}$ from projects in countries such as Spain, Portugal or Switzerland, among others. [18] proposes a range between 0.775-1.28 $\mathrm{M} € / \mathrm{MW}$ from projects in Germany and Luxembourg. Or [19], which proposes a range between 2-4.3 $\mathrm{M} \$ / \mathrm{MW}$. Note that the latter is expressed in \$. In all projects, the investment cost depends, among others, on whether or not the PSHP uses existing reservoirs, whether the project is new or upgraded by enlarging the existing reservoirs or increasing the installed capacity [20].

In order to cover all the possible projects, several investment costs per MW of installed capacity in generating mode have been considered for the FS-B PSHP, according to the information available in the literature. The considered range is between 0.5-4 M€/MW, discretised in 0.5 M€/MW.

Hydro industry experts estimate an increase between $30-40 \%$ of the investment costs when the plant is equipped with ternary units and between $7-15 \%$ when the plant is equipped with variable speed units [21], with respect to FS-B PSHPs. In this paper, extra costs of $32 \%, 7 \%$ and $15 \%$ are considered for the FS-TF and FS-TP PSHPs with respect to the FS-B PSHP, for the VS-FF and VS-BFF PSHP with respect to the FS-B PSHP, and for the VS-DF PSHP with respect to the FS-B PSHP, respectively. The reason to consider an extra cost of 32\% for the FS-TF and FS-TP PSHPs is arbitrarily but respecting the range proposed in the literature. The reason to consider an extra cost of $7 \%$ for the VS-DF PSHP and of $15 \%$ for the VS-FF PSHP (and the VS-BFF PSHP), is that the power rating of the converter in the former is usually $20-30 \%$ of the one of the induction machine [22], whereas in the latter the power rating of the converter is the same as the one of the synchronous machine.

There is an absolute lack of information about the extra cost that would imply to allow the PSHP to operate in hydraulic short-circuit mode. This extra investment cost is due to both 1) the reinforcement of the pipes in the short-circuit link and 2) the more complex design of the said pipe section in order to, 


\begin{tabular}{|c|c|c|c|c|c|c|c|c|c|c|c|c|}
\hline Cost FS-B & FS-B & FS-TF & FS-TP & VS-FF & VS-BFF & VS-DF & SC-B & SC-TF & SC-TP & SC-FF & SC-BFF & SC-DF \\
\hline \hline 0.5 & 12.8 & 10.8 & 7.5 & 5.6 & 7.4 & 8.6 & 12.9 & 8.9 & 5.9 & 5.6 & 7.4 & 8.6 \\
\hline 1 & 25.5 & 21.6 & 15.1 & 11.2 & 14.7 & 17.1 & 25.8 & 17.9 & 11.8 & 11.2 & 14.8 & 17.2 \\
\hline 1.5 & 38.3 & 32.4 & 22.4 & 16.7 & 22.1 & 25.7 & 38.7 & 26.8 & 17.7 & 16.8 & 22.2 & 25.8 \\
\hline 2 & 51.1 & 43.2 & 29.9 & 22.3 & 29.5 & 34.2 & 51.6 & 35.7 & 23.6 & 22.4 & 29.5 & 34.4 \\
\hline 2.5 & 63.9 & 54.1 & 37.4 & 27.9 & 36.9 & 42.8 & 64.5 & 44.7 & 29.5 & 27.9 & 36.9 & 42.9 \\
\hline 3 & 76.6 & 64.8 & 44.9 & 33.5 & 44.2 & 51.3 & 77.4 & 53.6 & 35.5 & 33.5 & 44.3 & 51.5 \\
\hline 3.5 & 89.4 & 75.6 & 52.4 & 39.1 & 51.6 & 59.9 & 90.3 & 62.5 & 41.4 & 39.1 & 51.7 & 60.1 \\
\hline 4 & 102.2 & 86.4 & 59.9 & 44.6 & 59.1 & 68.4 & 103.2 & 71.5 & 47.3 & 44.7 & 59.1 & 68.7 \\
\hline
\end{tabular}

MINIMUM THEORETICAL PAY-BACK PERIOD, IN YEARS, WITH THE CONSIDERED INVESTMENT COSTS (0.5-4 M€/MW OF THE FS-B PSHP).

respectively, resist pressure oscillations of a higher amplitude [23] and to reduce the hydraulic losses. In this paper, we assume that the extra investment cost related to permit a PSHP to operate in the hydraulic short-circuit mode is $3 \%$. Therefore, the investment costs of the SC-B PSHP increase 3\% with respect the FS-B PSHP, and of the SC-TF and SC-TP PSHPs increases 35\% with respect the FS-B PSHP, i.e., an increase of $32 \%$ because of the ternary units and of $3 \%$ because of the hydraulic short-circuit operation. Finally, the investment costs of the SC-FF, SC-BFF and SC-DF PSHPs increase 18\%, 18\% and $10 \%$, respectively, with respect to the FS-B PSHP because of the use of variable speed units $(15 \%, 15 \%$ and $7 \%)$ and the hydraulic short-circuit operation (3\%).

The investment cost, expressed in M€/MW, of each PSHP considering the proposed cost range for the FS-B PSHP (0.5-4 $\mathrm{M} € / \mathrm{MW}$ ) and the above-mentioned hypothesis are shown in Table III.

\section{ECONOMIC VIABILITY}

The economic viability is analysed using the MTPB, i.e. the minimum number of years that the investment costs are expected to be recovered according to the MTI of the PSHPs. The calculation of the MTPB assumes that the interest rate and the expected increase of the MTI due to an increase in the demand or the energy or reserve prices will be $0 \%$ in the whole pay-back period. Table IV shows the estimated MTPBs corresponding to the MTIs included in Table II and the investment costs included in Table III. They are coloured with the following assumptions: green cells consider a MTPB lower or equal 25 years and that the investment in the PSHP is interesting, yellow cells consider a MTPB greater than 25 years and lower or equal 35 years and that the investment in the PSHP is partially interesting, and red cells consider a MTPB greater than 35 years and that the investment in the PSHP is not interesting. The colours are chosen arbitrarily taking into account the lifetime of the PSHP between 60 years (see for example [1] or [2]) and 100 years [24].

According to the investment costs proposed in the literature, the lowest MTPBs correspond to the VS-FF, SC-FF and SC-TP PSHPs, respectively, in all the investment cost cases. Assuming the above-mentioned lifetime of the PSHPs between 60-100 years, even the fixed-speed PSHPs with ternary units and without the possibility of operating in hydraulic short-circuit mode (FS-TF and FS-TP PSHPs), can be economically viable as long as their investment costs are lower than $2.64 \mathrm{M} € / \mathrm{MW}$. This proves that the operation of the PSHPs in the DM and the SRS improves significantly the economic viability of PSHPs in comparison to the results if the PSHPs only participates in the DM (see for example [6]).

The use of fully-fed variable speed binary units (VS-FF PSHP) helps to decrease the MTPBs in all the FS PSHPs and in all the investment cost cases: by $56.3 \%$ with respect to the FS-B PSHP, by $48.3 \%$ with respect to the FS-TF PSHP and by $25.4 \%$ with respect to the FS-TP PSHP. Note that the increase or decrease of the MTPB between two PSHPs are the same in each investment cost case because the MTIs do not change. However, the MTPB of the PSHP equipped with fully-fed variable speed binary units increases by $32.2 \%$ if the converter is bypassed in generating mode (VS-BFF PSHP). The reason to this was mentioned in Section III: bypassing the frequency converter yields a higher electrical efficiency in generating mode in the VS-BFF PSHP but a narrower operating range in comparison to the VS-FF PSHP; the narrower operating range has a stronger negative impact for the participation in the SRS than the positive impact of the higher electrical efficiency in generating mode. The use of doubly-fed variable speed binary units (VS-DF PSHP) decreases the MTPBs with respect to the FS-B PSHP (by 33.1\%) and with respect to the FS-TF PSHP (by $20.8 \%$ ), but to a lower extent than the VS-FF PSHP, and increases the MTPB with respect to the VS-BFF PSHP (by $16 \%)$. The reason to this was also mentioned in Section III: the VS-DF PSHP has a narrower operating range in generating mode with respect to the VS-FF PSHP and in pumping mode with respect to the VS-FF and the VS-BFF PSHPs.

The possibility of operating in hydraulic short-circuit mode decreases in general the MTPBs of all PSHPs without the variable speed technology. However, the decrease strongly depends on the configuration of the PSHP. If the PSHP is equipped with ternary units and Francis turbines (FS-TF and SC-TF PSHPs), the MTPB is reduced by $17.2 \%$. If the PSHP is equipped with ternary units and Pelton turbines (FS-TP and SC-TP PSHPs), the MTPB is reduced by $21 \%$. Finally, if the PSHP is equipped with fixed speed or variable speed binary units (FS-B, VS-FF, VS-BFF, VS-DF, SC-B, SC-FF, SC-BFF and SC-DF PSHPs), the possibility of operating in hydraulic short-circuit mode does not appreciably modify the MTPB. As it was explained in section III, the flexibility introduced by the hydraulic short-circuit operation is higher for the PSHPs with ternary units since both the turbine and the pump can operate simultaneously. The hydraulic short-circuit operation 
with binary units is performed by using one unit in pumping mode and the other in generating mode, and does not therefore add an appreciable flexibility to be offered in the SRS.

Despite the foregoing, further research must be carried out because, in this paper, perfect information is assumed in all uncertain data. Although the interest of the results from this paper is unquestionable, specially because it is the first paper in the literature shedding light about the profitability of PSHPs with variable speed units or operating in hydraulic short-circuit mode, the incomes are expected to be reduced whereas the pay-back periods are expected to be enlarged because of the effects of imperfect information. To give an idea, the value of perfect information of the price in the DM can be around 25\% of the MTI according to the results presented in [15].

\section{Vi. Conclusions}

The economic viability of twelve closed-loop and daily-cycle PSHPs equipped with binary or ternary units, with and without the variable speed technology and with and without considering the operation in hydraulic short-circuit mode has been evaluated in this paper. The PSHPs are assumed to participate in the day-ahead energy market as a price-taker and in the day-ahead secondary regulation reserve market as a price-maker. In addition, the net income from the real-time use of the committed reserves has been also taken into account within the model formulation. The economic viability has been studied by means of the minimum theoretical pay-back periods, which have been estimated considering different investment costs values per MW of the installed capacity according to the technical literature.

Results show that the minimum theoretical pay-back periods of the PSHPs are in most cases lower than their lifetime, if the investment cost of the base case (the PSHP with binary units and fixed speed) is lower than $2.5 \mathrm{M} € / \mathrm{MW}$. Therefore, the economic viability is not discarded. The PSHPs with the variable speed technology and full converter with and without the possibility to operate in hydraulic short-circuit mode, and the PSHP with ternary units and being operated in hydraulic short-circuit mode obtain the lowest minimum theoretical pay-back periods. Furthermore, the inclusion of the variable speed technology or the operation in hydraulic short-circuit mode decrease significantly the minimum theoretical pay-back periods of PSHPs. In addition to this, it has been proven that the maximum theoretical income, obtained with the developed optimization model, of the proposed PSHPs are notably higher in comparison to the real income obtained by PSHPs that are currently operating in the Iberian system. Nonetheless, all these results have been obtained assuming perfect information of all the uncertain data in the day-ahead energy and reserve scheduling. Further work is necessary to estimate the economic viability of the PSHPs taking into account uncertainty. In addition, the consideration of other markets such as the intraday markets or other ancillary services such as the tertiary regulation service, would be also necessary to provide a more complete and realistic insight on the economic viability of the PSHPs.

\section{REFERENCES}

[1] A. Evans, V. Strezov, and T. Evans, "Assessment of utility energy storage options for increased renewable energy penetration," Renewable and Sustainable Energy Reviews, vol. 16, no. 6, pp. 4141-4147, 2012.

[2] N. S. Pearre and L. G. Swan, "Technoeconomic feasibility of grid storage: Mapping electrical services and energy storage technologies," Applied Energy, vol. 137, pp. 501-510, 2015.

[3] B. C. Ummels, E. Pelgrum, and W. L. Kling, "Integration of large-scale wind power and use of energy storage in the Netherlands' electricity supply," IET Renewable Power Generation, vol. 2, no. 1, pp. 34-46, 2008.

[4] A. Tuohy and M. O'Malley, "Pumped storage in systems with very high wind penetration," Energy Policy, vol. 39, no. 4, pp. 1965-1974, 2011.

[5] H. S. de Boer, L. Grond, H. Moll, and R. Benders, "The application of power-to-gas, pumped hydro storage and compressed air energy storage in an electricity system at different wind power penetration levels," Energy, vol. 72, pp. 360-370, 2014.

[6] D. Connolly, H. Lund, P. Finn, B. Mathiesen, and M. Leahy, "Practical operation strategies for pumped hydroelectric energy storage (PHES) utilising electricity price arbitrage," Energy Policy, vol. 39, no. 7, pp. 4189-4196, 2011.

[7] K. Bradbury, L. Pratson, and D. Patiño-Echeverri, "Economic viability of energy storage systems based on price arbitrage potential in real-time U.S. electricity markets," Applied Energy, vol. 114, pp. 512-519, 2014.

[8] C. K. Ekman and S. H. Jensen, "Prospects for large scale electricity storage in Denmark," Energy Conversion and Management, vol. 51, no. 6, pp. 1140-1147, 2010.

[9] J. I. Pérez-Díaz, M. Chazarra, J. García-González, G. Cavazzini, and A. Stoppato, "Trends and challenges in the operation of pumped-storage hydropower plants," Renewable and Sustainable Energy Reviews, vol. 44, pp. 767-784, 2015.

[10] M. Chazarra, J. Pérez-Díaz, and J. García-González, "Optimal Operation of Variable Speed Pumped Storage Hydropower Plants Participating in Secondary Regulation Reserve Markets," in European Energy Market (EEM), 2014.

[11] M. Chazarra, J. I. Pérez-Díaz, and J. García-González, "Optimal Energy and Reserve Scheduling of Pumped-Storage Power Plants Considering Hydraulic Short-Circuit Operation," IEEE Transactions on Power Systems, vol. 32, no. 1, pp. 344-353, 2017.

[12] J. I. Pérez-Díaz, G. Cavazzini, F. Blázquez, C. Platero, J. Fraile-Ardanuy, J. A. Sánchez, and M. Chazarra, "Technological Developments for Pumped-Hydro Energy Storage," in Mechanical Storage Subprogramme, Joint Programme on Energy Storage, European Energy Research Alliance, 2014.

[13] E. Lobato, I. Egido, L. Rouco, and G. López, "An overview of ancillary services in Spain," Electric Power Systems Research, vol. 78, no. 3, pp. 515-523, 2008.

[14] ENTSO-E Working Group on Ancillary Services, "Survey on Ancillary services procurement, Balancing market design 2014," Tech. Rep. January, 2015. [Online]. Available: https://www.entsoe.eu/Documents/Publications/MarketCommitteepublica

[15] M. Chazarra, J. I. Pérez-Díaz, and J. García-González, "Value of Perfect Information of Spot Prices in the Joint Energy and Reserve Hourly Scheduling of Pumped Storage Plants," in European Energy Market (EEM), 2016.

[16] O. Nilsson and D. Sjelvgren, "Hydro Unit Start-up Costs and Their Impact on the Short Term Scheduling Strategies of Swedish Power Producers," IEEE Transactions on Power Systems, vol. 12, no. 1, pp. 38-44, 1997.

[17] H. Schlunegger and A. Thöni, "100 MW full-size converter in the Grimsel 2 pumped-storage plant," in HYDRO, 2013.

[18] B. Steffen, "Prospects for pumped-hydro storage in Germany," Energy Policy, vol. 45, pp. 420-429, 2012.

[19] E. Barbour, I. Wilson, J. Radcliffe, Y. Ding, and Y. Li, "A review of pumped hydro energy storage development in significant international electricity markets," Renewable and Sustainable Energy Reviews, vol. 61, pp. 421-432, 2016.

[20] J. Deane, B. Ó-Gallachóir, and E. McKeogh, "Techno-economic review of existing and new pumped hydro energy storage plant," Renewable and Sustainable Energy Reviews, vol. 14, no. 4, pp. 1293-1302, 2010.

[21] A. Botterud, T. Levin, and V. Koratirov, "Pumped Storage Hydropower: Benefits for Grid Reliability and Integration of Variable Renewable Energy," Tech. Rep., 2014.

[22] T. Kunz, "Business Cases WP4," in eStorage Annual Workshop, 2015. 
[23] J. I. Pérez-Díaz, J. I. Sarasúa, and J. R. Wilhelmi, "Contribution of a hydraulic short-circuit pumped-storage power plant to the load-frequency regulation of an isolated power system," Electrical Power and Energy Systems, vol. 62, pp. 199-211, 2014.

[24] G. Ardizzon, G. Cavazzini, and G. Pavesi, "A new generation of small hydro and pumped-hydro power plants: Advances and future challenges," Renewable and Sustainable Energy Reviews, vol. 31, pp. 746-761, 2014. 


\subsection{Paper-D: Value of Perfect Information of Spot Prices in the Joint Energy and Reserve Hourly Scheduling of Pumped Storage Plants}

The preliminary version of this paper was published in [Chazarra et al., 2016b], and orally presented in an International Conference. In this paper entitled "Value of Perfect Information of Spot Prices in the Joint Energy and Reserve Hourly Scheduling of Pumped Storage Plants" [Chazarra et al., 2017f], it is studied the value of perfect information of the day-ahead energy market prices in the context of the operation of a closed-loop and daily-cycle PSHP participating in the day-ahead energy market and in the secondary regulation service of the Iberian and the Spanish electricity systems, respectively. In order to study the mentioned value of perfect information, a day-ahead energy and reserve scheduling model is proposed. The model is based on the ones previously developed in the Thesis in [Chazarra et al., 2017d] and [Chazarra et al., 2017e], and are adapted to model the PSHP as a price-maker in the secondary regulation reserve market. Therefore, the model presented in this paper changes with respect to the previous ones, being based on mixed integer quadratic programming. Note that the PSHP is equipped with fixed-speed pump-turbine units in this paper, and that the model assumes perfect information in all the electric power system data of the problem except in the day-ahead energy market prices. The main contribution of this paper with respect to the literature is to study the extent to which the value of perfect information of the day-ahead energy market prices when the PSHP participates in both the the day-ahead energy market and in the secondary regulation service can be reduced in comparison to only participate in the day-ahead energy market.

This publication is linked to the objectives of the Thesis (Figure 1.8) as follows: the model formulation includes the price-maker approach in the operation of PSHPs in the secondary regulation reserve market for the first time in the Thesis. Therefore, this paper applies for all the objectives of the Thesis as the price-maker approach is used not only in the model formulation of the main objective of the Thesis but also in the first three secondary objectives of the Thesis. Furthermore, it is also used as a tool to develop the main goal of the Thesis (the risk-averse optimisation model with look ahead period, Chapter 3) because the day-ahead energy market prices are predicted with the forecasting model that obtains the lowest value of perfect information. Finally, this paper directly applies for a part of the first secondary objective of the Thesis (to analyse the value of perfect information of the electric power system data). 


\title{
Value of perfect information of spot prices in the joint energy and reserve hourly scheduling of pumped storage plants
}

\author{
Manuel Chazarra ${ }^{a, *}$, Juan I. Pérez-Díaz ${ }^{\text {a }}$ Javier García-González ${ }^{\text {b }}$ \\ a Department of Hydraulic, Energy and Environmental Engineering, Escuela de Ingenieros de Caminos, Canales y Puertos, Technical University of Madrid, \\ 28040, Spain \\ ${ }^{\mathrm{b}}$ Institute for Research in Technology, ICAI School of Engineering, Comillas Pontifical University, 28015 Madrid, Spain
}

\section{A R T I C L E I N F O}

\section{Article history:}

Received 8 July 2016

Received in revised form 13 January 2017

Accepted 18 March 2017

\section{Keywords:}

Pumped-storage plant

Secondary regulation service

Price forecasting

Value of perfect information

\begin{abstract}
A B S T R A C T
The value of perfect information of the day-ahead energy prices is studied in the context of the operation of a closed-loop and daily-cycle pumped-storage hydropower plant, participating in the spot market as a price-taker and in the secondary regulation reserve market as a price-maker. The impact of the real-time use of the regulation reserves is also taken into account. Results show that the value of perfect information of the spot prices in the Iberian electricity market decreases if the plant also participates in the secondary regulation service. Several novel indicators to better explain the value of perfect information are presented and evaluated. Finally, several regression models to roughly estimate the value of perfect information of any price forecasting model are obtained. These might help to evaluate the investment in pumped-storage hydropower plants.
\end{abstract}

(c) 2017 Elsevier B.V. All rights reserved.

\section{Introduction}

Competition has been introduced in many electricity power systems worldwide in order to, among others, improve the economic efficiency. An agent that participates in liberalised electricity markets must deal with several sources of uncertainty before submitting the bids, for instance the uncertainty of the spot and reserve prices which are not known in advance. The value of perfect information of the spot prices (VPI, also called profit loss due to the uncertainty) depends on the quality of the forecasting tool that is used to forecast the prices but also depends on the technology of the power producer [1].

In this paper, the VPI is studied in the context of a PSHP that participates not only in the spot market, but also in the secondary regulation service, with the aim of enlarging the expected income and reducing the payback period of the investment. In order to analyse the VPI, a day-ahead energy and reserve scheduling model is proposed. The model is based on mixed integer quadratic programming. The objective function of the model consists in maximizing the income of a PSHP participating in the spot market as a price-taker and in the secondary regulation reserve market as a price-maker, in the framework of the Iberian electric power

\footnotetext{
* Corresponding author.

E-mail address: manuel.chazarra@upm.es (M. Chazarra).
}

system (MIBEL [2,3]). The upward and downward secondary regulation energy due to the real-time use of the committed reserves is also considered in the model formulation. In the Spanish electric power system, there is a single day-ahead reserve market where the available upward and downward secondary regulation reserves are determined and remunerated by the same marginal price. In addition, the upward and downward secondary regulation energy is also remunerated ${ }^{1}$ according to the marginal price of the upward and downward tertiary regulation energy prices, respectively. In order to participate in the secondary regulation service, the PSHP has to participate in the spot market previously. Note that the procedure for the procurement of secondary regulation is not exclusive of the Spanish system. For instance, a similar procedure is implemented in Norway, Sweden, Finland, Slovenia, Czech Republic and Romania in the short-term (less than a week) and in Denmark, Netherlands, Belgium, Germany, Austria and Switzerland in the long-term (more than a week) [4].

The proposed model is based on the one proposed in [5], which has been revised in order to consider the PSHP as a price-maker in the secondary regulation reserve market. The PSHP under study is closed-loop and daily-cycle, as in [5], and is equipped with a single reversible Francis pump-turbine unit. In order to obtain representative enough as well as useful results, the VPI is calculated running

\footnotetext{
1 The upward (resp. downward) secondary regulation energy represents an income (resp. cost).
} 


\section{Nomenclature \\ Superscripts \\ $d \quad$ indicates that the magnitude is related to genera- tion/discharge \\ $p \quad$ indicates that the magnitude is related to consump- tion/pumping \\ sec indicates that the magnitude is related to the sec- ondary regulation service (reserve or energy)}

Sets

$t \quad$ hourly period, running from 1 to $T$

\section{Parameters}

$c S U^{d} \quad$ start-up cost in generating mode, $€$

$c S U^{p} \quad$ start-up cost in pumping mode, $€$

$\delta^{d} \quad$ energy coefficient in generating mode, $\mathrm{MW} / \mathrm{Mm}^{3} / \mathrm{h}$

fv target water volume in the last hour of the time

horizon (in this study, the last hour of the day), $\mathrm{Mm}^{3}$

$\bar{g}^{d}, g^{d} \quad$ maximum and minimum technical power generation, MW

$\bar{g}^{p} \quad$ maximum technical power consumption (there is no minimum power consumption as this study considers a pump-turbine unit with fixed speed in pumping mode), MW

$l_{t} \quad$ time length of period $t, 1 \mathrm{~h}$

$\lambda_{D, t} \quad$ day-ahead electricity market price, $€ / \mathrm{MWh}$

$\lambda_{S, t}^{0}$ the intercept of the linear approximation of a residual demand curve of the secondary regulation reserve market, i.e. the secondary regulation reserve price when the residual reserve quantity of the system is zero, $€ / \mathrm{MW}$

$\lambda_{S, t}^{m} \quad$ the slope of the linear approximation of a residual demand curve of the secondary regulation reserve market, $€ / \mathrm{MW} / \mathrm{MW}$

$\lambda_{\text {up,t }} \quad$ upward secondary regulation energy price, $€ / \mathrm{MWh}$

$\lambda_{d w, t}$ downward secondary regulation energy price, $€ / \mathrm{MWh}$

$N \quad$ a big number, $10^{6}$

$\bar{\eta}^{d}, \underline{\eta}^{d} \quad$ efficiency in generating mode at maximum and minimum water discharge, \%

$\eta^{p} \quad$ efficiency in pumping mode (only at maximum pumped water as this study considers a pumpturbine unit with fixed speed in the said mode), \%

$\bar{q}^{d}, \underline{q}^{d} \quad$ maximum and minimum technical water discharge, $\mathrm{Mm}^{3} / \mathrm{h}$

$\bar{q}^{p} \quad$ maximum technical pumped water (there is no minimum pumped water as this study considers a pump-turbine unit with fixed speed in pumping mode), $\mathrm{Mm}^{3} / \mathrm{h}$

$\rho_{t}^{u p}, \rho_{t}^{d w}$ percentage of the offered upward and downward secondary regulation reserves that will be used by the TSO

$R_{t}^{S M} \quad$ ratio between the required upward and the total secondary regulation reserve, set by the TSO in advance

$\bar{v}, \underline{v} \quad$ maximum and minimum water storage limits of the upper reservoir due to design characteristics, $\mathrm{Mm}^{3}$

Positive variables

$g_{t}^{d}, g_{t}^{p} \quad$ power generation and consumption, MW

$q_{t}^{d} \quad$ total water discharge, which includes water for the real-time use of reserves, $\mathrm{Mm}^{3} / \mathrm{h}$ $q_{t}^{p} \quad$ pumped water, which does not include water for the real-time use of reserves as this study considers a pump-turbine unit with fixed speed in pumping mode, $\mathrm{Mm}^{3} / \mathrm{h}$

$q s_{t}^{d} \quad$ water discharge above the minimum technical limit, $\mathrm{Mm}^{3} / \mathrm{h}$

$g_{t}^{\text {sec, up }} \quad$ upward secondary regulation reserve, MW

$g_{t}^{\text {sec, } d w}$ downward secondary regulation reserve, MW

$\lambda_{S, t} \quad$ clearing price in the secondary regulation reserve market, dependent on the price-maker agent activity, $€ / \mathrm{MW}$

$e_{t}^{\mathrm{sec}, u p} \quad$ upward secondary regulation reserve requested in real-time by the TSO, MWh

$e_{t}^{\mathrm{sec}, d w}$ downward secondary regulation reserve requested in real-time by the TSO, MWh

$v_{t} \quad$ water volume of the upper reservoir at the end of time period $t, \mathrm{Mm}^{3}$

\section{Binary variables}

$u_{t}^{d} \quad$ On/off state in generating mode

$u_{t}^{p} \quad$ On/off state in pumping mode

$y_{t}^{d} \quad 1$ if the pump-turbine unit is started-up in generat-

ing mode, 0 otherwise

$y_{t}^{p} \quad 1$ if the pump-turbine unit is started-up in pumping

mode, 0 otherwise

$\phi_{t} \quad 1$ if there is more upward than downward secondary regulation reserve requested in real-time during time period $t, 0$ otherwise

the model, day by day, with a similar methodology as in [1] or [6], for a period of one year (the selected year is 2014) and for thirteen forecasting tools of the spot prices.

The goals and contributions of this paper are twofold: 1) to study the extent to which the VPI of the spot prices in the operation of conventional PSHPs participating in the spot market and in the secondary regulation service can be reduced in comparison to PSHPs participating only in the spot market and 2) to propose and evaluate novel indicators to better explain the VPI in comparison to others proposed in the literature such as MAPE and Rank Correlation.

In the literature, the VPI of the spot prices has been studied in the context of load-shifting industrial plants [6], demand-side market customers [7], distributed storage systems (batteries) [8], and thermal and hydro power produces [9-11]. As far as we know, [1] is the only work published so far where the VPI of the spot prices has been studied in the context of PSHPs. The results presented in that paper show that the profit loss due to the errors in forecasting the spot prices is higher for PSHPs than for hydro or thermal power plants. In the paper here presented, we take a step ahead of [1] by considering the participation of the PSHP in the secondary regulation service. As demonstrated in [12], the traditional PSHP operation strategy based on the well-known price arbitrage does not allow justifying the investment. The said operation strategy is therefore evolving to an "ancillary services driven" one [13], in which the PSHP diversifies its sources of revenue among the different energy and ancillary services markets.

In order to evaluate the profitability of a PSHP, it is necessary to simulate its operation over a long time horizon within the context of the electricity market where the PSHP is planned to operate. Such simulation is often done by means of a deterministic approach, using either historical prices or synthetically generated future prices, and assuming a perfect price forecast. The regression models presented in this paper can be used to obtain a rough estimate of the VPI of any price forecasting model, as a function 
of the proposed indicators, without the need to perform any optimization and post-optimal simulation processes and can, therefore, be helpful for PSHP pre-feasibility studies. Given the huge number of ongoing and planned PSHP projects all over the world [14], the results here presented might make an appreciable impact on the hydropower sector. In addition, the results presented in the paper can be useful for power utilities to choose the most suitable model among a set of in-house available spot price forecasting models.

The paper is organised as follows: the price-maker approach and the model formulation are described in Section 2 and 3, respectively. The case study is described in Section 4 . Section 5 presents the results and discussion and finally, conclusions and acknowledgement are described in Sections 6 and 7.

\section{Price-maker approach in the secondary regulation reserve market}

The PSHP is considered in this study as a price-maker in the secondary regulation reserve market, i.e. we assume that the offers submitted by the PSHP can have a notable impact in the clearing price. As it was stated in [15], an agent can be considered as a pricemaker in the spot market of the MIBEL when his/her market quota is higher than $10 \%$ of the demand. ${ }^{2}$ In addition, the slope of the residual demand curves in the secondary reserve market (hereafter referred to as the residual reserve curves, RRCs) in the solution of the clearing procedure, can also give an idea of the impact of the offers on the market price. The mean value of the slope in 2014 was $-0.0335 € / \mathrm{MW} / \mathrm{MW}$ with a mean marginal price in the reserve market of $23.14 € / M W$. Note that the PSHP considered in this paper (see Section 4.2) has an installed capacity of 793 MW and can therefore have a significant impact on the marginal price of the reserve market. As the PSHP considered in this paper is assumed to be a new participant in the reserve market, the RRC of each hour (Fig. 1(b)) can be obtained as the difference between the reserve demand and supply functions, Fig. 1(a).

The price-maker approach makes the scheduling problem nonlinear, because the income in the reserve market is the result of the marginal price multiplied by the reserve. Several approaches have been adopted in the literature to model the residual demand curves in the spot market (it also applies to RRCs) and cope with the said nonlinearity [16]: 1) polynomial approximation, 2) piecewise linear approximation and 3) stepwise approximation. The method adopted in this work is a linear approximation of the entire RRCs, dashed line in Fig. 1(c), defined by a slope and an intercept [17]. Therefore, the income in the reserve market is a quadratic function of the agent reserve offer. According to the results obtained in [16], the deviation due to the use of a linear RRC in comparison to a multi-step RRC is expected to be lower than $2 \%$ of the estimated income.

The income for the upward $g_{t}^{\mathrm{sec}, u p}$ and downward $g_{t}^{\mathrm{sec}, d w}$ reserves, ${ }^{3} I_{S}$ is directly the result of the total reserve multiplied by the marginal reserve price (1), $\lambda_{S, t}$. The marginal reserve price $\lambda_{S, t}$ is estimated as a linear approximation of the RRC (2) (Fig. 1(c)). In the Spanish electricity system, the transmission system operator (TSO) forces all regulation zones to meet an hourly ratio $R_{t}^{S M}$ between the upward and the total reserve (3). If (2) is included in (1), the income of the upward and downward reserves can be

\footnotetext{
2 The historical hourly demand of the upward and downward secondary regulation reserve market in the Spanish electricity system (the so-called hourly requirement of upward and downward reserves for the system), has been always lower or equal to $900 \mathrm{MW}$ and $800 \mathrm{MW}$, respectively.

3 The secondary regulation reserve market is cleared only once per day to assign both the upward and downward hourly reserves of the following day according to the ratio $R_{t}^{S M}$, set by the TSO in advance.
}

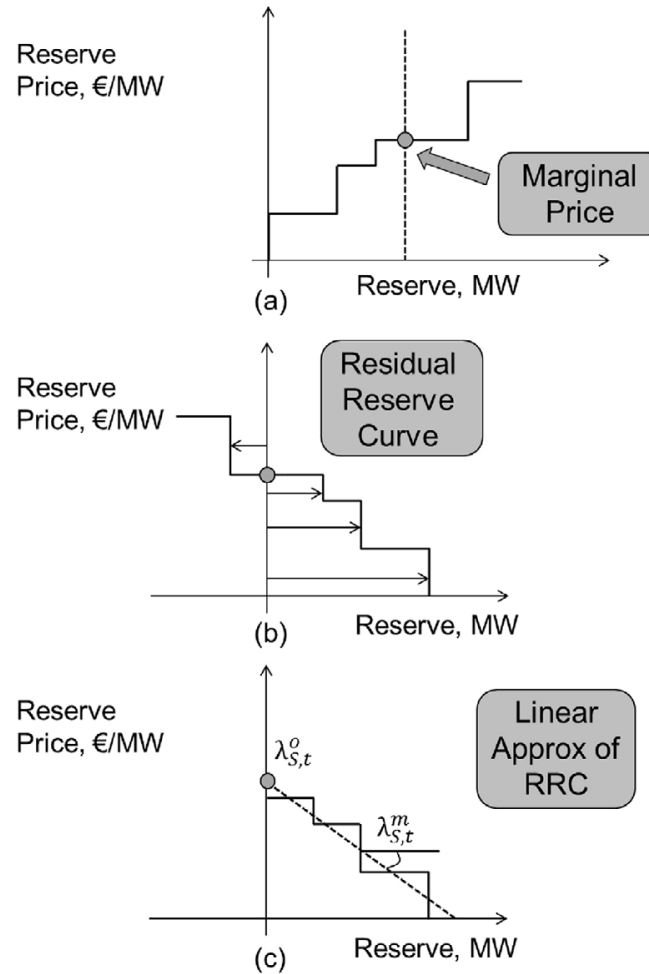

Fig. 1. (a) Reserve supply and demand functions (solid and dashed lines, respectively), and the marginal price of the market. (b) Process to obtain the RRCs. (c) RRC and its linear approximation (solid and dashed lines, respectively).

expressed as a quadratic function of the marginal reserve price (4). Note that the fraction in (4) is the total (upward and downward) secondary regulation reserves, i.e., the expression between brackets in (1), expressed as a function of the intercept and the slope of the linear approximation of the RRC.

$$
\begin{aligned}
& I_{S}=\sum_{t}\left(g_{t}^{\mathrm{sec}, u p}+g_{t}^{\mathrm{sec}, d w}\right) \lambda_{S, t} \\
& \lambda_{S, t}=\lambda_{S, t}^{o}+\lambda_{S, t}^{m}\left(g_{t}^{\mathrm{sec}, u p}+g_{t}^{\mathrm{sec}, d w}\right) \quad \forall t \\
& g_{t}^{\mathrm{sec}, u p}=R_{t}^{S M}\left(g_{t}^{\mathrm{sec}, u p}+g_{t}^{\mathrm{sec}, d w}\right) \quad \forall t \\
& I_{S}=\sum_{t} \frac{\left(\lambda_{S, t}-\lambda_{S, t}^{o}\right)}{\lambda_{S, t}^{m}} \cdot \lambda_{S, t}
\end{aligned}
$$

\section{Model formulation}

The formulation of the day-ahead energy and reserve scheduling model is composed by Eqs. (5)-(21) in addition to Eqs. (2) and (3).

\subsection{Objective function}

The objective function of the model maximises the net income of the PSHP in the spot market, and for the different "products" comprised within the secondary regulation service of the Spanish electric power system [3]. The incomes in the secondary regulation service come from: 1) reserve and 2) the real-time use of the reserve (regulation energy). In (5), the first term expresses the net income in the spot market and the start-up costs in generating and pumping mode, respectively. The second term expresses the quadratic income for the upward and downward reserves put at disposal of the TSO (see Section 2 for details). And, finally, the 
third term expresses the net income for the secondary regulation energy. Note that in case of reducing the energy with respect to the energy schedule of the spot market, instead of an additional revenue, the agent will have to pay for the downward secondary regulation energy.

$$
\begin{aligned}
\operatorname{Maxz}= & \sum_{t}\left[\left(g_{t}^{d}-g_{t}^{p}\right) \lambda_{D, t}-c S U^{d} \cdot y_{t}^{d}-c S U^{p} \cdot y_{t}^{p}\right. \\
& \left.+\frac{\left(\lambda_{S, t}-\lambda_{S, t}^{o}\right)}{\lambda_{S, t}^{m}} \cdot \lambda_{S, t}+\left(e_{t}^{\mathrm{sec}, u p} \cdot \lambda_{u p, t}-e_{t}^{\mathrm{sec}, d w} \cdot \lambda_{d w, t}\right)\right]
\end{aligned}
$$

\subsection{Constraints}

\subsubsection{Water balance}

The water balance in the upper reservoir, (6) does not include any water inflow because a closed-loop PSHP is considered in this article. In addition to this, limits are imposed to the water volume in all hours (7). The water balance and limits in the lower reservoir are not included in the proposed model formulation for the sake of clarity, as we assume the typical configuration where the upper reservoir is the one which constrains the operation. Note that $q_{t}^{d}$ is total water discharge, which includes the water flow for the realtime use of reserves (11).

$v_{t}=v_{t-1}+l_{t}\left(q_{t}^{p}-q_{t}^{d}\right) \quad \forall t$

$\underline{v} \leq v_{t} \leq \bar{v} \quad \forall t$

A target water volume in the upper reservoir at the end of the time horizon (in this article, last hour of the day) is imposed by (8). The target water volume is deemed as input data to the model.

$v_{t}=f v \quad t=\mathrm{T}$

\subsubsection{Hydropower generation and consumption}

The generation/consumption curve of the pump-turbine unit used in the paper can be seen in Fig. 2 and is modelled with (9)-(13). The curve represents the relationship between water discharged and pumped (on $x$-axes) with hydropower generation and consumption (on $y$-axes), respectively. For clarity, the proposed formulation assumes that the upper reservoir has a negligible head variation in comparison with the available gross head. Hence, head dependency is not included in the model. See [5] as an example to include head dependency in a PSHP.

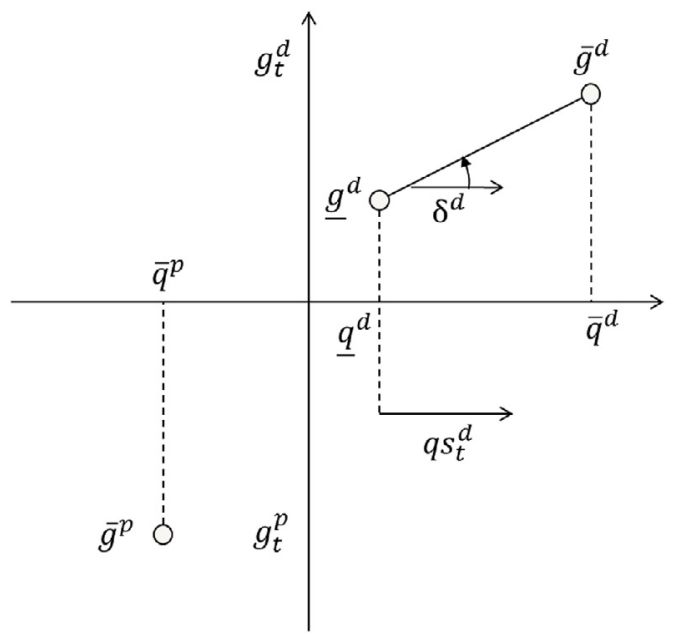

Fig. 2. Generation and consumption curve of a reversible Francis pump-turbine unit, considered in this study.
The feasible operating range in generating mode (between maximum and minimum power generation) is ensured by (9) and (10). In addition, the total water discharge includes not only water for the energy committed in the spot market but also extra water discharge for the real-time use of the upward reserve and water that is kept in the upper reservoir due to the real-time use of the downward reserve (11).

$g_{t}^{d}=u_{t}^{d} \cdot \underline{g}^{d}+\delta^{d} \cdot q s_{t}^{d} \quad \forall t$

$q s_{t}^{d} \leq u_{t}^{d}\left(\bar{q}^{d}-\underline{q}^{d}\right) \quad \forall t$

$q_{t}^{d}=u_{t}^{d} \cdot \underline{q}^{d}+q s_{t}^{d}+\frac{1}{\delta^{d}}\left(\rho_{t}^{u p} \cdot g_{t}^{\mathrm{sec}, u p}-\rho_{t}^{d w} \cdot g_{t}^{\mathrm{sec}, d w}\right) \quad \forall t$

The consumption operation is modelled by (12) and (13). A single operating point is considered in pumping mode, corresponding to a fixed speed pump-turbine unit. Consistently, no reserve or regulation energy is considered in pumping mode.

$g_{t}^{p}=u_{t}^{p} \cdot \bar{g}^{p} \quad \forall t$

$q_{t}^{p}=u_{t}^{p} \cdot \bar{q}^{p} \quad \forall t$

A reversible Francis pump-turbine unit is not able to operate in generating and pumping mode simultaneously (14). Finally, the start-up decisions are modelled by (15) in generating mode and by (16) in pumping mode.

$u_{t}^{d}+u_{t}^{p} \leq 1 \quad \forall t$

$y_{t}^{d} \geq u_{t}^{d}-u_{t-1}^{d} \quad \forall t$

$y_{t}^{p} \geq u_{t}^{p}-u_{t-1}^{p} \quad \forall t$

\subsubsection{Secondary regulation service}

The secondary regulation service (also called load-frequency control service) in the Spanish electricity system comprises the hourly power reserve, that is modelled with (3), (17) and (18), and the real-time use of reserves, i.e. the regulation energy, that is modelled with (19)-(21). According to these equations, if $\phi_{t}=1, e_{t}^{\mathrm{sec}, d w}$ $=0$ by Eq. (21) and $e_{t}^{\mathrm{sec}, u p}$ is between 0 and $N$ by Eq. (20) and equals the right-side of Eq. (19). Analogously, if $\phi_{t}=0, e_{t}^{\text {sec }, u p}=0$ by Eq. (20) and $e_{t}^{\mathrm{sec}, d w}$ is between 0 and $N$ by Eq. (21) and equals the right-side of equation (19).

$g_{t}^{\mathrm{sec}, u p} \leq u_{t}^{d} \cdot \bar{g}^{d}-g_{t}^{d} \quad \forall t$

$g_{t}^{\mathrm{sec}, d w} \leq g_{t}^{d}-u_{t}^{d} \cdot \underline{g}^{d} \quad \forall t$

$e_{t}^{\mathrm{sec}, u p}-e_{t}^{\mathrm{sec}, d w}=\rho_{t}^{u p} \cdot g_{t}^{\mathrm{sec}, u p}-\rho_{t}^{d w} \cdot g_{t}^{\mathrm{sec}, d w} \quad \forall t$

$0 \leq e_{t}^{\mathrm{sec}, u p} \leq \phi_{t} \cdot N \quad \forall t$

$0 \leq e_{t}^{\mathrm{sec}, d w} \leq\left(1-\phi_{t}\right) N \quad \forall t$

\section{Case study}

A closed-loop and daily-cycle PSHP with a single fixed-speed reversible Francis pump-turbine unit is considered in this study. The VPI associated to several forecasting models of the spot prices is calculated in the year 2014 considering that the PSHP participates only in the spot market or both in the spot and reserve markets.

\subsection{Electric power system data}

The electric power system data used in this paper correspond to hourly values of: 1 ) the spot price, 2 ) the reserve price, 3 ) the upward and downward regulation energy prices, 4) the percentages of the real-time use of reserves and 5) the ratio between the upward and total reserves, $R_{t}^{S M}$. The actual percentages of the realtime use of reserves provided by each power plant in Spain is not 
Table 1

Approaches used to forecast the spot price, and their Mean Absolute Percentage Error (MAPE) throughout 2014.

\begin{tabular}{lll}
\hline Case & Spot price & MAPE \\
\hline A & Perfect knowledge & No error \\
B & Mean hourly price of 2013 & $35.4 \%$ \\
C & Historical price of the previous week & $24.6 \%$ \\
D & Historical price of the previous day & $19.6 \%$ \\
E & SARIMA $(0,1,1)(1,1,1)_{24}$ model & $22.3 \%$ \\
F & SARIMAX model with demand & $18.3 \%$ \\
G & SARIMAX model with demand and wind & $19 \%$ \\
H & GARCH-ARIMAX model & $16.4 \%$ \\
I & Historical price and error N(0,3) $€$ & $9.8 \%$ \\
J & Eight scenarios of Case I & $n / a$ \\
K & Eight scenarios of Case H and error N $(0,3) €$ & $n / a$ \\
L & Eight scenarios of Case H and error N $(0,6) €$ & $n / a$ \\
M & ARIMA model from [19] & $17.6 \%$ \\
$\mathrm{~N}$ & GARCH model from [18] & $16.9 \%$ \\
\hline
\end{tabular}

publicly available. It is assumed that the percentages are given by the historical hourly ratio of the aggregate power delivery and the aggregate assigned reserves in the entire Spanish electric power system.

Perfect knowledge is assumed in all data except in the spot prices. This assumption is made in order to better analyse (in an isolated way) the impact of the forecasting errors of the spot prices. If all uncertainties are considered in the same problem, it is not possible to distinguish which part of the profit loss corresponds to the forecast errors of the spot prices and the rest of the random variables. In addition, considering independently imperfect knowledge of the RRCs, the percentages of the real-time use of reserves and the secondary regulation energy prices has a significantly lower impact on the results (VPI is around $6-7 \%, 5 \%$ and $2 \%$ of the maximum theoretical income, respectively), according to unpublished results from the authors. The profit loss due to the forecasting errors of the rest of random variables would affect all the analysed cases, with perfect (Case A) and imperfect information (Cases B-N) of the spot prices. Therefore, it seems reasonable not to expect significant changes in the Conclusions of the paper when considering imperfect knowledge of the rest of random variables.

Thirteen Cases are analysed, each corresponding to a different approach to forecast the spot prices, Table 1 . Note that Case A assumes perfect knowledge also in the spot prices, and that its results are the maximum theoretical income against which the results of the other Cases are checked. The forecasting model of Case B assumes that the spot price in hour $t$ of a certain day of 2014 is the average of the spot price in the said hour across all days in 2013. The forecasting models of Case $C$ and $D$ assume that the spot price in a day $d$ follows the historical price profile of the day $d-7$ (previous week) and the day $d-1$ (previous day), respectively.

The forecasting models of Case E-H are adjusted as follows. The price series is transformed into a regular and seasonal stationary process by means of a logarithmic transformation to obtain a more stable variance and by means of a first order regular and seasonal differentiations to obtain a more stable mean. The regular and seasonal autoregressive and moving average parameters of the forecasting model are obtained by an iterative process in which the autocorrelation and partial autocorrelation plots of the transformed time series and of the residuals of the fitted models are inspected at each iteration step. The iterative process is stopped when the residuals are a white noise process, i.e. zero mean, constant variance, uncorrelated process and normal distribution, and using the parsimony criteria: as few parameters as required to properly explain the data are selected.

Particularly, the forecasting model of Case $\mathrm{E}$ is a seasonal autoregressive integrated moving average model (SARIMA) with period 24. The forecasting models of Case $F$ and Case $G$ correspond to
Table 2

Technical data of the reversible Francis pump-turbine unit, power in $M W$, flow in $\mathrm{Mm}^{3} / h$, efficiency in \% and start-up costs in $€$.

\begin{tabular}{lllllllllll}
\hline $\bar{q}^{d}$ & $\bar{g}^{d}$ & $\bar{\eta}^{d}$ & $\underline{q}^{d}$ & $\underline{g}^{d}$ & $\underline{\eta}^{d}$ & $\bar{q}^{p}$ & $\bar{g}^{p}$ & $\eta^{p}$ & ${ }^{c} C S U^{d}$ & ${ }^{2} S U^{p}$ \\
\hline 0.833 & 793 & $90 \%$ & 0.358 & 287.9 & $76 \%$ & 0.636 & 793 & $90 \%$ & 2667 & 2118
\end{tabular}

a SARIMA model with period 24 and with explanatory variables (SARIMAX $\left.(0,1,1)(0,1,1)_{24}\right)$. The former uses the forecast demand in the Spanish electric power system as explanatory variable, whereas the latter uses both the forecast demand and the forecast wind power in the system. ${ }^{4}$ The forecasting model of Case $\mathrm{H}$ corresponds to $\operatorname{GARCH}(1,3)$ and $\operatorname{ARIMAX}(10,1,0)^{5}$ with the forecast wind power of the system as explanatory variable. In the autoregressive polynomial, the terms with lags 1,2, 3, 4, 24, 144, 168, 169, 192 and 193 have a non-zero coefficient. The orders of the GARCH model are selected according to [18].

Case I uses the historical price profiles in each day, adding a random error which is modelled by a normal distribution with 0 $€$ mean and $3 €$ standard deviation. Case J uses an scenario tree composed by eight scenarios obtained from Case I. Note that Case I and Case J are not in fact forecasting models as their results assume certain knowledge of the real spot prices. Case K (resp. Case L) uses the forecast price profile with the GARCH-ARIMAX model proposed in Case $\mathrm{H}$ and adds a random error which is modelled by a normal distribution with $0 €$ mean and $3 €$ standard deviation (resp. $6 €$ standard deviation). Finally, Cases $\mathrm{M}$ and $\mathrm{N}$ are reproduced according to [19,18], respectively, and applied for the year 2014 . The forecasting model of Case $\mathrm{M}$ is an ARIMA model with the terms with lags $1-5,23,24,47,48,72,96,120,144,168,336$ and 504 having a non-zero coefficient in the autoregressive polynomial and 1 , $2,24,168,336$ and 504 in the moving average polynomial. The forecasting model of Case $\mathrm{N}$ is a $\operatorname{GARCH}(1,3)$ and ARIMA(12,1,0) model with the terms with lags $1,2,3,4,24,144,168,169,192,193$, 216 and 504 having a non-zero coefficient in the autoregressive polynomial.

\subsection{Technical data}

Technical data of the reversible Francis pump-turbine unit are presented in Table 2. A constant gross head of $400 \mathrm{~m}$ and hydraulic losses of $3 \%$ of the gross head are assumed. In generating mode, the minimum water discharge and efficiencies at both maximum and minimum water discharges are calculated from typical performance curves in [20]. A linear relationship between water discharge and power generation is assumed. The efficiency in pumping mode is $90 \%$ [21]; this corresponds to a round-trip efficiency of $76.3 \%$. The start-up costs in generating and pumping modes have been calculated according to [22].

The upper reservoir has a storage capacity of $5 \mathrm{Mm}^{3}\left(\bar{v}=5 \mathrm{Mm}^{3}\right.$ and $\left.\underline{v}=0 \mathrm{Mm}^{3}\right)$, starting and finishing the day at the same water volume of $2.5 \mathrm{Mm}^{3}$.

\subsection{Methodology}

The VPI in each Case is calculated in the year 2014 by following the next three steps, Fig. 3:1) the optimal generation and consumption schedules of the PSHP are obtained sequentially (day by day) by solving the above described scheduling model with the forecast spot price (imperfect information). The model is solved by the

\footnotetext{
${ }^{4}$ Both the forecast demand and the forecast wind power of the system are publicly available in the day $D-1$ on the website https://www.esios.ree.es/en of the TSO.

${ }^{5}$ The order of the autoregressive part of the ARIMA model was selected from a trial and error approach.
} 


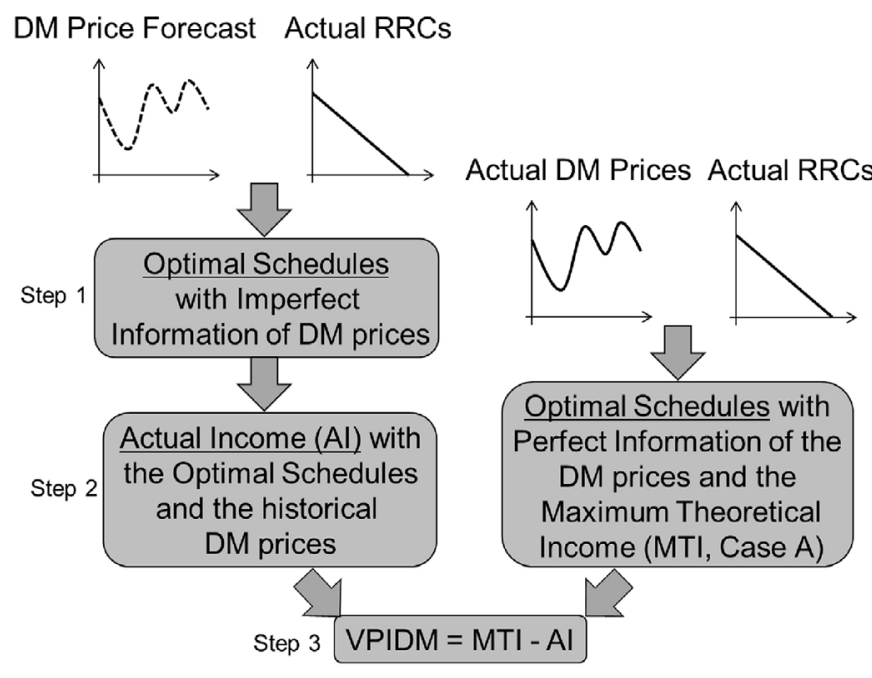

Fig. 3. Methodology to obtain the value of perfect information of spot prices in each Case (except for Case A).

branch and cut algorithm in Cplex in a computer with a $2.4 \mathrm{GHz}$ Intel Core i5-450M CPU and 4 GB of RAM memory (365 daily problems in each Case);2) the actual net income in the spot market (DM Income) is calculated in a post-optimal simulation process from the optimal energy schedule obtained in the previous step and the historical hourly spot prices, and 3) the VPI in each Case is calculated as the difference between the maximum theoretical income (MTI, Case A) and the actual total income (AI) in each Case, which considers the DM Income from the previous step. Note that the methodology presented in Fig. 3 is applied both when the PSHP only participates in the spot market (AI = DM Income - start-up costs) and when it also participates in the secondary regulation service $(\mathrm{AI}=\mathrm{DM}$ Income + net income in the secondary regulation service - start-up costs).

\section{Results and discussion}

\subsection{Value of perfect information}

The DM Income, the AI and the VPI in $€$ and in \% of the MTI are presented in Table 3 when the PSHP only participates in the spot market, and in Table 4 when the PSHP also participates in the secondary regulation service (SRS). In Table 4, the income in the secondary regulation reserve market (SM Income), the income for the real-time use of the upward reserve (ER2UP Income) and the cost of the downward secondary regulation energy (ER2DW Cost) are also shown.

\section{Table 3}

Results when the PSHP participates only in the spot market: actual net income in the spot market (DM Income) in $€$, actual total income (AI) in $€$ and value of perfect information (VPI) in $€$ and \%.

\begin{tabular}{lllll}
\hline Case & DM Income & AI & VPI & VPI \\
\hline A & 15323401 & 13110914 & - & - \\
B & 9164408 & 6458701 & 6652213 & $50.7 \%$ \\
C & 8951347 & 6719714 & 6391199 & $48.7 \%$ \\
D & 6572766 & 4360279 & 8750635 & $66.7 \%$ \\
E & 8865832 & 6972309 & 6138604 & $46.8 \%$ \\
F & 9642518 & 7583119 & 5527796 & $42.2 \%$ \\
G & 9794609 & 7863817 & 5247097 & $40 \%$ \\
H & 10031773 & 8343340 & 4767573 & $36.4 \%$ \\
I & 14394601 & 11543486 & 1567428 & $11.9 \%$ \\
J & 15174217 & 12944778 & 166136 & $1.3 \%$ \\
K & 9822546 & 8079345 & 5031569 & $38.4 \%$ \\
L & 9484671 & 7641655 & 5469259 & $41.7 \%$ \\
M & 8534745 & 6993742 & 6117172 & $46.7 \%$ \\
N & 7791278 & 6795594 & 6315320 & $48.2 \%$ \\
\hline
\end{tabular}

As can be observed in Tables 3 and 4, the VPI is significant (except Case I and Case J, which are quite optimistic as their prices assume certain knowledge of the historical price profile) with a mean VPI value of $28.9 \%$ and $39.9 \%$ if the PSHP participates or not in the SRS, respectively. Case D obtains the worst results: the VPI is $40.4 \%$ and $66.7 \%$ if the PSHP participates or not in the SRS, respectively. However, as observed in [1], the MAPE does not explain the VPI perfectly as can be concluded from the results of Case D whose MAPE is not the highest whereas its VPI is the highest. Further research to better explain the VPI is carried out in Section 5.2, where the so-called Kendal's Rank Correlation (RC) and the total volatility - adjusted $\mathrm{RC}$, both used in [6], are obtained, and where three new indicators are proposed and evaluated.

In Tables 3 and 4, it can also be observed that the VPI in $€$ increases in all Cases when the PSHP also participates in the SRS. This result confirms one of those obtained in [23]: the PSHP is still using the SRS as the priority source of income, and the spot market as a subsidiary means to maximize the participation in the reserve market, even if the market agent is modelled as a price-maker in the reserve market. By contrast, the VPI in \% decreases in all Cases when the PSHP also participates in the SRS. This seemingly contradictory result is due to the fact that when the PSHP also participates in the SRS, the AI increases whereas the DM Income decreases but to a lower extent. Hence, the positive impact of the participation in the SRS of a PSHP is proven.

\subsection{Rank indicator of the value of perfect information}

Several indicators have been used to try to rank the forecast models in a correct order of their VPI. The VPI both when the PSHP participates only in the spot market (VPI in DM) and when the PSHP also participates the SRS (VPI in DM \& SRS) are shown in Table 5, along with the used indicators. Note that Case A is not included as it does not have any error. In the literature, the mean absolute percentage error (MAPE), the Kendal's rank correlation (RC) and the total volatility - adjusted RC are well-documented indicators (see, for example, [1] for MAPE and [6] for RC and total volatility adjusted RC). Since none of these indicators successfully explains the VPI, three additional indicators (Storage-RC1, Storage-RC2, and Storage-RC3) are proposed in the paper for the said purpose, and obtained as follows:

- The Storage-RC1 indicator is the average across the year of the daily MAPE between the following couple of vectors ( $V_{1}$ and $V_{2}$ in each day). In a given day, the $i$ th element of $V_{1}$ is the ratio between the $i$ th highest and the $i$ th lowest actual DM prices. The $i$ th element of $V_{2}$ is the ratio between the forecast DM prices in the positions of the $i$ th highest and the $i$ th lowest DM prices of the actual DM price profile. Note that $V_{1}$ and $V_{2}$ are formed by twelve elements (24/2 ratios). In both $V_{1}$ and $V_{2}$, only the $k$ first values are used to calculate the daily MAPE, corresponding to the $k$ ratios of the actual DM price profile higher than the inverse of the round-trip efficiency (i.e. $k$ profitable ratios).

- The Storage-RC2 indicator is the average across the year of the daily MAPE between the following couple of vectors ( $V_{1}$ and $V_{2}$ in each day). $V_{1}$ is the actual DM price profile of a given day sorted from the highest to the lowest price. $V_{2}$ is the forecast DM price profile sorted by the positions of $V_{1}$ : the first element of $V_{2}$ is the forecast DM price in the hour of the highest actual DM price, the second is the forecast DM price in the hour of the second highest actual DM price and so on. Note that $V_{1}$ and $V_{2}$ are formed by twenty four elements ( $24 \mathrm{~h})$.

- The Storage-RC3 indicator is the average across the year of the daily MAPE between the following couple of vectors $\left(V_{1}\right.$ and $V_{2}$ in each day). In a given day, the $i$ th element of $V_{1}$ is the ratio 
Table 4

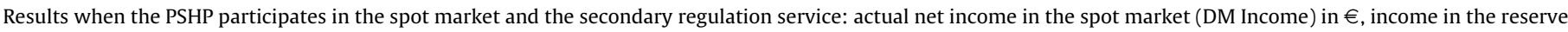

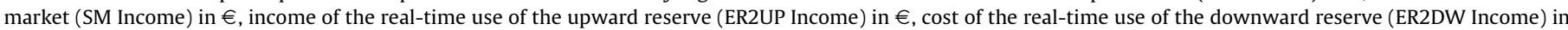
$€$, actual total income (AI) in $€$ and value of perfect information (VPI) in $€$ and \%.

\begin{tabular}{|c|c|c|c|c|c|c|c|}
\hline Case & DM Income & SM Income & ER2UP Income & ER2DW Cost & AI & VPI & VPI \\
\hline A & 11408606 & 15650021 & 6212865 & -4631308 & 24875026 & - & - \\
\hline B & 2486626 & 14810111 & 5303372 & -3335915 & 15718582 & 9156444 & $36.8 \%$ \\
\hline $\mathrm{C}$ & 868763 & 16301226 & 6664775 & -4128330 & 15789135 & 9085891 & $36.5 \%$ \\
\hline $\mathrm{D}$ & -438515 & 16556726 & 6630558 & -4146403 & 14809660 & 10065366 & $40.4 \%$ \\
\hline E & 1457727 & 15857905 & 6332034 & -3564435 & 16220402 & 8654624 & $34.8 \%$ \\
\hline $\mathrm{F}$ & 1347415 & 16361032 & 6584475 & -3949156 & 16554999 & 8320028 & $33.5 \%$ \\
\hline G & 804139 & 16557038 & 6639064 & -3822623 & 16370953 & 8504074 & $34.2 \%$ \\
\hline $\mathrm{H}$ & 3258998 & 16159056 & 6083230 & -3744275 & 18164160 & 6710866 & $26.9 \%$ \\
\hline I & 10114684 & 15820790 & 6234372 & -4685958 & 23145990 & 1729037 & $6.9 \%$ \\
\hline $\mathrm{J}$ & 10976703 & 15717785 & 6310582 & -4541889 & 24646545 & 228482 & $0.9 \%$ \\
\hline $\mathrm{K}$ & 2882049 & 16189779 & 6175700 & -3704331 & 17882392 & 6992635 & $28.1 \%$ \\
\hline $\mathrm{L}$ & 2143090 & 16530666 & 6370136 & -4020531 & 17153277 & 7721750 & $31 \%$ \\
\hline M & -869399 & 16792060 & 7403601 & -3060876 & 16646311 & 8228716 & $33.1 \%$ \\
\hline $\mathrm{N}$ & 1514664 & 15268979 & 5831689 & -2721290 & 16804207 & 8070820 & $32.5 \%$ \\
\hline
\end{tabular}

Table 5

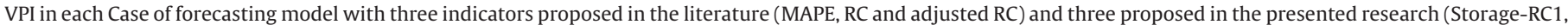
2 and 3 )

\begin{tabular}{|c|c|c|c|c|c|c|c|c|}
\hline Case & VPI in DM & VPI in DM \&SRS & MAPE & $\mathrm{RC}$ & Adjusted RC & Storage RC1 & Storage RC2 & Storage RC3 \\
\hline B & $50.7 \%$ & $36.8 \%$ & $32.1 \%$ & 0.577 & 209.6 & 0.225 & 0.707 & 0.12 \\
\hline C & $48.7 \%$ & $36.5 \%$ & $25.3 \%$ & 0.615 & 31.7 & 0.28 & 0.395 & 0.115 \\
\hline $\mathrm{D}$ & $66.7 \%$ & $40.4 \%$ & $21.6 \%$ & 0.552 & 27.97 & 0.282 & 0.305 & 0.157 \\
\hline $\mathrm{E}$ & $46.8 \%$ & $34.8 \%$ & $23.8 \%$ & 0.565 & 34.5 & 0.252 & 0.36 & 0.136 \\
\hline $\mathrm{F}$ & $42.2 \%$ & $33.5 \%$ & $20.5 \%$ & 0.593 & 20.1 & 0.209 & 0.275 & 0.135 \\
\hline G & $40 \%$ & $34.2 \%$ & $20.9 \%$ & 0.578 & 28.3 & 0.215 & 0.292 & 0.139 \\
\hline $\mathrm{H}$ & $36.4 \%$ & $26.9 \%$ & $17.8 \%$ & 0.641 & 16.4 & 0.203 & 0.26 & 0.109 \\
\hline I & $11.9 \%$ & $6.9 \%$ & $9.8 \%$ & 0.704 & 51.96 & 0.086 & 0.07 & 0.06 \\
\hline $\mathrm{J}$ & $1.3 \%$ & $0.9 \%$ & $\mathrm{n} / \mathrm{a}$ & $\mathrm{n} / \mathrm{a}$ & $\mathrm{n} / \mathrm{a}$ & $\mathrm{n} / \mathrm{a}$ & $\mathrm{n} / \mathrm{a}$ & $\mathrm{n} / \mathrm{a}$ \\
\hline K & $38.4 \%$ & $28.1 \%$ & $\mathrm{n} / \mathrm{a}$ & $\mathrm{n} / \mathrm{a}$ & $\mathrm{n} / \mathrm{a}$ & $\mathrm{n} / \mathrm{a}$ & $\mathrm{n} / \mathrm{a}$ & $\mathrm{n} / \mathrm{a}$ \\
\hline $\mathrm{L}$ & $41.7 \%$ & $31 \%$ & $\mathrm{n} / \mathrm{a}$ & $\mathrm{n} / \mathrm{a}$ & $\mathrm{n} / \mathrm{a}$ & $\mathrm{n} / \mathrm{a}$ & $\mathrm{n} / \mathrm{a}$ & $\mathrm{n} / \mathrm{a}$ \\
\hline M & $46.7 \%$ & $33.1 \%$ & $17.6 \%$ & 0.581 & 14.8 & 0.229 & 0.274 & 0.137 \\
\hline $\mathrm{N}$ & $48.2 \%$ & $32.5 \%$ & $16.9 \%$ & 0.637 & 20.6 & 0.247 & 0.27 & 0.115 \\
\hline
\end{tabular}

between the $i$ th highest and the $i$ th lowest actual DM prices. The $i$ th element of $V_{2}$ is the ratio between the actual DM prices in the positions of the $i$ th highest and the $i$ th lowest DM prices of the forecast DM price profile. Note that $V_{1}$ in the Storage-RC1 and 3 are the same. As in the Storage-RC1, only the $k$ profitable ratios in $V_{1}$ and $V_{2}$ are used to calculate the daily MAPE.

The three proposed indicators are somehow based on the idea that the maximum income that a price-taker closed-loop and dailycycle PSHP can get in the spot market will be obtained by the generating and consuming power during the hours with higher (peak) and lower (off-peak) prices, respectively, provided that the ratios between the peak and off-peak prices are higher than the inverse of the PSHP round-trip efficiency [24].

In order to evaluate the effectiveness of each indicator for evaluating the VPI of every forecasting model, the following analyses have been carried out:

- The least squares method is used to obtain a linear regression model that estimates the VPI as a function of each indicator. The results of this analysis are summarised in Fig. 4. Each subfigure in Fig. 4 shows the VPI when the PSHP only participates in the spot market in black circles and the VPI when the PSHP participates also in the SRS in white circles, against each indicator, as well as the obtained regression models in solid and dashed line, respectively.

- The squared Euclidean distances [25] between the obtained regression models and the VPI results, and the parameters of the said regression models are calculated and shown in Table 6, both when the PSHP participates only in the spot market and when the PSHP participates also in the SRS. The parameters of the regression models are composed by pairs: values on the left (resp. right) of the slash refer to the slope (resp. the intercept with the $y$-axis).

As can be seen in Table 6, the regression models corresponding to the proposed indicators Storage-RC1 and Storage-RC3 have lower Euclidean distances than those corresponding to the indicators proposed in the literature, being the Storage-RC1 the indicator with the lowest Euclidean distance both when the PSHP participates only in the DM and also in the SRS. This result can be confirmed by inspecting Fig. 4.

Despite the foregoing, the observed reduction of the VPI in \% when the PSHP participates also in the secondary regulation service should be confirmed by independently analysing the VPI of all uncertain variables for which a perfect knowledge was assumed in this paper, namely: the RRCs, the regulation energy prices and

Table 6

Squared Euclidean distances (Dist) of the VPI and the linear regression models, and the parameters of the regression models (first value the slope/second value the intercept with the $y$-axis).

\begin{tabular}{llllll}
\hline & \multicolumn{2}{l}{ VPI in DM } & & \multicolumn{2}{l}{ VPI in DM \&SRS } \\
\cline { 2 - 3 } \cline { 6 - 6 } \cline { 5 - 6 } & Dist & Regression & & Dist & Regression \\
\hline MAPE & 31.68 & $1.52 / 12.56$ & & 18.33 & $1.2 / 6.86$ \\
RC & 23.37 & $-249.7 / 194.7$ & & 13.01 & $-180.6 / 140.7$ \\
Adjusted RC & 41.38 & $0.018 / 43.02$ & & 27.91 & $0.013 / 30.95$ \\
Storage-RC1 & 15.07 & $232.7 /-8$ & & 9.75 & $157.9 /-3.64$ \\
Storage-RC2 & 34.53 & $47.92 / 28.46$ & & 21.6 & $37.1 / 19.66$ \\
Storage-RC3 & 21.55 & $449.8 /-11.17$ & & 12.25 & $319.4 /-7.5$ \\
\hline
\end{tabular}



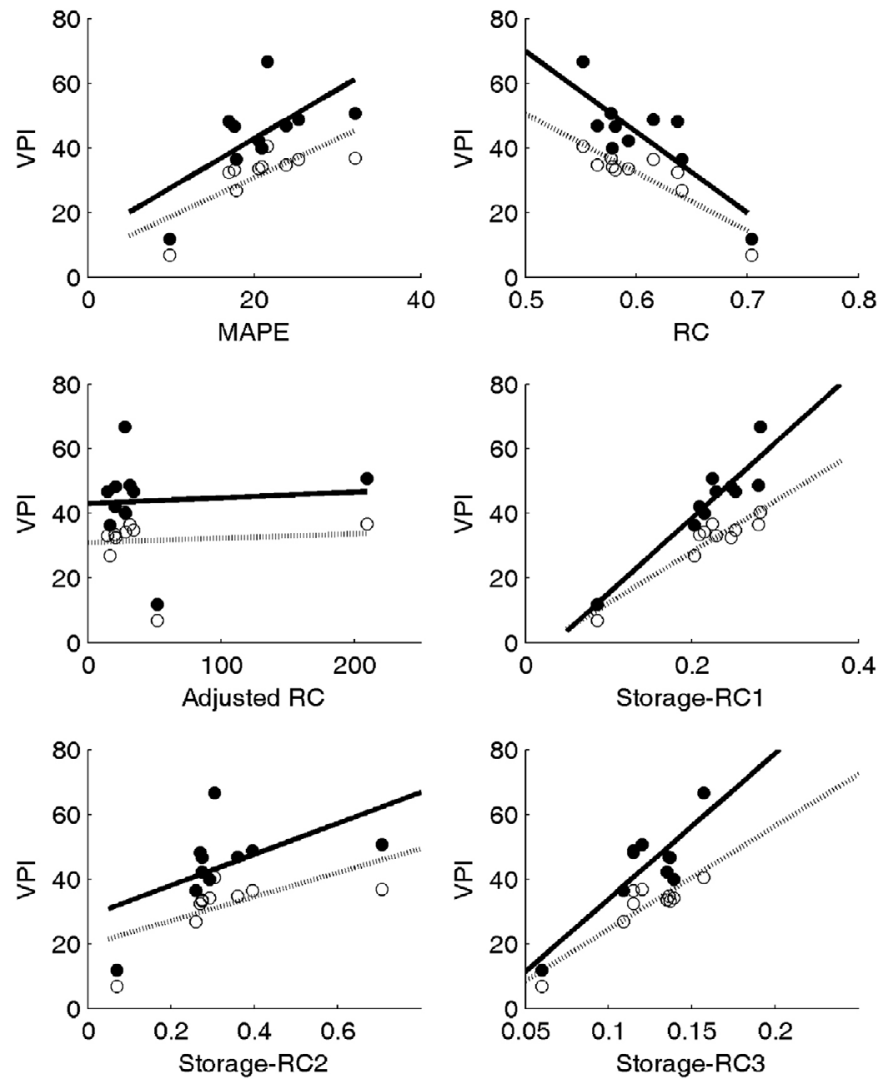

Fig. 4. Linear approximation of VPI in DM (solid line and black circles) and VPI in DM \& SRS (dashed line and white circles) with the three indicators proposed in the literature and the three proposed in this research.

the real-time use of the reserves. This is proposed as a future work. In addition, the obtained regression models need further research in order to be used for different years than 2014 and for different sizes of PSHPs. This is also proposed as a future work.

\section{Conclusions}

The value of perfect information of the spot prices, i.e. the profit loss due to the errors in forecasting the spot prices, in the operation of a closed-loop and daily-cycle PSHP, participating in the spot market as a price-taker and in the secondary regulation reserve market as a price-maker, is significant, $28.9 \%$ of the maximum theoretical income as the mean value between all the Cases analised. However, the participation in the secondary regulation service reduces notably the value of perfect information in $\%$ of the maximum theoretical income, comparing to participate only in the spot market: from $39.9 \%$ to $28.9 \%$ as the mean values between all the Cases analised. Besides, the proposed indicator named Storage Rank Correlation 1 is chosen as the one that best estimates the value of perfect information of the spot prices in the operation of a PSHP of the above-mentioned characteristics. Finally, analysing the value of perfect information with more flexible PSHPs such as variable speed PSHPs and PSHPs in hydraulic short-circuit is established as a future work in addition to calculating independently the value of perfect information of the RRCs, the regulation energy prices and the percentage of the real-time use of reserves.

\section{Acknowledgements}

The authors acknowledge the Spanish Ministry of Economy and Competitiveness for funding partially this work under the project of The National Scientific Research, Development and Technological Innovation Plan 2008-2011 "Optimal operation and control of pumped-storage hydropower plants” (Ref. ENE2012-32207).

\section{References}

[1] E. Delarue, P. Van Den Bosch, W. D'haeseleer, Effect of the accuracy of price forecasting on profit in a Price Based Unit Commitment, Electr. Power Syst. Res. 80 (10) (2010) 1306-1313.

[2] Mercado Ibérico de la Electricidad. [Online]. Available at: http://www.mibel. $\mathrm{com} /$.

[3] E. Lobato, I. Egido, L. Rouco, G. López, An overview of ancillary services in Spain, Electr. Power Syst. Res. 78 (3) (2008) 515-523.

[4] ENTSO-E Working Group on Ancillary Services, Survey on Ancillary services procurement, Balancing market design 2014, Tech. Rep. January, 2015. [Online]. Available at: https://www.entsoe.eu/Documents/Publications/ MarketCommitteepublications/150127_WGAS_Survey_2014.pdf.

[5] M. Chazarra, J.I. Pérez-Díaz, J. García-González, Optimal energy and reserve scheduling of pumped-storage power plants considering hydraulic short-circuit operation, IEEE Trans. Power Syst. 32 (1) (2017) 344-353.

[6] T. Mathaba, X. Xia, J. Zhang, Analysing the economic benefit of electricity price forecast in industrial load scheduling, Electr. Power Syst. Res. 116 (2014) $158-165$.

[7] H. Zareipour, C. Canizares, K. Bhattacharya, Economic impact of electricity market price forecasting errors: a demand-side analysis, IEEE Trans. Power Syst. 25 (1) (2010) 254-262.

[8] K.H. Ahlert, C. Block, Assessing the impact of price forecast errors on the economics of distributed storage systems, in: 43rd Annual Hawaii International Conference on System Sciences, 2010.

[9] M. Maenhoudt, G. Deconinck, A novel offering strategy to reduce profit risk, in: Proceedings of the Universities Power Engineering Conference, 2013.

[10] B. Mohammadi-Ivatloo, H. Zareipour, M. Ehsan, N. Amjady, Economic impact of price forecasting inaccuracies on self-scheduling of generation companies, Electr. Power Syst. Res. 81 (2) (2011) 617-624.

[11] M. Maenhoudt, G. Deconinck, Strategic offering to maximize day-ahead profit by hedging against an infeasible market clearing result, IEEE Trans. Power Syst. 29 (2) (2014) 854-862.

[12] D. Connolly, H. Lund, P. Finn, B. Mathiesen, M. Leahy, Practical operation strategies for pumped hydroelectric energy storage (PHES) utilising electricity price arbitrage, Energy Policy 39 (7) (2011) 4189-4196.

[13] J.I. Pérez-Díaz, M. Chazarra, J. García-González, G. Cavazzini, A. Stoppato, Trends and challenges in the operation of pumped-storage hydropower plants, Renew. Sustain. Energy Rev. 44 (2015) 767-784.

[14] IHA (International Hydropower Association), 2016 Key trends in Hydropower, Tech. Rep., 2016. [Online]. Available at: https://www.hydropower.org/2016key-trends-in-hydropower.

[15] H. Pousinho, J. Contreras, J. Catal ao, Short-term optimal scheduling of a price-maker hydro producer in a pool-based day-ahead market, IET Gener. Transm. Distrib. 6 (12) (2012) 1243-1251.

[16] A. Marulanda, J. Martínez, A. Gómez, A comparison of residual demand models for oligopolistic markets, in: Power Systems Computation Conference (PSCC), August, 2005, pp. 22-26.

[17] A.M. Calmarza, J. de la Fuente, New forecasting method for the residual demand curves using time series (ARIMA) models, in: 7th International Conference on Probabilistic Methods Applied to Power Systems, 2002.

[18] R.C. García, J. Contreras, M.V. Akkeren, J.B.C. García, A GARCH forecasting model to predict day-ahead electricity prices, IEEE Trans. Power Syst. 20 (2) (2005) 867-874.

[19] J. Contreras, R. Espínola, F.J. Nogales, A.J. Conejo, ARIMA models to predict next-day electricity prices, IEEE Trans. Power Syst. 18 (3) (2003) 1014-1020.

[20] U.S. Bureau of Reclamation, Selecting Hydraulic Reaction Turbines. U.S. Government Printing Office, 1976.

[21] J. Raabe, Hydro Power - The Design, Use and Function of Hydromechanical, Hydraulic and Electrical Equipment, VDI Verlag, 1985.

[22] O. Nilsson, D. Sjelvgren, Hydro unit start-up costs and their impact on the short term scheduling strategies of Swedish power producers, IEEE Trans. Power Syst. 12 (1) (1997) 38-44.

[23] M. Chazarra, J. Pérez-Díaz, J. García-González, Optimal operation of variable speed pumped storage hydropower plants participating in secondary regulation reserve markets, in: European Energy Market (EEM), 2014.

[24] N. Lu, J. Chow, A. Desrochers, Pumped-storage hydro-turbine bidding strategies in a competitive electricity market, IEEE Trans. Power Syst. 19 (2) (2004) 834-841.

[25] B. Everitt, S. Landau, M. Leese, D. Stahl, Cluster Analysis, Willey, UK, 2011. 


\subsection{Paper-H: Economic Impact of Forecasting Errors in Re- sidual Reserve Curves in the Day-ahead Scheduling of Pumped Storage Plants}

In this paper entitled "Economic Impact of Forecasting Errors in Residual Reserve Curves in the Day-ahead Scheduling of Pumped Storage Plants" [Chazarra et al., 2017g], it is studied the value of perfect information of the residual demand curves of the secondary regulation reserve market in the context of the operation of a closed-loop and daily-cycle PSHP participating in the day-ahead energy market and in the secondary regulation service of the Iberian and the Spanish electricity systems, respectively. The model used in this paper is the same as the one published in [Chazarra et al., 2017f]. This paper can be considered as a continuation of [Chazarra et al., 2017f] because the case study considers the same PSHP with the same technical data and in the same time period than the one used in [Chazarra et al., 2017f] in order to establish comparisons between the value of perfect information of the day-ahead energy market prices and the one of the residual demand curves of the secondary regulation reserve market. Note that in this paper, the model assumes perfect information in all the electric power system data of the problem except in the residual demand curves of the secondary regulation reserve market.

This publication is linked to the objectives of the Thesis (Figure 1.8) as follows: it is used as a tool to develop the main goal of the Thesis (the risk-averse optimisation model with look ahead period, Chapter 3) because the residual demand curves of the secondary regulation reserve market are predicted with the forecasting model that obtains the lowest value of perfect information. Besides, it applies for the forth secondary objective of the Thesis (to develop forecasting models). Finally, this paper also applies for a part of the first secondary objective of the Thesis (to analyse the value of perfect information of the electric power system data). 


\section{Economic Impact of Forecasting Errors in Residual Reserve Curves in the Day-ahead Scheduling of Pumped Storage Plants}

\author{
Manuel Chazarra and Juan I. Pérez-Díaz \\ Technical University of Madrid (UPM) \\ Madrid, Spain \\ manuel.chazarra@upm.es; ji.perez@upm.es
}

\author{
Javier García-González \\ Institute for Research in Technology \\ Comillas Pontifical University \\ Madrid, Spain \\ javier.garcia@iit.comillas.edu
}

\author{
Arild Helseth \\ SINTEF Energy Research \\ Trondheim, Norway \\ arild.helseth@ sintef.no
}

\begin{abstract}
The economic impact of forecasting errors in the residual demand curves of the secondary regulation reserve market is analysed in the context of the operation of a closed-loop and daily-cycle pumped-storage hydropower plant. The plant participates in the day-ahead energy market as a price-taker and in the secondary regulation reserve market as a price-maker. The secondary regulation energy due to the real-time use of the committed reserves is also considered in the optimization model. The results show that profit is significantly more sensitive to forecast errors in the day-ahead energy market prices than in the residual demand curves of the secondary regulation reserve market.
\end{abstract}

Index Terms-Pumped-Storage Plant, Secondary Regulation Service, Residual Reserve Curve Forecasting, Value of Perfect Information.

\section{NOMENCLATURE}

$\begin{array}{ll}\text { Acronyms } & \\ \text { AP } & \text { Actual total profit } \\ \text { DM Prices } & \begin{array}{l}\text { Day-ahead energy market prices } \\ \text { DM Profit in the day-ahead energy market }\end{array} \\ \text { ER2 Prices } & \begin{array}{l}\text { Upward and downward secondary regulation } \\ \text { energy prices }\end{array} \\ \text { ER2UP } & \begin{array}{l}\text { Income due to the real-time use of the upward } \\ \text { reserves } \\ \text { Cost due to the real-time use of the downward } \\ \text { reserves }\end{array} \\ \text { ER2DW } & \begin{array}{l}\text { Maximum theoretical income } \\ \text { MTI }\end{array} \\ \text { PSHP } & \begin{array}{l}\text { Pumped-storage hydropower plant } \\ \text { Residual reserve curve, i.e. the residual demand } \\ \text { curve of the secondary regulation reserve market }\end{array} \\ \text { RTURs } & \begin{array}{l}\text { Percentage of the real-time use of the upward and } \\ \text { downward reserves }\end{array}\end{array}$

SM Income Actual income in the secondary regulation reserve market

VPI Value of perfect information

VPI-DM Value of perfect information of the day-ahead energy prices

VPI-RRC Value of perfect information of the residual reserve curve

\section{INTRODUCTION}

Traditionally, pumped-storage hydropower plants (PSHPs) have been operated following a price-arbitrage strategy in the day-ahead energy market (selling energy during peak hours and buying energy during off-peak hours) [1]. Recently, several papers have dealt with the joint operation of PSHPs in the day-ahead energy market and in ancillary services such as the tertiary regulation service [2] and the secondary regulation service modelling the plant as a price-taker [3], [4] or as a price-maker [5], [6].

In the context of the Spanish power system, the income from the secondary regulation reserve market is often higher than from the day-ahead energy market or from the real-time use of reserves [3], [5]. For this reason, we believe that studying the economic impact of the forecasting errors in the secondary regulation reserve market market can make a significant contribution to the technical literature.

The value of perfect information of the day-ahead energy prices has been studied in the technical literature in the context of: i) load-shifting industrial plants [7], ii) demand-side market customers [8], iii) a thermal and hydro-based generation company [9], iv) PSHPs participating in the day-ahead energy market [10] and v) PSHPs participating in the day-ahead energy market and in the secondary regulation service [5]. However, to the author's knowledge, there is no paper in the literature where the value of perfect information of the residual demand curves of the secondary regulation reserve market (hereafter referred to as the residual reserve curves, RRCs) is studied.

This paper can be considered as a continuation of [5]. Firstly, the presented case study considers the same PSHP with the same technical data and in the same time period than the one used in [5] in order to establish comparisons. And secondly, the presented paper covers some remaining questions regarding the uncertain data of the problem. According to the results presented in [5], the value of perfect information (also called the economic impact [8] or the profit loss [10]) of the day-ahead energy prices is between $26-40 \%$ of the maximum theoretical income, representing an important loss of profit 
due to the errors in forecasting the day-ahead energy market prices.

Therefore, the main goal of this paper is to calculate and analyse the value of perfect information (VPI) of the residual reserve curves (hereafter referred to as the VPI-RRCs) and to compare it to the VPI of the day-ahead energy prices, in the context of the operation of conventional ${ }^{1}$ PSHPs, participating in the day-ahead energy market and the secondary regulation service (power and energy) of the Spanish power system. For this purpose, a deterministic mixed integer quadratic programming model is used. The objective function of the model aims at maximizing the income of a PSHP participating in the day-ahead energy market and in the secondary regulation service, in the framework of the Iberian electricity market [11], [12].

The secondary regulation service in the Spanish electricity market comprises: 1) a day-ahead reserve market, which takes place after having cleared the day-ahead energy market and where the secondary regulation reserve requirements of the system are assigned. The assigned upward and downward reserves are remunerated by the same marginal market price, and 2) power reserve delivery in real-time according to the assigned reserve in the day-ahead reserve market and the system requirements in real-time. The upward and downward secondary regulation energy is remunerated by the marginal price of the upward and downward tertiary regulation market, respectively [12]. The procedure for the procurement of secondary regulation is not exclusive of the Iberian system. For instance, a similar procedure is implemented in the Swiss system in the short-term (less than a week) and in the Dutch, Belgian, German or Danish electricity systems in a longer-term (more than a week) [13].

The model, used to estimate the VPI-RRCs of a realistic closed-loop and daily-cycle PSHP, is described in [5]. The PSHP is supposed to be a price-taker in the day-ahead energy market and a price-maker in the secondary regulation reserve market. For the purpose to estimate the VPI-RRCs, the model was run, day by day, for a period of one year (2014), in order to obtain representative enough results.

The rest of the paper is organised as follows: the data and the methodology to obtain the VPI-RRCs are presented in Section II. Section III shows the results and discussion and finally, conclusions are presented in Section IV.

\section{IMPACT OF RRC FORECASTING ACCURACY ON INCOME}

\section{A. PSHP technical Data}

The PSHP considered in this paper is the same as in [5]. It is composed by a single reversible Francis pump-turbine unit, whose technical data are presented in Table I: $g$ refers to power, $q$ refers to flow, $\eta$ refers to efficiency and $c S U$ refers to start-up cost. Superscript $d$ refers to generating mode whereas $p$ refers to pumping mode. The gross head is $400 \mathrm{~m}$ with

\footnotetext{
${ }^{1}$ A conventional PSHP is operated with fixed speed in pumping mode and therefore, it cannot participate in the secondary regulation service in the said mode.
}

hydraulic losses of $3 \%$ of the gross head. The head is assumed to be constant. The efficiencies at minimum and maximum water discharges and the minimum water discharge, all of them in generating mode, are calculated following the guidelines of [14]. The relationship between the water discharge and the power generation is assumed to be linear. In pumping mode, the efficiency is $90 \%$ [15]. Therefore, the round-trip efficiency of the plant is $76.3 \%$. The start-up costs in generating and pumping modes are obtained following the guidelines of [16]. The maximum and minimum storage capacities of the upper reservoir are $5 \mathrm{Mm}^{3}$ and $0 \mathrm{Mm}^{3}$, respectively. In each day, the upper reservoir is operated meeting the daily-cycle of the PSHPs, starting and finishing at the storage of $2.5 \mathrm{Mm}^{3}$.

TABLE I

TECHNICAL DATA OF THE PSHP. FLOWS ARE EXPRESSED IN $\mathrm{m}^{3} / \mathrm{s}$ POWER IN $M W$ AND START-UP COST IN $€$.

\begin{tabular}{|c|c|c|c|c|c|c|}
\hline $\bar{q}^{d}$ & $\bar{g}^{d}$ & $\bar{\eta}^{d}$ & $q^{d}$ & \multicolumn{2}{|c|}{$\underline{g}^{d}$} & $\eta^{d}$ \\
\hline 231.5 & 793 & $90 \%$ & 99.5 & \multicolumn{2}{|c|}{287.9} & $76 \%$ \\
\hline $\bar{q}^{p}$ & $\bar{g}^{p}$ & $\eta^{p}$ & \multicolumn{2}{|c|}{$c S U^{d}$} & \multicolumn{2}{|c|}{$c S U^{p}$} \\
\hline 176.6 & 793 & $90 \%$ & & & & \\
\hline
\end{tabular}

\section{B. Historical data of the electric power system}

In this paper, the historical data of the electric power system correspond to: i) the values of the hourly day-ahead energy market prices, ii-iii) the values of the hourly upward and downward regulation energy prices, iv-v) the hourly percentages of the real-time use of the committed upward and downward reserves and vi) the hourly ratios between the offers of the upward and total reserves. Note that the historical data of the RRCs are also considered for obtaining the maximum theoretical income of the problem, as it is presented below. The historical hourly data of iv) and v) provided by each power plant in Spain is not publicly available. Hence, it is assumed that the hourly percentages of the real-time use of the committed upward/downward reserves are given by the historical hourly ratio of the total upward/downward secondary regulation energy and the total assigned upward/downward secondary regulation reserve, respectively, in the entire Spanish electric power system.

\section{Forecasting models}

Perfect knowledge is assumed in all data except in the RRCs. Four Cases are analysed, each corresponding to a different approach to forecast the RRCs, see Table II. In this paper, the RRCs are modelled as a linear function of the upward reserve, Fig. 1b. Forecasting an RRC entails therefore the forecast of two random variables: the intercept and the slope of the linear approximation. According to the results obtained in [17], the error due to the use of a linear RRC is expected to be lower than $2 \%$ of the estimated income using the real historical RRC.

Case A assumes perfect knowledge also in the RRCs, and its results are the maximum theoretical income against which the results of the other Cases are checked. The forecasting 
TABLE II

Cases to forecast the Residual reserve curves, and the Mean Absolute Percentage Error (MAPE) throughout 2014

\begin{tabular}{|c|c|c|c|}
\hline Case & Forecasting Model & MAPE Intercept & MAPE Slope \\
\hline \hline A & Perfect knowledge & No error & No error \\
\hline B & Mean hourly price of 2013 & $35.9 \%$ & $34 \%$ \\
\hline C & Historical RRC of the previous week & $27.1 \%$ & $25.9 \%$ \\
\hline D & Historical RRC of the previous day & $22.6 \%$ & $22.2 \%$ \\
\hline E & SARIMA $(0,1,1)(0,1,1)^{24}$ model & $21.2 \%$ & $25.8 \%$ \\
\hline
\end{tabular}

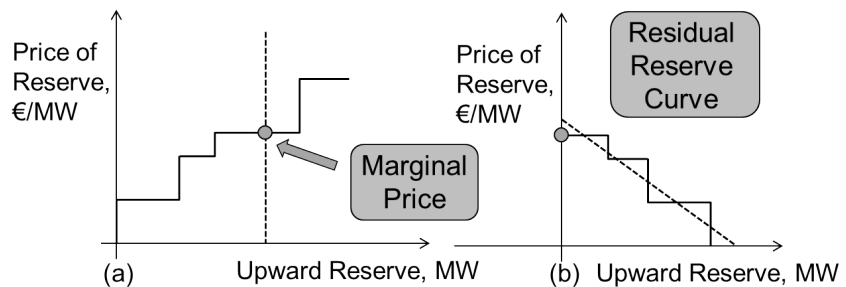

Fig. 1. (a) Supply and demand functions (solid and dashed lines, respectively), and the marginal price of the market. (b) RRC of the upward reserve and its linear approximation (solid and dashed lines, respectively)

model of Case B assumes that the intercept and the slope of the RRC in hour $t$ of a certain day of 2014 is the average intercept and slope in the said hour across all days in 2013, respectively, Fig. 2.

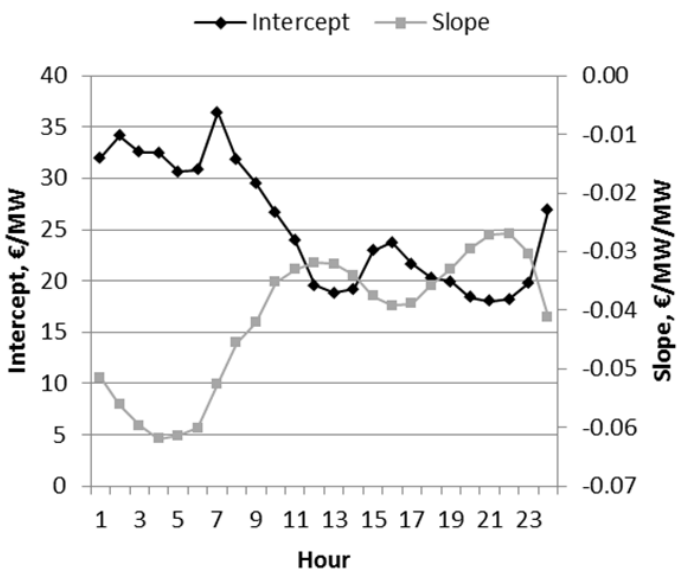

Fig. 2. Intercept and slope of each RRC from Case B

The forecasting models of Case C and D assume that the intercept and the slope of the RRCs in a day $d$ is equal to the historical intercepts and slopes of the RRC of the day $d-7$ (previous week) and the day $d-1$ (previous day), respectively. According to Section 5.9.2 in [18], both the system supply and demand functions of the secondary regulation reserve market in Spain are publicly available daily after having cleared the day-ahead reserve market at 5:45 pm in $d-1$.

The forecasting model of Case $\mathrm{E}$, which is a seasonal autoregressive integrated moving average model (SARIMA) with period 24 , is adjusted as follows. Firstly, a logarithmic transformation and first order regular and seasonal differentiations are carried out to the time series of the intercept and slope in order to obtain regular and seasonal stationary processes. The former transformation is for stabilising the variance whereas the latter is for stabilising the mean. The regular and seasonal autoregressive and moving average parameters of the forecasting model are obtained by an iterative process in which the autocorrelation and partial autocorrelation plots of the transformed time series and of the residuals of the fitted models are inspected at each iteration step. The iterative process is stopped selecting as few parameters as required to properly explain the data and when the residuals are a white noise process ${ }^{2}$.

\section{Methodology}

The VPI-RRCs in each Case is calculated in a given day throughout 2014 by following the next three steps, Fig. 3:

1) the optimal generation and consumption schedules for the day-ahead energy market and the optimal upward and downward secondary regulation reserve schedules for the reserve market are obtained by solving the mixed integer quadratic programming model proposed in [5]. Imperfect information is considered with the forecast RRCs whereas perfect information is assumed in the rest of the data. The rest of the data correspond to the historical values of the day-ahead energy prices (DM Prices), the upward and downward secondary regulation energy prices (ER2 Prices) and the percentage of the real-time use of the upward and downward reserves (RTURs). The model is solved by the branch and cut algorithm in CPLEX 12.2 in a computer with a $2.4 \mathrm{GHz}$ Intel Core i5-450M CPU and 4 GB of RAM memory. Each Case, composed by 365 daily problems, is solved in around $30 \mathrm{~min}$.

2) the actual profit in the secondary regulation reserve market is calculated in a post-optimal simulation process from the optimal hourly reserve schedule obtained in the previous step and the actual hourly price of reserve. Note that the latter is the result of evaluating the optimal hourly reserve schedule with the linear approximation of the historical RRC.

3) the VPI-RRC in each Case is calculated as the difference between the maximum theoretical income (MTI) and the actual total profit (AP) in each Case. The MTI is obtained assuming perfect information in all data (Case

\footnotetext{
${ }^{2}$ A white noise process has zero mean, constant variance, uncorrelated process and normal distribution.
} 


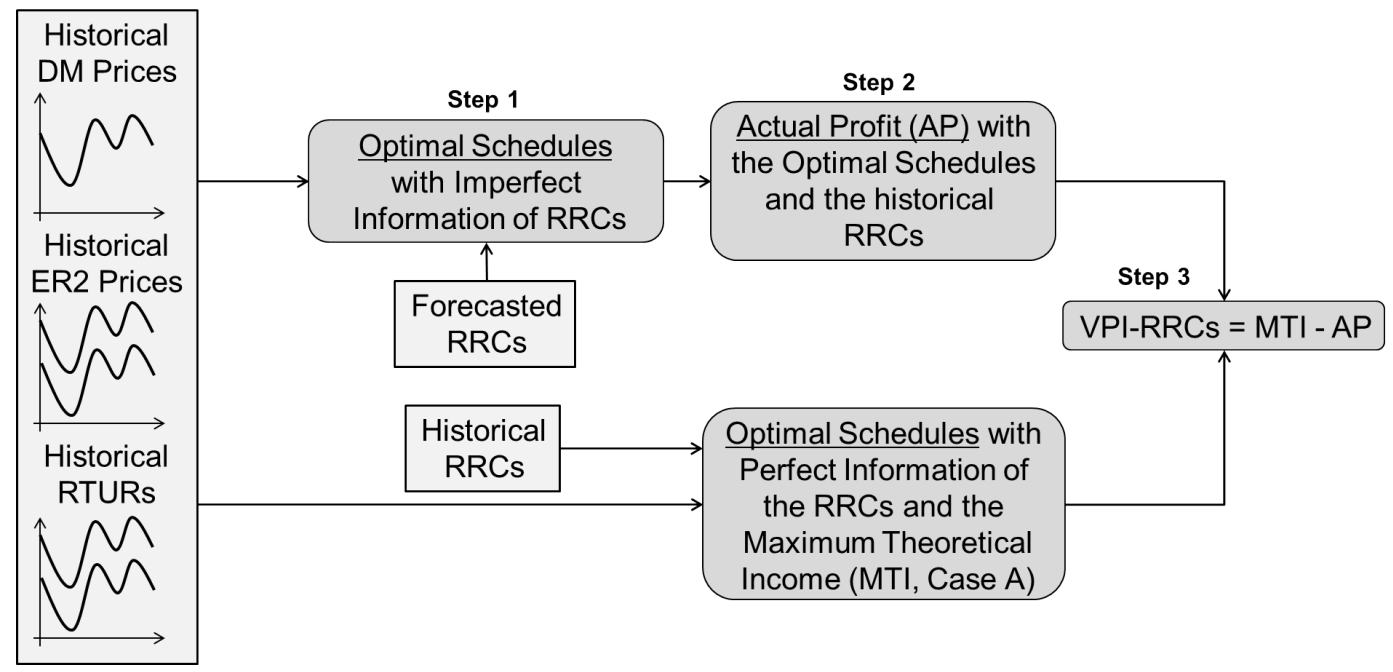

Fig. 3. Methodology to obtain the VPI-RRCs in each Case (except for Case A)

A) whereas the AP considers the SM Income from the previous step. The methodology presented in Fig. 3 is based on the one proposed in [7] and [10]. Note that the AP is the result of the profit in the day-ahead energy market, the income of the secondary regulation service (capacity and energy) and the start-up costs in generating and pumping modes $(\mathrm{AP}=\mathrm{DM}$ Profit + net income in the secondary regulation service - start-up costs).

\section{RESULTS AND DISCUSSION}

The economic results are shown in Table III. They comprise the profit in the day-ahead energy market (DM Profit) as the difference between the income due to the sold energy minus the cost due to the purchased energy, the actual income in the secondary regulation reserve market (SM Income), the income due to the real-time use of the upward reserves (ER2UP), the cost due to the real-time use of the downward reserves (ER2DW), the start-up costs in generating $\left(c S U^{d}\right)$ and pumping $\left(c S U^{p}\right)$ modes, the AP, and the VPI-RRCs in $€$ and in $\%$ of the maximum theoretical income.

The obtained VPI-RRCs ranges between $6.28-7.58 \%$ of the MTI. The VPI-RRCs is significantly lower in all Cases than the value of perfect information of the day-ahead energy prices (VPI-DM) published in the technical literature $[5]^{3}$. The Case with the lowest VPI-RRCs is Case E, which forecasts the RRCs with a SARIMA model. The Case with the highest VPI-RRCs corresponds to Case B, which predicts the RRCs with a naive forecasting model (the hourly average intercept and slope of the RRCs across all days of the previous year).

There seems to be a certain positive correlation between the MAPE of the proposed forecasting models and the VPI-RRCs, Fig. 4, especially for the forecasting models of the RRCs intercept.

\footnotetext{
${ }^{3}$ The VPI-DM published in [5] ranges from 26.9 to $40.4 \%$ of the maximum theoretical income. Note that the case study in [5] uses the same PSHP with the same technical data and in the same time period (2014) than the one used in the presented paper.
}

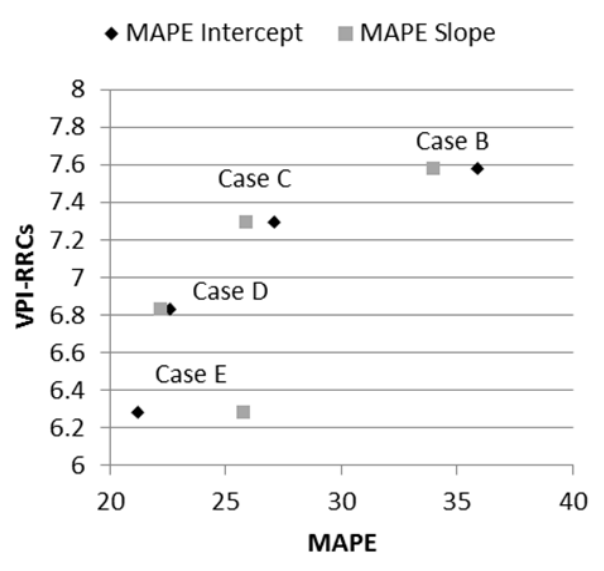

Fig. 4. Relationship between the indicator MAPE and the VPI-RRCs for all the analysed Cases.

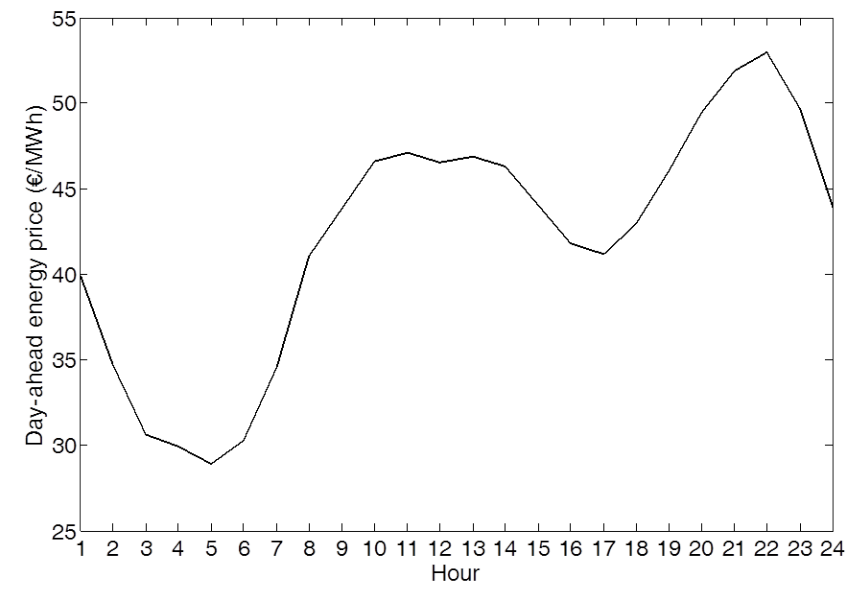

Fig. 5. Hourly average price of the day-ahead energy market across all days in 2014 
TABLE III

ECONOMIC RESULTS AND THE VPI-RRCS THROUGHOUT 2014. INCOME, PROFIT AND VPI-RRCS IN $€$

\begin{tabular}{|c|c|c|c|c|c|c|c|c|c|}
\hline Case & DM Profit & SM Income & ER2UP & ER2DW & $c S U^{d}$ & $c S U^{p}$ & AP & \multicolumn{2}{|c|}{ VPI-RRCs } \\
\hline A & 11408606.9 & 15650021 & 6212864.8 & -4631307.6 & -2462010.2 & -1303148.1 & 24875026.9 & - & - \\
\hline B & 10487924.6 & 15495998.7 & 6944690.4 & -5795952.6 & -2686071.8 & -1457830.7 & 22988758.7 & 1886268.2 & $7.58 \%$ \\
\hline $\mathrm{C}$ & 10737505 & 14610301.7 & 6468411.8 & -4844905.1 & -2528695.2 & -1381548.9 & 23061069.3 & 1813957.6 & $7.29 \%$ \\
\hline $\mathrm{D}$ & 1171481.4 & 14261552.3 & 6312814.5 & -4648837.5 & -2544699.6 & -1377311 & $23 \quad 175000.2$ & 1700026.7 & $6.83 \%$ \\
\hline E & 13101013.3 & 12329141.9 & 5670286.9 & -4259814.8 & -2 275292.2 & -1252293.5 & 23313041.5 & 1561985.3 & $6.28 \%$ \\
\hline
\end{tabular}

Several reasons can be discussed to understand why the VPI-RRCs is not significant in comparison to the VPI-DM.

1) As the PSHP is operated with fixed speed in pumping mode, it cannot participate in the secondary regulation service in the said mode. Therefore, the forecast errors of the day-ahead energy prices at peak and off-peak hours have an impact on the PSHP income. However, only the forecast errors of the RRCs at peak hours of the day-ahead energy prices (when the plant is typically scheduled to operate in generating mode) have an impact on the PSHP income.

2) A PSHP with fixed speed is usually operated in generating mode at peak hours (when the day-ahead energy price is high). At these hours, the intercept of the RRCs is roughly half of the day-ahead energy price (see Figs. 2 and 5). Considering that, in the Spanish power system, the hourly ratio between the upward and total (upward + downward) reserve is requested to be close to 0.5 , an error in the RRC intercept has inevitably a lower impact on the PSHP income than an error of the same magnitude (in relative terms) in the day-ahead energy price.

In order to better understand this discussion, we invite the reader to imagine three different situations in a specific hour, see Table IV. In Situation 1, the PSHP sells $500 \mathrm{MW}$ in the day-ahead energy market and 200 MW of upward and downward reserve in the reserve market. In Situation 2, the PSHP sells also 500 MW in the day-ahead market and only $30 \mathrm{MW}$ of upward and downward reserve in the reserve market. And in Situation 3, the PSHP sells 350 MW in the day-ahead energy market and also 30 MW of upward and downward reserve in the reserve market. Considering an average peak energy price of $50 € / \mathrm{MWh}$ (Fig. 5), and an average RRC intercept of $20 € / \mathrm{MW}$ at peak hours of the day-ahead energy market (Fig. 2), an error of $20 \%$ means a forecast day-ahead energy price and RRC intercept of $40 € / \mathrm{MWh}$ and $16 € / \mathrm{MW}$, respectively. Assuming a conservative value of the RRC slope $(-0.03 € / \mathrm{MW} / \mathrm{MW})$, the actual and forecast price of reserve would be, respectively, 14 and $10 € / M W$, in Situation 1, and 19.1 and 15.1 €/MW, in Situation 2 and 3. The error in day-ahead energy price means $5000 €$ in Situation 1 and 2 and $3500 €$ in Situation 3, whereas the error in the intercept means $1600 €$ in Situation 1 and $240 €$ in Situation 2 and 3. Although the forecast error is the same (20\%), the error in the RRC intercept has a much lower impact on the PSHP income, regardless of the scheduled reserve (high in Situation 1 or low in Situation 2 and 3).

3) Analogously, an error in the RRC slope results in an error in the price of the secondary regulation reserve that has a lower impact on the PSHP income than an error of the same magnitude (in relative terms) in the day-ahead energy price.

Using the same three Situations described above (see Table IV) and considering an average RRC slope of $-0.03 € / M W / M W$ at peak hours of the day-ahead energy market (Fig. 2), an error of $20 \%$ means a RRC slope of $-0.036 € / M W / M W$. Assuming a RRC intercept of 20 $€ / \mathrm{MW}$, the actual and forecast price of reserve would be, respectively, 14 and $12.8 € / \mathrm{MW}$ in Situation 1, and 19.1 and $18.92 € / M W$ in Situation 2 and 3. The error in day-ahead energy price means $5000 €$ in Situation 1 and 2 and $3500 €$ in Situation 3, whereas the error in the RRC slope means $480 €$ in Situation 1 and 10.8 $€$ in Situation 2 and 3. Although the forecast error is the same (20\%), the error in the RRC slope has a much lower impact on the PSHP income, regardless of the scheduled reserve.

TABLE IV

SITUATIONS TO UNDERSTAND WHY THE VPI-RRCS IS NOT SIGNIFICANT IN COMPARISON TO THE VPI-DM

\begin{tabular}{|c|c|c|c|}
\hline & Situation 1 & Situation 2 & Situation 3 \\
\hline Produced Power, $g^{d}, \mathrm{MW}$ & 500 & 500 & 350 \\
\hline Upward Reserve, MW & 200 & 30 & 30 \\
\hline Downward Reserve, MW & 200 & 30 & 30 \\
\hline Energy Price, $€$ /MWh & 50 & 50 & 50 \\
\hline $\begin{array}{c}\text { Energy Price with Error, } \\
€ / M W h\end{array}$ & 40 & 40 & 40 \\
\hline Price of Reserve, $€ / M W$ \\
\hline $\begin{array}{c}\text { Price of Reserve with Error } \\
\text { in the Intercept, } € / M W\end{array}$ & 10 & 15.1 & 19.1 \\
\hline $\begin{array}{c}\text { Price of Reserve with Error } \\
\text { in the Slope, } € / M W\end{array}$ & 12.8 & 18.92 & 18.92 \\
\hline VPI-DM, $€$ & 5000 & 5000 & 3500 \\
\hline $\begin{array}{c}\text { VPI-RRC with Error in the } \\
\text { Intercept, } €\end{array}$ & 1600 & 240 & 240 \\
\hline $\begin{array}{c}\text { VPI-RRC with Error in the } \\
\text { Slope, } €\end{array}$ & 480 & 10.8 & 10.8 \\
\hline
\end{tabular}

Consequences of the obtained results in the presented paper are the following: 
1) Harder effort is to be carried out in forecasting the day-ahead energy prices in comparison to forecasting the RRCs as the profit loss due to forecast errors in the former is larger than in the latter, in the context of the day-ahead scheduling of conventional PSHPs participating in the day-ahead energy market and in the secondary regulation service of the Spanish power system.

2) Among all the uncertain parameters that are presented in the day-ahead energy and reserve scheduling (the day-ahead energy prices, the RRCs, the upward and downward secondary regulation energy prices and the real-time use of the upward and downward reserves), the uncertainty of the RRCs might be reasonably modelled with an expected value in order to reduce the computational burden and the size of the scenario tree in a stochastic optimization scheduling model.

Despite the foregoing, the observed profit loss due to the RRCs forecast errors should be complemented by independently analysing the VPI of the rest of uncertain variables that are involved in the secondary regulation service, namely: the secondary regulation energy prices and the real-time use of the reserves. This is proposed as a future work. In addition to this, it is also expected an increase in the VPI-RRCs in advanced PSHPs such as those operating in hydraulic short-circuit mode or with variable speed as they are able to participate in the secondary regulation service also when they are pumping. To study the extent to which the VPI-RRCs increases in advanced PSHPs is also proposed as a future work.

\section{Conclusions}

The economic impact of forecasting errors in the residual demand curves of the secondary regulation reserve market has been analysed in the hourly scheduling of a closed-loop and daily-cycle PSHP. The PSHP has been allowed to participate in the day-ahead energy market as a price-taker and in the secondary regulation reserve market as a price-maker. The economic impact was found to be $6-8 \%$ of the maximum theoretical income, which is significantly lower than the impact of the errors in forecasting the day-ahead energy prices (between $26-40 \%$ of the maximum theoretical income according to the technical literature for the same PSHP in the same case study). Therefore, it seems reasonable to conclude that among all the uncertain variables involved in the day-ahead scheduling, the residual reserve curves can be modelled with an expected value in order to reduce the computational burden in a stochastic optimization scheduling model.

As a future work, it is proposed to analyse the value of perfect information of the residual reserve curves for more flexible PSHPs such as those operating in hydraulic short-circuit mode or with variable speed, and to calculate independently the value of perfect information of the rest of the uncertain variables of the secondary regulation service: the upward and downward regulation energy prices and the percentage of the real-time use of the upward and downward reserves.

\section{ACKNOWLEDGEMENTS}

The authors acknowledge the Spanish Ministry of Economy and Competitiveness for funding this work under the project of The National Scientific Research, Development and Technological Innovation Plan 2008-2011 “Optimal operation and control of pumped-storage hydropower plants" (Ref. ENE2012-32207).

\section{REFERENCES}

[1] J. I. Pérez-Díaz, M. Chazarra, J. García-González, G. Cavazzini, and A. Stoppato, "Trends and challenges in the operation of pumped-storage hydropower plants," Renewable and Sustainable Energy Reviews, vol. 44, pp. 767-784, 2015.

[2] A. Ortner and C. Graf, "Multi-market unit-commitment and capacity reserve prices in systems with a large share of hydro power: A case study," in European Energy Market (EEM), 2013.

[3] M. Chazarra, J. Pérez-Díaz, and J. García-González, "Optimal Operation of Variable Speed Pumped Storage Hydropower Plants Participating in Secondary Regulation Reserve Markets,' in European Energy Market (EEM), 2014.

[4] J. M. Filipe, C. L. Moreira, and B. A. Silva, "Optimization of the Variable Speed Pump Storage Participation in Frequency Restoration Reserve Market," in European Energy Market (EEM), 2016.

[5] M. Chazarra, J. I. Perez-Diaz, and J. Garcia-Gonzalez, "Value of perfect information of spot prices in the joint energy and reserve hourly scheduling of pumped storage plants," Electric Power Systems Research, vol. 148, pp. 303-310, 2017.

[6] J. Lagarto and I. Adeeea, "Multi-market optimal scheduling of a power generation portfolio with a price-maker pumped-storage hydro unit," in European Energy Market (EEM), 2016.

[7] T. Mathaba, X. Xia, and J. Zhang, "Analysing the economic benefit of electricity price forecast in industrial load scheduling," Electric Power Systems Research, vol. 116, pp. 158-165, 2014.

[8] H. Zareipour, C. Canizares, and K. Bhattacharya, "Economic Impact of Electricity Market Price Forecasting Errors: A Demand-Side Analysis," IEEE Transactions on Power Systems, vol. 25, no. 1, pp. 254-262, 2010.

[9] B. Mohammadi-Ivatloo, H. Zareipour, M. Ehsan, and N. Amjady, "Economic impact of price forecasting inaccuracies on self-scheduling of generation companies," Electric Power Systems Research, vol. 81, no. 2, pp. 617-624, 2011.

[10] E. Delarue, P. Van Den Bosch, and W. D'haeseleer, "Effect of the accuracy of price forecasting on profit in a Price Based Unit Commitment," Electric Power Systems Research, vol. 80, no. 10, pp. 1306-1313, 2010.

[11] "Mercado Ibérico de la Electricidad." [Online]. Available: http://www.mibel.com/

[12] C. Fernandes, P. Frías, and J. Reneses, "Participation of intermittent renewable generators in balancing mechanisms: A closer look into the Spanish market design," Renewable Energy, vol. 89, pp. 305-316, 2016.

[13] E. Rivero, J. Barquín, and L. Rouco, "European Balancing Markets," in European Energy Market (EEM), 2011.

[14] U.S. Bureau of Reclamation, Selecting Hydraulic Reaction Turbines. U.S. Government Printing Office, 1976.

[15] J. Raabe, Hydro Power - The Design, Use and Function of Hydromechanical, Hydraulic and Electrical Equipment. VDI Verlag, 1985.

[16] O. Nilsson and D. Sjelvgren, "Hydro Unit Start-up Costs and Their Impact on the Short Term Scheduling Strategies of Swedish Power Producers," IEEE Transactions on Power Systems, vol. 12, no. 1, pp 38-44, 1997.

[17] A. Marulanda, J. Martínez, and A. Gómez, "A comparison of residual demand models for oligopolistic markets," in Power Systems Computation Conference (PSCC), no. August, 2005, pp. 22-26.

[18] Ministerio de Industria Energía y Turismo, "Procedimiento de Operación 9.0, sobre la Información Intercambiada por el Operador del Sistema," pp. 119831-119853, 2015. 


\subsection{Paper-E: Deriving Optimal End of Day Storage for Pumped- Storage Power Plants in the Joint Energy and Reserve Day-ahead Scheduling}

In this paper entitled "Deriving Optimal End of Day Storage for Pumped-Storage Power Plants in the Joint Energy and Reserve Day-ahead Scheduling" [Chazarra et al., 2017a], it is presented a methodology to maximise the income and derive the optimal end-of-day storages of closed-loop and daily-cycle PSHPs. The plants participate in the day-ahead energy market as a price-taker and in the secondary regulation reserve market as a price-maker, in the context of the Iberian and the Spanish electricity systems, respectively. The activation of the secondary regulation reserves is also considered in the model formulation. The model used in this paper is based on the one published in [Chazarra et al., 2017f]. The model assumes perfect information in all the electric power system data. The operation of the PSHPs with the proposed methodology is compared to the one that use the price-arbitrage strategy (an endof-day storage of an empty reservoir) and to a one that has been previously used in the Thesis (an end-of-day storage half of the storage capacity). The comparison is carried out, among others, to quantify the extent to which the presented methodology can enlarge the maximum theoretical income with respect to the rest of operation strategies (end-of-day storages of an empty or half empty reservoir), and to quantify the extent to which the participation of the PSHP in the day-ahead energy market and the secondary regulation reserve market can enlarge its maximum theoretical income with respect to the participation only in the day-ahead energy market with the presented methodology. In the case study, the previously mentioned comparisons are carried out for nine different PSHPs, which are chosen to cover almost all the range of daily-cycle PSHPs (between 4-12 hours of empting the upper reservoir at maximum water discharge). The PSHPs are assumed to be equipped with one binary unit operating at fixed speed.

This publication is linked to the objectives of the Thesis (Figure 1.8) as follows: the proposed methodology of using a look ahead period is included in the risk-averse optimisation model with look ahead period of the main goal of the Thesis, Chapter 3. Besides, it applies for the third secondary objective of the Thesis (to analyse different methodologies to derive the optimal end-of-day storages). 
Article

\title{
Deriving Optimal End of Day Storage for Pumped-Storage Power Plants in the Joint Energy and Reserve Day-Ahead Scheduling
}

\author{
Manuel Chazarra ${ }^{1, *}$, Juan I. Pérez-Díaz ${ }^{1}$ and Javier García-González ${ }^{2}$ \\ 1 Department of Hydraulic, Energy and Environment Engineering, Escuela de Ingenieros de Caminos, \\ Canales y Puertos, Universidad Politécnica de Madrid, 28040 Madrid, Spain; ji.perez@upm.es \\ 2 Institute for Research in Technology, Technical School of Engineering (ICAI), Comillas Pontifical University, \\ 28015 Madrid, Spain; javiergg@iit.comillas.edu \\ * Correspondence: manuel.chazarra@upm.es; Tel.: +34-616-648-842; ORCID ID: 0000-0003-2221-220X
}

Academic Editor: Ånund Killingtveit

Received: 8 March 2017; Accepted: 9 June 2017; Published: 15 June 2017

\begin{abstract}
This paper presents a new methodology to maximise the income and derive the optimal end of day storage of closed-loop and daily-cycle pumped-storage hydropower plants. The plants participate in the day-ahead energy market as a price-taker and in the secondary regulation reserve market as a price-maker, in the context of the Iberian electricity system. The real-time use of the committed reserves is considered in the model formulation. The operation of the plants with the proposed methodology is compared to the ones that use an end of day storage of an empty reservoir or half of the storage capacity. Results show that the proposed methodology increases the maximum theoretical income in all the plants analysed both if they only participate in the day-ahead energy market and if they also participate in the secondary regulation service. It is also shown that the increase in the maximum theoretical income strongly depends on the size of the plant. In addition, it is proven that the end of day storages change notably in the new reserve-driven strategies of pumped-storage hydropower plants and that the proposed methodology is even more recommended if the secondary regulation service is considered.
\end{abstract}

Keywords: pumped-storage hydropower plants; secondary regulation service; end of day storage; price-maker approach; water value

\section{Introduction}

Closed-loop and daily-cycle pumped-storage hydropower plants (PSHPs) (A closed-loop pumped-storage hydropower plant does not receive natural water inflows in the upper reservoir and does not release water from the lower reservoir. In addition, a daily-cycle pumped-storage hydropower plant is able to empty and refill the upper reservoir in less than $24 \mathrm{~h}$.) have been traditionally operated by the so-called price-arbitrage strategy [1]. The strategy is based on participating in the day-ahead energy market selling energy at peak price hours and purchasing energy at off-peak price hours. The peak/off-peak price hours usually happen in the morning/at night, respectively. In order to maximize the income of the PSHP under the mentioned strategy, the upper reservoir usually starts every day at 0:00 hours empty (to pump water and store energy at night) and finishes the day in the same conditions to fulfil the daily-cycle.

However, nowadays the economic viability of a PSHP might not be guaranteed if they are operated just with the price-arbitrage strategy [2]. Due to this, in the past years, several publications have proposed the PSHPs to participate in other markets and services, apart from the day-ahead energy market, in order to enlarge their income: in the secondary regulation service [3], in the tertiary 
regulation service [4] and in the intraday markets [5]. In this paper, we focus on the participation in the secondary regulation service because it has been little studied [6].

The participation of PSHPs in the secondary regulation service might change the traditional operation strategy [7] as regards the end of day storages: on the one hand, starting the following day empty may not be optimum because the PSHP does not have enough water to participate in the secondary regulation service (If the PSHP participates in the secondary regulation service, enough storage is required to deal with the real-time use of the upward reserves. It is important to note that conventional PSHPs can participate in the secondary regulation service only in generating mode.) and, on the other hand, starting the following day with the upper reservoir full may not be optimum because the PSHP does not have enough storage capacity in the upper reservoir to pump water at low prices of the day-ahead energy market. Therefore, in order to determine the optimum end of day storage, the decision maker should deal with the trade-off between: (1) having sufficient storage capacity if the model decides to pump water; and (2) having sufficient water if the model decides to participate in the secondary regulation reserve market.

The main goals and contributions of this paper are: (i) to propose a methodology to maximize the income and determine the optimal end of day storage of closed-loop and daily-cycle PSHPs participating in the day-ahead energy market (DM) and in the secondary regulation service (SRS) of the Spanish power system; (ii) to quantify the extent to which the proposed methodology can enlarge the maximum theoretical income with respect to the traditional operation strategy; and (iii) to quantify the extent to which the participation of the PSHP in the DM and the SRS can enlarge its maximum theoretical income with respect to the participation only in the DM with the proposed methodology.

The SRS of the Spanish power system comprises two concepts $[8,9]$. The first one is a day-ahead reserve market $(\mathrm{SM})$, which takes place after having cleared the DM and where the upward and downward secondary regulation reserves are assigned, and remunerated according to the same marginal market price. The second one is the secondary regulation energy, i.e., the reserves that are used in real-time by the transmission system operator (TSO) in order to ensure the demand-generation balance. This upward/downward secondary regulation energy is remunerated according to the marginal price of the upward/downward tertiary regulation market. The upward/downward secondary regulation energy represents an income/cost for the PSHP. Note that the procedure for the procurement of the SRS is not exclusive of the Spanish system. A similar procedure is implemented in Norway, Sweden, Finland, Slovenia, Czech Republic and Romania in the short-term (less than a week) and in Denmark, Netherlands, Belgium, Germany, Austria and Switzerland in the long-term (more than a week) [10].

The proposed methodology is based, in part, on the one described in [11,12]. The methodology in [11] uses a look-ahead period of up to six days for the day-ahead energy and reserve scheduling of closed-loop and weekly-cycle PSHPs from a centralized (system-based) point of view. The methodology proposed in this paper makes also use of a look-ahead period for the day-ahead energy and reserve scheduling of closed-loop and daily-cycle PSHPs. Main differences of the presented paper with respect to [11] are: (1) the model here presented is aimed to maximize the income of the PSHP, whereas the one presented in [11] is aimed to reduce the operation cost of the power system; (2) the use in real-time of the committed reserves for the provision of upward and downward secondary regulation energy is considered in this paper; and (3) the proposed methodology is applied for several PSHPs. The work presented in [12] also proposes a methodology similar to the one in [11], with a rolling horizon optimization and a look-ahead period in the context of electricity storage arbitrage in the DM. The main difference of the methodology here presented with respect to the one proposed in [12] is that in the presented paper both energy and reserve are jointly scheduled for the next day. Thus, this paper deals with one of the challenges that was identified in [7] for the operation of PSHPs, as regards the definition of optimal end of day storages in reserve-driven operation strategies of PSHPs.

This paper is organized as follows. Section 2 describes the methodology and model formulation for optimizing the end of day storages. Section 3 presents the case study in which the presented 
methodology is tested. Section 4 shows the results of this research and the discussion of them. Finally, Section 5 presents the main conclusions and the future work.

\section{Derivation of End of Day Storages}

In this paper, two methodologies for the joint day-ahead scheduling of the energy and secondary regulation reserves of a PSHP are compared with each other. The first one considers an end of day storage equal to the initial water volume, as it is usually done in the literature [13], whereas the second one uses a look-ahead period. Hereinafter, the former will be referred to as the methodology without a look-ahead period, and the latter as the one with a look-ahead period. In this context, the look-ahead period refers to the number of hourly steps after a Day D that is considered in the model to decide the optimal energy and reserve schedules in D.

The methodology without a look-ahead period is based on the following (see the upper part of Figure 1). The day-ahead scheduling decisions for Day D are obtained as a result of an optimization problem with a 24-h time horizon, discretized in hourly steps. The initial water volume of the upper reservoir in $\mathrm{D}$ is known by the decision maker, and is usually equal to the minimum one (empty at 0:00), and the final water volume is forced to equal the initial volume in order to fulfill the daily-cycle of the PSHP.
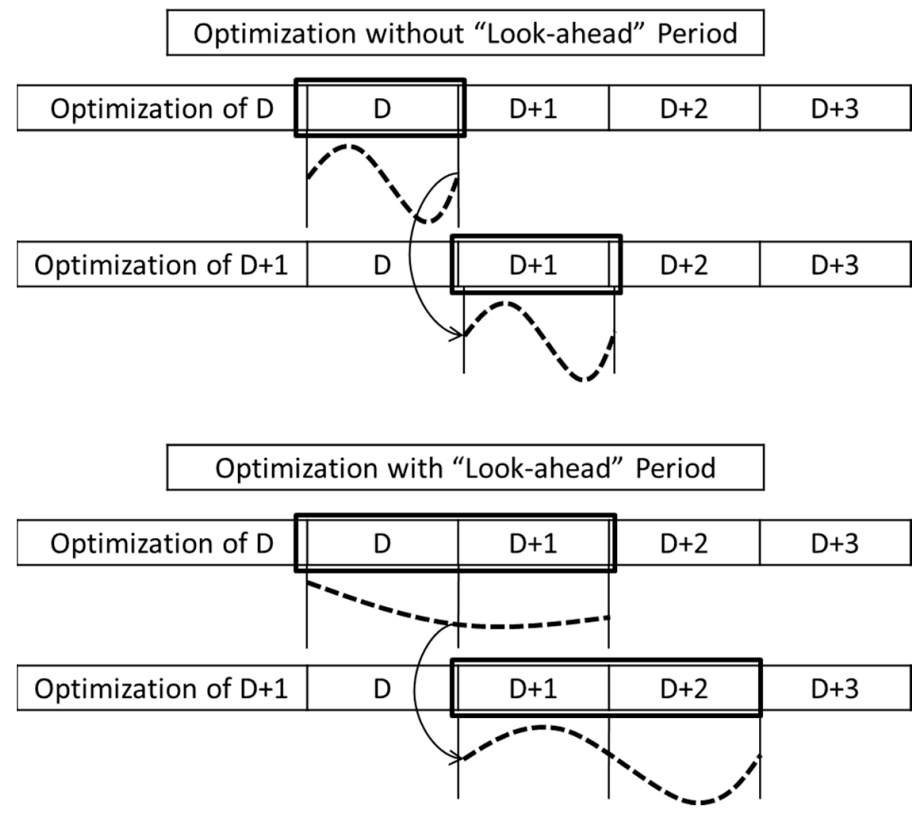

Figure 1. Scheme of the proposed methodology to determine the reservoir initial volume.

The methodology with a look-ahead period uses future information of the electricity power system data and is based on the following (see the lower part of Figure 1). The day-ahead scheduling decisions for Day D are obtained as a result of an optimization problem with a $(24 \times(1+n))$-hour time horizon, i.e., $\mathrm{D}, \mathrm{D}+1, \mathrm{D}+2, \ldots, \mathrm{D}+n$ (with $n>0$ ), also discretized in hourly steps. Note that the lower part of Figure 1 is a particular case of the proposed methodology with one day of look-ahead period, i.e., $n=1$. The initial water volume of the upper reservoir in $\mathrm{D}$ is known by the decision maker, and is obtained as a result of the optimization problem for D - 1. It is important to note that there are no water volume targets at the end of any day $(\mathrm{D}, \mathrm{D}+1, \ldots, \mathrm{D}+n)$.

The above-described methodology with a look-ahead period is conceptually analogous to a water value-based approach because of the size of the PSHPs and the size of the upper reservoir that are considered in this paper: daily-cycle PSHPs, which have a small storage capacity equivalent to few hours (lower or equal $12 \mathrm{~h}$ ) pumping/discharging water at maximum flow. 
The model formulation for both methodologies is based on the one presented in [14], where the impact of the operation of the PSHPs on the market clearing prices of the DM and SM were neglected. Given that the approach presented in [14] assumes a price-taker behavior for both the DM and the SM, the obtained incomes in the SM could be significantly overestimated. In order to overcome this drawback, the model presented in [14] has been conveniently updated in this paper in order to consider the impact in the SM prices of the secondary regulation reserves offered by the PSHP (price-maker approach). The formulation used to model the PSHP as a price-maker is based on the one presented in [15], using a linear approximation of the residual demand curves of the secondary regulation reserve market (RRCs). Note that the PSHPs are modeled as a price-taker in the DM because the maximum power of the analyzed PSHPs (between 400 and $1200 \mathrm{MW}$ ) represents $0.87-2.62 \%$ of the maximum demand of the Spanish system in the said market.

The objective function of the model consists in maximizing the net income in the DM (income due to the sold energy minus cost due to the purchased energy), plus the income for the reserves put at disposal of the TSO in the SM, plus the net income for the secondary regulation energy due to the real-time use of the committed reserves (income/cost due to the real-time use of the upward/downward reserves) and minus the start-up costs in generating and pumping modes. The optimal solution of the model is composed by the hourly schedules in the DM and in the SM, in addition to the hourly schedules of the net secondary regulation energy. Among others, the operation of the PSHPs is restricted to the technical limits of the pump-turbine units and to the maximum and minimum water storage capacity of the upper reservoir.

\section{Case Study}

\subsection{Technical Data}

In the presented paper, nine different PSHPs are studied. They are chosen in order to cover almost all the range of daily-cycle PSHPs: between 4 and $12 \mathrm{~h}$ of empting or refilling the upper reservoir at maximum water discharge and pumped water flow, respectively. The PSHPs are assumed to be equipped with one binary unit operating at fixed speed. A binary unit is composed by a reversible Francis pump-turbine unit and a synchronous motor-generator. The technical data of each PSHP is shown in Table 1. The maximum generation capacity of the $6-12 \mathrm{~h}$ units is close to the one of the largest hydropower units in the world: see [16] for further information about the $805 \mathrm{MW}$ turbine in the Columbia River or see [17] about the 800 MW Francis turbines at the Chinese Xiangjiaba underground hydropower plant. The $4 \mathrm{~h}$ and $5 \mathrm{~h}$ units are also studied for illustrative purposes although their maximum generation capacity is higher. Unpublished results of the authors show that the operation and the economic results are the same for both a $1 \times 1200$ MW PSHP and a $2 \times 600$ MW PSHP.

Table 1. Technical data of each PSHP. $g$ refers to power, $q$ refers to flow and $c S U$ refers to start-up cost. Superscript $d$ refers to generating mode and $p$ refers to pumping mode. Flows are expressed in $\mathrm{m}^{3} / \mathrm{s}$, power in MW and start-up costs in $€$.

\begin{tabular}{ccccccccc}
\hline PSHP & $\bar{q}^{d}$ & $\bar{g}^{d}$ & $q^{d}$ & $g^{d}$ & $\bar{q}^{p}$ & $\bar{g}^{p}$ & $c S U^{d}$ & $c S U^{p}$ \\
\hline 4h & 350.3 & 1200 & 150.6 & 529 & 350.3 & 1573.1 & 3971.1 & 4078.3 \\
5 h & 280.2 & 960 & 1.5 & 423.2 & 280.2 & 1258.5 & 3201.9 & 3287.7 \\
6 h & 233.5 & 800 & 100.4 & 352.7 & 233.5 & 1048.8 & 2689.2 & 2760.7 \\
7 h & 200.2 & 685.7 & 86.1 & 302.3 & 200.2 & 898.9 & 2322.9 & 2384.2 \\
8 h & 175.2 & 600 & 75.3 & 264.5 & 175.2 & 786.6 & 2048.3 & 2101.8 \\
9 h & 155.7 & 533.3 & 66.9 & 235.1 & 155.7 & 699.2 & 1834.6 & 1882.2 \\
$10 \mathrm{~h}$ & 140.1 & 480 & 60.3 & 211.6 & 140.1 & 629.3 & 1663.7 & 1706.5 \\
11 h & 127.4 & 436.4 & 54.8 & 192.4 & 127.4 & 572.1 & 1523.8 & 1562.8 \\
12 h & 116.8 & 400 & 50.2 & 176.3 & 116.8 & 524.4 & 1407.3 & 1443.1 \\
\hline
\end{tabular}


Maximum water discharge and pumped water flow have been chosen in order to empty and refill the upper reservoir in 4-12 hours. Note that the upper reservoir has a storage capacity of $5.0443 \mathrm{M} \cdot \mathrm{m}^{3}$ in all cases. For example, the $6 \mathrm{~h}$ PSHP empties/refills the upper reservoir in six hours at its maximum water discharge/pumped water. The gross head is considered to be $400 \mathrm{~m}$ while the hydraulic losses are considered $3 \%$ of the gross head [18].

In generating mode, the minimum flow and efficiencies at maximum and minimum flows are determined from typical performance curves in [18]. A linear relationship between water discharge and power generation is assumed. As the reversible Francis pump-turbine unit is operated at fixed speed in pumping mode, it has a single operating point with a typical efficiency of $90 \%$ [19]. Start-up costs in generating and pumping modes have been calculated following the guidelines of [20].

\subsection{Electric Power System Data}

The electric power system data used in the presented paper are historical hourly values of the prices of the following markets and services for the year 2014: (i) the day-ahead energy market; (ii) the secondary regulation reserve market; (iii) the upward secondary regulation energy; and (iv) the downward secondary regulation energy. Note that as the PSHPs are modeled as a price-maker in (ii), the data of the secondary regulation reserve market are the historical hourly RRCs. Each historical hourly RRC is linearly approximated and defined by the intercept with the price axis and the slope of the linear approximation, as in [15].

The hourly percentage of the committed upward and downward secondary regulation reserves that is requested in real time by the TSO as upward or downward secondary regulation energy is assumed to be equal to the historical hourly ratio of the aggregate use of the reserves and the aggregate committed reserves in the entire system. Moreover, the hourly ratio between the upward and the total (upward plus downward) reserve offers to be submitted in the SM (expressed as ratio in Table 2) is assumed to be equal to the historical hourly ratio of the upward and total secondary regulation reserve requirements in the entire system. The mean values of the above-mentioned electric power system data throughout 2014 are shown in Table 2.

Table 2. Mean values of the electric power system data of the problem throughout 2014. Energy prices and intercept of the reserve curves are expressed in $€ / M W \cdot h$ and $€ / M W$, respectively. The slope of the reserve curves is expressed in $€ / \mathrm{MW} / \mathrm{MW}$.

\begin{tabular}{ccccccccc}
\hline Year & DM & Intercept RRC & Slope RRC & ER2up & ER2dw & RTURup & RTURdw & Ratio \\
\hline 2014 & 42.15 & 20.09 & -0.0335 & 47.36 & 31.34 & $31.98 \%$ & $22.55 \%$ & $57.13 \%$ \\
\hline
\end{tabular}

\subsection{Methodology}

The optimization model is used to obtain the maximum theoretical income (MTI) with and without the mentioned look-ahead period and with and without participating in the SRS. We use the term MTI to refer to the income that the PSHP would obtain assuming perfect information of the hourly energy prices of the DM, the RRCs of the SM, the percentages of the committed reserves effectively used in real-time and the regulation energy prices of $\mathrm{D}$ and the following days $(\mathrm{D}+1, \mathrm{D}+2, \ldots, \mathrm{D}+n)$.

To obtain the MTI throughout 2014, the model was run, day by day, over the 365 days of the year to: (1) prove that the proposed methodology with a look-ahead period to derive the end of day storage is feasible for realistic PSHPs described in Section 3.1; (2) quantify the extent to which the proposed methodology with a look-ahead period can enlarge the MTI with respect to strategies without look-ahead period; and (3) quantify the extent to which the participation, with the proposed methodology, in the DM and the SRS, can enlarge the MTI with respect to the participation only in the DM. Each problem is solved with a branch and cut algorithm in Cplex in a $2.2 \mathrm{GHz}$ Dual Core AMD Turion CPU, with 4 GB of RAM memory. 
Three operation strategies are compared with each other: (1) the SRS/DM D + 1 strategy uses the methodology proposed in this paper with a 1-day look-ahead period (It is proven in Section 4.1 that the proposed methodology with a look-ahead period of one day is enough to obtain a close to maximum income with a reasonable CPU time consumption, in the context of closed-loop and daily-cycle PSHPs participating in the DM as a price-taker and in the SM as a price-maker.), participating/not participating in the SRS; (2) the SRS/DM V0 strategy, which corresponds to the traditional price-arbitrage strategy [2], uses the methodology without look-ahead period, participating/not participating in the SRS, and starting and finishing each day with the upper reservoir empty; and (3) the SRS/DM Vm strategy is the same as (2) but starting and finishing each day at the mean volume of the storage capacity of the upper reservoir. The mean water volume is chosen in strategy (3) in order to have sufficient storage capacity at the beginning of each day if the model decides to pump water and to have sufficient water at the beginning of each day if the model decides to participate in the SRS.

\section{Results and Discussion}

\subsection{Length of the Look-Ahead Period}

The results shown in Figure 2 and Table 3 provide insight on the length of the look-ahead period that allows obtaining a close to maximum income with a reasonable CPU time consumption. In Figure 2, the MTIs of each PSHP participating in the DM and the SRS without (SRS D) and with different look-ahead periods (1-3 days) are shown (SRS D + 1, SRS D + 2, SRS D + 3). In addition, the mean CPU time consumption per problem in each case is also shown (Time $\mathrm{D}$, Time $\mathrm{D}+1$, Time $\mathrm{D}+2$, Time $\mathrm{D}+3$ ). In this comparison, the model without look-ahead period assumes that the upper reservoir is empty at the beginning and the end of each day.

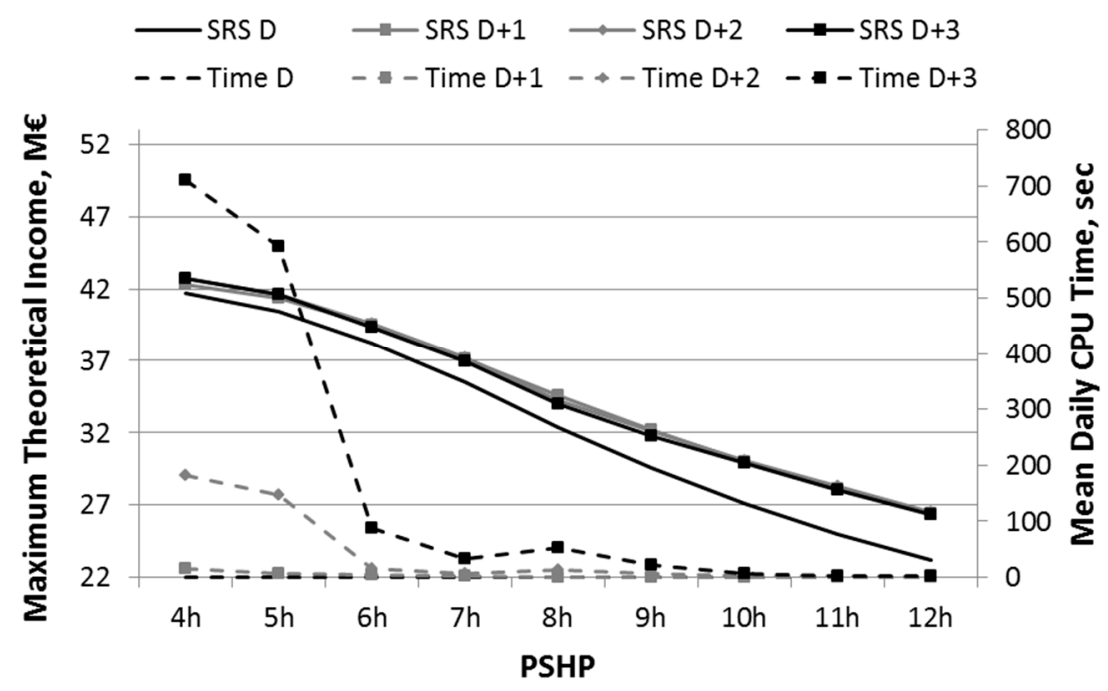

Figure 2. Annual maximum theoretical income, in millions of $€$, and the mean CPU time consumption of each daily problem, in seconds, for $n$ days of look-ahead period and without look-ahead period.

Table 3. Mean CPU time consumption of each daily problem, in seconds, for $n$ days of look-ahead period.

\begin{tabular}{cccccccccc}
\hline Strategy & $\mathbf{4 h}$ & $\mathbf{5} \mathbf{h}$ & $\mathbf{6} \mathbf{h}$ & $\mathbf{7} \mathbf{h}$ & $\mathbf{8} \mathbf{h}$ & $\mathbf{9 h}$ & $\mathbf{1 0} \mathbf{h}$ & $\mathbf{1 1} \mathbf{h}$ & $\mathbf{1 2} \mathbf{h}$ \\
\hline Time D & 1.0455 & 0.7792 & 0.7003 & 0.6214 & 0.5819 & 0.5129 & 0.5227 & 0.4833 & 0.4438 \\
Time D + 1 & 16.18 & 7.49 & 3.82 & 1.75 & 1.11 & 0.82 & 1.09 & 0.66 & 0.57 \\
Time D + 2 & 183.05 & 147.86 & 15.79 & 7.75 & 13.99 & 7.11 & 2.3 & 1.51 & 1.23 \\
Time D + 3 & 709.5 & 591.5 & 88.5 & 33.2 & 53.3 & 22.2 & 6.4 & 3.2 & 3.2 \\
\hline
\end{tabular}


As expected, the more days that are considered in the look-ahead period, the higher the mean daily CPU time consumption is. Nevertheless, the annual MTIs are not always higher. For example, in the $4 \mathrm{~h}$ and $5 \mathrm{~h}$ PSHPs, the mean daily CPU time consumption is $183 \mathrm{~s}$ and $147 \mathrm{~s}$ for D +2 , respectively, whereas if one extra day is considered in the look-ahead period (i.e., D + 3), the CPU time consumption increases up to $709 \mathrm{~s}$ and $591 \mathrm{~s}$, respectively. However, the annual MTI slightly decreases (42.75 to 42.7 $\mathrm{M} €$ and 41.63 to $41.58 \mathrm{M} €$, respectively).

The mean daily CPU time consumption of the $4-12 \mathrm{~h}$ PSHPs is more clearly shown in Table 3. The differences in seconds of the CPU time consumption between the cases without look-ahead period (Time D) and with one day of look-ahead period (Time D +1 ) are not significant. However, as can be seen in Figure 2, the annual MTIs with one day of look-ahead period (SRS D + 1) are higher than without look-ahead period (SRS D) for all PSHPs. Regarding the results considering two or three days of look-ahead period, Table 3 confirms that the increase in the CPU time consumption is not always justified by the one in the annual MTI. For example, the $12 \mathrm{~h}$ PSHP increases $13.8 \%$ the MTIs (from 23.2 M€ to $26.41 \mathrm{M} €$ ) if one day of look-ahead period is considered, increasing slightly the CPU time consumption (from $0.44 \mathrm{~s}$ to $0.57 \mathrm{~s}$ per day). However, if three days of look-ahead period are considered, the MTIs decrease from 26.41 M€ to $26.33 \mathrm{M} €$, increasing the mean daily CPU time consumption (from $0.57 \mathrm{~s}$ to $3.23 \mathrm{~s}$ ).

As a conclusion, in the context of closed-loop and daily-cycle PSHPs participating in the DM as a price-taker and in the SM as a price-maker, it seems to be enough to consider a look-ahead period of one day. This is because the increase of the mean daily CPU time consumption for considering longer look-ahead periods (two or three days) does not imply an increase of the annual MTI for any analyzed PSHP.

\subsection{Maximum Theoretical Income}

The MTIs of all PSHPs under each above-described strategy (SRS/DM D + 1/V0/Vm) are presented in Figure 3. See Section 3.3 for further details of each strategy.

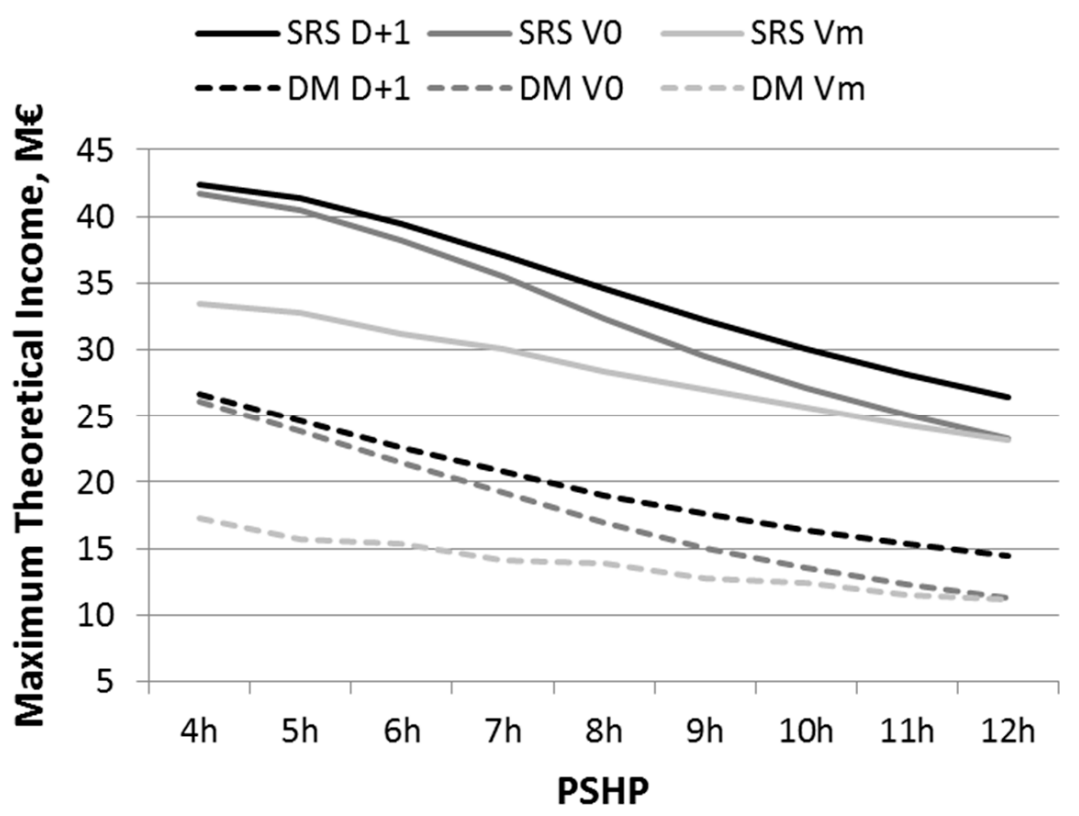

Figure 3. Annual maximum theoretical income, in millions of $€$, of each PSHP participating in the DM and the SRS (solid lines) and only in the DM (dashed lines).

The strategy that obtains the highest MTIs is the SRS D + 1, followed by the SRS V0 and, finally, the SRS Vm. The SRS D + 1 increases the MTI by $1-14 \%$ and by $519-8012 € / M W$ of installed 
capacity in generating mode with respect to the SRS V0 and by $14-27 \%$ and by $7443-10,388 €$ / MW with respect to the SRS Vm. Note that the increase in the maximum theoretical income strongly depends on the size of the plant. The highest economic differences between the SRS D + 1 and the SRS V0 occur in the $12 \mathrm{~h}$ PSHP and between the SRS V0 and the SRS Vm in the $4 \mathrm{~h}$ PSHP.

Similar trends can be seen in the economic results with the DM D + 1, DM V0 and DM Vm strategies. Differences appear in the relative increases between strategies: the DM D + 1 strategy obtains $2.1-27 \%$ and $455-7798 € / \mathrm{MW}$ of installed capacity in generation mode higher MTIs than the DM V0 and $29-57 \%$ and 7770-9645 €/MW higher MTIs than the DM Vm.

Furthermore, from the results shown in Figure 3, one can conclude that the participation in the SRS is strongly recommended. An increase of the MTIs is remarkable in all the considered strategies when the PSHP participates in the SRS. With the SRS/DM D + 1 strategies, the MTIs increase by $59-84 \%$ when the PSHP participates in the SRS; with the SRS/DM V0 strategies, by 60-106\%; and with the SRS/DM Vm strategies, by $93-111 \%$. Although the relative increase between strategies is quite different, the absolute increase (measured in $€$ ) is analogous.

Finally, if the comparison is carried out between PSHPs, it can be seen in Figure 3 that the MTI monotonically decreases as the number of hours increases (4-12 h), or as the installed capacity of the PSHP decreases (1200-400 MW): the $4 \mathrm{~h} / 12 \mathrm{~h}$ PSHP obtains the highest/lowest MTI in absolute numbers. However, if the same comparison is carried out with the MTI per MW of installed capacity in generating mode, the results are exactly the opposite (see Figure 4). Except with the DM V0 strategy, the MTI per MW monotonically increases as the number of hours increases (4-12 h), or as the installed capacity of the PSHP decreases (1200-400 MW): the 4 h/12 h PSHP obtains the lowest/highest MTI per MW of installed capacity.

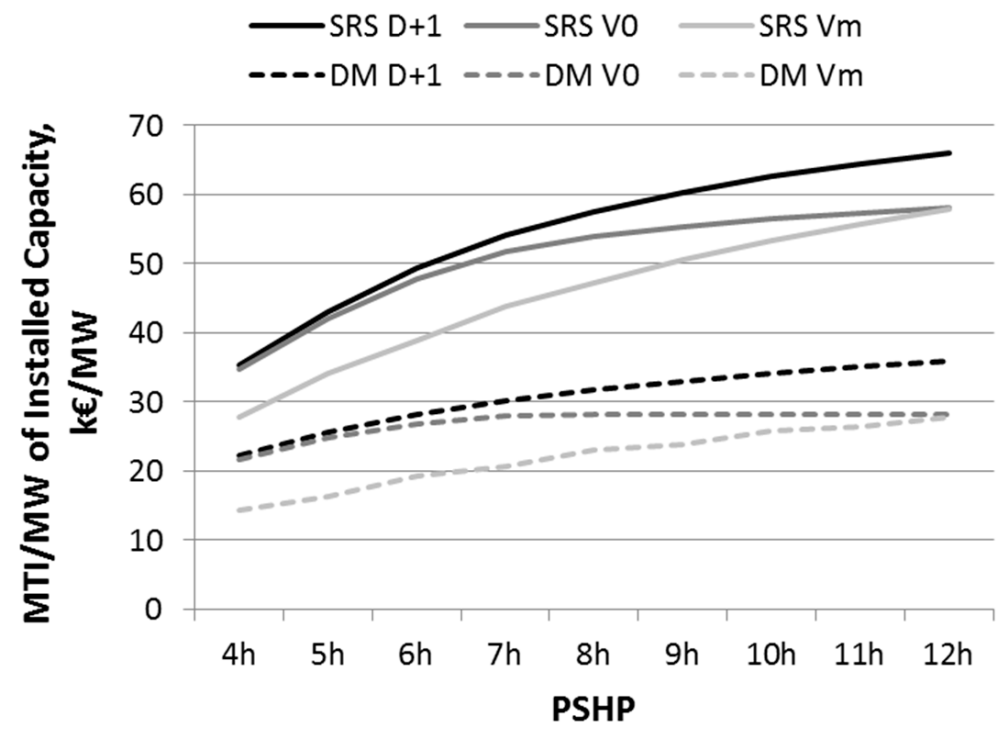

Figure 4. Annual maximum theoretical income (MTI) per MW of the installed capacity in generating mode, of each PSHP participating in the DM and the SRS (solid lines) and only in the DM (dashed lines).

The incomes and costs obtained with the SRS D + 1 strategy is distributed among the considered markets and services as shown in Table 4. It shows the net income in the DM, i.e., the income for selling energy in generating mode ( $\mathrm{DM}+)$ minus the cost for purchasing energy in pumping mode (DM-), the income in the SM, the income for the real-time use of the upward reserves (ER2up), the cost for the real-time use of the downward reserves (ER2dw), the start-up costs in generating mode $\left(c S U^{d}\right)$ and in pumping mode $\left(c S U^{p}\right)$ and, finally, the profit of the operation of the PSHPs (Total). 
Table 4. Annual incomes and costs, expressed in M€, obtained by all the PSHPs in each market and service with the SRS D + 1 strategy.

\begin{tabular}{cccccccccc}
\hline PSHP & DM+ & DM - & DM & SM & ER2up & ER2dw & $c S U^{d}$ & $c S U^{p}$ & Total \\
\hline 4 h & 107.29 & -73.21 & 34.08 & 15.7 & 5.9 & -8 & -3.11 & -2.24 & 42.33 \\
$5 \mathrm{~h}$ & 101.69 & -72.45 & 29.24 & 17.97 & 6.24 & -7.6 & -2.72 & -1.78 & 41.36 \\
$6 \mathrm{~h}$ & 93.87 & -68.2 & 25.67 & 18.58 & 5.94 & -6.9 & -2.34 & -1.49 & 39.47 \\
$7 \mathrm{~h}$ & 86.7 & -63.95 & 22.75 & 18.38 & 5.56 & -6.26 & -2.04 & -1.29 & 37.1 \\
$8 \mathrm{~h}$ & 79.31 & -58.81 & 20.5 & 17.53 & 5.13 & -5.67 & -1.78 & -1.17 & 34.53 \\
9 h & 72.68 & -54.16 & 18.52 & 16.64 & 4.78 & -5.13 & -1.6 & -1.06 & 32.16 \\
$10 \mathrm{~h}$ & 66.78 & -49.59 & 17.19 & 15.5 & 4.34 & -4.66 & -1.39 & -0.95 & 30.03 \\
$11 \mathrm{~h}$ & 61.75 & -45.96 & 15.8 & 14.65 & 4.03 & -4.27 & -1.23 & -0.87 & 28.1 \\
$12 \mathrm{~h}$ & 57.64 & -42.86 & 14.78 & 13.79 & 3.74 & -3.96 & -1.13 & -0.81 & 26.41 \\
\hline
\end{tabular}

The main income source is the DM, representing $56-80 \%$ of the MTI for the $12-4 \mathrm{~h}$ PSHP, respectively (Table 4). This result contradicts one of the conclusions of [21] and [22], where it was stated that the SM is the main income source in the operation of PSHPs participating in the DM and the SRS. The main reason of the presented result in comparison to the one published in the literature is that, in this paper, the effect of the reserve schedule in the clearing price of the SM is taken into account (price-maker approach in the SM). Hence, the income in the SM with respect to the total is less representative than the one in the DM (between $37 \%$ and $52 \%$ of the MTI for the $4-12 \mathrm{~h} \mathrm{PSHP}$, respectively). Note that the lower the installed capacity of the PSHP, the higher the income in the SM in relative terms of the MTI, because the impact in the marginal price of the SM is lower.

The economic results of each PSHP with each SRS strategy are presented for the DM in Figure 5, for the SM in Figure 6 and for the secondary regulation energy in Figure 9. The results for the DM strategy are not presented in Figure 5 because they are similar to Figure 3 but subtracting only the start-up costs, and are not presented in Figure 6 and Figure 9 because the SRS does not apply.

From the point of view of the participation in the DM, the SRS D + 1 strategy obtains the highest income (left y-axis in Figure 5) and income per MW of installed capacity (right y-axis in Figure 5) for all PSHPs, following a similar tendency as the MTI in Figure 3 and the MTI per MW of installed capacity in Figure 4, respectively.

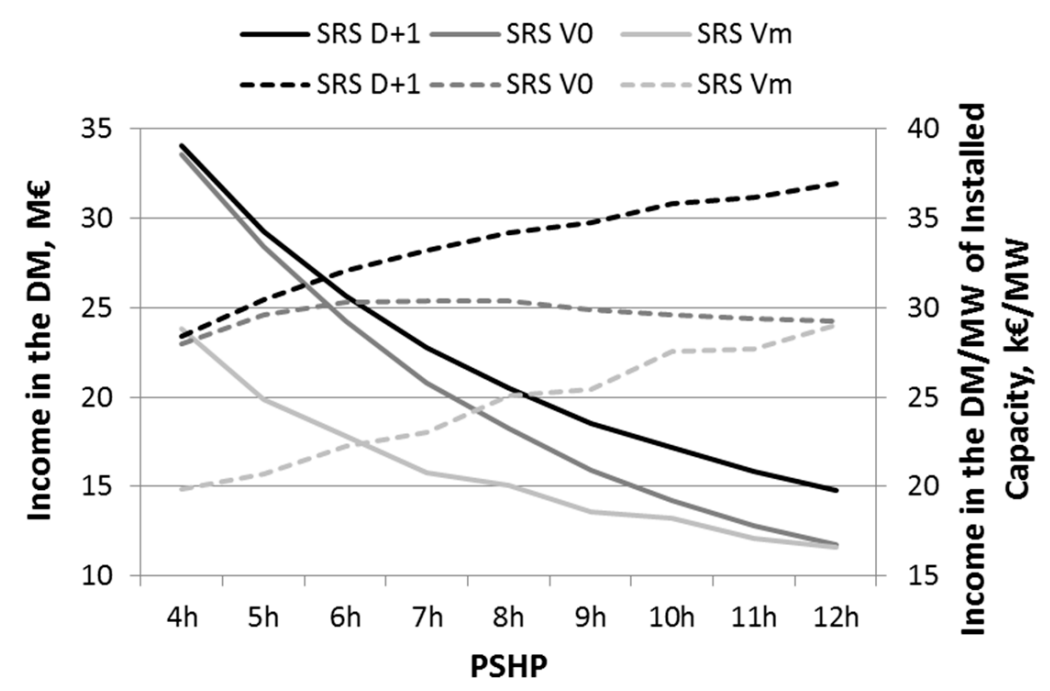

Figure 5. Annual maximum theoretical income in the DM (solid lines) and per MW of the installed capacity in generating mode (dashed lines) of each PSHP.

Regarding the economic results in the SM, the MTIs of each PSHP with the SRS D + 1, SRS V0 and SRS Vm strategies are shown on the left y-axis of Figure 6 and the MTIs per MW of the installed 
capacity in generating mode are shown on the right y-axis. Notice that the MTIs and the MTIs per MW in the SM do not change significantly between strategies for each PSHP. The behavior of the MTI in the SM per MW is analogous to the one of the MTI per MW of the installed capacity (Figure 4) or to the MTI in the DM per MW of installed capacity (Figure 5): monotonically increasing as the number of hours increases (4-12 h) or as the installed capacity of the PSHPs decreases (1200-400 MW).

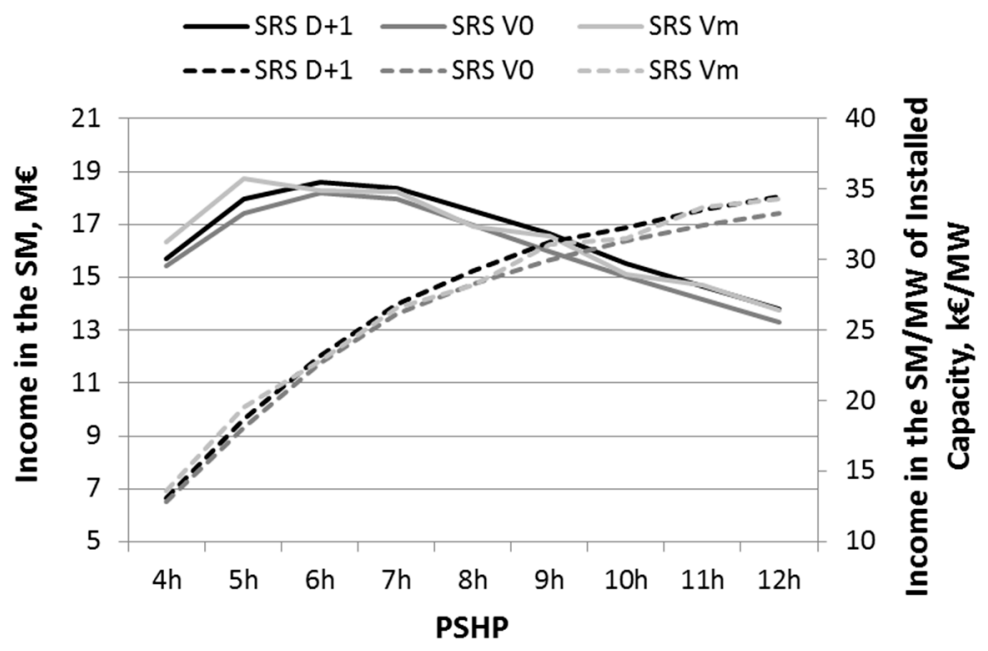

Figure 6. Annual maximum theoretical income in the SM (solid lines) and per MW of the installed capacity in generating mode (dashed lines) of each PSHP.

It is interesting to note that the MTI in the SM (left y-axis of Figure 6) does not monotonically decrease with the number of hours necessary to empty the upper reservoir as in the DM (left y-axis of Figure 5). The higher the installed capacity of the PSHP, the higher the MTI in the SM, up to a certain level of installed capacity (up to the $6 \mathrm{~h}$ PSHP). The $4 \mathrm{~h}$ and $5 \mathrm{~h}$ PSHPs obtain less income in the SM in comparison to the $6 \mathrm{~h}$ PSHP. This result can be explained by a combination of two aspects: firstly, the effects of the price-maker approach; and secondly, the number of hours in which the PSHPs participate in the DM generating energy and, therefore, in the SRS. The former is explained with Figure 7. It shows the mean hourly energy generation in the DM and the mean hourly secondary regulation reserves (upward plus downward reserves), in the left y-axis. The mean hourly values are obtained only using the hours in which the PSHPs participate in the DM and the SM, respectively. Besides, it is also shown, in the right y-axis of Figure 7, the percentage of the mean hourly energy generation in the DM and reserves in the SM with respect to the operating range (maximum minus minimum power) and with respect to the available reserves, respectively. One hundred/zero percentage means a mean hourly energy generation in the DM of maximum/minimum power and a mean hourly reserve in the SM of maximum/zero reserve availability, respectively. For example, the $8 \mathrm{~h}$ PSHP has a mean hourly energy generation in the DM of $41 \%$ of the operating range and mean hourly total reserves offered in the SM of $96 \%$ of the available ones (Most PSHPs have a mean hourly energy generation in the DM of $40 \%$ of the operating range. One reason for this is the rules of the SM in the Spanish electricity system. The bids submitted to the SM have to fulfill a ratio between the upward and downward secondary regulation reserves. The mean hourly ratio in 2014 was $57.13 \%$ and $42.87 \%$ for the upward and downward reserves, respectively). It can be seen in Figure 7 that the $4 \mathrm{~h}$ and $5 \mathrm{~h}$ PSHPs have more available reserves than the optimum because they offer less $(83 \%$ and $90 \%$ of the available reserves, respectively) in comparison to the rest of PSHPs (between $93.4 \%$ and $96 \%$ ). As mentioned above, the reason to this is the effects of the price-maker approach: the higher the bids presented in the SM, the higher the cleared price reduction. 


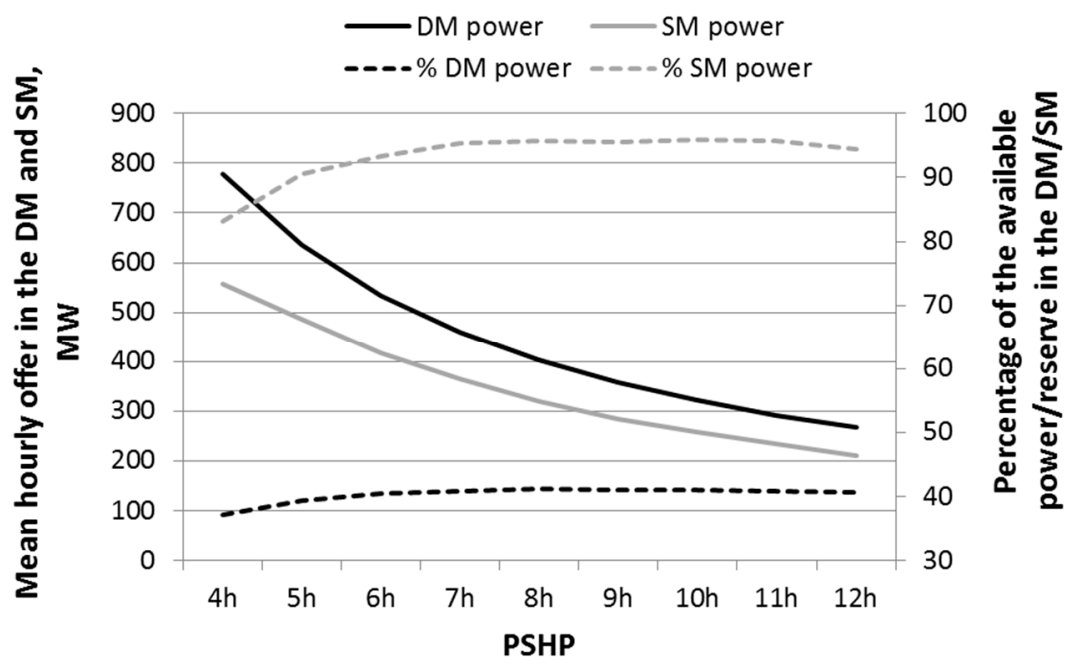

Figure 7. Mean hourly power generation in the DM/total reserves offered to the SM, for each PSHP (black/grey solid lines) and percentages of the total available power in the DM/reserve to the SM (black/grey dashed lines).

The above-mentioned second aspect that explains that the MTI in the SM (left y-axis of Figure 6) does not monotonically decrease is the number of hours in which the PSHPs participate in the DM and, therefore, in the SRS. This is explained with Figure 8. It shows the mean daily hours in which the PSHPs generate/consume energy in the DM with the SRS D + 1 strategy (Gen/Cons SRS) and with the DM D + 1 strategy (Gen/Cons DM). It is important to note that the PSHPs participate in the SM in the $99 \%$ of hours in which they generate energy in the DM.

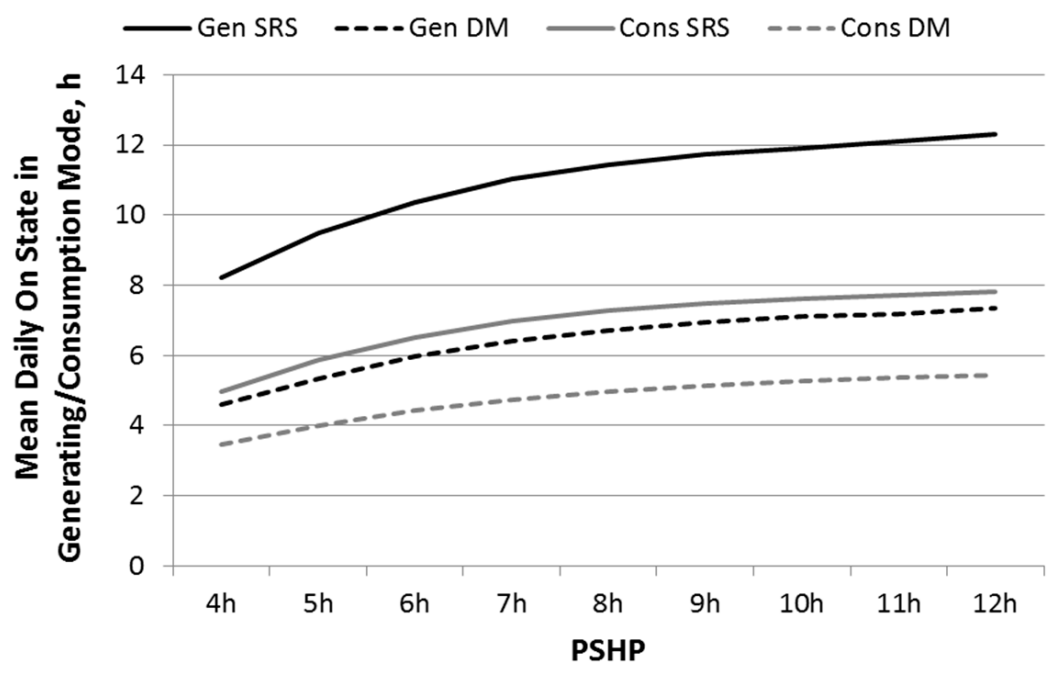

Figure 8. Mean daily hours generating/consuming energy each PSHP participating in the DM and the SRS (black/grey solid lines) and participating only in the DM (black/grey dashed lines).

The $4 \mathrm{~h}$ and $5 \mathrm{~h}$ PSHPs are the ones that participate in the DM generating energy fewer hours and, therefore, they will participate in the SRS fewer hours. However, they prefer to reduce the generation energy in the DM down to 37\% and 39\%, respectively, of the operating range (Figure 7) to increase the number of hours that they participate in the DM and, therefore, in the SRS (to enlarge their income). This is confirmed by comparing the mean daily number of hours of the $4 \mathrm{~h}$ and $12 \mathrm{~h}$ PSHPs generating energy in the DM: $8 \mathrm{~h}$ and $12 \mathrm{~h}$, respectively. 
In addition, it can be seen in Figure 8 that all PSHPs generate and consume in the DM during more hours, as a mean, if they participate in the DM and the SRS in comparison to only participate in the DM. The reason to this is the inclusion of the SRS: the more hours generating energy in the DM, the more hours the PSHPs can participate in the SRS and, therefore, they are able to enlarge their income. In order to generate energy during more hours, the PSHPs are able to consume energy during more hours and/or reduce the power generation in each hour. This is confirmed by Figure 8: the increase in the number of hours in which the PSHPs are generating energy due to the inclusion of the SRS is higher than the increase when the PSHPs are consuming energy.

Finally, the economic results of the income/cost due to the real-time use of the upward/downward secondary regulation reserves (Figure 9) are similar between strategies. The monotonically decrease of the ER2up income seems to be broken in the $4 \mathrm{~h}$ PSHP because of the above-mentioned aspects: the effects of the price-maker approach in the SM and the number of hours in which the PSHPs participate in the DM generating energy and, therefore, in the SRS (Figures 7 and 8).

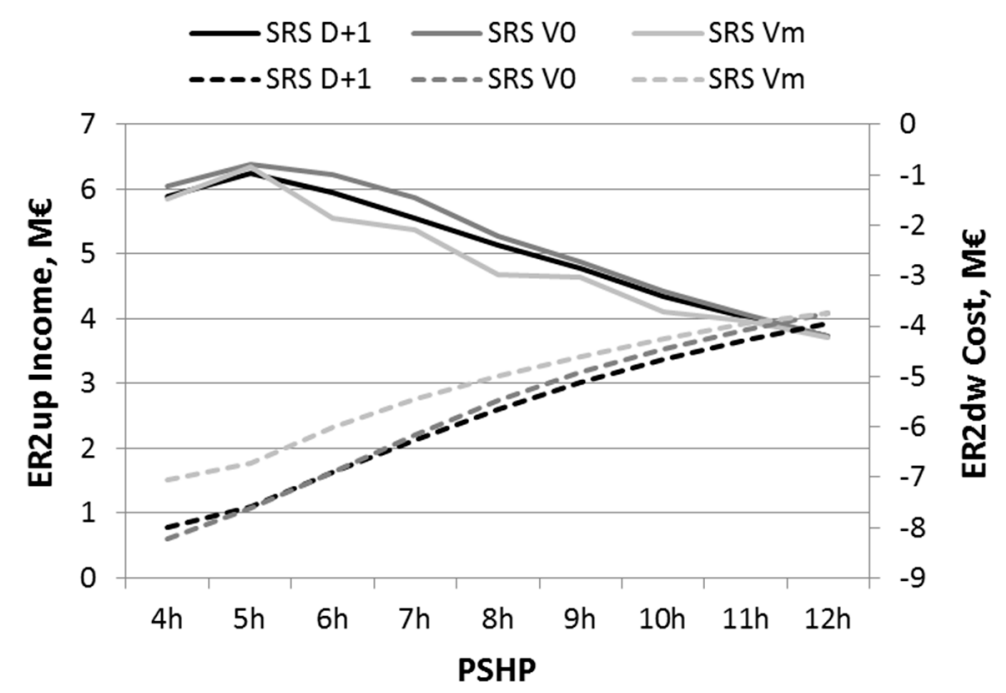

Figure 9. Annual maximum theoretical income due to the real-time use of the upward (ER2up, solid lines) and the downward (ER2dw, dashed lines) reserves of each PSHP.

\subsection{End of Day Storage}

The histograms of the end of day storage for each PSHP participating in the DM, and in the DM and the SRS can be seen in Figures 10 and 11, respectively. Note that these results are obtained with the DM D + 1 and the SRS D + 1 strategies, respectively.

The most frequent end of day storage interval is the one that is closer to zero, regardless whether the PSHP participates only in the DM or in the DM and the SRS. However, the number of days in which the end of day storage is in the mentioned interval is higher if the PSHP participates in the DM than if it participates in the DM and the SRS (for example, 293 days if the $4 \mathrm{~h}$ PSHP only participates in the DM whereas 236 days if it participates in the DM and the SRS).

In addition to this, the water volume interval that is closer to the maximum storage has a higher number of days if the PSHPs only participate in the DM than if they also participate in the SRS. The main reason for this is the relative values of the price profiles of the DM between $\mathrm{D}$ and $\mathrm{D}+1$. If the price profile for the following day is higher in most of the hours with respect to the current day, the model is able to: (i) mostly pump water during the current day; (ii) finish the day as full as possible and (iii) generate energy the following day. To illustrate this, an example for 2-3 June 2014 with the DM D +1 and the SRS D +1 strategies and the $4 \mathrm{~h}$ PSHP are presented in Figures 12 and 13, respectively. 

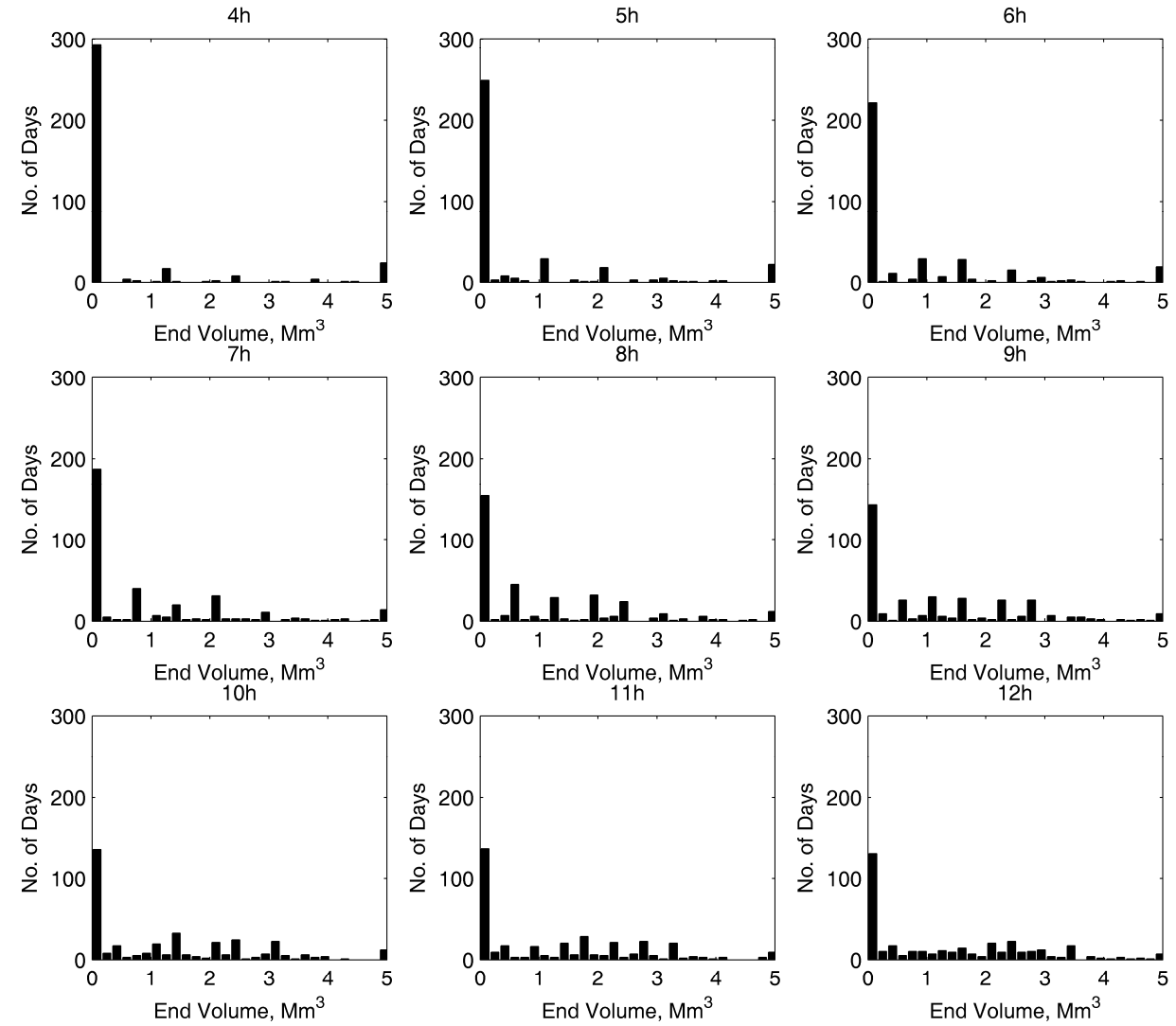

Figure 10. Histogram of the end of day volumes for each PSHP participating in the DM.
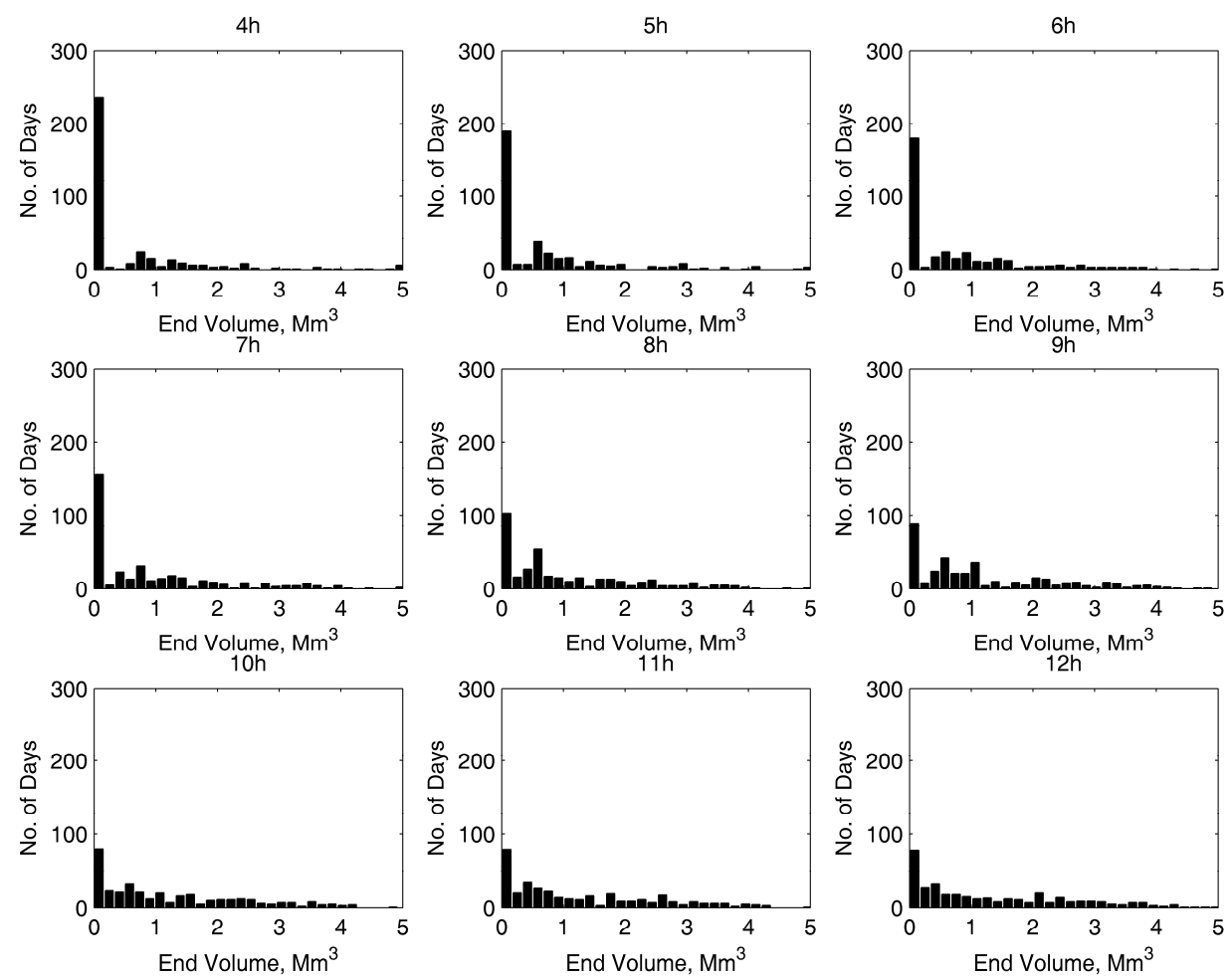

Figure 11. Histogram of the end of day volumes for each PSHP participating in the DM and SRS. 
Figure 12 is divided into two subfigures where the following variables are depicted. The upper subfigure shows the water volume trajectory of the upper reservoir in solid line and the total water through the turbines (positive) or pumps (negative) in bars. The lower subfigure shows the energy schedule in the DM in bars and the price of the DM in solid line. Figure 13 is divided into three subfigures. The two first are the same as in Figure 12. In the lower subfigure of Figure 13, the following variables are depicted: the secondary regulation reserve schedule in bars and the price of the SM in solid line, which takes into account the reduction due to the presented bids of the agent (price-maker effects). The water volume at hour 24 changes significantly if the SRS is included $\left(1.23 \mathrm{Mm}^{3}\right)$ or not $\left(5.04 \mathrm{Mm}^{3}\right)$. In the latter, the model decides to pump water at hours 3-5 and, instead of generating energy at peak hours of the DM in D, it is carried out at peak hours of the DM in D + 1 (at hours 32-38). The energy schedule significantly changes if the PSHP also participate in the SRS: the model decides to pump water at the same hours 3-5 in D but instead of keeping the water for the following day, it decides to generate energy at hours 7-11 and 23, also participating in the SRS. Due to this, it finishes the day at a much lower water volume than with the DM D + 1 strategy. In order to participate again in the SRS the following day, the model pumps water at hours 28-29, and generates energy and participates in the SRS at hours 31-35. This confirms that the importance of the price-arbitrage in the DM decreases if the SRS is deemed.
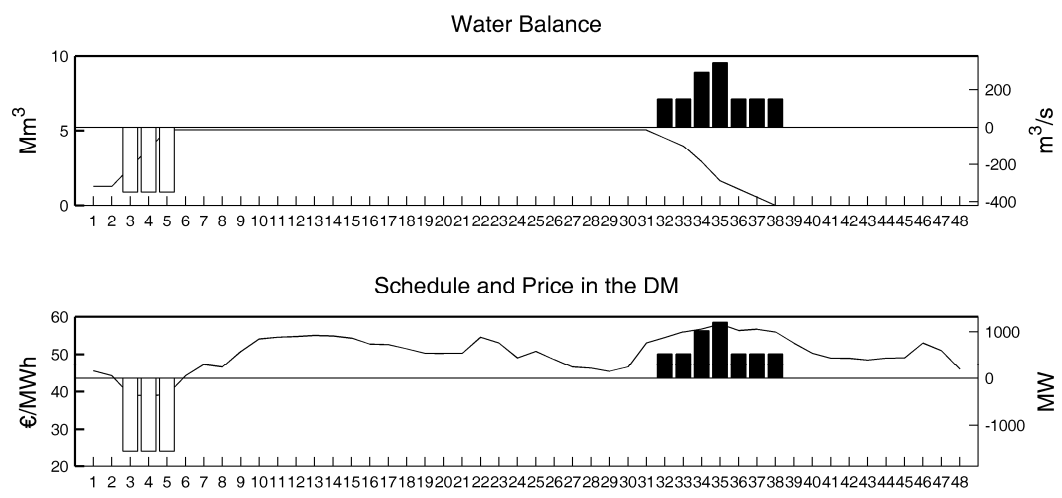

Figure 12. Optimal operation of the $4 \mathrm{~h}$ PSHP with the DM D + 1 strategy on 2-3 June 2014.
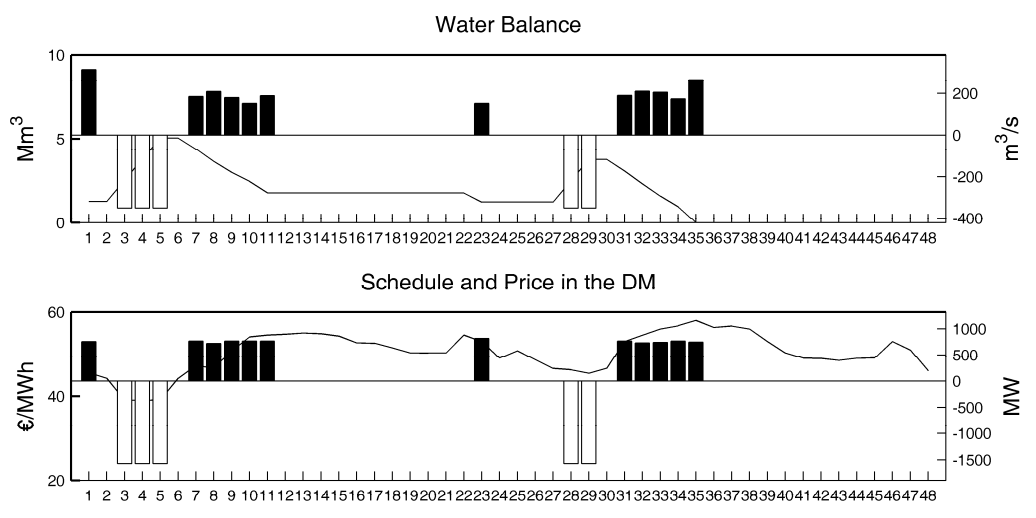

Schedule and Price in the SM

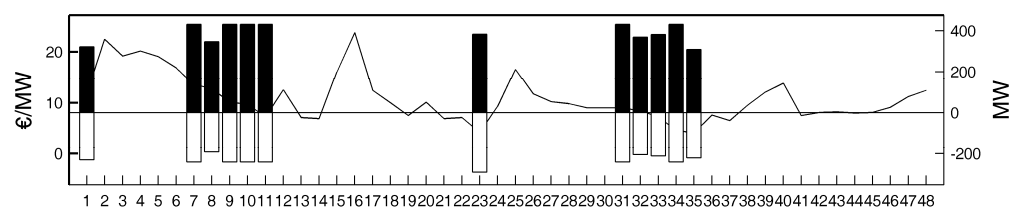

Figure 13. Optimal operation of the $4 \mathrm{~h}$ PSHP with the SRS D + 1 strategy on the 2-3 June 2014. 
As a conclusion, comparing Figures 10 and 11, the end of day storage if the PSHPs also participate in the SRS have a less extreme behavior (less number of days in the interval closer to zero and to the maximum) with respect to the ones if the PSHPs only participate in the DM. Hence, it is proven that the end of day storage change notably in the new reserve-driven strategies of PSHPs.

As a future work, the authors would like to analyze the impact that the variable speed technology or the operation in hydraulic short-circuit mode has in the operation of PSHPs with the DM D + 1 and, especially, with the SRS D + 1 strategies. The variable speed technology and the operation in hydraulic short-circuit mode permit the PSHPs to regulate power in pumping mode and, hence, to also participate in the SRS at hours in which the PSHPs are consuming. As shown in Figure 13, the PSHP cannot participate in the SRS at hours 3-5 and 28-29 because, in this paper, PSHPs with fixed speed are deemed.

Finally, the importance of the proposed methodology with a look-ahead period (DM D + 1 and SRS $\mathrm{D}+1$ strategies) is also confirmed by the results obtained in Figures 14 and 15. They show the histograms of the deviations with respect to the traditional price-arbitrage operation, i.e., the deviations between the total pumped and discharged water volumes, with the DM D +1 and SRS D + 1 strategies, respectively. A positive/negative deviation means that in a certain day, there is more pumped/discharged water than discharged/pumped water. The traditional price-arbitrage operation starts and finishes each day with the same water volume. Thus, it would obtain zero deviation in all days.

The most frequent deviation interval is the one that is closer to zero, regardless whether the PSHP participates only in the DM or in the DM and the SRS. However, similarly as it was observed in Figures 10 and 11 with the end of day storage, the number of days in which the deviations are in the mentioned interval is higher if the PSHP participates in the DM than if it participates in the DM and the SRS (for example, 256 days if the $4 \mathrm{~h}$ PSHP only participates in the DM whereas 175 days if it participates in the DM and the SRS). If Figures 14 and 15 are compared, the histograms of the deviations with the SRS D + 1 strategy have a more weighted tails in comparison to the ones of the DM D + 1 strategy. This result confirms that the traditional price-arbitrage strategy, which is restricted to meet the daily-cycle, is not the optimum and that the operation strategies with a look-ahead period are even more recommended if the SRS is considered.
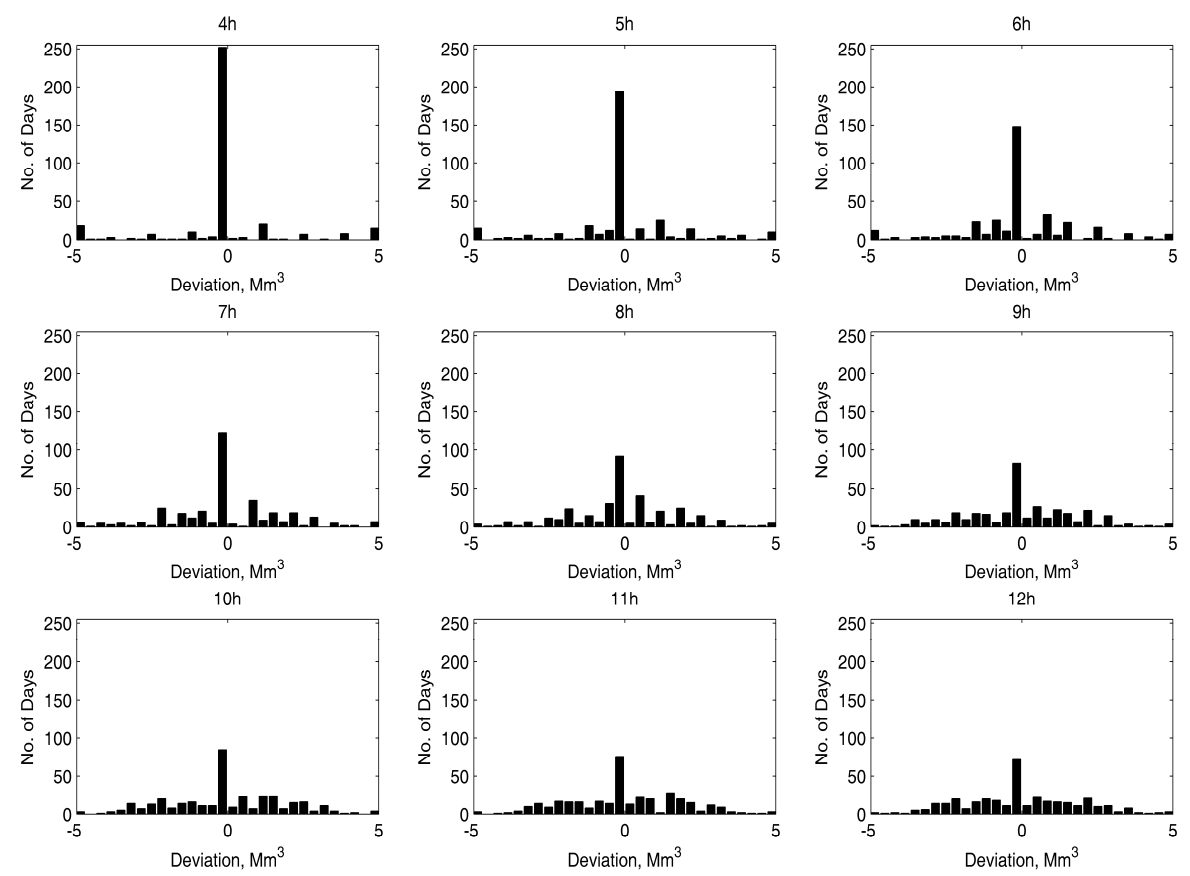

Figure 14. Histogram of the deviations with respect to the daily-cycle operation, of each PSHP participating in the DM. 

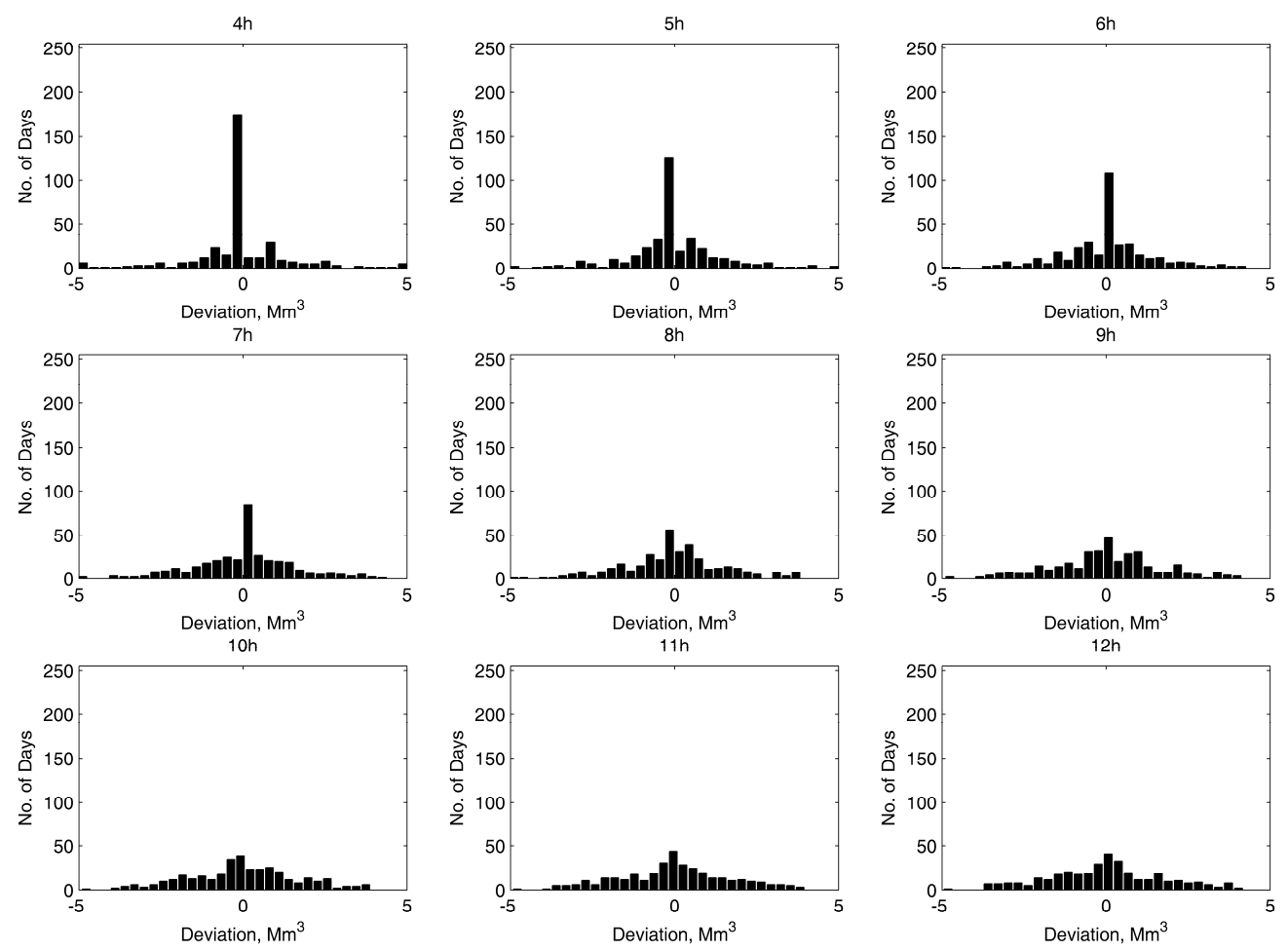

Figure 15. Histogram of the deviations with respect to the daily-cycle operation, of each PSHP participating in the DM and the SRS.

\section{Conclusions}

A new methodology to maximize the income and determine the optimal end of day storage of closed-loop and daily-cycle pumped-storage hydropower plants participating in the day-ahead energy and the secondary regulation reserve markets is presented in this paper. It uses a look-ahead period with future information of the electricity power system data. The plants participate in the day-ahead energy market as a price-taker and in the secondary regulation reserve market as a price-maker. The real-time use of the committed reserves is also considered in the model formulation. The results obtained in the paper indicate that using a look-ahead period of one day is sufficient to highly increase the income without a significant increase in the CPU time consumption. Furthermore, the proposed methodology enlarges the annual maximum theoretical income of the plants between 455 and $9645 € / \mathrm{MW}$ of the installed capacity if they only participate in the day-ahead energy market and between 519 and $10388 € / \mathrm{MW}$ of installed capacity if they also participate in the secondary regulation reserve service, in comparison to methodologies without a look-ahead period. The relative increase in the maximum theoretical income strongly depends on the size of the plant. Finally, it has been proven that the end of day storage has a less extreme behavior in the new reserve-driven strategies of pumped-storage hydropower plants. Therefore, the hourly scheduling tools of closed-loop and daily-cycle pumped-storage hydropower plants that only consider the day-ahead energy market or do not use a look-ahead period might deviate notably from the optimal operation.

As a future work, the authors would like to study the following issues: (1) the extent to which the proposed methodology is able to enlarge the plant income without assuming perfect knowledge of the electricity power system data; (2) the impact of the proposed methodology in the operation of pumped-storage hydropower plants operating with variable speed or in hydraulic short-circuit mode; and (3) the impact in the end of day storage of the participation of pumped-storage hydropower plants in other markets (such as the intraday market) or in other ancillary services (such as the tertiary regulation service). 
Acknowledgments: This work was supported by the Spanish Ministry of Economy and Competitiveness under the project "Optimal operation and control of pumped-storage hydropower plants" of The National Scientific Research, Development and Technological Innovation Plan 2008-2011 (Ref. ENE2012-32207).

Author Contributions: Manuel Chazarra was involved in conceiving the methodology presented in the paper, formulating the scheduling model, gathering the electric power system data and obtaining the results. Juan Ignacio Pérez-Díaz was involved in conceiving the methodology presented in the paper. Manuel Chazarra wrote the manuscript. Juan Ignacio Pérez-Díaz and Javier García-González contributed to the integrity of the work as a whole. Finally, all the authors have been involved in the analysis of the results and the obtaining of the conclusions.

Conflicts of Interest: The authors declare no conflict of interest.

\section{Nomenclature}

DM Day-ahead energy market

ER2up Upward secondary regulation energy, i.e., the real-time use of the upward committed reserves

ER2dw Downward secondary regulation energy, i.e., the real-time use of the downward committed reserves

MTI Maximum theoretical income

PSHP Pumped-storage hydropower plant

RRC Residual reserve curve, i.e., the residual demand curve of the secondary regulation reserve market

SM Secondary regulation reserve market

SRS Secondary regulation service

TSO Transmission system operator

\section{References}

1. Graves, F.; Jenkin, T.; Murphy, D. Opportunities for electricity storage in deregulating markets. Electr. J. 1999, 12, 46-56. [CrossRef]

2. Connolly, D.; Lund, H.; Finn, P.; Mathiesen, B.V.; Leahy, M. Practical operation strategies for pumped hydroelectric energy storage (PHES) utilising electricity price arbitrage. Energy Policy 2011, 39, 4189-4196. [CrossRef]

3. Chazarra, M.; García-González, J.; Pérez-Díaz, J.I.; Arteseros, M. Stochastic optimization model for the weekly scheduling of a hydropower system in day-ahead and secondary regulation reserve markets. Electr. Power Syst. Res. 2016, 130, 67-77. [CrossRef]

4. Ortner, A.; Graf, C. Multi-market unit-commitment and capacity reserve prices in systems with a large share of hydro power: A case study. In Proceedings of the 2013 10th International Conference on the European Energy Market (EEM), Stockholm, Sweden, 27-31 May 2013.

5. Ugedo, A.; Lobato, E.; Franco, A.; Rouco, L.; Fernandez-Caro, J.; Chofre, J. Strategic bidding in sequential electricity markets. Gener. Transm. Distrib. IEE Proc. 2006, 153, 431-442. [CrossRef]

6. Steeger, G.; Barroso, L.A.; Member, S.; Rebennack, S. Optimal bidding strategies for hydro-electric producers: A literature survey. IEEE Trans. Power Syst. 2014, 29, 1758-1766. [CrossRef]

7. Pérez-Díaz, J.I.; Chazarra, M.; García-González, J.; Cavazzini, G.; Stoppato, A. Trends and challenges in the operation of pumped-storage hydropower plants. Renew. Sustain. Energy Rev. 2015, 44, 767-784. [CrossRef]

8. Lobato, E.; Egido, I.; Rouco, L.; López, G. An overview of ancillary services in Spain. Electr. Power Syst. Res. 2008, 78, 515-523. [CrossRef]

9. Saraiva, J.T.; Heitor, H.; Correia, N.; Araújo, R. Ancillary services-The current situation in the Iberian electricity market and future possible developments. In Proceedings of the 2011 IEEE Trondheim PowerTech Conference, Trondheim, Norway, 19-23 June 2011.

10. ENTSO-E Working Group on Ancillary Services. Survey on Ancillary Services Procurement, Balancing Market Design. Available online: https:/ / www.entsoe.eu/Documents/Publications /Market\% 20Committee\%20publications/150127_WGAS_Survey_2014.pdf (accessed on 14 June 2017).

11. Deane, J.; Mckeogh, E.; Gallachóir, B. Derivation of intertemporal targets for large pumped hydro energy storage with stochastic optimization. IEEE Trans. Power Syst. 2013, 28, 2147-2155. [CrossRef]

12. Brijs, T.; Geth, F.; Siddiqui, S.; Hobbs, B.F.; Belmans, R. Price-based unit commitment electricity storage arbitrage with piecewise linear price-effects. J. Energy Storage 2016, 7, 52-62. [CrossRef] 
13. Kazempour, S.; Moghaddam, M.; Haghifam, M.R.; Yousefi, G.R. Risk-constrained dynamic self-scheduling of a pumped-storage plant in the energy and ancillary service markets. Energy Convers. Manag. 2009, 50, 1368-1375. [CrossRef]

14. Chazarra, M.; Pérez-Díaz, J.I.; García-González, J. Optimal energy and reserve scheduling of pumped-storage power plants considering hydraulic short-circuit operation. IEEE Trans. Power Syst. 2017, 32, 344-353. [CrossRef]

15. Chazarra, M.; Pérez-Díaz, J.I.; García-González, J. Value of perfect information of spot prices in the joint energy and reserve hourly scheduling of pumped storage plants. Electr. Power Syst. Res. 2017, 148, 303-310. [CrossRef]

16. Bonneville Power Administration. BPA Partners on Overhaul of World's Largest Turbines. Available online: https:/ / www.bpa.gov/news/newsroom/Pages/BPA-partners-on-overhaul-of-worlds-largest-turbines. aspx (accessed on 14 June 2017).

17. Alstom. Alstom Commissions World's Most Powerful Hydroelectric Units at Xiangjiaba Hydro Power Plant, in China. Available online: http:/ / www.alstom.com/press-centre/2013/7/alstom-commissions-worldsmost-powerful-hydroelectric-units-at-xiangjiaba-hydro-power-plant-in-china/ (accessed on 12 June 2017).

18. U.S. Bureau of Reclamation. Selecting Hydraulic Reaction Turbines; U.S. Government Printing Office: Washington, DC, USA, 1976; p. 54.

19. Merino, J.; Lopez, A. ABB Varspeed generator boosts efficiency and operating flexibility of hydropower plant. ABB Rev. 1996, 3, 33-38.

20. Nilsson, O.; Sjelvgren, D. Hydro unit start-up costs and their impact on the short term scheduling strategies of Swedish power producers. IEEE Trans. Power Syst. 1997, 12, 38-44. [CrossRef]

21. Chazarra, M.; Pérez-Díaz, J.; García-González, J. Optimal Operation of Variable Speed Pumped Storage Hydropower Plants Participating in Secondary Regulation Reserve Markets. In Proceedings of the 2014 11th International Conference on the European Energy Market (EEM), Krakow, Poland, 28-30 May 2014.

22. Pinto, J.; Sousa, J.; Neves, M. The value of a pumping-hydro generator in a system with increasing integration of wind power. In Proceedings of the 2011 8th International Conference on the European European Energy Market (EEM), Zagreb, Croatia, 25-27 May 2011.

(c) 2017 by the authors. Licensee MDPI, Basel, Switzerland. This article is an open access article distributed under the terms and conditions of the Creative Commons Attribution (CC BY) license (http:/ / creativecommons.org/licenses/by/4.0/). 


\section{Chapter 3}

\section{Risk-averse model with look-ahead period}

The model formulation proposed in Chapter 3 optimises the operation of a PSHP equipped with variable-speed or fixed-speed pump-turbine units, and/or being operated in hydraulic short-circuit mode. The PSHP is proposed to participate in the day-ahead energy market and in the secondary regulation service of the Iberian electricity system. The PSHP is modelled as a price-taker in the day-ahead energy market and as a price-maker in the secondary regulation reserve market, in the same way as it has been presented in the articles of the Thesis. The main contributions of this model formulation with respect to the ones included in the Thesis previously are explained in Section 3.2. The uncertainty is modelled by a scenario-based approach, according to the results that have been already published in the technical literature from this Thesis and according to new results from this Thesis presented in Section 3.1.

\subsection{Value of perfect information}

The methodology used in the Thesis for obtaining the value of perfect information of each random variable from the electric power system data has been previously presented in Section 1.6. The random variables from the electric power system data correspond to: 1) the day-ahead energy market prices, 2) the residual demand curves of the secondary regulation reserve market, 3) the upward secondary regulation energy prices, 4) the downward secondary regulation energy prices, 5) the percentages of the real-time use of the upward reserves, and 6) the percentages of the real-time use of the downward reserves.

The main conclusions of the article entitled "Value of Perfect Information of Spot Prices in the Joint Energy and Reserve Hourly Scheduling of Pumped Storage Plants" from this Thesis for the day-ahead energy market prices and of the article entitled "Economic Impact of Forecasting Errors in Residual Reserve Curves in the Day-ahead Scheduling of Pumped 
Storage Plants" from this Thesis for the residual demand curves of the secondary regulation reserve market, both used for the risk-averse optimisation model with look-ahead period, are presented in subsection 3.1.1 and 3.1.2, respectively. Besides, new results (still unpublished) from this Thesis regarding the value of perfect information of the rest of the random variables are presented in subsection 3.1.3 for the upward and downward secondary regulation energy prices, and in subsection 3.1.4 for the percentages of the real-time use of the upward and downward reserves.

\subsubsection{Day-ahead energy prices}

As it is presented in the article entitled "Value of Perfect Information of Spot Prices in the Joint Energy and Reserve Hourly Scheduling of Pumped Storage Plants" from this Thesis, the said value of the day-ahead energy market prices (VPI-DM) is significant (28.9\% of the maximum theoretical income as the mean value between all the forecasting models analysed). Therefore, considering the impact of the imperfect information of this random variable in the risk-averse optimisation model with look-ahead period is important. The uncertainty of the day-ahead energy market prices will be modelled forecasting three representative scenarios. Each corresponds to a 24-h price profile obtained from the forecasting model of Case $\mathrm{H}$ in the article entitled "Value of Perfect Information of Spot Prices in the Joint Energy and Reserve Hourly Scheduling of Pumped Storage Plants" from this Thesis: a $\operatorname{GARCH}(1,3)$ and $\operatorname{ARIMAX}(10,1,0)$ with the forecast wind power of the system as explanatory variable. In the autoregressive polynomial, the terms with lags 1, 2, 3, 4, 24, 144, 168, 169, 192 and 193 have a

non-zero coefficient. The orders of the autoregressive part of the ARIMA model was selected from a trial and error approach.

\subsubsection{Residual reserve curves of the secondary regulation reserve market}

As it is presented in the article entitled "Economic Impact of Forecasting Errors in Residual Reserve Curves in the Day-ahead Scheduling of Pumped Storage Plants" from this Thesis, the said value of the residual demand curves of the secondary regulation reserve market (VPI$\mathrm{RRC}$ ) is not as significant as the one of the day-ahead energy market prices (between 6-8\% of the maximum theoretical income in all the forecasting models analysed). Therefore, the uncertainty of the residual demand curves of the secondary regulation reserve market will be modelled with an expected value in order to reduce the computational burden, reducing the total number of scenarios in the model. The expected values correspond to the ones of the Case E from the article entitled "Economic Impact of Forecasting Errors in Residual Reserve Curves in the Day-ahead Scheduling of Pumped Storage Plants" from this Thesis: a $\operatorname{SARIMA}(0,1,1)(0,1,1)^{24}$. 


\subsubsection{Secondary regulation energy prices}

The value of perfect information of the secondary regulation energy prices (VPI-ER2) has not been published in the technical literature yet. However, it is calculated in the Thesis, and is here presented in Table 3.2. Note that the case study for obtaining the VPI-ER2 considers the same PSHP with the same technical data and in the same time period than the ones of the VPI-DM and the VPI-RRC in order to establish comparisons. Two forecasting models of the secondary regulation energy prices are proposed, Table 3.1. The forecasting model of Case B assumes that the upward/downward secondary regulation energy price in hour $t$ of a certain day of 2014 is the average of the upward/downward secondary regulation energy price in the said hour across all days in 2013. The heuristic forecasting model is based on an analysis of the mean hourly price profiles of the day-ahead energy market and the upward and downward secondary regulation energy of 2013, in the first ten hours (the reason to choose the first ten hours is arbitrarily). The heuristic forecasting model proposes to increase $7.98 € / M W h$ the day-ahead energy market prices for the upward secondary regulation energy prices, and to decrease $16.97 € / M W h$ the day-ahead energy market prices for the downward secondary regulation energy prices restricted to be non-negative (in the Spanish electricity market, negative prices are not allowed).

TABLE 3.1: Cases to forecast the upward (ER2UP) and downward (ER2DW) secondary regulation energy prices, and the Mean Absolute Percentage Error (MAPE) throughout 2014

\begin{tabular}{|c|c|c|c|}
\hline & & \multicolumn{2}{|c|}{ MAPE } \\
\hline Case & Forecasting Model & ER2UP & ER2DW \\
\hline \hline A & Perfect knowledge & No error & No error \\
\hline B & Mean hourly price of 2013 & $28.7 \%$ & $49.8 \%$ \\
\hline C & Heuristic Model & $21.3 \%$ & $30.5 \%$ \\
\hline
\end{tabular}

The economic results shown in Table 3.2 comprise the profit in the day-ahead energy market (DM Profit) as the difference between the income due to the sold energy minus the cost due to the purchased energy, the income in the secondary regulation reserve market (SM Income), the actual income due to the real-time use of the upward reserves (remunerated with the actual upward secondary regulation energy price, ER2UP), the actual cost due to the real-time use of the downward reserves (remunerated with the actual downward secondary regulation energy price, ER2DW), the start-up costs in generating $\left(c S U^{d}\right)$ and pumping $\left(c S U^{p}\right)$ modes, the actual profits $(\mathrm{AP})$, and the VPI-ER2 in $€$ and in $\%$ of the maximum theoretical income.

The VPI-ER2 is even lower than the VPI-RRC (between 1.8-5\% of the maximum theoretical income in all the forecasting models analysed). Therefore, the uncertainty of the secondary regulation energy prices will be modelled with an expected value in order to re- 
duce the computational burden, reducing the total number of scenarios in the model. The expected values correspond to the ones of the Case C.

TABLE 3.2: Economic results and the VPI-ER2 throughout 2014. Income, profit and VPI$\mathrm{ER} 2$ in $\mathrm{k} €$

\begin{tabular}{|c|c|c|c|c|c|c|c|c|c|}
\hline Case & DM Profit & SM Income & ER2UP & ER2DW & $c S U^{d}$ & $c S U^{p}$ & AP & \multicolumn{2}{|c|}{ VPI-ER2 } \\
\hline \hline A & 11408.6 & 15650 & 6212.9 & -4631.3 & -2462 & -1303.1 & 24875 & - & - \\
\hline B & 13711.6 & 15705.2 & 4903 & -6649.2 & -2664.7 & -1356.1 & 23649.7 & 1225.3 & $4.93 \%$ \\
\hline C & 11237.1 & 15622.8 & 5827 & -4641.4 & -2355.3 & -1265 & 24425.1 & 449.9 & $1.81 \%$ \\
\hline
\end{tabular}

\subsubsection{Real-time use of the committed secondary regulation reserves}

The value of perfect information of the percentages of the real-time use of the secondary regulation reserves (VPI-RTURs) has been preliminary studied in the Thesis and published in [Chazarra et al., 2016c]. However, further research was proposed in that paper, which is presented in this Thesis in Table 3.4. Note that the case study for obtaining the VPI-RTURs considers the same PSHP with the same technical data and in the same time period than the

ones of the VPI-DM, the VPI-RRC and the VPI-ER2 in order to establish comparisons. Five forecasting models of the percentages of the real-time use of reserves are proposed, Table 3.3. They are based on how the real-time use of reserves is considered in the technical literature. Most of the Cases are all the possible combinations of $0 \%$ and/or $100 \%$ of real-time use of reserves in all hours, except Case $\mathrm{D}$, which assumes that the percentage of the real-time use of the upward/downward secondary regulation reserve in hour $t$ of a certain day of 2014 is the average of the percentages of the real-time use of the upward/downward reserves, respectively, in the said hour across all days in 2013. 
TABLE 3.3: Cases to forecast the percentages of the upward and downward real-time use of the committed reserves, and the Mean Absolute Percentage Error (MAPE) throughout 2014

\begin{tabular}{|c|c|c|c|c|}
\hline \multirow[t]{2}{*}{ Case } & \multicolumn{2}{|c|}{ Upward Real-Time Use of Reserves } & \multicolumn{2}{|c|}{ Downward Real-Time Use of Reserves } \\
\hline & Forecasting Model & MAPE & Forecasting Model & MAPE \\
\hline $\mathrm{A}$ & Perfect knowledge & No error & Perfect knowledge & No error \\
\hline $\mathrm{B}$ & $\begin{array}{l}100 \% \text { in all hours, } \\
\text { [Li \& Shahidehpour, 2005] } \\
\text { and [Chazarra et al., 2016a] }\end{array}$ & $76.5 \%$ & $\begin{array}{l}0 \% \text { in all hours, } \\
\text { [De Ladurantaye et al., 2007] } \\
\text { and [Chazarra et al., 2016a] }\end{array}$ & $15.3 \%$ \\
\hline $\mathrm{C}$ & $\begin{array}{l}0 \% \text { in all hours, } \\
\text { [De Ladurantaye et al., 2007] } \\
\text { and [Chazarra et al., 2016a] }\end{array}$ & $21.5 \%$ & $\begin{array}{c}100 \% \text { in all hours, } \\
\text { [Li \& Shahidehpour, 2005] } \\
\text { and [Chazarra et al., 2016a] }\end{array}$ & $90.5 \%$ \\
\hline $\mathrm{D}$ & $\begin{array}{l}\text { Mean hourly price of } 2013 \text {, } \\
\text { [Kazempour et al., 2009] } \\
\text { and [Chazarra et al., 2016a] }\end{array}$ & $23.6 \%$ & $\begin{array}{l}\text { Mean hourly price of } 2013 \text {, } \\
\text { [Kazempour et al., 2009] } \\
\text { and [Chazarra et al., 2016a] }\end{array}$ & $22.2 \%$ \\
\hline $\mathrm{E}$ & $0 \%$ in all hours & $21.5 \%$ & $0 \%$ in all hours & $15.3 \%$ \\
\hline $\mathrm{F}$ & $100 \%$ in all hours & $76.5 \%$ & $100 \%$ in all hours & $90.5 \%$ \\
\hline
\end{tabular}

The economic results shown in Table 3.4 comprise the profit in the day-ahead energy market (DM Profit) as the difference between the income due to the sold energy minus the cost due to the purchased energy, the income in the secondary regulation reserve market (SM Income), the actual income due to the historical hourly real-time use of the upward reserves (ER2UP), the actual cost due to historical hourly real-time use of the downward reserves (ER2DW), the start-up costs in generating $\left(c S U^{d}\right)$ and pumping $\left(c S U^{p}\right)$ modes, the income due to upward energy deviations (DESUP) and the cost due to the downward energy deviations (DESDW), the actual profits (AP), and the VPI-RTURs in $€$ and in \% of the maximum theoretical income. Due to the errors in forecasting the percentages of the real-time use of reserves, the actual water volume trajectory of the upper reservoir must be obtained in a post-optimal simulation process. Whether there is a violation of the maximum water storage capacity due to a lower upward or a higher downward real secondary regulation energy schedules in comparison to the expected ones, or there is a violation of the minimum water storage capacity due to a higher upward or a lower downward real secondary regulation energy schedules in comparison to the expected ones, the post-optimal simulation process introduces an energy deviation that is remunerated according to the deviation market of the Spanish power system.

The Case with the lowest VPI-RTURs (Case C) is significantly lower than the VPI-DM ( $5 \%$ in the former versus $28.9 \%$ in the latter, of the maximum theoretical income). Therefore, the uncertainty of the percentages of the real-time use of reserves will be modelled with an expected value in order to reduce the computational burden, reducing the total number of scenarios in the model. The expected values correspond to the ones of the Case C, i.e., 


\begin{tabular}{|c|c|c|c|c|c|c|c|}
\hline & 空 & & $\begin{array}{l}10 \\
10 \\
0 \\
\dot{0} \\
\text { ô }\end{array}$ & 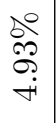 & $\begin{array}{l}\Delta 0 \\
\text { రे } \\
0 \\
0\end{array}$ & 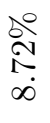 & $\begin{array}{l}0 \\
1 \\
1 \\
0 \\
0 \\
-1\end{array}$ \\
\hline & 5 & & $\begin{array}{l}20 \\
\text { đ̊ } \\
\mathscr{8} \\
\infty\end{array}$ & 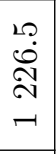 & 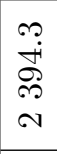 & $\begin{array}{l}0 \\
\infty \\
0 \\
0 \\
\sim\end{array}$ & 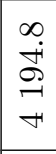 \\
\hline & $\frac{l_{4}}{4}$ & $\begin{array}{l}\stackrel{D}{D} \\
\infty \\
\stackrel{+}{N} \\
\stackrel{N}{1}\end{array}$ & $\begin{array}{l}\dddot{P} \\
\infty \\
\infty \\
\infty \\
10\end{array}$ & 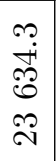 & 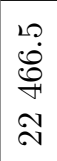 & 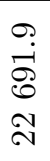 & $\begin{array}{l}\mathscr{8} \\
\mathscr{0} \\
\stackrel{2}{*}\end{array}$ \\
\hline & 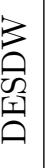 & & $\underset{\stackrel{20}{+}}{\stackrel{1}{1}}$ & 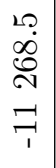 & 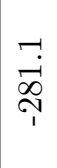 & $\stackrel{\stackrel{\sim}{\dot{\sigma}}}{\underset{+}{+}}$ & 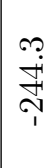 \\
\hline & 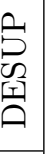 & & $\begin{array}{l}0 \\
0 \\
0 \\
0 \\
0 \\
10\end{array}$ & 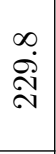 & $\begin{array}{l}0 \\
\dot{\leftrightarrow} \\
\stackrel{\sim}{0} \\
-1\end{array}$ & $\begin{array}{l}\mathfrak{1} \\
\infty \\
\infty\end{array}$ & $\begin{array}{l}\underset{D}{\infty} \\
\underset{N}{N} \\
-1\end{array}$ \\
\hline & $\begin{array}{c}2 \\
5 \\
\text { s. } \\
0\end{array}$ & $\begin{array}{l}\overrightarrow{0} \\
\tilde{8} \\
\dot{0} \\
\overrightarrow{1}\end{array}$ & $\begin{array}{l}0 \\
\dot{-} \\
\vec{\sigma} \\
\overrightarrow{1} \\
\rightarrow\end{array}$ & $\begin{array}{c}0 \\
\dot{-1} \\
\overparen{0} \\
-1 \\
1\end{array}$ & $\begin{array}{l}0 \\
10 \\
\stackrel{1}{H} \\
\text { N } \\
+1\end{array}$ & $\begin{array}{l}\vec{H} \\
\infty \\
\stackrel{\sim}{N} \\
\stackrel{+}{r}\end{array}$ & $\begin{array}{l}0 \\
\stackrel{0}{2} \\
\stackrel{\sim}{\sim} \\
\rightarrow\end{array}$ \\
\hline & $\begin{array}{c}5 \\
5 \\
5 \\
5\end{array}$ & \begin{tabular}{l} 
Oै \\
\multirow{T}{1}{} \\
r
\end{tabular} & 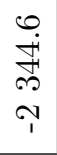 & $\begin{array}{l}\widetilde{-} \\
\stackrel{8}{1} \\
\sim \\
\sim\end{array}$ & 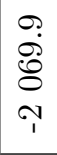 & 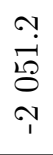 & $\begin{array}{l}0 \\
\infty \\
0 \\
ٍ \\
\sim \\
\sim\end{array}$ \\
\hline & 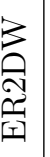 & 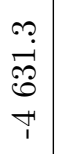 & $\begin{array}{l}\stackrel{\rho}{0} \\
\stackrel{\vec{p}}{\infty} \\
\overrightarrow{1}\end{array}$ & 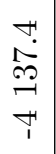 & $\begin{array}{l}\stackrel{\sim}{\sim} \\
\underset{H}{F} \\
\sim \\
\sim\end{array}$ & $\begin{array}{l}\stackrel{\Re}{+} \\
\stackrel{\overbrace{}}{\curvearrowright} \\
\stackrel{\sim}{\sim}\end{array}$ & $\begin{array}{l}0 \\
0 \\
\stackrel{1}{1} \\
7\end{array}$ \\
\hline & 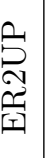 & $\begin{array}{l}\stackrel{\partial}{\mathrm{j}} \\
\vec{\sim} \\
\mathcal{0}\end{array}$ & $\begin{array}{l}\stackrel{\sim}{2} \\
\stackrel{\sim}{N} \\
0 \\
0\end{array}$ & 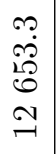 & $\begin{array}{l}\stackrel{20}{\rightarrow} \\
\stackrel{20}{+} \\
20\end{array}$ & $\begin{array}{l}\hat{1} \\
\stackrel{8}{8} \\
\stackrel{8}{0}\end{array}$ & $\begin{array}{l}\vec{H} \\
\infty \\
10 \\
10 \\
10\end{array}$ \\
\hline & 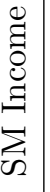 & $\begin{array}{l}0 \\
\stackrel{0}{0} \\
10 \\
\stackrel{10}{=}\end{array}$ & 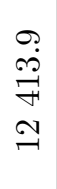 & 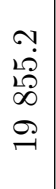 & $\begin{array}{l}\vec{H} \\
\text { ஸे } \\
\text { के } \\
\stackrel{\leftrightarrow}{\sim}\end{array}$ & 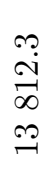 & 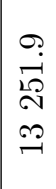 \\
\hline & 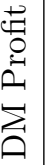 & 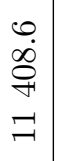 & 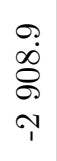 & $\begin{array}{l}0 \\
\stackrel{0}{\oplus} \\
\stackrel{N}{N} \\
\circ \\
\stackrel{-}{0}\end{array}$ & $\begin{array}{l}\vec{H} \\
\dot{\sigma} \\
\stackrel{\sigma}{r}\end{array}$ & 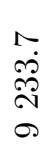 & $\begin{array}{l}0 \\
20 \\
i \stackrel{0}{1} \\
10\end{array}$ \\
\hline & 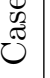 & $\varangle$ & 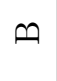 & 0 & ค & 되 & I \\
\hline
\end{tabular}


the transmission system operator will use $0 \%$ of the committed upward secondary regulation reserves and $100 \%$ of the committed downward secondary regulation reserves, in all hours.

\subsection{Model formulation for VS-PSHP}

The model formulation here presented in detail corresponds to the one of PSHPs with variablespeed pump-turbine units (VS-PSHP), from the article entitled "Optimal Joint Energy and Secondary Regulation Reserve Hourly Scheduling of Variable Speed Pumped Storage Hydropower Plants" from this Thesis. Main contributions with respect to this paper are the following:

1. The PSHP is modelled as a price-maker in the secondary regulation reserve market in order to take into account the effects of the reserve schedule in the cleared price of the reserve market. As it is discussed throughout the Thesis, the assumption that the PSHP is a price-taker in the reserve market can significantly overestimate the income obtained in it.

2. Uncertainty is also considered in the upward and downward secondary regulation energy prices and in the percentages of the real-time use of the committed upward and downward reserves. It is important to remark that, due to the errors in forecasting the percentages of the real-time use of reserves, the actual water volume trajectory of the upper reservoir must be also calculated in a post-optimal simulation process.

3. The optimal hourly energy and reserve schedules are obtained following the methodology presented in the article entitled "Deriving Optimal End of Day Storage for PumpedStorage Power Plants in the Joint Energy and Reserve Day-ahead Scheduling" from this Thesis. It is based on optimising the mentioned schedules using a look-ahead period, which uses future information of the electricity power system data. Please, see more details of the methodology with look ahead period in the mentioned article from this Thesis.

\subsubsection{Objective Function}

The objective function (3.1) maximises simultaneously the expected net income and the conditional value at risk, $C V a R$. Each term is weighted according to $\mu$, depending on the risk-aversion of the decision maker. Note that $\mu=0$ corresponds to the risk-neutral decision.

The net income in scenario $n$, i.e., $B_{n}$, of a PSHP equipped with variable-speed pumpturbine units participating in the day-ahead energy market and in the secondary regulation service in the framework of the Iberian electricity market [Lobato et al., 2008] is defined in 
(3.2). Note that the model formulation is a scenario-based one without non-anticipativity constraints, as the energy and reserve schedule decisions are taken in a single-stage. The obtained solution is the same for all scenarios, and this fact might resemble the non-anticipativity constraints. However, as there is no possibility to adapt the solution in a second stage, there are neither recourse functions so it does not seem appropriate to say that non-anticipativity constraints are implicitly implemented. The decisions are robust to the uncertainty of all the electric power system data, thanks to the maximization of the $C V a R$. The reason why the Thesis author has chosen to take both the energy and reserve schedule decisions in a single stage is motivated by the fact that the information disclosed after the clearing process of the day-ahead energy market has not a significant impact on the information used to take decisions in the secondary regulation reserve market in the Spanish electricity market (for instance, the correlation between the marginal prices of both markets was -0.47 in 2013). The first line in (3.2) expresses the net income in the day-ahead energy market and the quadratic income from the secondary regulation reserve market, respectively, whereas the second line accounts for the net income from the secondary regulation energy due to the real-time use of the reserves and the start-up costs in generating and pumping modes, respectively.

$$
\begin{gathered}
\text { Max } z=(1-\mu) \sum_{n} \pi_{n} B_{n}+\mu \cdot C V a R \\
B_{n}=\sum_{t}\left\{\sum_{c}\left(g_{c, t}^{d}-g_{c, t}^{p}\right) l_{t} \cdot \lambda_{D, n, t}+\frac{1}{\lambda_{S, n, t}^{m}}\left(\lambda_{S, n, t}-\lambda_{S, n, t}^{o}\right) \cdot \lambda_{S, n, t}\right. \\
\left.+\left(e_{t}^{s, u p} \cdot \lambda_{u p, n, t}-e_{t}^{s, d w} \cdot \lambda_{d w, n, t}\right)-\sum_{c}\left(c S U_{c}^{d} \cdot y_{c, t}^{d}+c S U_{c}^{p} \cdot y_{c, t}^{p}\right)\right\} \quad \forall n
\end{gathered}
$$

Imperfect information is considered in all the electric power system data of the problem: i) the day-ahead energy market prices, ii) the residual demand curves of the secondary regulation reserve market, iii-iv) the upward and downward secondary regulation energy prices, and v-vi) the percentages of the real-time use of the committed upward and downward reserves.

\subsubsection{Risk-Aversion Constraints}

As it is expressed in the paper "Optimal Joint Energy and Secondary Regulation Reserve Hourly Scheduling of Variable Speed Pumped Storage Hydropower Plants" from this Thesis, several techniques can be found in the technical literature to take into account the risk management in an optimization model. In [García-González et al., 2007], two techniques are compared: i) the introduction of a minimum profit constraint, by which a minimum profit is required for each scenario and ii) the introduction of a minimum $C V a R$. Both techniques 
do not guarantee feasible solutions, which depend on the minimum profit and $C V a R$ chosen. In the presented model formulation, the risk management is modelled in a similar way as in [Pousinho et al., 2011], which is based on [Rockafellar \& Uryasev, 2000], by equations (3.3) and (3.4). They represent simultaneously the $V a R$ and $C V a R$. Note that this approach corresponds to a linear formulation and that a feasible solution is always guaranteed.

$$
\begin{gathered}
V a R-\frac{1}{\beta} \sum_{n} \pi_{n} B_{n}^{-} \geq C V a R \\
B_{n}^{-} \geq V a R-B_{n} \quad \forall n
\end{gathered}
$$

\subsubsection{Water Balance}

The water balance, (3.5) does not include any water inflow because a closed-loop PSHP is considered in this Thesis. Water limits are imposed to the water volume variable, $v_{t}$ in all time periods, (3.6). Water balance and limits in the lower reservoir are not included in the model formulation for simplicity.

$$
\begin{gathered}
v_{t}=v_{t-1}+\sum_{c} l_{t}\left(q_{c, t}^{p}-q_{c, t}^{d}\right) \quad \forall t \\
\underline{v} \leq v_{t} \leq \bar{v} \quad \forall t
\end{gathered}
$$

In this model, there is no target water volume at the end of each day $\mathrm{D}$ following the methodology with a look-ahead period proposed in the article entitled "Deriving Optimal End of Day Storage for Pumped-Storage Power Plants in the Joint Energy and Reserve Dayahead Scheduling" from this Thesis. The methodology with a look-ahead period uses future information of the electricity power system data (information after each day D) and is based on: the scheduling decisions for day $\mathrm{D}$ are obtained as a result of an optimization problem with a 48-hour time horizon, i.e., $\mathrm{D}$ and $\mathrm{D}+1$, also discretised in hourly steps. The initial water volume of the upper reservoir in $\mathrm{D}$ is known by the decision maker, and is obtained as a result of the optimization problem for D-1. It is important to highlight that there are no water volume target constraints at the end of any day $(\mathrm{D}$ and $\mathrm{D}+1)$.

\subsubsection{Hydropower Generation}

Two generation/consumption curves, $k_{1}$ and $k_{2}$ have been considered in the formulation, and correspond to two different reservoir levels. Each curve is selected using the binary variable $d_{t}$ that only depends on the water volume of the upper reservoir (3.7) and (3.8), as we consider 
that the effect of the lower reservoir level on the net head is neglectable.

$$
\begin{aligned}
& v_{t} \geq \underline{v}\left(1-d_{t}\right)+\left(\underline{v}+\frac{\bar{v}-\underline{v}}{2}\right) d_{t} \quad \forall t \\
& v_{t} \leq \bar{v} \cdot d_{t}+\left(\underline{v}+\frac{\bar{v}-\underline{v}}{2}\right)\left(1-d_{t}\right) \quad \forall t \\
& g_{c, t}^{d} \leq u_{c, t}^{d} \cdot \underline{g}_{c, k}^{d}+q s_{c, t}^{d} \cdot \delta_{k}^{d}+\bar{g}_{c, k}^{d} \cdot d_{t} \quad \forall c, t, k=k_{1} \\
& g_{c, t}^{d} \geq u_{c, t}^{d} \cdot \underline{g}_{c, k}^{d}+q s_{c, t}^{d} \cdot \delta_{k}^{d}-\bar{g}_{c, k}^{d} \cdot d_{t} \quad \forall c, t, k=k_{1} \\
& g_{c, t}^{d} \leq u_{c, t}^{d} \cdot \underline{g}_{c, k}^{d}+q s_{c, t}^{d} \cdot \delta_{k}^{d}+\bar{g}_{c, k}^{d}\left(1-d_{t}\right) \quad \forall c, t, k=k_{2} \\
& g_{c, t}^{d} \geq u_{c, t}^{d} \cdot \underline{g}_{c, k}^{d}+q s_{c, t}^{d} \cdot \delta_{k}^{d}-\bar{g}_{c, k}^{d}\left(1-d_{t}\right) \quad \forall c, t, k=k_{2} \\
& q s_{c, t}^{d} \leq u_{c, t}^{d} \cdot \bar{q}_{c, k_{1}}^{d} \quad \forall c, t \\
& q s_{c, t}^{d} \leq\left(\bar{q}_{c, k_{1}}^{d}-\underline{q}_{c, k_{1}}^{d}\right)\left(1-d_{t}\right)+\left(\bar{q}_{c, k_{2}}^{d}-\underline{q}_{c, k_{2}}^{d}\right) d_{t} \quad \forall c, t \\
& q_{c, t}^{d} \leq u_{c, t}^{d} \cdot \underline{q}_{c, k}^{d}+q s_{c, t}^{d}+\bar{q}_{c, k}^{d} \cdot d_{t}+\frac{1}{\delta_{k}^{d}}\left(\rho_{t}^{u p} \cdot g_{c, t}^{d, s, u p}-\rho_{t}^{d w} \cdot g_{c, t}^{d, s, d w}\right) \quad \forall c, t, k=k_{1} \\
& q_{c, t}^{d} \geq u_{c, t}^{d} \cdot \underline{q}_{c, k}^{d}+q s_{c, t}^{p}-\bar{q}_{c, k}^{d} \cdot d_{t}+\frac{1}{\delta_{k}^{d}}\left(\rho_{t}^{u p} \cdot g_{c, t}^{d, s, u p}-\rho_{t}^{d w} \cdot g_{c, t}^{d, s, d w}\right) \quad \forall c, t, k=k_{1} \\
& q_{c, t}^{d} \leq u_{c, t}^{d} \cdot \underline{q}_{c, k}^{d}+q s_{c, t}^{d}+\bar{q}_{c, k}^{d}\left(1-d_{t}\right)+\frac{1}{\delta_{k}^{d}}\left(\rho_{t}^{u p} \cdot g_{c, t}^{d, s, u p}-\rho_{t}^{d w} \cdot g_{c, t}^{d, s, d w}\right) \quad \forall c, t, k=k_{2} \\
& q_{c, t}^{d} \geq u_{c, t}^{d} \cdot \underline{q}_{c, k}^{d}+q s_{c, t}^{d}-\bar{q}_{c, k}^{d}\left(1-d_{t}\right)+\frac{1}{\delta_{k}^{d}}\left(\rho_{t}^{u p} \cdot g_{c, t}^{d, s, u p}-\rho_{t}^{d w} \cdot g_{c, t}^{d, s, d w}\right) \quad \forall c, t, k=k_{2} \\
& g_{c, t}^{p} \leq u_{c, t}^{p} \cdot \underline{g}_{c, k}^{p}+q s_{c, t}^{p} \cdot \delta_{k}^{p}+\bar{g}_{c, k}^{p} \cdot d_{t} \quad \forall c, t, k=k_{1} \\
& g_{c, t}^{p} \geq u_{c, t}^{p} \cdot \underline{g}_{c, k}^{p}+q s_{c, t}^{p} \cdot \delta_{k}^{p}-\bar{g}_{c, k}^{p} \cdot d_{t} \quad \forall c, t, k=k_{1} \\
& g_{c, t}^{p} \leq u_{c, t}^{p} \cdot \underline{g}_{c, k}^{p}+q s_{c, t}^{p} \cdot \delta_{k}^{p}+\bar{g}_{c, k}^{p}\left(1-d_{t}\right) \quad \forall c, t, k=k_{2} \\
& g_{c, t}^{p} \geq u_{c, t}^{p} \cdot \underline{g}_{c, k}^{p}+q s_{c, t}^{p} \cdot \delta_{k}^{p}-\bar{g}_{c, k}^{p}\left(1-d_{t}\right) \quad \forall c, t, k=k_{2} \\
& q s_{c, t}^{p} \leq u_{c, t}^{p} \cdot \bar{q}_{c, k_{2}}^{p} \quad \forall c, t \\
& q s_{c, t}^{p} \leq\left(\bar{q}_{c, k_{1}}^{p}-\underline{q}_{c, k_{1}}^{p}\right)\left(1-d_{t}\right)+\left(\bar{q}_{c, k_{2}}^{p}-\underline{q}_{c, k_{2}}^{p}\right) d_{t} \quad \forall c, t
\end{aligned}
$$




$$
\begin{array}{cc}
q_{c, t}^{p} \leq u_{c, t}^{p} \cdot \underline{q}_{c, k}^{p}+q s_{c, t}^{p}+\bar{q}_{c, k}^{p} \cdot d_{t}+\frac{1}{\delta_{k}^{p}}\left(\rho_{t}^{d w} \cdot g_{c, t}^{p, s, d w}-\rho_{t}^{u p} \cdot g_{c, t}^{p, s, u p}\right) & \forall c, t, k=k_{1} \\
q_{c, t}^{p} \geq u_{c, t}^{p} \cdot \underline{q}_{c, k}^{p}+q s_{c, t}^{p}-\bar{q}_{c, k}^{p} \cdot d_{t}+\frac{1}{\delta_{k}^{p}}\left(\rho_{t}^{d w} \cdot g_{c, t}^{p, s, d w}-\rho_{t}^{u p} \cdot g_{c, t}^{p, s, u p}\right) & \forall c, t, k=k_{1} \\
q_{c, t}^{p} \leq u_{c, t}^{p} \cdot \underline{q}_{c, k}^{p}+q s_{c, t}^{p}+\bar{q}_{c, k}^{p}\left(1-d_{t}\right)+\frac{1}{\delta_{k}^{p}}\left(\rho_{t}^{d w} \cdot g_{c, t}^{p, s, d w}-\rho_{t}^{u p} \cdot g_{c, t}^{p, s, u p}\right) & \forall c, t, k=k_{2} \\
q_{c, t}^{p} \geq u_{c, t}^{p} \cdot \underline{q}_{c, k}^{p}+q s_{c, t}^{p}-\bar{q}_{c, k}^{p}\left(1-d_{t}\right)+\frac{1}{\delta_{k}^{p}}\left(\rho_{t}^{d w} \cdot g_{c, t}^{p, s, d w}-\rho_{t}^{u p} \cdot g_{c, t}^{p, s, u p}\right) & \forall c, t, k=k_{2}
\end{array}
$$

Generation/consumption curves of each variable-speed pump-turbine unit are modelled by equations (3.9)-(3.28); the formulation is based on the one proposed in [Conejo et al., 2002]. The power generation is calculated from (3.9)-(3.12), as a function of $d_{t}$ and $u_{c, t}^{d}$. With equations (3.13) and (3.14), the maximum and minimum water discharges, which depend on the water level in the upper reservoir, are considered. In addition to this, the water discharge takes into account not only the flow that is used to produce the energy committed or scheduled in the day-ahead energy market but also the extra flow that is required in order to provide the upward regulation energy and the flow that is kept upstream in order to provide the downward regulation energy (3.15)-(3.18). The water discharge used for deploying the secondary regulation energy also depends on the water level in the upper reservoir.

Head dependency in consumed power and pumped water is modelled analogously by (3.19)(3.28). The pumped water also takes into account the extra flow that is pumped in order to provide the downward regulation energy and the flow that is kept downstream in order to provide the upward regulation energy (3.25)-(3.28).

\subsubsection{Secondary Regulation Service}

The procurement of the secondary regulation service in the Spanish electricity market is described in subsection 1.2.2.2, and comprises the day-ahead secondary regulation reserve market and the real-time use of the committed reserves. The secondary regulation reserve schedule is modelled with (3.29)-(3.37). Note that the auxiliary variables $a u x \_g_{c, t}^{d, s}$ and $a u x \_g_{c, t}^{p, s}$ avoid non-linearities in the formulation of the downward and upward secondary regulation reserve in generating and pumping modes, respectively, due to the head dependency in the available reserves. When a unit is off in generating mode $\left(u_{c, t}^{d}=0\right)$, there is no available reserves by (3.31), and $a u x \_g_{c, t}^{d, s}$ will take a value greater than or equal to the expression in square brackets in (3.30) and lower than $\bar{g}_{c, k_{1}}^{d}$ by (3.32). In addition, when a unit is on in generating mode $\left(u_{c, t}^{d}=1\right)$, aux $\_g_{c, t}^{d, s}$ equals zero through (3.32). The same behaviour can be seen with aux $g_{c, t}^{p, s}$ in pumping mode with (3.34)-(3.36). Finally, the Spanish transmission system operator forces all regulation zones to meet an hourly ratio $R_{t}^{S M}$ between the upward 
and the total reserves in order to ensure certain equilibrium between the upward and downward reserves, preventing them from offering only upward reserves or only downward reserves (3.37).

$$
\begin{aligned}
& g_{c, t}^{d, s, u p} \leq\left[\bar{g}_{c, k_{2}}^{d} \cdot d_{t}+\bar{g}_{c, k_{1}}^{d}\left(1-d_{t}\right)\right]-g_{c, t}^{d} \quad \forall c, t \\
& g_{c, t}^{d, s, d w}-a u x \_g_{c, t}^{d, s} \leq g_{c, t}^{d}-\left[\underline{g}_{c, k_{2}}^{d} \cdot d_{t}+\underline{g}_{c, k_{1}}^{d}\left(1-d_{t}\right)\right] \quad \forall c, t \\
& g_{c, t}^{d, s, u p}+g_{c, t}^{d, s, d w} \leq \bar{g}_{c, k_{1}}^{d} \cdot u_{c, t}^{d} \quad \forall c, t \\
& a u x \_g_{c, t}^{d, s} \leq \bar{g}_{c, k_{1}}^{d}\left(1-u_{c, t}^{d}\right) \quad \forall c, t \\
& g_{c, t}^{p, s, d w} \leq\left[\bar{g}_{c, k_{2}}^{p} \cdot d_{t}+\bar{g}_{c, k_{1}}^{p}\left(1-d_{t}\right)\right]-g_{c, t}^{p} \quad \forall c, t \\
& g_{c, t}^{p, s, u p}-a u x \_g_{c, t}^{p, s} \leq g_{c, t}^{p}-\left[\underline{g}_{c, k_{2}}^{p} \cdot d_{t}+\underline{g}_{c, k_{1}}^{p}\left(1-d_{t}\right)\right] \quad \forall c, t \\
& g_{c, t}^{p, s, u p}+g_{c, t}^{p, s, d w} \leq \bar{g}_{c, k_{2}}^{p} \cdot u_{c, t}^{p} \quad \forall c, t \\
& \text { aux_g g } g_{c, t}^{p, s} \leq \bar{g}_{c, k_{2}}^{p}\left(1-u_{c, t}^{p}\right) \quad \forall c, t \\
& \sum_{c}\left(g_{c, t}^{d, s, u p}+g_{c, t}^{p, s, u p}\right)=R_{t}^{S M} \cdot\left(g_{c, t}^{d, s, u p}+g_{c, t}^{p, s, u p}+g_{c, t}^{d, s, d w}+g_{c, t}^{p, s, d w}\right) \quad \forall t
\end{aligned}
$$

The secondary regulation energy in each period $t$ of the Spanish electricity market is remunerated according to the net energy, i.e. the upward regulation energy in generating and pumping modes minus the downward regulation energy in generating and pumping modes, (3.38)-(3.40). A positive net regulation energy $\left(\phi_{t}=1\right)$ is remunerated according to the upward regulation energy price, whereas if the net regulation energy is negative $\left(\phi_{t}=0\right)$, the PSHP must pay the downward regulation energy price. If $\phi_{t}=1, e_{t}^{s, d w}=0$ by equation (3.40) and $e_{t}^{s, u p}$ equals the right-side of equation (3.38). Analogously, if $\phi_{t}=0, e_{t}^{s, u p}=0$ by equation (3.39) and $e_{t}^{s, d w}$ equals the right-side of equation (3.38).

$$
\begin{gathered}
e_{t}^{s, u p}-e_{t}^{s, d w}=\sum_{c}\left[\rho_{t}^{u p}\left(g_{c, t}^{d, s, u p}+g_{c, t}^{p, s, u p}\right)-\rho_{t}^{d w}\left(g_{c, t}^{d, s, d w}+g_{c, t}^{p, s, d w}\right) \quad \forall t\right] \\
0 \leq e_{t}^{s, u p} \leq \phi_{t} \cdot \bar{g}_{c, k_{1}}^{d} \quad \forall t \\
0 \leq e_{t}^{s, d w} \leq\left(1-\phi_{t}\right) \bar{g}_{c, k_{1}}^{d} \quad \forall t
\end{gathered}
$$

Consider the PSHP as a price-maker in the secondary regulation reserve market (and in all markets in general) makes the income from the market a non-linear function, because it is the result of the marginal price multiplied by the reserve. Several approaches have been adopted in the literature to model the residual demand curves in the day-ahead energy market (it also applies for the reserve market) and to cope with the said nonlinearity 
[Marulanda et al., 2005]: 1) polynomial approximation, 2) piecewise linear approximation, and 3) stepwise approximation. The method adopted in this Thesis is a linear approximation of the entire residual demand curve of the reserve market, which is, therefore, defined by a slope and an intercept [Calmarza \& de la Fuente, 2002]. Due to this, the income in the reserve market is a quadratic function of the agent reserve offer. According to the results obtained in [Marulanda et al., 2005], the deviation due to the use of a linear residual demand curve of the reserve market in comparison to a multi-step residual demand curve of the reserve market is expected to be lower than $2 \%$ of the estimated income.

The income for the upward $\left(g_{c, t}^{d, s, u p}+g_{c, t}^{p, s, u p}\right)$ and downward $\left(g_{c, t}^{d, s, d w}+g_{c, t}^{p, s, d w}\right)$ reserves in a given scenario, $I_{S, n}$ is directly the result of the total reserves multiplied by the marginal reserve price (3.41), $\lambda_{S, n, t}$. The marginal reserve price $\lambda_{S, n, t}$ is estimated as a linear approximation of the residual demand curve of the reserve market (3.42). If (3.42) is included in (3.41), the income of the upward and downward reserves can be expressed as a quadratic function of the marginal reserve price (3.43). Note that the fraction and the term between brackets in (3.43) is the total (upward and downward) secondary regulation reserves, i.e., the expression between brackets in (3.41), expressed as a function of the intercept and the slope of the linear approximation of the residual demand curve of the reserve market.

$$
\begin{gathered}
I_{S, n}=\sum_{t} \sum_{c}\left(g_{c, t}^{d, s, u p}+g_{c, t}^{p, s, u p}+g_{c, t}^{d, s, d w}+g_{c, t}^{p, s, d w}\right) \lambda_{S, n, t} \quad \forall n \\
\lambda_{S, n, t}=\lambda_{S, n, t}^{o}+\lambda_{S, n, t}^{m} \cdot \sum_{c}\left(g_{c, t}^{d, s, u p}+g_{c, t}^{p, s, u p}+g_{c, t}^{d, s, d w}+g_{c, t}^{p, s, d w}\right) \quad \forall n, t \\
I_{S, n}=\sum_{t} \frac{1}{\lambda_{S, n, t}^{m}}\left(\lambda_{S, n, t}-\lambda_{S, n, t}^{o}\right) \cdot \lambda_{S, n, t} \quad \forall n
\end{gathered}
$$

\subsubsection{Other Constraints}

A pump-turbine unit cannot be operated simultaneously in generating and pumping modes (3.44).

$$
u_{c, t}^{d}+u_{c, t}^{p} \leq 1 \quad \forall c, t
$$

Moreover, a PSHP usually comprises a single penstock between the upper reservoir and the power station so it cannot operate simultaneously in generating and pumping modes (the whole plant), regardless of the number of pump-turbine units. Consequently, if there is at least one unit operating in pumping mode, no unit can be operated in generating mode, and vice versa (3.45). For instance, if the PSHP is composed by three units $(\mathrm{C}=3)$ and unit $c_{1}$ is pumping $\left(u_{c_{1}, t}^{p}=1\right)$, the right-side of equation (3.45) is zero when the equation is evaluated for $c=c_{1}$ and, therefore, the rest of the units have an off state in generating mode, i.e. 
$u_{c_{2}, t}^{d}=u_{c_{3}, t}^{d}=0$, left-side of the equation. Due to (3.44), when a unit is in pumping mode, it cannot be in generating mode, i.e. $u_{c_{1}, t}^{d}=0$ as $u_{c_{1}, t}^{p}=1$.

$$
\sum_{c^{\prime} \neq c} u_{c^{\prime}, t}^{d} \leq(\mathrm{C}-1)-(\mathrm{C}-1) u_{c, t}^{p} \quad \forall c, t
$$

Finally, start-up decisions are modelled in generating mode by (3.46) and in pumping mode by $(3.47)$.

$$
\begin{aligned}
& y_{c, t}^{d} \geq u_{c, t}^{d}-u_{c, t-1}^{d} \quad \forall c, t \\
& y_{c, t}^{p} \geq u_{c, t}^{p}-u_{c, t-1}^{p} \quad \forall c, t
\end{aligned}
$$

\subsection{Model formulation for SC-PSHP}

The model formulation of PSHPs with the operation in hydraulic short-circuit mode and equipped with fixed-speed binary units is composed by equations (3.1)-(3.47), except (3.45) and forcing that the units are operated in pumping mode with fixed speed. The latter condition is implemented if the minimum consumed power and the minimum pumped water equal the maximum consumed power and the maximum pumped water, respectively. Due to this, (3.19)-(3.28) and (3.33)-(3.36) significantly change, permitting that each unit is operated at a single operating point in pumping mode without participating in the secondary regulation reserve market in the said mode. Equation (3.45) must be removed due to the operation in hydraulic short-circuit mode, as if one unit is operated in generating mode, the rest can be also be operated in generating mode or in pumping mode.

The model formulation of PSHPs with the operation in hydraulic short-circuit mode and equipped with fixed-speed ternary units is the same as the one equipped with fixed-speed binary units, and removing 3.44, because a ternary unit can be operated simultaneously in generating and pumping mode.

\subsection{Model formulation for FS-PSHP}

The model formulation of conventional PSHPs, i.e., equipped with fixed-speed units and without the operation in hydraulic short-circuit mode, is composed by equations (3.1)-(3.47) forcing that the units are operated in pumping mode with fixed speed, i.e., the minimum consumed power and the minimum pumped water equal the maximum consumed power and the maximum pumped water, respectively. 


\subsection{Case study}

The proposed risk-averse optimisation model with look-ahead period is applied to obtain the optimal operation of nine PSHPs equipped with fixed-speed pump-turbine units, Table 3.5, with variable-speed pump-turbine units with an operating range in pumping mode between the maximum and the $85 \%$ of the maximum pumped water, Table 3.6, and with variablespeed pump-turbine units with an operating range in pumping mode between the maximum and the $70 \%$ of the maximum pumped water, Table 3.7 .

The nine PSHPs are chosen in order to cover almost all the range of daily-cycle PSHPs: between 4-12 hours of empting or refilling the upper reservoir at maximum water discharge and pumped water flow, respectively. The PSHPs are assumed to be equipped with one binary unit. The maximum generation capacity of the $6 \mathrm{~h}-12 \mathrm{~h}$ units is close to the one of the largest hydropower units in the world: see [Bonneville Power Administration, ] for further information about the $805 \mathrm{MW}$ turbine in the Columbia River or see [Alstom, ] about the 800 MW Francis turbines at the Chinese Xiangjiaba underground hydropower plant. The 4h and $5 \mathrm{~h}$ units are also studied for illustrative purposes although their maximum generation capacity is higher. Unpublished results of the Thesis author show that the conclusions are the same for both a 1x1200 MW PSHP and a 2x600 MW PSHP.

The upper reservoir has a storage capacity of $5.0443 \mathrm{Mm}^{3}$ in all cases, and the maximum water discharge and pumped water flow have been chosen in order to empty and refill the upper reservoir in 4-12 hours. For example, the $6 \mathrm{~h}$ PSHP empties/refills the upper reservoir in six hours at its maximum water discharge/pumped water. The gross head is considered to be $400 \mathrm{~m}$ while the hydraulic losses are considered $3 \%$ of the gross head [U.S. Bureau of Reclamation, 1976].

In generating mode, the minimum flow and efficiencies at maximum and minimum flows are determined from typical performance curves in [U.S. Bureau of Reclamation, 1976]. A linear relationship between water discharge and power generation is assumed. The fixedspeed and variable-speed pump-turbine units are assumed to have a typical efficiency of $90 \%$ in pumping mode according to [Merino \& Lopez, 1996]. Start-up costs in generating and pumping modes have been calculated following the guidelines of [Nilsson \& Sjelvgren, 1997]. 
TABLE 3.5: Technical data of the fixed-speed pump-turbine units. $g$ refers to power, $q$ refers to flow and $c S U$ refers to start-up cost. Superscript $d$ refers to generating mode whereas $p$ refers to pumping mode. Flows in $\mathrm{m}^{3} / \mathrm{s}$, power in $M W$ and start-up costs in $€$

\begin{tabular}{|c|c|c|c|c|c|c|c|c|c|}
\hline & $4 \mathrm{~h}$ & $5 \mathrm{~h}$ & $6 \mathrm{~h}$ & $7 \mathrm{~h}$ & $8 \mathrm{~h}$ & $9 \mathrm{~h}$ & $10 \mathrm{~h}$ & $11 \mathrm{~h}$ & $12 \mathrm{~h}$ \\
\hline $\bar{g}^{d}$ & 1200 & 960 & 800 & 685.71 & 600 & 533.33 & 480 & 436.36 & 400 \\
\hline$\underline{g}^{d}$ & 529.01 & 423.21 & 352.67 & 302.29 & 264.5 & 235.11 & 211.6 & 192.37 & 176.34 \\
\hline $\bar{q}^{d}$ & 350.3 & 280.24 & 233.53 & 200.17 & 175.15 & 155.69 & 140.12 & 127.38 & 116.77 \\
\hline$\underline{q}^{d}$ & 150.63 & 120.5 & 100.42 & 86.07 & 75.31 & 66.95 & 60.25 & 54.77 & 50.21 \\
\hline $\bar{g}^{p}$ & 1573.12 & 1258.5 & 1048.75 & 898.93 & 786.56 & 699.16 & 629.25 & 572.04 & 524.37 \\
\hline $\bar{q}^{p}$ & 350.3 & 280.24 & 233.53 & 200.17 & 175.15 & 155.69 & 140.12 & 127.38 & 116.77 \\
\hline$\underline{g}^{p}$ & 1573.12 & 1258.5 & 1048.75 & 898.93 & 786.56 & 699.16 & 629.25 & 572.04 & 524.37 \\
\hline$\underline{q}^{p}$ & 350.3 & 280.24 & 233.53 & 200.17 & 175.15 & 155.69 & 140.12 & 127.38 & 116.77 \\
\hline$c S U^{d}$ & 3971.1 & 3202 & 2689.2 & 2323 & 2048.3 & 1834.6 & 1663.7 & 1523.8 & 1407.3 \\
\hline$c S U^{p}$ & 4078.3 & 3287.7 & 2760.7 & 2384.2 & 2101.8 & 1882.2 & 1706.5 & 1562.8 & 1443 \\
\hline
\end{tabular}

TABLE 3.6: Technical data of the variable-speed pump-turbine units with an operating range between the maximum and the $85 \%$ of the maximum pumped water

\begin{tabular}{|c|c|c|c|c|c|c|c|c|c|}
\hline & $4 \mathrm{~h}$ & $5 \mathrm{~h}$ & $6 \mathrm{~h}$ & $7 \mathrm{~h}$ & $8 \mathrm{~h}$ & $9 \mathrm{~h}$ & $10 \mathrm{~h}$ & $11 \mathrm{~h}$ & $12 \mathrm{~h}$ \\
\hline $\bar{g}^{d}$ & 1200.00 & 960.00 & 800.00 & 685.71 & 600.00 & 533.33 & 480.00 & 436.36 & 400.00 \\
\hline$\underline{g}^{d}$ & 529.01 & 423.21 & 352.67 & 302.29 & 264.50 & 235.11 & 211.60 & 192.37 & 176.34 \\
\hline $\bar{q}^{d}$ & 350.30 & 280.24 & 233.53 & 200.17 & 175.15 & 155.69 & 140.12 & 127.38 & 116.77 \\
\hline$\underline{q}^{d}$ & 150.63 & 120.50 & 100.42 & 86.07 & 75.31 & 66.95 & 60.25 & 54.77 & 50.21 \\
\hline $\bar{g}^{p}$ & 1573.12 & 1258.50 & 1048.75 & 898.93 & 786.56 & 699.16 & 629.25 & 572.04 & 524.37 \\
\hline $\bar{q}^{p}$ & 350.30 & 280.24 & 233.53 & 200.17 & 175.15 & 155.69 & 140.12 & 127.38 & 116.77 \\
\hline$\underline{g}^{p}$ & 1326.34 & 1061.08 & 884.23 & 757.91 & 663.17 & 589.49 & 530.54 & 482.31 & 442.11 \\
\hline$\underline{q}^{p}$ & 297.75 & 238.20 & 198.50 & 170.14 & 148.88 & 132.33 & 119.10 & 108.27 & 99.25 \\
\hline$c S U^{d}$ & 3971.1 & 3202 & 2689.2 & 2323 & 2048.3 & 1834.6 & 1663.7 & 1523.8 & 1407.3 \\
\hline$c S U^{p}$ & 4078.3 & 3287.7 & 2760.7 & 2384.2 & 2101.8 & 1882.2 & 1706.5 & 1562.8 & 1443 \\
\hline
\end{tabular}


TABLE 3.7: Technical data of the variable-speed pump-turbine units with an operating range between the maximum and the $70 \%$ of the maximum pumped water

\begin{tabular}{|c|c|c|c|c|c|c|c|c|c|}
\hline & $4 \mathrm{~h}$ & $5 \mathrm{~h}$ & $6 \mathrm{~h}$ & $7 \mathrm{~h}$ & $8 \mathrm{~h}$ & $9 \mathrm{~h}$ & $10 \mathrm{~h}$ & $11 \mathrm{~h}$ & $12 \mathrm{~h}$ \\
\hline $\bar{g}^{d}$ & 1200.00 & 960.00 & 800.00 & 685.71 & 600.00 & 533.33 & 480.00 & 436.36 & 400.00 \\
\hline$\underline{g}^{d}$ & 529.01 & 423.21 & 352.67 & 302.29 & 264.50 & 235.11 & 211.60 & 192.37 & 176.34 \\
\hline $\bar{q}^{d}$ & 350.30 & 280.24 & 233.53 & 200.17 & 175.15 & 155.69 & 140.12 & 127.38 & 116.77 \\
\hline$\underline{q}^{d}$ & 150.63 & 120.50 & 100.42 & 86.07 & 75.31 & 66.95 & 60.25 & 54.77 & 50.21 \\
\hline $\bar{g}^{p}$ & 1573.12 & 1258.50 & 1048.75 & 898.93 & 786.56 & 699.16 & 629.25 & 572.04 & 524.37 \\
\hline $\bar{q}^{p}$ & 350.30 & 280.24 & 233.53 & 200.17 & 175.15 & 155.69 & 140.12 & 127.38 & 116.77 \\
\hline$\underline{g}^{p}$ & 1084.83 & 867.86 & 723.22 & 619.90 & 542.41 & 482.15 & 433.93 & 394.48 & 361.61 \\
\hline$\underline{q}^{p}$ & 245.21 & 196.17 & 163.47 & 140.12 & 122.60 & 108.98 & 98.08 & 89.17 & 81.74 \\
\hline$c S U^{d}$ & 3971.1 & 3202 & 2689.2 & 2323 & 2048.3 & 1834.6 & 1663.7 & 1523.8 & 1407.3 \\
\hline$c S U^{p}$ & 4078.3 & 3287.7 & 2760.7 & 2384.2 & 2101.8 & 1882.2 & 1706.5 & 1562.8 & 1443 \\
\hline
\end{tabular}

The imperfect information in all the electric power system data of the problem is considered following the results obtained in Section 3.1:

1. The imperfect information of the day-ahead energy market prices is modelled forecasting three representative scenarios. Each corresponds to a 24-h price profile obtained from the forecasting model of Case $\mathrm{H}$ from the article entitled "Value of Perfect Information of Spot Prices in the Joint Energy and Reserve Hourly Scheduling of Pumped Storage Plants" from this Thesis: a $\operatorname{GARCH}(1,3)$ and $\operatorname{ARIMAX}(10,1,0)$ with the forecast wind power of the system as explanatory variable. In the autoregressive polynomial, the terms with lags 1, 2, 3, 4, 24, 144, 168, 169, 192 and 193 have a non-zero coefficient.

2. The imperfect information of the residual demand curves of the secondary regulation reserve market is modelled with an expected value. The expected values correspond to the ones of the Case E from the article entitled "Economic Impact of Forecasting Errors in Residual Reserve Curves in the Day-ahead Scheduling of Pumped Storage Plants" from this Thesis: a $\operatorname{SARIMA}(0,1,1)(0,1,1)^{24}$.

3. The imperfect information of the secondary regulation energy prices is modelled with an expected value. The expected values correspond to the ones of the Case $\mathrm{C}$ presented in subsection 3.1.3.

4. The imperfect information of the percentages of the real-time use of reserves is modelled with an expected value. The expected values correspond to the ones of the Case 
$\mathrm{C}$ presented in Section 3.1.4: the transmission system operator will use $0 \%$ of the committed upward secondary regulation reserves and $100 \%$ of the committed downward secondary regulation reserves, in all hours.

\subsection{Methodology}

The methodology here used to obtain the optimal energy and reserve schedules is based on the one from the article entitled "Deriving Optimal End of Day Storage for PumpedStorage Power Plants in the Joint Energy and Reserve Day-ahead Scheduling" from this Thesis. The optimisation models described in Section 3.2 and 3.4 are used to obtain the income with and without the look-ahead period, with and without participating in the secondary regulation service and with and without assuming perfect information of the electric power system data. When perfect information is assumed, the obtained income corresponds to the maximum theoretical income whereas when imperfect information is considered, a postoptimal simulation process must be carried out. The post-optimal simulation process requires to calculate the actual income from all the above-described markets and services using the historical prices of the electric power system data of the problem, and to calculate the actual volume trajectory of due to the errors in forecasting the real-time use of reserves.

The operation and incomes of the above-described PSHPs are obtained for an entire year (2014), running the model with a branch and cut algorithm in Cplex in a $2.2 \mathrm{GHz}$ Dual Core AMD Turion CPU, with 4 GB of RAM memory, day by day, over the 365 days of the year in order to:

1. prove that the methodology with a look-ahead period to derive the end-of-day storages is feasible for realistic PSHPs even taking into account imperfect information of the electric power system data ${ }^{1}$.

2. quantify the extent to which the methodology with a look-ahead period can enlarge the income with respect to strategies without look-ahead period even taking into account imperfect information of the electric power system data.

3. quantify the extent to which the participation, with the methodology with a lookahead period, in the day-ahead energy market and in the secondary regulation service, can enlarge the income with respect to the participation only in the day-ahead energy market.

\footnotetext{
${ }^{1}$ Note that in the article entitled "Deriving Optimal End of Day Storage for Pumped-Storage Power Plants in the Joint Energy and Reserve Day-ahead Scheduling" from this Thesis, it was proven that the methodology with a look-ahead period to derive the end-of-day storages is feasible for realistic PSHPs assuming perfect information
} 
4. quantify the extent to which the incomes from PSHPs equipped with variable-speed pump-turbine units can be enlarged with respect to the ones from PSHPs equipped with fixed-speed units, with the methodology with a look-ahead period, participating in the day-ahead energy market and in the secondary regulation service, and with imperfect information.

\subsection{Results and discussion}

The incomes per MW of installed capacity in generation mode for the above-described PSHPs equipped with fixed-speed pump-turbine units are presented in Figure 3.1 with perfect information of the electric power system data, and in Figure 3.2 with imperfect information of the electric power system data. Note that the results here shown correspond to the risk-neutral version $(\mu=0)$ of the optimisation models described in Chapter 3.

The incomes shown in Figure 3.1 have been previously presented in the article entitled "Deriving Optimal End of Day Storage for Pumped-Storage Power Plants in the Joint Energy and Reserve Day-ahead Scheduling" from this Thesis, but they are here presented again to facilitate the reader the comparisons with respect to the incomes shown in Figure 3.2. Note that "Income with look ahead" corresponds to the ones obtained with the SRS D+1 and DM D+1 strategies and that the "Income w/o look ahead" corresponds to the ones obtained with the SRS V0 and DM V0 strategies from the above-mentioned article from this Thesis.
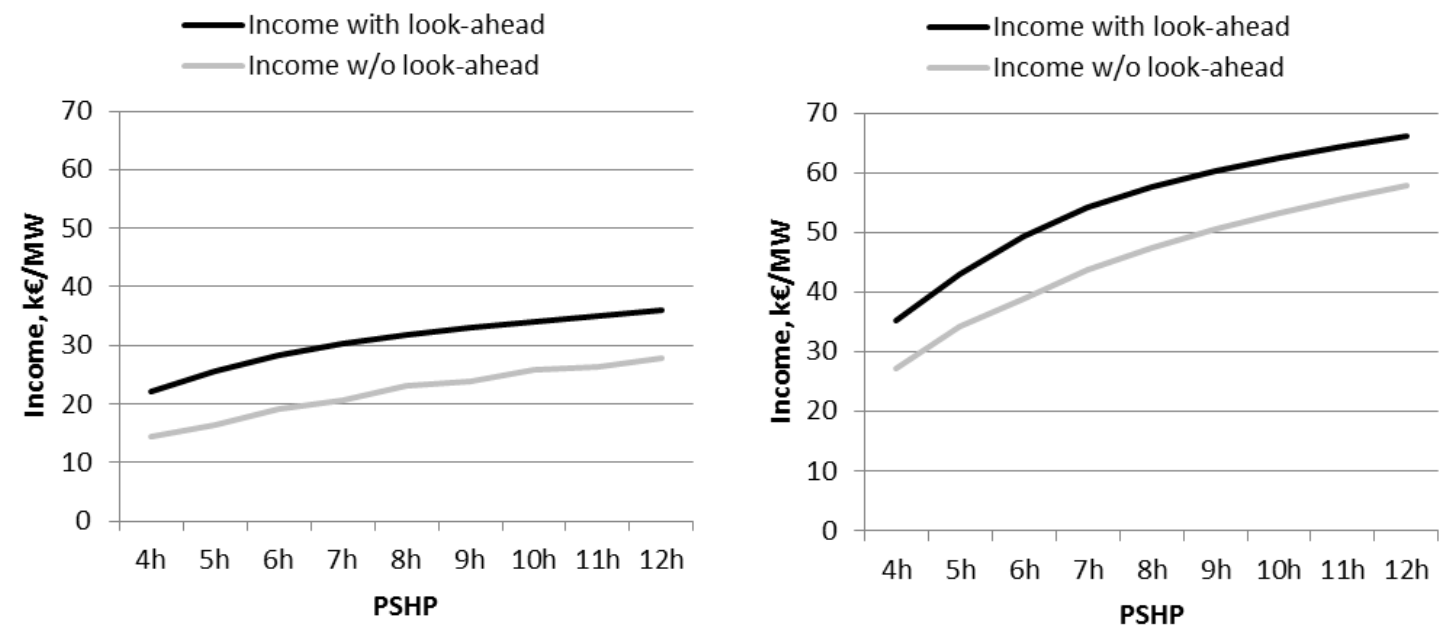

Figure 3.1: Annual income per MW of the installed capacity in generating mode of each PSHP equipped with fixed-speed pump-turbine units, participating only in the day-ahead energy market (left chart) and also in the secondary regulation service (right chart) with and without look-ahead period, and assuming perfect information

Whether imperfect information is considered in the electric power system data (see Figure 3.2 ), the income per MW of installed capacity decreases in comparison to the ones obtained 
assuming perfect information. It is important to note that the decrease is also called the VPI or the profit loss due to the errors in the forecasting models of the electric power system data. If the PSHPs only participate in the day-ahead energy market, the VPI is between 32.7-44.6\%. Note that the VPI for the $6 \mathrm{~h}$ PSHP is the same as the best Case obtained in the article entitled "Value of perfect information of spot prices in the joint energy and reserve hourly scheduling of pumped storage plants" from this Thesis (Case H, 36.4\%). The VPI monotonically increases as the number of hours increases (4-12h), or as the installed capacity of the PSHP decreases (1200-400 MW): the 4h/12h PSHP obtains the lowest/highest VPI in the day-ahead energy market. If the PSHPs also participate in the secondary regulation service, the VPI is between 27.6-52.8\%. Note that, in this situation, the VPI for the 6h PSHP (31.1\%) is not the same as the best Case obtained in the article entitled "Value of perfect information of spot prices in the joint energy and reserve hourly scheduling of pumped storage plants" from this Thesis (Case $\mathrm{H}, 26.9 \%$ ) because the imperfect information of the residual demand curves of the reserve market, the secondary regulation energy prices and the percentages of the real-time use of reserves are also considered in the former result. The VPI monotonically decreases as the number of hours increases (4-12h), or as the installed capacity of the PSHP decreases (1200$400 \mathrm{MW})$. It is also important to highlight that the VPI of all the electric power system data at the same time in the optimisation model (31.1\% for the $6 \mathrm{~h}$ PSHP) does not coincide and is lower than the sum of the VPI of each electric power system data calculated independently ( $26.9 \%$ for the day-ahead energy market prices, $6 \%$ for the residual demand curves of the reserve market, $1.8 \%$ for the secondary regulation energy prices, and $4.9 \%$ for the percentages of the real-time use of reserves, i.e., $39.6 \%$ ).

Furthermore, whether the look-ahead period is included in the methodology, the income increases in all PSHPs also considering imperfect information in the electric power system data, between $10.4-82.3 \%$ if the PSHPs only participate in the day-ahead energy market, and between $6.3-31 \%$ if the PSHPs also participate in the secondary regulation service. The income monotonically decreases as the number of hours increases (4-12h), or as the installed capacity of the PSHP decreases (1200-400 MW) if the PSHPs only participate in the dayahead energy market, and firstly decreases and secondly increases as the number of hours increases (4-12h), or as the installed capacity of the PSHP decreases (1200-400 MW) if the PSHPs also participate in the secondary regulation service. 

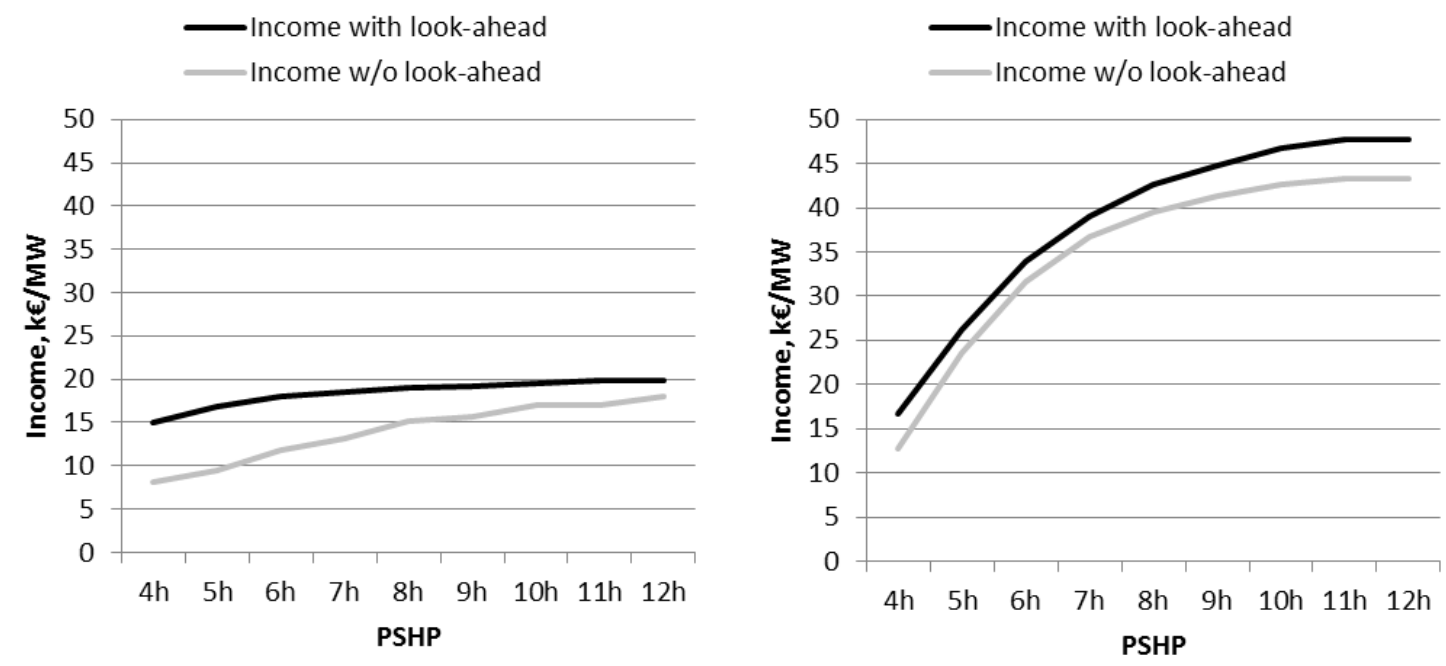

Figure 3.2: Annual income per MW of the installed capacity in generating mode of each PSHP equipped with fixed-speed pump-turbine units, participating only in the day-ahead energy market (left chart) and also in the secondary regulation service (right chart) with and without look-ahead period, and with imperfect information

The use of variable-speed pump-turbine units increases the income per MW of installed capacity in generation mode in all PSHPs participating in the day-ahead energy market and in the secondary regulation service, taking into account imperfect information of the electric power system data and using the look-ahead period in the methodology (see Figure 3.3). The incomes monotonically increases as the number of hours increases (4-12h), or as the installed capacity of the PSHP decreases (1200-400 MW). Besides, the incomes increases as the operating range in pumping mode becomes wider: between 30.7-61.8\% comparing the PSHPs equipped with fixed-speed and 15q-variable-speed pump-turbine units, and between 51.7-84.9\% comparing the PSHPs equipped with fixed-speed and 30q-variable-speed pumpturbine units.

Furthermore, similarly as it was carried out in the article entitled "Economic Viability of Pumped-Storage Power Plants Participating in the Secondary Regulation Service" from this Thesis, Figure 3.3 also compares the income per MW in 2014 of PSHPs equipped with fixedspeed and variable-speed pump-turbine units to the ones obtained by three real closed-loop and daily-cycle PSHPs that are currently operating in the Iberian electricity system. Note that the number of hours to empty the upper reservoir of each real PSHP is deployed in Figure 3.3. For the sake of clarity, one of the real PSHP empties the upper reservoir in 16 hours but it is depicted with 12 hours. Although the economic results of the real PSHPs are publicly available in the information system of the Spanish transmission system operator, the Thesis author prefers not to reveal their names. It is important to remark that the income of the real PSHPs comes from more markets: the day-ahead energy market, the intraday 
markets, the congestion management markets of the day-ahead energy market, the secondary and the tertiary regulation services, the real-time congestion management market and, finally, the balancing market. The incomes obtained by the PSHPs equipped with fixed-speed units with the models proposed in the Thesis are notably higher than the ones obtained by the real PSHPs (the real PSHPs are not equipped with variable-speed units), and are able to be significantly higher whether the PSHPs use variable-speed pump-turbine units. Note that in this result, imperfect information is considered as it is the situation of the operation of the real PSHPs.

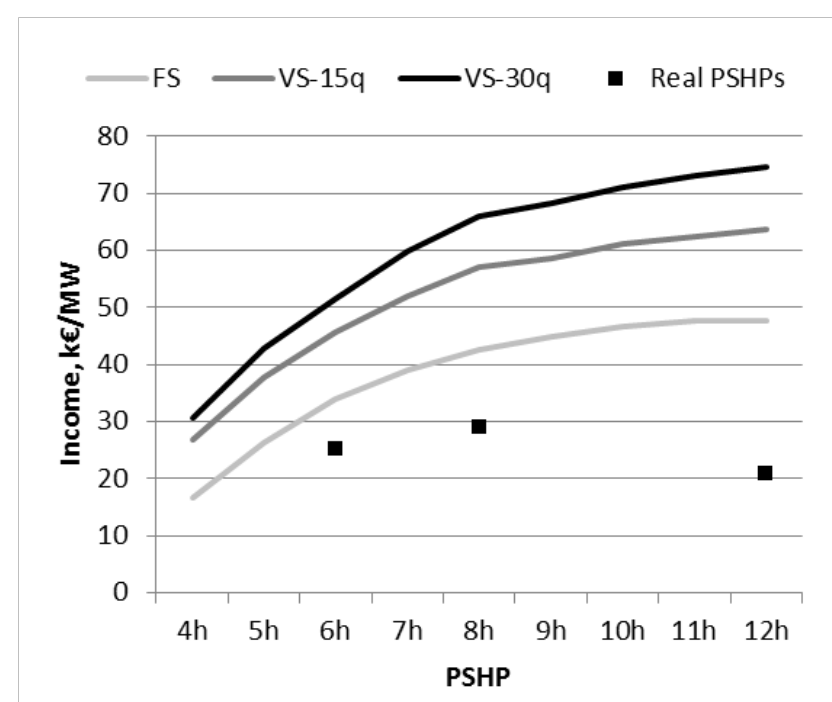

Figure 3.3: Annual income per MW of the installed capacity in generating mode of each PSHP equipped with fixed-speed (FS) or variable-speed pump-turbine units (15q and 30q), participating in the day-ahead energy market and in the secondary regulation service with look-ahead period and with imperfect information. The results are compared to the ones obtained from real PSHPs 


\section{Chapter 4}

\section{Conclusions}

This chapter presents the main conclusions and contributions of the Thesis in addition to the several gaps and challenges that are still pending to be covered and in which the Thesis author would like to work in the coming years.

\subsection{Conclusions}

Regarding the main conclusions of the Thesis, they can be divided into:

1. It has been proven in the Thesis that the value of perfect information of the dayahead energy prices in the operation of a closed-loop and daily-cycle pumped-storage hydropower plant, participating in the day-ahead energy market as a price-taker and in the secondary regulation reserve market as a price-maker, is significant. It is shown that the mentioned value is $28.9 \%$ of the maximum theoretical income as the mean value between all the Cases analysed and in the context of the case study presented in the article entitled "Value of Perfect Information of Spot Prices in the Joint Energy and Reserve Hourly Scheduling of Pumped Storage Plants". However, it is interesting to remark that the participation in the secondary regulation service reduces notably the value of perfect information in $\%$ of the maximum theoretical income, comparing to participate only in the day-ahead energy market: from $39.9 \%$ to $28.9 \%$ as the mean values between all the Cases analysed.

2. The economic impact of forecasting errors in the residual demand curves of the secondary regulation reserve market has been also analysed in the context of the hourly energy and reserve scheduling of a closed-loop and daily-cycle pumped-storage hydropower plant. The pumped-storage hydropower plant has been allowed to participate in the day-ahead energy market as a price-taker and in the secondary regulation reserve market as a price-maker. The economic impact was found to be $6-8 \%$ of the maximum theoretical 
income, which is significantly lower than the impact of the errors in forecasting the day-ahead energy prices. Therefore, it seems reasonable to conclude that among all the uncertain variables involved in the day-ahead energy and reserve scheduling, the residual demand curves of the secondary regulation reserve market can be modelled with an expected value in order to reduce the computational burden in a stochastic optimization scheduling model.

3. It has been proven in the Thesis that the value of perfect information of the secondary regulation energy prices in the operation of a closed-loop and daily-cycle pumped-storage hydropower plant, participating in the day-ahead energy market as a price-taker and in the secondary regulation reserve market as a price-maker, is significantly lower than the value of perfect information of the day-ahead energy prices. It is shown that the former is between $1.8-5 \%$ of the maximum theoretical income in all the cases analysed. Therefore, it seems reasonable to conclude that among all the uncertain variables involved in the day-ahead energy and reserve scheduling, the secondary regulation energy prices can be modelled with an expected value in order to reduce the computational burden in a stochastic optimization scheduling model.

4. It has been proven in the Thesis that the value of perfect information of the percentages of the real-time use of the committed upward and downward secondary regulation reserves, in the operation of a closed-loop and daily-cycle pumped-storage hydropower plant, participating in the day-ahead energy market as a price-taker and in the secondary regulation reserve market as a price-maker, is significantly lower than the value of perfect information of the day-ahead energy prices. It is shown that the former is $5 \%$ of the maximum theoretical income in the case of considering $0 \%$ and $100 \%$ for the real-time use of the upward and downward reserves, respectively, in all hours. Therefore, it seems reasonable to conclude that among all the uncertain variables involved in the day-ahead energy and reserve scheduling, the percentages of the real-time use of the committed upward and downward secondary regulation reserves can be modelled with an expected value in order to reduce the computational burden in a stochastic optimization scheduling model.

5. In the presented Thesis, the economic viability of twelve closed-loop and daily-cycle pumped-storage hydropower plants equipped with binary or ternary units, with and without the variable speed technology and with and without considering the operation in hydraulic short-circuit mode has been evaluated. The pumped-storage hydropower plants were assumed to participate in the day-ahead energy market as a price-taker and in the day-ahead secondary regulation reserve market as a price-maker. In addition, the net income from the real-time use of the committed reserves was also taken into account 
within the model formulation. The economic viability has been studied by means of the minimum theoretical pay-back periods, which have been estimated considering different investment costs values per MW of the installed capacity according to the technical literature. Results show that the minimum theoretical pay-back periods of the pumpedstorage hydropower plants are in most cases lower than their lifetime, if the investment cost of the base case (the pumped-storage hydropower plant with fixed-speed binary units) is lower than $2.5 \mathrm{M} € / \mathrm{MW}$. Therefore, the economic viability is not discarded. The pumped-storage hydropower plants with the variable speed technology and full converter with and without the possibility to operate in hydraulic short-circuit mode, and the pumped-storage hydropower plant with ternary units and being operated in hydraulic short-circuit mode obtain the lowest minimum theoretical pay-back periods. Furthermore, the inclusion of the variable speed technology or the operation in hydraulic short-circuit mode decrease significantly the minimum theoretical pay-back periods of pumped-storage hydropower plants. In addition to this, it has been also proven that the maximum theoretical income, obtained with an optimization model developed in the Thesis, of the proposed pumped-storage hydropower plants are notably higher in comparison to the real income obtained by pumped-storage hydropower plants that are currently operating in the Iberian system.

6. In the presented Thesis, a new methodology to maximise the income and determine the optimal end-of-day storage of closed-loop and daily-cycle pumped-storage hydropower plants participating in the day-ahead energy and the secondary regulation reserve markets is presented in this paper. The methodology uses a look-ahead period with future information of the electricity power system data. The plants participate in the dayahead energy market as a price-taker and in the secondary regulation reserve market as a price-maker. The real-time use of the committed reserves is also considered in the model formulation. The results obtained indicate that using a look-ahead period of one day is sufficient to highly increase the income without a significant increase in the CPU time consumption. Furthermore, the proposed methodology enlarges the maximum theoretical income of the plants between $455-9645 € / \mathrm{MW}$ of the installed capacity if they only participate in the day-ahead energy market and between 519-10388 €/MW of installed capacity if they also participate in the secondary regulation reserve service, in comparison to methodologies without a look-ahead period. The relative increase in the maximum theoretical income strongly depends on the size of the plant. In addition, it has been proven that the end-of-day storage have a less extreme behaviour in the new reserve-driven strategies of pumped-storage hydropower plants and that the proposed methodology with a look-ahead period is even more recommended if the secondary reg- 
ulation service is considered.

7. Whether imperfect information is considered in all the electric power system data, the income per MW of installed capacity decreases in comparison to the ones obtained assuming perfect information. If the pumped-storage hydropower plants only participate in the day-ahead energy market, the mentioned decrease is between $32.7-44.6 \%$ of the maximum theoretical income, and monotonically increases as the installed capacity of the pumped-storage hydropower plant decreases. If the pumped-storage hydropower plants also participate in the secondary regulation service, the mentioned decrease is between 27.6-52.8\%, and monotonically decreases as the installed capacity of the pumped-storage hydropower plant decreases. Furthermore, the value of perfect information of all the electric power system data at the same time in the optimisation model (31.1\% of the maximum theoretical income for the reference pumped-storage hydropower plant) does not coincide and is lower than the sum of the values of perfect information of each electric power system data calculated independently $(26.9 \%$ for the day-ahead energy market prices, $6 \%$ for the residual demand curves of the reserve market, $1.8 \%$ for the secondary regulation energy prices, and $4.9 \%$ for the percentages of the real-time use of reserves, i.e., $39.6 \%$ ).

8. Whether imperfect information is considered in all the electric power system data, the use of variable-speed pump-turbine units increases the income per MW of installed capacity in generation mode in comparison to pumped-storage hydropower plants equipped with fixed-speed pump-turbine units participating in the day-ahead energy market and in the secondary regulation service. The incomes per MW monotonically increase as the installed capacity of the pumped-storage hydropower plant decreases. Besides, the incomes per MW increase as the operating range in pumping mode of the variable-speed pump-turbine units becomes wider: between 30.7-61.8\% comparing pumped-storage hydropower plants equipped with fixed-speed units and with variable-speed units with an operating range in pumping mode between $85-100 \%$ of the nominal pumped water flow, and between 51.7-84.9\% comparing pumped-storage hydropower plants equipped with fixed-speed units and with variable-speed units with an operating range in pumping mode between $70-100 \%$ of the nominal pumped water flow.

9. The incomes per MW in 2014 of pumped-storage hydropower plants equipped with fixedspeed and variable-speed pump-turbine units obtained using the models developed in the Thesis and considering imperfect information in all the electric power system data of the problem are compared to the real ones (publicly available in the Spanish system) obtained by three real closed-loop and daily-cycle pumped-storage hydropower plants that are currently operating in the Iberian electricity system. It is important to remark 
that the income of the real pumped-storage hydropower plants comes from more markets than the ones proposed to participate the pumped-storage hydropower plants in the Thesis: the day-ahead energy market, the intraday market, the congestion management markets of the day-ahead energy market, the secondary and the tertiary regulation services, the real-time congestion management market and the balancing market. The incomes obtained by the pumped-storage hydropower plants equipped with fixed-speed units using the models developed in the Thesis are notably higher than the ones obtained by the real pumped-storage hydropower plants, and are able to be significantly higher whether the pumped-storage hydropower plants use variable-speed pump-turbine units. 


\section{2 $\quad$ Future works}

Regarding the main future works that the Thesis author would like to work in the coming years, they are divided into:

1. The optimisation models presented in the Thesis propose the pumped-storage hydropower plants to participate in the day-ahead energy market and in the secondary regulation reserve market, also taking into account the secondary regulation energy due to the real-time use of the reserves. In this context, the Thesis author proposes as a future work to include in the model formulation the participation in the intraday market. Note that the description of the main features of the Spanish intraday market can be seen in subsection 1.2.2. The main goal of the participation in the intraday market is to correct deviations due to the errors in forecasting the real-time use of reserves. However, the inclusion of the intraday market is challenging as new uncertainty sources are introduced, making the scheduling even more complex. At least six new uncertainty sources are introduced, one for each cleared price of each session of the intraday market of the Spanish power system.

2. The optimisation models presented in the Thesis propose the pumped-storage hydropower plants to participate in the day-ahead energy market and in the secondary regulation reserve market, also taking into account the secondary regulation energy due to the real-time use of the reserves. In this context, the Thesis author proposes as a future work to include in the model formulation the participation in the tertiary regulation service. Note that the description of the main features of the Spanish tertiary regulation service can be seen in subsection 1.2.2. One of the main characteristics of the pumped storage technology is that it is able to ramp-up and down pretty fast. Therefore, it is a technology well-prepared to participate in the secondary regulation service, with a time response of 2 minutes, and even better for the participation in the tertiary regulation service. Including the tertiary regulation service allows the pumped-storage hydropower plants to have more market opportunities and, at the end, to enlarge the income and make the investment more profitable. Nevertheless, the inclusion of the tertiary regulation service is challenging as new uncertainty sources are introduced, making the scheduling even more complex. At least four new uncertainty sources are introduced: i) the upward tertiary regulation energy prices, ii) the downward tertiary regulation energy prices, iii) the upward tertiary regulation requirement and iv) the downward tertiary regulation requirement. Note that the tertiary regulation service only remunerate for the energy and not for the reserves (capacity) as it is carried out in the secondary regulation service. 
3. In this Thesis, the value of perfect information of the day-ahead energy prices, the residual demand curves of the secondary regulation reserve market, the secondary regulation energy prices and the percentages of the real-time use of the reserves has been analysed for pumped-storage hydropower plant equipped with fixed-speed pump-turbine units. It is proposed as a future work to expand the analysis for more flexible pumped-storage hydropower plants:

(a) variable speed pumped-storage hydropower plants.

(b) pumped-storage hydropower plants operated in hydraulic short-circuit mode.

4. In the presented Thesis, the economic viability of twelve closed-loop and daily-cycle pumped-storage hydropower plants equipped with binary or ternary units, with and without the variable speed technology and with and without considering the operation in hydraulic short-circuit mode has been evaluated assuming perfect knowledge in all the uncertain data from the Spanish power system. Further work is necessary to estimate the economic viability of the pumped-storage hydropower plants taking into account the uncertainty in order to provide a more complete and realistic insight on the economic viability of pumped-storage hydropower plants.

5. It is also proposed as a future work to analyse the economic viability of the abovementioned twelve closed-loop and daily-cycle pumped-storage hydropower plants considering the participation not only in the day-ahead energy and secondary regulation reserve markets but also in the intraday markets or in other ancillary services such as the tertiary regulation service, would be also necessary in order to enlarge the income and, therefore, to reduce the pay-back periods.

6. Regarding the hierarchical coordination between the long-term and the short-term to derive end-of-day and end-of-week water storages, the Thesis author proposes as a future work:

(a) to analyse the extent to which the proposed methodology with a look-ahead period is able to enlarge the income of pumped-storage hydropower plants without assuming perfect knowledge of the electricity power system data.

(b) to analyse the impact of the proposed methodology with a look-ahead period in the operation of pumped-storage hydropower plants operating with variable speed or in hydraulic short-circuit mode.

(c) to analysed the impact in the end-of-day storage of the participation of pumpedstorage hydropower plants in other markets (such as the intraday market) or in other ancillary services (such as the tertiary regulation service). 
7. The forecasting models used in the Thesis to predict the electric power system data of the problem are proposed to be further improved with the aim of reducing the value of perfect information of the random variables. Among all of them, it is proven in the Thesis that the day-ahead energy market prices have the highest impact in the operation and economic results of closed-loop and daily-cycle pumped-storage hydropower plants. 


\section{Nomenclature}

\section{Superscripts}

$d, d^{\prime} \quad$ Indicates that the magnitude is related to generation/discharge. The superscript $d$ refers to pump-turbine units with variable speed (using a converter). When the superscript includes the prime symbol, i.e. $d^{\prime}$, it refers to pump-turbine units with fixed speed (without using a converter)

$p, p^{\prime} \quad$ Indicates that the magnitude is related to consumption/pumping. The superscript $p$ refers to pump-turbine units with variable speed (using a converter). When the superscript includes the prime symbol, i.e. $p^{\prime}$, it refers to pump-turbine units with fixed speed (without using a converter)

$s \quad$ Indicates that the magnitude is related to the secondary regulation service (reserve or energy)

\section{Sets}

c Pump-turbine unit, running from 1 to $\mathrm{C}$

$k \quad$ Discrete generation curves

$n \quad$ Price scenario of the day-ahead energy market, the secondary regulation reserve market, and the secondary regulation energy

$t \quad$ Hourly period, running from 1 to $\mathrm{T}$

\section{Parameters}

$\beta \quad$ Confidence interval

$c S U_{c}^{d} \quad$ Start-up cost in generating mode, $€$

$c S U_{c}^{p} \quad$ Start-up cost in pumping mode, $€$

$\delta_{c, k}^{d} \quad$ Energy coefficient in generating mode, $\mathrm{MW} / \mathrm{Mm}^{3} / \mathrm{h}$ 
$\delta_{c, k}^{p} \quad$ Energy coefficient in pumping mode, $\mathrm{MW} / \mathrm{Mm}^{3} / \mathrm{h}$

$\bar{g}_{c, k}^{d}, \underline{g}_{c, k}^{d}$ Maximum and minimum technical power generation, MW

$\bar{g}_{c, k}^{p^{\prime}} \quad$ Maximum technical power consumption of fixed speed pump-turbine units, MW. Note that the minimum technical power consumption equals the maximum as they operate with fixed speed

$\bar{g}_{c, k}^{p}, \underline{g}_{c, k}^{p}$ Maximum and minimum technical power consumption of variable speed pumpturbine units, MW

$l_{t} \quad$ Time length of period $t, 1 \mathrm{~h}$

$\lambda_{D, n, t} \quad$ Day-ahead energy market price, $€ / \mathrm{MWh}$

$\lambda_{S, n, t}^{o} \quad$ the intercept of the linear approximation of a residual demand curve of the secondary regulation reserve market, i.e. the secondary regulation reserve price when the residual reserve quantity of the system is zero, $€ / \mathrm{MW}$

$\lambda_{S, n, t}^{m} \quad$ the slope of the linear approximation of a residual demand curve of the secondary regulation reserve market, $€ / \mathrm{MW} / \mathrm{MW}$

$\lambda_{\text {up }, n, t} \quad$ Upward secondary regulation energy price, $€ / \mathrm{MWh}$

$\lambda_{d w, n, t} \quad$ Downward secondary regulation energy price, $€ / \mathrm{MWh}$

$\mu \quad$ Risk-averse weight factor, $\mu \in[0,1]$

$\bar{\eta}_{c, k}^{d}, \underline{\eta}_{c, k}^{d}$ Efficiency at maximum and minimum water discharge, $\%$

$\bar{\eta}_{c, k}^{p}, \underline{\eta}_{c, k}^{p}$ Efficiency at maximum and minimum pumped water, $\%$

$\pi_{n} \quad$ Probability of the price scenario

$\bar{q}_{c, k}^{d^{\prime}}, \underline{q}_{c, k}^{d^{\prime}}$ Maximum and minimum technical water discharge of fixed speed pump-turbine units, $\mathrm{Mm}^{3} / \mathrm{h}$

$\bar{q}_{c, k}^{d}, \underline{q}_{c, k}^{d}$ Maximum and minimum technical water discharge of variable speed pump-turbine units, $\mathrm{Mm}^{3} / \mathrm{h}$

$\bar{q}_{c, k}^{p^{\prime}} \quad$ Maximum technical pumped water of fixed speed pump-turbine units, $\mathrm{Mm}^{3} / \mathrm{h}$

$\bar{q}_{c, k}^{p}, \underline{q}_{c, k}^{p}$ Maximum and minimum technical pumped water of variable speed pump-turbine units, $\mathrm{Mm}^{3} / \mathrm{h}$

$\rho_{t}^{u p}, \rho_{t}^{d w}$ Percentage of the real-time use of the upward and downward secondary regulation reserves with respect to the secondary reserve capacity cleared in the market 
$R_{t}^{S M} \quad$ Ratio between the upward secondary regulation reserve and the total regulation reserve, set by the TSO in advance, that needs to be satisfied by the offered reserves by each agent

$\bar{v}, \underline{v} \quad$ Maximum and minimum technical water storage limits of the upper reservoir due to design characteristics, $\mathrm{Mm}^{3}$

\section{Positive Variables}

$\lambda_{S, n, t} \quad$ Secondary regulation reserve market price, $€ / \mathrm{MW}$

$B_{n} \quad$ Net profit in scenario $n, €$

$B_{n}^{-} \quad$ auxiliary variable which is equal to zero when the net profit is higher than the $V a R$, and it is equal to the difference between them in the opposite case, $€$

VaR Value at risk, $€$

CVaR Conditional value at risk, $€$

$g_{c, t}^{d} \quad$ Power generation, MW

$g_{c, t}^{p} \quad$ Power consumption, MW

$q_{c, t}^{d}, q_{c, t}^{p} \quad$ Total water discharge and total pumped water, which include water for the real-time use of the upward and downward secondary regulation reserves, $\mathrm{Mm}^{3} / \mathrm{h}$

$q s_{c, t}^{d} \quad$ Water discharge above the minimum technical limit, $\mathrm{Mm}^{3} / \mathrm{h}$

$q s_{c, t}^{p} \quad$ Pumped water above the minimum technical limit, $\mathrm{Mm}^{3} / \mathrm{h}$

$g_{c, t}^{d, s, u p} \quad$ Upward secondary regulation reserve in generating mode, MW

$g_{c, t}^{p, s, u p} \quad$ Upward secondary regulation reserve in pumping mode, MW

$g_{c, t}^{d, s, d w} \quad$ Downward secondary regulation reserve in generating mode, MW

$g_{c, t}^{p, s, d w} \quad$ Downward secondary regulation reserve in pumping mode, MW

aux $\_g_{c, t}^{d, s}$ Auxiliary variable associated with $g_{c, t}^{d, s, d w}, \mathrm{MW}$

aux_ $g_{c, t}^{p, s}$ Auxiliary variable associated with $g_{c, t}^{p, s, u p}, \mathrm{MW}$

$e_{t}^{s, u p} \quad$ Upward secondary regulation reserve requested in real-time by the TSO, MWh

$e_{t}^{s, d w} \quad$ Downward secondary regulation reserve requested in real-time by the TSO, MWh

$v_{t} \quad$ Water volume of the upper reservoir, $\mathrm{Mm}^{3}$ 


\section{Binary Variables}

$d_{t} \quad$ Variable used for the discretization of the hydropower generation/consumption curves to take into account the net head dependency

$u_{c, t}^{d} \quad$ On/Off state in generating mode

$u_{c, t}^{p} \quad$ On/Off state in pumping mode

$y_{c, t}^{d} \quad 1$ if the pump-turbine unit is started-up in generating mode, 0 otherwise

$y_{c, t}^{p} \quad 1$ if the pump-turbine unit is started-up in pumping mode, 0 otherwise

$\phi_{t} \quad 1$ if there is more upward secondary regulation reserve requested in real-time than downward regulation reserve, 0 otherwise 


\section{References}

[Kop, ] Kopswerk II Official Web Page.

[Aggarwal et al., 2009] Aggarwal, S., Saini, L., \& Kumar, A. (2009). Electricity price forecasting in deregulated markets: A review and evaluation. International Journal of Electrical Power \& Energy Systems, 31(1), 13-22.

[Al-Sunaidy \& Green, 2006] Al-Sunaidy, A. \& Green, R. (2006). Electricity deregulation in OECD (Organization for Economic Cooperation and Development) countries. Energy, 31(67), 769-787.

[Alizadeh-Mousavi \& Nick, 2016] Alizadeh-Mousavi, O. \& Nick, M. (2016). Stochastic Security Constrained Unit Commitment with Variable-Speed Pumped-Storage Hydropower Plants. In Power Systems Computation Conference (PSCC).

[Alstom, ] Alstom. Alstom commissions world's most powerful hydroelectric units at Xiangjiaba hydro power plant, in China.

[Ambrosio et al., 2017] Ambrosio, G., Couto-Santos, F., \& Cunha, D. (2017). COP21: outcomes and framework analysis. Espacios, 38(7), 19-31.

[Amjady \& Keynia, 2011] Amjady, N. \& Keynia, F. (2011). A new prediction strategy for price spike forecasting of day-ahead electricity markets. Applied Soft Computing Journal, 11(6), 4246-4256.

[Ardizzon et al., 2014] Ardizzon, G., Cavazzini, G., \& Pavesi, G. (2014). A new generation of small hydro and pumped-hydro power plants: Advances and future challenges. Renewable and Sustainable Energy Reviews, 31, 746-761.

[Are Suul, 2009] Are Suul, J. (2009). Variable Speed Pumped Storage Hydropower Plants for Integration of Wind Power in Isolated Power Systems. In Renewable Energy.

[Barbour et al., 2016] Barbour, E., Wilson, I., Radcliffe, J., Ding, Y., \& Li, Y. (2016). A review of pumped hydro energy storage development in significant international electricity markets. Renewable and Sustainable Energy Reviews, 61, 421-432. 
[Baslis \& Bakirtzis, 2011] Baslis, C. G. \& Bakirtzis, A. G. (2011). Mid-Term Stochastic Scheduling of a Price-Maker Hydro Producer With Pumped Storage. IEEE Transactions on Power Systems, 26(4), 1856-1865.

[Bocquel \& Janning, 2005] Bocquel, A. \& Janning, J. (2005). Analysis of a 300 MW Variable Speed Drive for Pump-Storage Plant Applications. In European Conference on Power Electronics and Applications.

[Bonneville Power Administration, ] Bonneville Power Administration. BPA partners on overhaul of world's largest turbines.

[Botterud et al., 2014] Botterud, A., Levin, T., \& Koratirov, V. (2014). Pumped Storage Hydropower: Benefits for Grid Reliability and Integration of Variable Renewable Energy. Technical report.

[Bradbury et al., 2014] Bradbury, K., Pratson, L., \& Patiño-Echeverri, D. (2014). Economic viability of energy storage systems based on price arbitrage potential in real-time U.S. electricity markets. Applied Energy, 114, 512-519.

[Brijs et al., 2016] Brijs, T., Geth, F., Siddiqui, S., Hobbs, B. F., \& Belmans, R. (2016). Price-based unit commitment electricity storage arbitrage with piecewise linear price-effects. Journal of Energy Storage, 7, 52-62.

[Calmarza \& de la Fuente, 2002] Calmarza, A. M. \& de la Fuente, J. (2002). New Forecasting Method for the Residual Demand Curves using Time Series (ARIMA) Models. In 7th International Conference on Probabilistic Methods Applied to Power Systems.

[Campos et al., 2016] Campos, A., Muñoz, A., Sánchez-Úbeda, E., \& Portela, J. (2016). Strategic Bidding in Secondary Reserve Markets. IEEE Transactions on Power Systems, 31(4), $2847-2856$.

[Caralis et al., 2012] Caralis, G., Papantonis, D., \& Zervos, A. (2012). The role of pumped storage systems towards the large scale wind integration in the Greek power supply system. Renewable and Sustainable Energy Reviews, 16(5), 2558-2565.

[Chalisgaonkar \& Mohan, 2015] Chalisgaonkar, R. \& Mohan, M. (2015). Prospects of Developing Pumped Storage Projects Utilising the Reservoir of Existing Hyropower Project in the State of Uttarakhand. In Hydropower for Sustainable Development (pp. 520-527).

[Chaves-Ávila \& Fernandes, 2015] Chaves-Ávila, J. P. \& Fernandes, C. (2015). The Spanish intraday market design: A successful solution to balance renewable generation? Renewable Energy, 74, 422-432. 
[Chazarra et al., 2016a] Chazarra, M., García-González, J., Pérez-Díaz, J. I., \& Arteseros, M. (2016a). Stochastic optimization model for the weekly scheduling of a hydropower system in day-ahead and secondary regulation reserve markets. Electric Power Systems Research, 130, 67-77.

[Chazarra et al., 2014] Chazarra, M., Pérez-Díaz, J., \& García-González, J. (2014). Optimal Operation of Variable Speed Pumped Storage Hydropower Plants Participating in Secondary Regulation Reserve Markets. In European Energy Market (EEM).

[Chazarra et al., 2016b] Chazarra, M., Pérez-Díaz, J. I., \& García-González, J. (2016b). Value of Perfect Information of Spot Prices in the Joint Energy and Reserve Hourly Scheduling of Pumped Storage Plants. In European Energy Market (EEM).

[Chazarra et al., 2017a] Chazarra, M., Pérez-Díaz, J. I., \& García-González, J. (2017a). Deriving Optimal End of Day Storage for Pumped-Storage Power Plants in the Joint Energy and Reserve Day-ahead Scheduling. Energies, 813(10).

[Chazarra et al., 2017b] Chazarra, M., Pérez-Díaz, J. I., \& García-González, J. (2017b). Economic Viability of Pumped-Storage Power Plants Equipped with Ternary Units and Considering Hydraulic Short-Circuit Operation. Journal of Physics: Conference Series, 813(1), 012013.

[Chazarra et al., 2017c] Chazarra, M., Pérez-Díaz, J. I., \& García-González, J. (2017c). Economic Viability of Pumped-Storage Power Plants Participating in the Secondary Regulation Service. Applied Energy, Submitted.

[Chazarra et al., 2017d] Chazarra, M., Pérez-Díaz, J. I., \& García-González, J. (2017d). Optimal Energy and Reserve Scheduling of Pumped-Storage Power Plants Considering Hydraulic Short-Circuit Operation. IEEE Transactions on Power Systems, 32(1), 344-353.

[Chazarra et al., 2017e] Chazarra, M., Pérez-Díaz, J. I., \& García-González, J. (2017e). Optimal Joint Energy and Secondary Regulation Reserve Hourly Scheduling of Variable Speed Pumped Storage Hydropower Plants. IEEE Transactions on Power Systems, in press.

[Chazarra et al., 2017f] Chazarra, M., Perez-Diaz, J. I., \& Garcia-Gonzalez, J. (2017f). Value of perfect information of spot prices in the joint energy and reserve hourly scheduling of pumped storage plants. Electric Power Systems Research, 148, 303-310.

[Chazarra et al., 2016c] Chazarra, M., Pérez-Díaz, J. I., García-González, J., \& Helseth, A. (2016c). Modeling the Real-Time use of Reserves in the Joint Energy and Reserve Hourly Scheduling of a Pumped Storage Plant. Energy Procedia, 87, 53-60. 
[Chazarra et al., 2017g] Chazarra, M., Pérez-Díaz, J. I., García-González, J., \& Helseth, A. (2017g). Economic Impact of Forecasting Errors in Residual Reserve Curves in the Dayahead Scheduling of Pumped Storage Plants. In PowerTech.

[Conejo et al., 2002] Conejo, A., Arroyo, J., Contreras, J., \& Apolinar, F. (2002). Selfscheduling of a hydro producer in a pool-based electricity market. IEEE Transactions on Power Systems, 17(4), 1265-1272.

[Conejo et al., 2005] Conejo, A. J., Plazas, M. a., Espínola, R., Member, S., \& Molina, A. B. (2005). Day-Ahead Electricity Price Forecasting Using the Wavelet Transform and ARIMA Models. IEEE Transactions On Power Systems, 20(2), 1035-1042.

[Connolly et al., 2011] Connolly, D., Lund, H., Finn, P., Mathiesen, B., \& Leahy, M. (2011). Practical operation strategies for pumped hydroelectric energy storage (PHES) utilising electricity price arbitrage. Energy Policy, 39(7), 4189-4196.

[Crampes \& Moreaux, 2010] Crampes, C. \& Moreaux, M. (2010). Pumped storage and cost saving. Energy Economics, 32(2), 325-333.

[de Boer et al., 2014] de Boer, H. S., Grond, L., Moll, H., \& Benders, R. (2014). The application of power-to-gas, pumped hydro storage and compressed air energy storage in an electricity system at different wind power penetration levels. Energy, 72, 360-370.

[De Ladurantaye et al., 2007] De Ladurantaye, D., Gendreau, M., \& Potvin, J. (2007). Strategic Bidding for Price-Taker Hydroelectricity Producers. IEEE Transactions on Power Systems, 22(4), 2187-2203.

[Deane et al., 2013] Deane, J., Mckeogh, E., \& Gallachóir, B. (2013). Derivation of Intertemporal Targets for Large Pumped Hydro Energy Storage With Stochastic Optimization. IEEE Transactions on Power Systems, 28(3), 2147-2155.

[Deane et al., 2010] Deane, J., Ó-Gallachóir, B., \& McKeogh, E. (2010). Techno-economic review of existing and new pumped hydro energy storage plant. Renewable and Sustainable Energy Reviews, 14(4), 1293-1302.

[Deb, 2000] Deb, R. (2000). Operating Hydroelectric Plants and Pumped Storage Units in a Competitive Environment. The Electricity Journal, 13(3), 24-32.

[Delgadillo \& Reneses, 2013] Delgadillo, A. \& Reneses, J. (2013). Analysis of the Spanish congestion management mechanism. In Power and Energy Society General Meeting. 
[Denholm \& Sioshansi, 2009] Denholm, P. \& Sioshansi, R. (2009). The value of compressed air energy storage with wind in transmission-constrained electric power systems. Energy Policy, 37(8), 3149-3158.

[Díaz-González et al., 2012] Díaz-González, F., Sumper, A., Gomis-Bellmunt, O., \& Villafáfila-Robles, R. (2012). A review of energy storage technologies for wind power applications. Renewable and Sustainable Energy Reviews, 16(4), 2154-2171.

[Ekman \& Jensen, 2010] Ekman, C. K. \& Jensen, S. H. (2010). Prospects for large scale electricity storage in Denmark. Energy Conversion and Management, 51(6), 1140-1147.

[Ela et al., 2011] Ela, E., Milligan, M., \& Kirby, B. (2011). Operating Reserves and Variable Generation. Technical report.

[European Comission, 2009] European Comission (2009). Directive 2009/28/EC of the European Parliament and of the Council of 23 April 2009 on the promotion of the use of energy from renewable sources and amending and subsequently repealing Directives 2001/77/EC and 2003/30/EC. Official Journal of the European Union, 140, 16-62.

[European Council, 2014] European Council (2014). Conclusions, EUCO 169/14. Technical report.

[European Wind Energy Association, 2015] European Wind Energy Association (2015). Wind energy scenarios for 2030. Technical report.

[Fernandes et al., 2016] Fernandes, C., Frías, P., \& Reneses, J. (2016). Participation of intermittent renewable generators in balancing mechanisms: A closer look into the Spanish market design. Renewable Energy, 89, 305-316.

[Filipe et al., 2016] Filipe, J. M., Moreira, C. L., \& Silva, B. A. (2016). Optimization of the Variable Speed Pump Storage Participation in Frequency Restoration Reserve Market. In European Energy Market (EEM).

[Foley et al., 2015] Foley, A. M., Leahy, P. G., Li, K., McKeogh, E. J., \& Morrison, A. P. (2015). A long-term analysis of pumped hydro storage to firm wind power. Applied Energy, $137,638-648$.

[Furuya et al., 1993] Furuya, S., Taguchi, T., Kusunoki, K., Yanagisawa, T., Kageyama, T., \& Kanai, T. (1993). Successful achievement in a variable speed pumped storage power system at Yagisawa power plant. In Power Conversion Conference (pp. 603-608).

[Galasso, 1991] Galasso, G. (1991). Adjustable Speed Operation of Pumped Hydroplants. In International Conference on AC and DC Power Transmission (pp. 424-427). 
[García et al., 2005] García, R. C., Contreras, J., Akkeren, M. V., \& García, J. B. C. (2005). A GARCH Forecasting Model to Predict Day-Ahead Electricity Prices. IEEE Transactions on Power Systems, 20(2), 867-874.

[García-González et al., 2007] García-González, J., Parrilla, E., \& Mateo, A. (2007). Riskaverse profit-based optimal scheduling of a hydro-chain in the day-ahead electricity market. European Journal of Operational Research, 181(3), 1354-1369.

[González et al., 2014] González, P., Villar, J., Díaz, C., \& Campos, F. A. (2014). Joint energy and reserve markets: Current implementations and modeling trends. Electric Power Systems Research, 109, 101-111.

[Graves et al., 1999] Graves, F., Jenkin, T., \& Murphy, D. (1999). Opportunities for Electricity Storage in Deregulating Markets. The Electricity Journal, 12(8), 46-56.

[Greaves et al., 2009] Greaves, B., Collins, J., Parkes, J., \& Tindal, A. (2009). Temporal forecast uncertainty for ramp events. Wind Engineering, 33(4), 309-320.

[Grotenburg et al., 2001] Grotenburg, K., Koch, F., Erlich, I., \& Bachmann, U. (2001). Modeling and dynamic simulation of variable speed pump storage units incorporated into the German electric power system. In 9th European conference on power electronics.

[Henry et al., 2012] Henry, J., Houdeline, J., Ruiz, S., \& Kunz, T. (2012). How reversible pump-turbines can support grid variability: The variable speed approach. In HYDRO.

[Holttinen et al., 2011] Holttinen, H., Meibom, P., Orths, A., Lange, B., Malley, O., Tande, J., Estanqueiro, A., Gomez, E., Söder, L., Strbac, G., Smith, J., \& Hulle, F. (2011). Impacts of large amounts of wind power on design and operation of power systems. Wind Energy, 14(2), 179-192.

[Ibrahim et al., 2008] Ibrahim, H., Ilinca, A., \& Perron, J. (2008). Energy storage systemsCharacteristics and comparisons. Renewable and Sustainable Energy Reviews, 12(5), 12211250.

[IHA, 2016] IHA (2016). Key Trends in Hydropower. Technical report.

[IHA (International Hydropower Association), 2017] IHA (International Hydropower Association) (2017). Key Trends in Hydropower. Technical report.

[Illwerke, ] Illwerke. Hydropower Plant Kops II.

[Iswadi et al., 2015] Iswadi, H. R., Best, R. J., \& Morrow, D. J. (2015). Irish power system primary frequency response metrics during different system non synchronous penetration. In PowerTech. 
[Kanakasabapathy \& Shanti Swarup, 2010] Kanakasabapathy, P. \& Shanti Swarup, K. (2010). Bidding strategy for pumped-storage plant in pool-based electricity market. Energy Conversion and Management, 51(3), 572-579.

[Kapsali et al., 2012] Kapsali, M., Anagnostopoulos, J. S., \& Kaldellis, J. K. (2012). Wind powered pumped-hydro storage systems for remote islands: A complete sensitivity analysis based on economic perspectives. Applied Energy, 99, 430-444.

[Kazempour et al., 2009] Kazempour, S., Moghaddam, M., Haghifam, M., \& Yousefi, G. (2009). Risk-constrained dynamic self-scheduling of a pumped-storage plant in the energy and ancillary service markets. Energy Conversion and Management, 50(5), 1368-1375.

[Koritarov et al., 2014a] Koritarov, V., Guo, T., Ela, E., Trouille, B., Feltes, J., \& Reed, M. (2014a). Modeling and Simulation of Advanced Pumped-Storage Hydropower Technologies and their Contributions to the Power System. In Proceedings of HydroVision.

[Koritarov et al., 2014b] Koritarov, V., Veselka, T., Gasper, J., \& Bethke, B. (2014b). Modeling and analysis of value of advanced pumped storage hydropower in the United States. Technical report.

[Krajačić et al., 2013] Krajačić, G., Lončar, D., Duić, N., Zeljko, M., Lacal Arántegui, R., Loisel, R., \& Raguzin, I. (2013). Analysis of financial mechanisms in support to new pumped hydropower storage projects in Croatia. Applied Energy, 101, 161-171.

[Kunz, 2015] Kunz, T. (2015). Business Cases WP4. In eStorage Annual Workshop.

[Kuwabara et al., 1996] Kuwabara, T., Shibuya, A., Furuta, H., Kita, E., \& Mitsuhashi, K. (1996). Design and dynamic response characteristics of $400 \mathrm{MW}$ adjustable speed pumped storage unit for Ohkawachi Power Station. IEEE Transactions on Energy Conversion, 11(2), 376-382.

[Lagarto \& Adeeea, 2016] Lagarto, J. \& Adeeea, I. (2016). Multi-market optimal scheduling of a power generation portfolio with a price-maker pumped-storage hydro unit. In European Energy Market (EEM).

[Li \& Hedman, 2016] Li, N. \& Hedman, K. W. (2016). Evaluation of the adjustable-speed pumped hydro storage in systems with renewable resources. In Transmission and Distribution Conference and Exposition.

[Li \& Shahidehpour, 2005] Li, T. \& Shahidehpour, M. (2005). Price-Based Unit Commitment: A Case of Lagrangian Relaxation Versus Mixed Integer Programming. IEEE Transactions on Power Systems, 20(4), 2015-2025. 
[Lippold et al., 2012] Lippold, F., Hellstern, N., Hydro, V., \& Gmbh, H. (2012). HongrinLéman hydroelectric pumped storage plant, Veytaux II powerhouse - Developing a new generation of multistage storage pumps. In $H Y D R O$.

[Lobato et al., 2008] Lobato, E., Egido, I., Rouco, L., \& López, G. (2008). An overview of ancillary services in Spain. Electric Power Systems Research, 78(3), 515-523.

[Lu et al., 2004] Lu, N., Chow, J., \& Desrochers, A. (2004). Pumped-Storage Hydro-Turbine Bidding Strategies in a Competitive Electricity Market. IEEE Transactions on Power Systems, 19(2), 834-841.

[Lu et al., 2009] Lu, X., McElroy, M. B., \& Kiviluoma, J. (2009). Global potential for windgenerated electricity. Proceedings of the National Academy of Sciences of the USA, 106(27), 10933-10938.

[Ma et al., 2014] Ma, T., Yang, H., Lu, L., \& Peng, J. (2014). Technical feasibility study on a standalone hybrid solar-wind system with pumped hydro storage for a remote island in Hong Kong. Renewable Energy, 69, 7-15.

[Ma et al., 2015] Ma, T., Yang, H., Lu, L., \& Peng, J. (2015). Pumped storage-based standalone photovoltaic power generation system: Modeling and techno-economic optimization. Applied Energy, 137, 649-659.

[Marulanda et al., 2005] Marulanda, A., Martínez, J., \& Gómez, A. (2005). A comparison of residual demand models for oligopolistic markets. In Power Systems Computation Conference (PSCC), number August (pp. 22-26).

[Mateo et al., 2005] Mateo, A., Muñoz, A., \& García-González, J. (2005). Modeling and Forecasting Electricity Prices with Input/Output Hidden Markov Models. IEEE Transactions on Power Systems, 20(1), 13-24.

[Merino \& Lopez, 1996] Merino, J. \& Lopez, A. (1996). ABB Varspeed generator boosts efficiency and operating flexibility of hydropower plant. ABB Review, 3, 33-38.

[Merino et al., 2012] Merino, J., Veganzones, C., Sanchez, J. A., Martinez, S., \& Platero, C. A. (2012). Power system stability of a small sized isolated network supplied by a combined wind-pumped storage generation system: A case study in the canary islands. Energies, 5(7), 2351-2369.

[Ministerio de Industria Energía y Turismo, 2009a] Ministerio de Industria Energía y Turismo (2009a). Procedimiento de Operación 7.2, sobre la Regulación Secundaria. 
[Ministerio de Industria Energía y Turismo, 2009b] Ministerio de Industria Energía y Turismo (2009b). Procedimiento de Operación 7.3, sobre la Regulación Terciaria.

[Ministerio de Industria Energía y Turismo, 2015] Ministerio de Industria Energía y Turismo (2015). Reglas de Funcionamiento de los Mercados Diario e Intradiario de Producción de Energía Eléctrica.

[Ministerio de Industria Turismo y Comercio de España, 2010] Ministerio de Industria Turismo y Comercio de España (2010). Plan de acción nacional de energías renovables de españa (PANER) 2011-2020. Technical report.

[Mitteregger \& Penninger, 2008] Mitteregger, A. \& Penninger, G. (2008). Austrian pumped storage power stations supply peak demands. World Pumps, (pp. 16, 18, 20-21).

[Nagura et al., 2010] Nagura, O., Higuchi, M., Tani, K., \& Oyake, T. (2010). Hitachi's adjustable-speed pumped-storage system contributing to prevention of global warming. Hitachi Review, 59(3), 99-105.

[NHA, a] NHA. Challenges and Opportunities For New Pumped Storage Development. Technical report.

[NHA, b] NHA. Pumped storage strengthens the grid.

[Nilsson \& Sjelvgren, 1997] Nilsson, O. \& Sjelvgren, D. (1997). Hydro Unit Start-up Costs and Their Impact on the Short Term Scheduling Strategies of Swedish Power Producers. IEEE Transactions on Power Systems, 12(1), 38-44.

[Olsson \& Söder, 2008] Olsson, M. \& Söder, L. (2008). Modeling Real-Time Balancing Power Market Prices Using Combined SARIMA and Markov Processes. IEEE Transactions on Power Systems, 23(2), 443-450.

[Ortega et al., 2013] Ortega, M., Del Río, P., \& Montero, E. (2013). Assessing the benefits and costs of renewable electricity. the Spanish case. Renewable and Sustainable Energy Reviews, 27, 294-304.

[Ortner \& Graf, 2013] Ortner, A. \& Graf, C. (2013). Multi-market unit-commitment and capacity reserve prices in systems with a large share of hydro power: A case study. In European Energy Market (EEM).

[Padrón et al., 2011] Padrón, S., Medina, J. F., \& Rodríguez, A. (2011). Analysis of a pumped storage system to increase the penetration level of renewable energy in isolated power systems. Gran Canaria: A case study. Energy, 36(12), 6753-6762. 
[Pérez et al., 2008] Pérez, J. I., Wilhelmi, J. R., \& Maroto, L. (2008). Adjustable speed operation of a hydropower plant associated to an irrigation reservoir. Energy Conversion and Management, 49(11), 2973-2978.

[Pérez-Díaz, 2008] Pérez-Díaz, J. I. (2008). Modelos de Explotación a Corto Plazo de Centrales Hidroeléctricas. Aplicación a la Generación Hidroeléctrica con Velocidad Variable. $\mathrm{PhD}$ thesis.

[Pérez-Díaz et al., 2014a] Pérez-Díaz, J. I., Cavazzini, G., Blázquez, F., Platero, C., FraileArdanuy, J., Sánchez, J. A., \& Chazarra, M. (2014a). Technological Developments for Pumped-Hydro Energy Storage. In Mechanical Storage Subprogramme, Joint Programme on Energy Storage, European Energy Research Alliance.

[Pérez-Díaz et al., 2015] Pérez-Díaz, J. I., Chazarra, M., García-González, J., Cavazzini, G., \& Stoppato, A. (2015). Trends and challenges in the operation of pumped-storage hydropower plants. Renewable and Sustainable Energy Reviews, 44, 767-784.

[Pérez-Díaz \& Jiménez, 2016] Pérez-Díaz, J. I. \& Jiménez, J. (2016). Contribution of a pumped-storage hydropower plant to reduce the scheduling costs of an isolated power system with high wind power penetration. Energy, 109, 92-104.

[Pérez-Díaz et al., 2014b] Pérez-Díaz, J. I., Sarasúa, J. I., \& Wilhelmi, J. R. (2014b). Contribution of a hydraulic short-circuit pumped-storage power plant to the load-frequency regulation of an isolated power system. Electrical Power and Energy Systems, 62, 199-211.

[Pinto et al., 2011] Pinto, J., Sousa, J., \& Neves, M. (2011). The Value of a Pumping-Hydro Generator in a System with Increasing Integration of Wind Power. In European Energy Market (EEM).

[Pousinho et al., 2011] Pousinho, H. M. I., Mendes, V. M. F., \& Catalão, J. P. S. (2011). A risk-averse optimization model for trading wind energy in a market environment under uncertainty. Energy, 36(8), 4935-4942.

[Quaia et al., 2005] Quaia, S., Marchesin, A., Marsigli, B., \& Pascucci, A. (2005). Using pumped storage loads in restoration paths: A field test in the italian national grid. IEEE Transactions on Power Systems, 20(3), 1580-1587.

[Rehman et al., 2015] Rehman, S., Al-Hadhrami, L. M., \& Alam, M. M. (2015). Pumped hydro energy storage system: A technological review. Renewable and Sustainable Energy Reviews, 44, 586-598.

[Rockafellar \& Uryasev, 2000] Rockafellar, R. T. \& Uryasev, S. (2000). Optimization of Conditional Value-at-risk. Journal of Risk, 2(3), 21-41. 
[Sáenz de Miera et al., 2008] Sáenz de Miera, G., del Río González, P., \& Vizcaíno, I. (2008). Analysing the impact of renewable electricity support schemes on power prices: The case of wind electricity in Spain. Energy Policy, 36(9), 3345-3359.

[Schlunegger \& Thöni, 2013] Schlunegger, H. \& Thöni, A. (2013). 100 MW full-size converter in the Grimsel 2 pumped-storage plant. In HYDRO.

[Schweppe, 1988] Schweppe, F. (1988). Management of a spot price based energy marketplace. Energy Policy, 16(4), 359-368.

[Sivakumar et al., 2014] Sivakumar, N., Das, D., \& Padhy, N. (2014). Variable speed operation of reversible pump-turbines at Kadamparai pumped storage plant - A case study. Energy Conversion and Management, 78, 96-104.

[Sousa et al., 2014] Sousa, J. a. M., Teixeira, F., \& Faias, S. (2014). Impact of a price-maker pumped storage hydro unit on the integration of wind energy in power systems. Energy, $69,3-11$.

[Steffen, 2012] Steffen, B. (2012). Prospects for pumped-hydro storage in Germany. Energy Policy, 45, 420-429.

[Swider, 2007] Swider, D. J. (2007). Simultaneous bidding in day-ahead auctions for spot energy and power systems reserve. Electrical Power \& Energy Systems, 29(6), 470-479.

[Teale, 1930] Teale, E. (1930). A Ten-Mile Storage Battery. Popular Science Monthly, July, 60.

[Teller, 2012] Teller, O. (2012). STEPs, pour que l'énergie reste renouvelable.

[Tsai et al., 2009] Tsai, C., Cheng, Y., Liang, S., \& Lee, W. (2009). The Co-Optimal Bidding Strategy of Pumped-Storage Unit in ERCOT Energy Market. In North American Power Symposium (NAPS).

[Tuohy \& O'Malley, 2011] Tuohy, A. \& O'Malley, M. (2011). Pumped storage in systems with very high wind penetration. Energy Policy, 39(4), 1965-1974.

[UCTE, 2009] UCTE (2009). Load-Frequency Control and Performance. Technical report.

[Ugedo \& Lobato, 2010] Ugedo, A. \& Lobato, E. (2010). Validation of a strategic bidding model within the Spanish sequential electricity market. In Conference on Probabilistic Methods Applied to Power Systems (pp. 396-401). 
[Ummels et al., 2008] Ummels, B. C., Pelgrum, E., \& Kling, W. L. (2008). Integration of large-scale wind power and use of energy storage in the Netherlands' electricity supply. IET Renewable Power Generation, 2(1), 34-46.

[U.S. Bureau of Reclamation, 1976] U.S. Bureau of Reclamation (1976). Selecting Hydraulic Reaction Turbines. U.S. Government Printing Office.

[Weigt, 2009] Weigt, H. (2009). Germany's wind energy: The potential for fossil capacity replacement and cost saving. Applied Energy, 86(10), 1857-1863.

[Yang \& Jackson, 2011] Yang, C.-J. \& Jackson, R. B. (2011). Opportunities and barriers to pumped-hydro energy storage in the United States. Renewable and Sustainable Energy Reviews, 15(1), 839-844.

[Zakeri \& Syri, 2015] Zakeri, B. \& Syri, S. (2015). Electrical energy storage systems: A comparative life cycle cost analysis. Renewable and Sustainable Energy Reviews, 42, 569596. 